\title{
COMPETITIVENESS AND EFFICIENCY OF RICE PRODUCTION IN MALAYSIA
}

\author{
Dissertation \\ to obtain the $\mathrm{Ph}$. D. degree \\ in the International Ph. D. Program for Agricultural Sciences in Goettingen (IPAG) \\ at the Faculty of Agricultural Sciences, \\ Georg-August-University Göttingen, Germany
}

presented by

FAZLEEN ABDUL FATAH

born in Kelantan, Malaysia

Göttingen, February 2017 
D7

1. Name of supervisor : Professor Dr. Stephan von Cramon-Taubadel

2. Name of co-supervisor: Professor Dr. Bernhard Brümmer

Date of dissertation: $3^{\text {rd }}$ February 2017 


\section{Acknowledgement}

I knew from the beginning that pursuing my doctoral degree would be both a painful and rewarding experience. This poignant journey has taught me the importance of persevering despite hardship. However, despite having endured challenging times, I am grateful for all of the support and contributions I received during this journey. As I reflect upon this mesmerizing adventure, I realize that I owe my success to the camaraderie and assistance of numerous people who I am indebted to. Words cannot express my gratitude to all of the people who have helped me in many ways.

First and foremost, I would like to give my sincere thanks to my honorific advisor, Professor Dr. Stephan von Cramon-Taubadel, who accepted me as his PhD student without hesitation when I presented him with my first proposal nearly three years ago. Ever since, he has supported me not only by consistently providing excellent resources and scholarly inputs, but also by delivering academic and emotional support along the difficult road to finishing this dissertation. He gave me countless advice, patiently offered his supervision and always guided me in the right direction. I am especially grateful for his ability to understand my needs while writing this dissertation. During the most difficult times, he gave me the permission I needed to move on. I cannot imagine having a better advisor and mentor for my PhD study.

I am also very grateful to my second advisor, Professor Dr. Bernhard Brümmer for his scientific advice, knowledge and suggestions, which led to numerous insightful discussions. He is my primary resource for answering technical questions and was instrumental in helping me crank out the decomposition section of my dissertation; thanks to him I was able to accomplish this in one month! In addition to my advisors, I would like to thank another essential member of my dissertation committee, Professor Dr. Reimund P. Rötter for his perceptive comments and encouragement, but also for posing the tough questions, which encouraged me to widen my research from various perspectives.

My sincere thanks additionally go to the local people and stakeholders in Muda Agricultural Development Authority (MADA), Kedah; the experts working with BERNAS, the Ministry of Agriculture Malaysia (MOA); and the Kemubu Agricultural Development Authority (KADA), Kelantan. Each of these individuals generously gave their time and ideas during the research assessment. I wish to deliver a special thanks to En. Kamaruddin Dahuli and En. Rumzi bin Ahmad from Muda Agricultural Development Authority (MADA). These individuals allowed me to conduct my study in the local area and provided me with access to the necessary data and research facilities. Without their precious support and invaluable inputs, it would not have been possible to conduct this research. I am especially grateful to En. Sufri, Cik Anis Azura Abd. Rahman and En. Yusoff who offered me their time and cooperation when I collected important data for my dissertation.

I would like also to convey my heartfelt thanks to the Ministry of Higher Education (MOHE) Malaysia and the Universiti Teknologi MARA, Malaysia (UiTM) for awarding me the Academic Training Scheme for Lecturers (SLAI) Scholarship for my postgraduate study. Without their support and financial assistance, I would not have been able to successfully complete this dissertation.

A lot of people say that the pursuit of your $\mathrm{PhD}$ can be quite a lonely process. I was fortunate enough to have the opposite experience as I was surrounded by a brilliant and supportive 
community. For that, I thank my dearest Kamlisa Uni Kamlun who has been a very critical and passionate friend- someone whom I could trust and soundboard with, and even voice my frustrations to. She inspired strength when I was feeling lost. Thanks for the stimulating discussions, for the sleepless nights we spent together before deadlines and, of course, during the difficult, early stages of my pregnancy, and for all the fun we had in the last two and half years in Göttingen. You have always been a great friend and words cannot express how truly grateful I am to you and your wonderful family. Special thanks also to my friends in Göttingen for their support from the beginning of my arrival in Göttingen until the end: Alisa Ali, Shahril Anuar Bahari, Suhaidah Mohd Jofrry and Wan Ilma Dewiputri.

In addition, I would like to extend a thank you to all the colleagues at the Chair of Agricultural Policy for the lively discussions and support during these years: Antje Wagener, Dr. Said Tifaoui, Dr. Ganzorig Gonchigsumlaa, Dr. Nelissa Jamora, Dr. Sebastian Lakner, Dr. Carsten Holst, Evgeniya Pavlova, Luis De los Santos, Qu Yi and Jorge Carcamo. Particularly, I am utmost grateful to Dr. Jonathan Holtkamp for providing me with ample guidance and support with solving a lot of research and technical problems.

Thank you to the friends I have made along the way in Göttingen for your unconditional love and support: Dr. Nadzifah Yaakob, Syahidah Mohd Nor and Wan Elhami Wan Omar. Special thanks to the top management of the Faculty of Plantation and Agrotechnology, UiTM: Assoc. Professor. Dr. Fauziah Ismail and Assoc. Professor Dr. Asmah Awal who helped me secure scholarships when I expressed my desire to pursue my $\mathrm{PhD}$ degree at the University of Göttingen in Germany. Their encouragement and assistance enabled me to confidently fulfill my desire and to overcome the challenges I encountered.

I especially thank my dad, Abdul Fatah Haron, my mom, Rahimah Hussein and my family. My hardworking parents dedicated their lives to ensuring the well-being of my siblings and myself and they have provided us with unconditional love and care. I love them so much and I would not have made it this far without them. My sisters and brothers have been my best friends all my life. I love them dearly and I thank them for all their advice and support. I know that I can always count on my family when times are tough.

Special thanks to my devoted husband, Ahmad Zulhilmi Mokhtar, as well as my father-inlaw, Dr. Mokhtar Nor and my mother-in-law, Kamariah Ismail, and the rest of Zulhilmi's wonderful family who have been supportive and caring during this process. My husband has been a true and great supporter and has loved me unconditionally during my good and bad times. He has reserved judgment and was instrumental in instilling confidence in me. These past several years have not been an easy ride, both academically and personally. I truly thank him for sticking by my side, even when I was irritable and depressed. Playing the role of both father and mother while I was studying was not an easy task for him. He assumed every responsibility and graciously cared for my son and my family. Finally, thank you to our children: our darling Fudhail Zahran who was such a good boy, and to the newest addition to our family, baby ' $F$ ', who was such a sweet little angel in my tummy for the past seven months, because of that it was possible for me to complete what I started. I owe my every achievement to them.

Above all, I owe it all to ALLAH, the Almighty God, for granting me the wisdom, health and strength to undertake this research task and enabling me to ensure its completion. 


\begin{abstract}
Rice is one of the most essential staple foods for a large part of the world's human population and has a large influence on human nutrition, the livelihood and food security of several billion people living across the globe. Similar to other Asian countries, the rice crop plays an important role in Malaysian society as it fosters agricultural activity and is a major source of employment for many Malaysian farmers. However, the advent of free trade agreements, including the Asean Free Trade Agreement (AFTA) and the WTO accession, pose challenges for the Malaysian rice production as the sector must compete with low-cost exporting countries. This outcome implies the need for not only structural changes in trade, but also adjustments at the farm level to improve efficiency and competitiveness. Further developments in the rice sector will therefore depend on the availability of sufficient, relatively low-cost and high-quality rice, or in other words, on the competitiveness of rice production.
\end{abstract}

In line with that, the primary objective of this dissertation is to look into a competitiveness assessment of rice production in Malaysia. Furthermore, the work aims to analyze the changes in farm level efficiency over time for rice farms in Malaysia and to gain insight into the factors that determine the distribution of efficiency and competitiveness. Finally, by establishing the linkage between both comparative advantage/competitiveness and technical efficiency, the results of this research would then provide us with a foundation for understanding the information, the measurements and the characteristics associated with each method and how this link may contribute to explaining competitiveness. Overall, this newly accumulated knowledge has the potential to guide the direction of the policy's effects.

In order to achieve the established goals, the dissertation adopts a new extension to the Policy Analysis Matrix approach proposed by Monke and Pearson (1989) using farm level survey data. The measurement of competitiveness in agriculture is often based on the average farms or aggregate data. If the farms that are summarized in this manner are heterogeneous, inferences based on aggregated measure can be misleading. As means of addressing misrepresentative information and the pitfalls of using aggregated data, this extension will allow us to take farm level heterogeneity into account and study the distributions of the competitiveness scores for each rice farm. Subsequently, we conduct an empirical technical efficiency analysis with unobserved heterogeneity and employ a recent fixed effect model. The static decomposition of competitiveness, which is presented by linking comparative advantage/competitiveness and technical efficiency, concludes this PhD dissertation.

The main findings of this dissertation can be summarized in the following points: three out of four granary areas have comparative advantages in rice production using the average data; however, regional averages can hide considerable variation among farms. Between 2011 and 2014, the average SCB ratios were greater than 1, which indicates that rice production was not competitive in MADA granary areas. Despite this observation, many farmers appear to be competitive; more than $60 \%$ of farms produce rice competitively and these competitive farms account for a disproportionately large share of rice production when using disaggregate data. Additionally, in the period from 2010 to 2014, many farms showed improvements in the technical efficiency with more efficient farms produced disproportionately more rice outputs. Specifically, the mean values were around 50-60\%, implying many farms were far from the frontier. However, the rice output per farm can be increased through the efficient use of the resources. Finally, the results presented in this dissertation demonstrate that competitiveness has a positive relationship with the level of technical efficiency, thus confirming our perception of the static decomposition. 


\section{Table of Content}

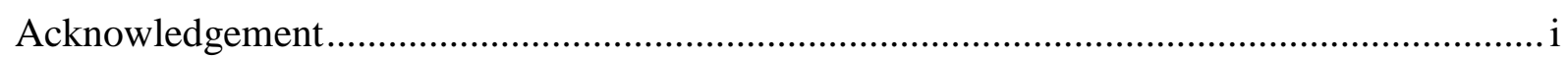

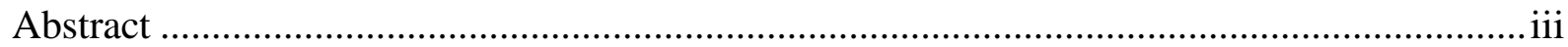

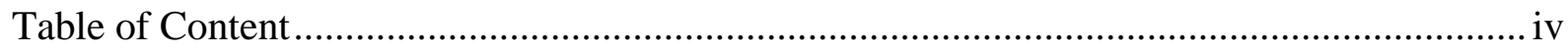

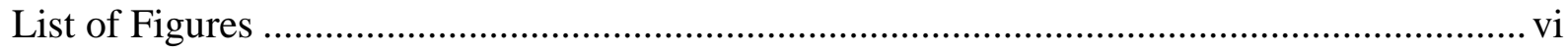

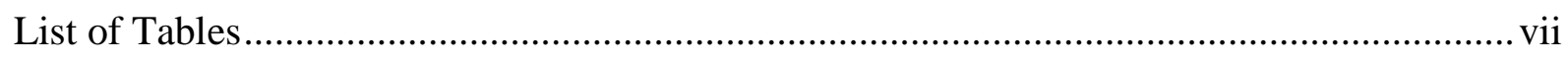

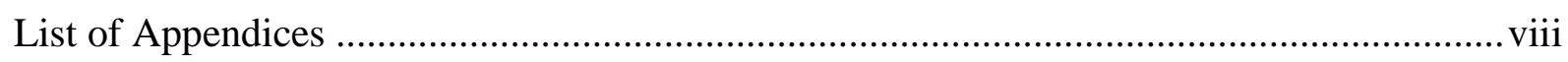

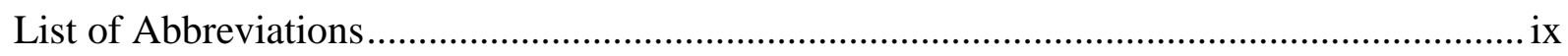

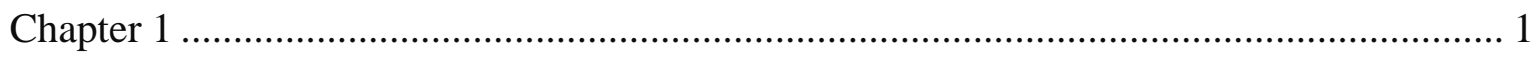

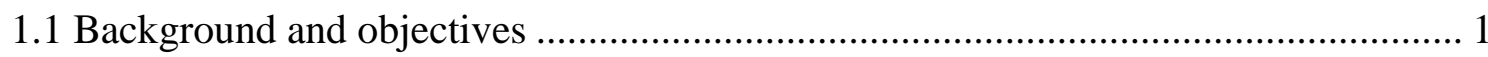

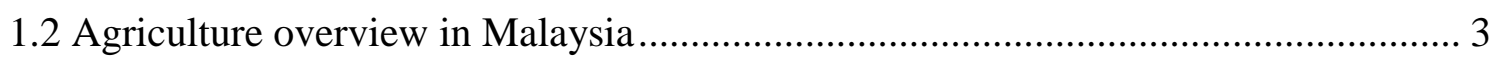

1.2.1 Significant roles of rice in Malaysian economy ….......................................... 5

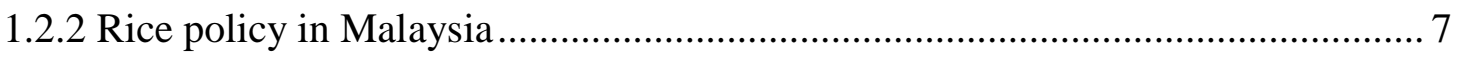

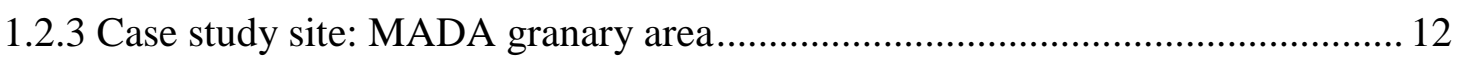

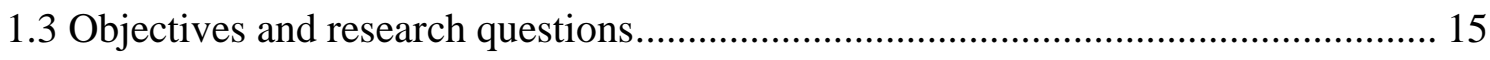

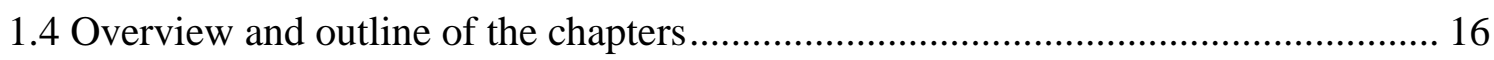

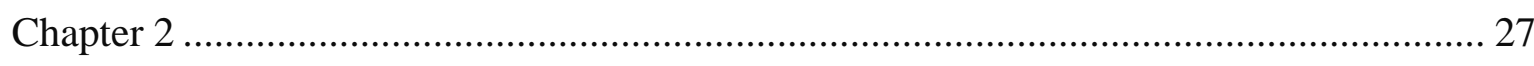

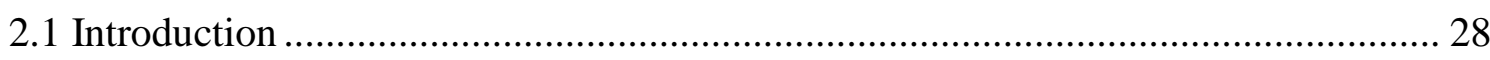

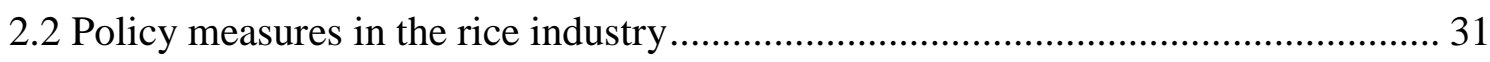

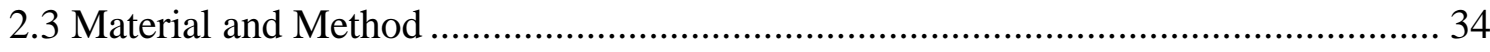

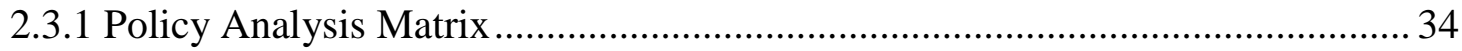

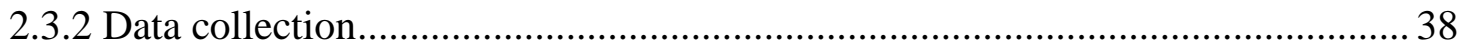

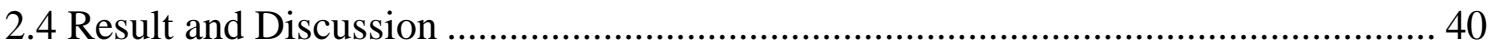

2.4.1 Policy analysis matrix in the context of import parity price of rice .................... 40

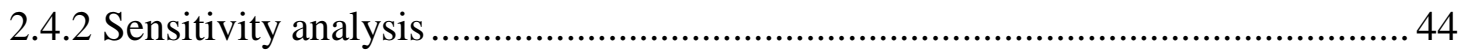

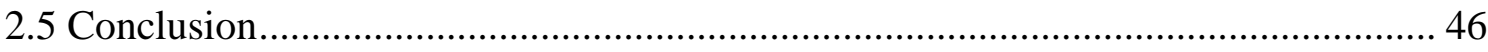

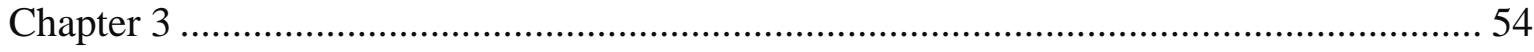

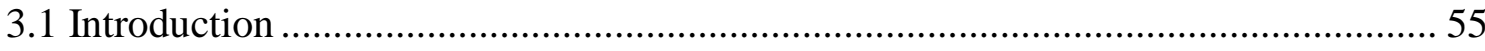

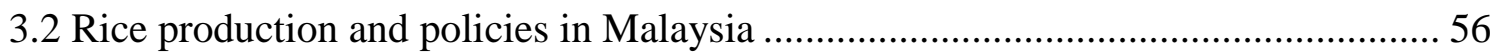




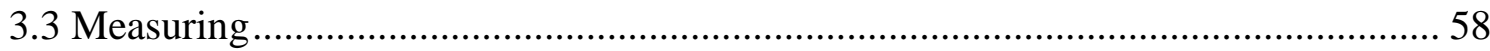

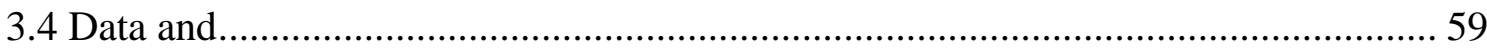

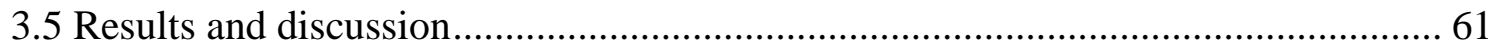

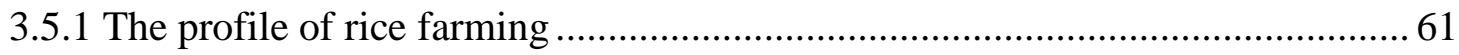

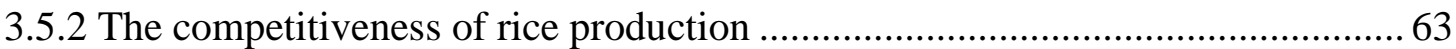

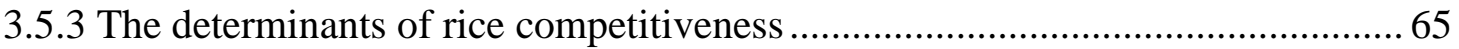

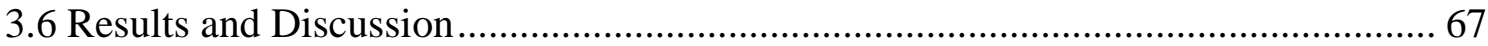

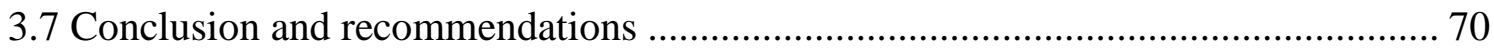

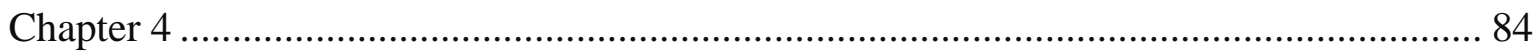

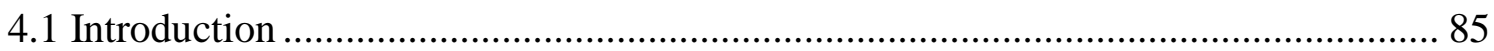

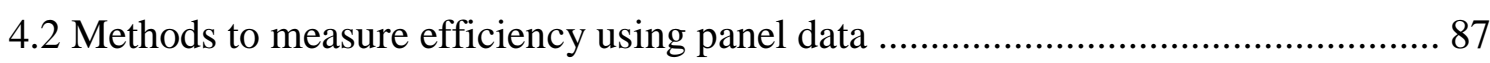

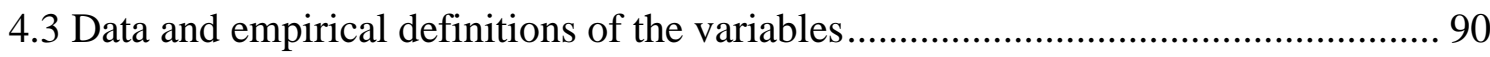

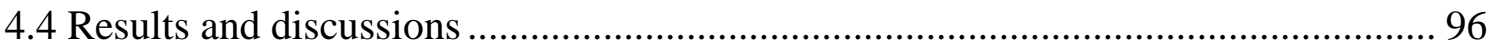

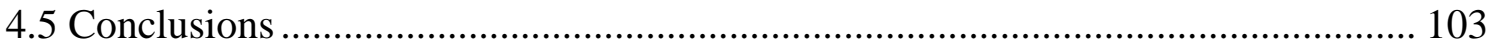

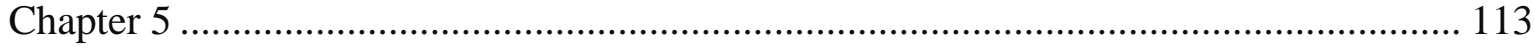

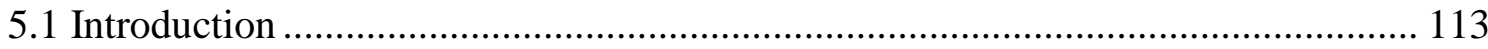

5.2 Strength and weaknesses of the PAM and SFA approaches ................................ 116

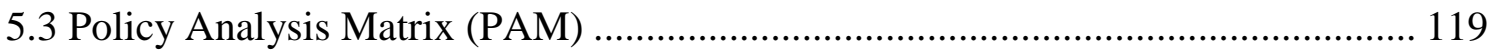

5.4 Stochastic Frontier Analysis (SFA) approach .................................................. 122

5.4.1 Fixed effect panel model using CFE estimation .......................................... 122

5.4.2 A primal system of Profit Maximization........................................................ 124

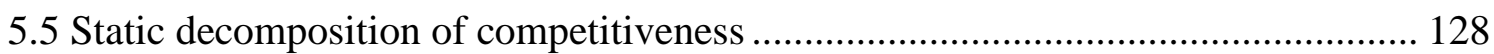

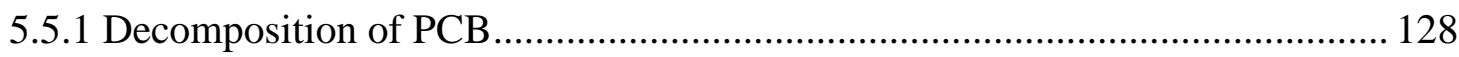

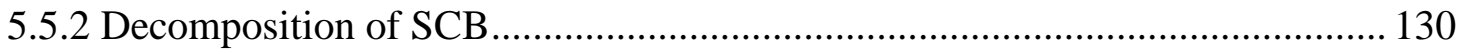

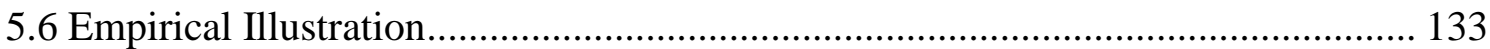

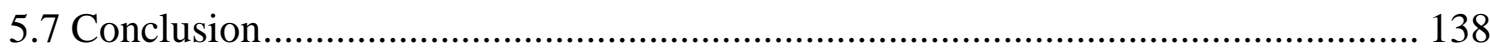

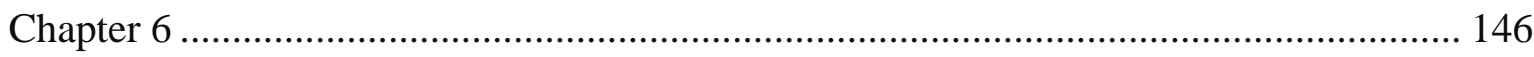

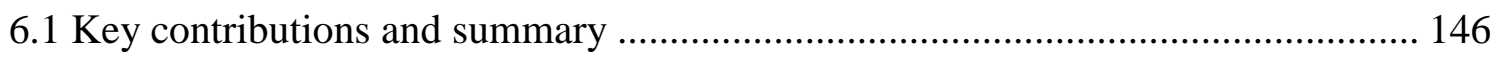

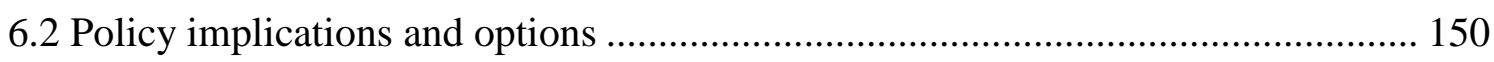

6.3 Data limitations and methodological issues ..................................................... 153

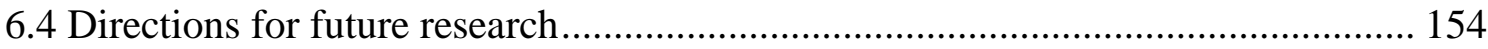




\section{List of Figures}

Figure 2.1: Rice Production, Consumption, Yield and Harvested Area in Malaysia (19802013) .29

Figure 2.2: Change of Domestic resource cost (DRC) in the import rice prices in Malaysia.. 44 Figure 3.1: Average rice yields, ASEAN countries for 2010-2013 ....................................... 57

Figure 3.2: Distribution of competitiveness scores (SCB) for the rice farms, 2010-2014...... 64

Figure 4.1: Distribution of the TE of rice farms, 2010-2014 ............................................. 99

Figure 5.1: Distribution of rice farms' competitiveness scores (PCB and SCB) ................... 133

Figure 5.2: Distribution rice farms' technical efficiency, 2010-2014 ................................... 134

Figure 5.3: Demonstration of decomposition of competitiveness level (logPCB versus TE) 135

Figure 5.4: Distributions of Technical Inefficiency (TI) and Allocative Inefficiency (AI) ... 136 


\section{List of Tables}

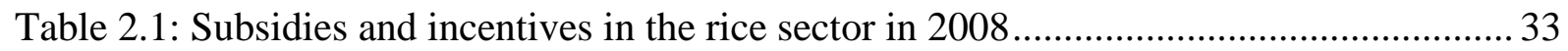

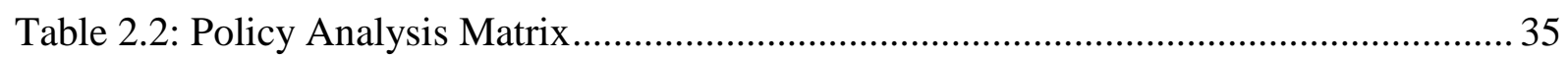

Table 2.3: Summary results of different indicators of protection and comparative advantage 41

Table 2.4: PAM results of rice production in major granary areas in Malaysia in 2011-2012 43

Table 2.5: Change in selected tradable input prices .......................................................... 45

Table 3.1: Comparison of household income between main season and off-season, 2010-2014

Table 3.2: Summary of SCB results by share of individual farms and total rice production, 2010- 2014

Table 3.3: Definitions of variables and summary statistics during the period 2010-2014...... 66

Table 3.4: SGMM estimates for rice competitiveness

Table 4.1: Summary of rice production data and descriptive statistics, MADA granary area, 2010-2014 95

Table 4.2: Estimation results of the CFE Model. .98

Table 4.3: Technical efficiency (TE) and technical efficiency change (TEC) of rice farms . 100

Table 4.4: Determinants of technical inefficiency 101

Table 5.1: Policy Analysis Matrix 121

Table 5.2: Profit loss due to technical inefficiency, allocative inefficiency or both 136

Table 5.3: Results of static decompositions of competitiveness 137 


\section{List of Appendices}

Appendix 2.1: Rice Production in Major Granary Areas, Malaysia (2008- 2010) 48

Appendix 2.2: Private and social costs calculations for the rice farms in KADA, MADA, KETARA and BLS granary areas in Malaysia (RM/ha) in 2011 49

Appendix 2.3: Private and social costs calculations for the rice farms in KADA, MADA, KETARA and BLS granary areas in Malaysia (RM/ha) in 2012. 49

Appendix 3.1: Contribution of MADA to the total granary areas and National Production, 2010- 2013 .74

Appendix 3.2: Policy Analysis Matrix .75

Appendix 3.3: Scheme of Import Parity Price Calculations for Rice, Malaysia. .76

Appendix 3.4: Private and social valuations of inputs in rice production, 2010- 2014 .78

Appendix 3.5: Distribution of competitiveness scores (SCB) for the rice farms, 2010-2014 . 79

Appendix 4.1: Estimation results of CFE Model and LSDV Model 105

Appendix 5.1: Demonstration of decomposition of PCB, 2010-2014 141

Appendix 5.2: Demonstration of decomposition of SCB, 2010- 2014 141 


\section{List of Abbreviations}

$\begin{array}{ll}\% & \text { Percentage } \\ \text { ha } & \text { hectare } \\ \text { km } & \text { kilometre } \\ \text { kg } & \text { kilogram } \\ \text { RM } & \text { Ringgit Malaysia } \\ \text { NPK } & \text { nitrogen, phosphate and potassium } \\ \text { SRI } & \text { System of Rice Intensification } \\ \text { GMP } & \text { guaranteed minimum price } \\ \text { ASEAN } & \text { Association of Southeast Asian Nations } \\ \text { AFTA } & \text { Asian Free Trade Agreement } \\ \text { AEC } & \text { ASEAN Economic Community } \\ \text { WTO } & \text { World Trade Organization } \\ \text { CCS } & \text { Crop Cutting Survey } \\ \text { GDP } & \text { Gross domestic product } \\ \text { OECD } & \text { Organization for Economic Cooperation and Development } \\ \text { SFA } & \text { Stochastic Frontier Analysis } \\ \text { DEA } & \text { Data Envelopment Analysis } \\ \text { BERNAS } & \text { Padiberas Nasional Berhad } \\ \text { PAM } & \text { Policy Analysis Matrix } \\ \text { DRC } & \text { Domestic Resource Cost } \\ \text { SCB } & \text { Social Cost Benefit } \\ \text { PCB } & \text { Private Cost Benefit } \\ \text { NPC } & \text { Nominal Protection Coefficient } \\ \text { NPCI } & \text { Nominal Protection Coefficient of Input } \\ \text { NPCO } & \text { Nominal Protection Coefficient of Output } \\ \text { EPC } & \text { Effective protection coefficient } \\ \text { PNRL } & \text { Private net return to land } \\ \text { SNRL } & \text { Social net return to land } \\ \text { SRP } & \text { Subsidy Ratio to producers } \\ \text { MADA } & \text { Muda Agricultural Development Authority } \\ \text { KADA } & \text { Kemubu Agricultural Development Authority } \\ \text { IADA } & \text { Integrated Agricultural Development Area } \\ \text { GMP } & \text { Guaranteed minimum price } \\ \text { CIF } & \text { Cost, insurance and freight } \\ \text { FOB } & \text { Free on board } \\ \text { SGMM } & \text { System generalized method of moments } \\ \text { TE } & \text { Technical efficiency } \\ \text { TI } & \text { Technical inefficiency } \\ \text { AE } & \text { Allocative efficiency } \\ \text { AI } & \text { Allocative inefficiency } \\ \text { TFE } & \text { True fixed effect } \\ \text { CFE } & \text { Consistent fixed effect } \\ \text { CSN } & \text { Closed Skew Normal } \\ \text { MLE } & \text { Maximum likelihood estimation } \\ \text { MLDVE } & \text { Maximum likelihood dummy variables estimator } \\ \text { AR } & \text { Telf-sufficiency level } \\ & \end{array}$




\section{Chapter 1}

\section{Background of study}

\subsection{Background and objectives}

Rice is the most economically important staple food crop for a large part of the human population, providing more than 3 billion people in Asia with two thirds of their caloric intake, and supplying nearly 1.5 billion people in Africa and Latin America with one third of their caloric needs (FAO, 1995a). The total rice harvested globally in 2010 equated to approximately 154 million hectare (ha). The majority of this amount was harvested in Asia (137 million ha or $88 \%$ of the rice harvested globally), $31 \%$ of which, or about 48 million ha, was harvested in Southeast Asia alone (Redfern et al, 2012).

Given the economic predominance of rice and its direct link to global food security, the state of the economy in the region in which rice is produced plays a significant role. The World Food Summit (1996) succinctly describes food security as "when all people, at all times, have physical and economic access to sufficient, safe and nutritious food to meet their dietary needs and food preferences for an active and healthy life". In Asia, food security has been defined as maintaining stable prices for rice in the major urban markets of each country (The Asia Foundation, 2010) in which rice is a major staple food for more than half of the population. In South Asia, rice makes up a dominant portion of approximately $70 \%$ of the population's diet. This degree of rice consumption is the highest in the world; hence food security is essentially a reflection of rice security in this region. Therefore, an effective way to promote national level food security is by achieving self-sufficiency in rice production (Bishwajit et al, 2013).

When food security is equated with food self-sufficiency, this strategy makes sense since it is easier to stabilize domestic food prices using domestic production by stimulating high prices than to depend on the world rice market, which has great price volatility. However, this approach may significantly increase the spread of poverty as it forces poor consumers to pay high prices for rice. As Timmer (2010) argued, if the countries were more open to the rice trade, they would be richer not poorer. 
At the same time, most governments in Southeast Asia have pursued price stabilization mechanisms or provided supports to protect their domestic producers. These mechanisms incorporate a vast array of instruments from storage, input subsidies, income supports, floor prices and rice distribution programs to trade policies, such as tariffs and quantitative restrictions. However, these mechanisms and supports have been subject to intense debate in the policy analysis arena since five decades ago (Timmer, 1989). On the one hand, rice prices need to be affordable so that poor consumers benefit most from the stable rice prices. In contrast, farm prices need to be high enough for the farmers, who often lead precarious lives and are net rice sellers, to sustain their incomes. Additionally, rice prices must be high enough to provide farmers with adequate incentives to continue investing in rice production. However, simultaneously protecting both producers and consumers is very costly (Warr and Yusuf, 2014) and has become a politically contentious issue.

Recently, the implementation of the Asian Free Trade Agreement (AFTA) and the Association of Southeast Asian Nations (ASEAN) Economic Community (AEC) has signified a major milestone in the region's economic integration and free trade status. The region has remained ambitious with aims of becoming integrated, competitive, innovative and dynamic enough to integrate domestic markets fully into the global economy. In the context of the products and crops sectors of Malaysia's farms particularly rice, this objective leads to increased competition with other countries exporting rice at a low-cost. Furthermore, the introduction of domestic markets into the global economy creates opportunities for trade between ASEAN countries and imposes new conditions on local farms that include opportunities to enhance profits, while potentially enhances competitiveness of each farm's production. This implies that not only structural changes to trading practices, but also adjustments at the farm level are required to improve each farm's efficiency and profitability. Further developments in the rice sector will, therefore, depend on the availability of sufficient, relatively low-cost and high-quality rice, or in other words, on the competitiveness of rice production. Consequently, understanding the key factors, the driving forces and the limitations of rice production under the dynamics of the global rice market is crucial to improving the overall competitiveness and efficiency of Malaysia's rice production. 


\subsection{Agriculture overview in Malaysia}

Malaysia is located in Southeast Asia and has a total area of 329,758 square kilometers (127,320 square miles). It is divided into two similarly sized regions, Peninsular Malaysia and East Malaysia (Malaysian Borneo). Peninsular Malaysia is bordered by Thailand in the north, Indonesia and Singapore in the south, and the Philippines in the east, while East Malaysia borders with Brunei and Indonesia (Kalimantan). The country consists of 13 states, and is divided into 2 parts: 11 states are located in Peninsular Malaysia and 2 states are situated on the island of Borneo (see map). The Malaysian population is nearly 28 million, while the population density was 86 people per square kilometer in 2010 (Department of Statistics Malaysia, 2011)

Sixty eight percent of the total population makes up the labor force of the country and 11 percent of the total labor forces are engaged in agricultural activities. The average unemployment rate is 3 percent (Department of Statistics Malaysia, 2015). The work force in the agricultural sector, however showed a declining trend from 1.28 million employed persons in 2000 to 0.93 million in 2010. The annual productivity per worker, on the other hand, increased from RM14,450 in 2000 to RM24,730 in 2010 (see Table 1.1), thus accounting for the positive growth of the GDP in this sector. The agricultural sector is successful and competitive because of the technological advancements to reduce labour requirements and increase agricultural worker productivity, on which it still relies today.

The three main key drivers to the Malaysian economy are the service sector, manufacturing and agriculture. In 2016, the service sector contributed nearly 54\% to the Gross Domestic Product (GDP), followed by manufacturing (23\%) and the agricultural sector (9\%) (Department of Statistics Malaysia, 2016). The GDP growth rate is approximately 4.3 percent per annum. In addition, exports grew by $1.9 \%$ to reach a value of almost 780 billion Ringgit Malaysia (RM) and agricultural commodities and products represented nearly 9 percent of the total export value in 2015 (Department of Statistics Malaysia, 2016). Palm oil and natural rubber are the main agricultural exported items. On the other hand, imports increased by RM2.71 billion and the total import share were approximately 686 billion RM in 2015 . The significant imported agricultural inputs include agriculture chemicals such as pesticides and herbicides, animal feed and agricultural tractors and machinery. As a result, the world prices, trade and market situation have strongly influenced the Malaysian economy, especially its agriculture sector. 


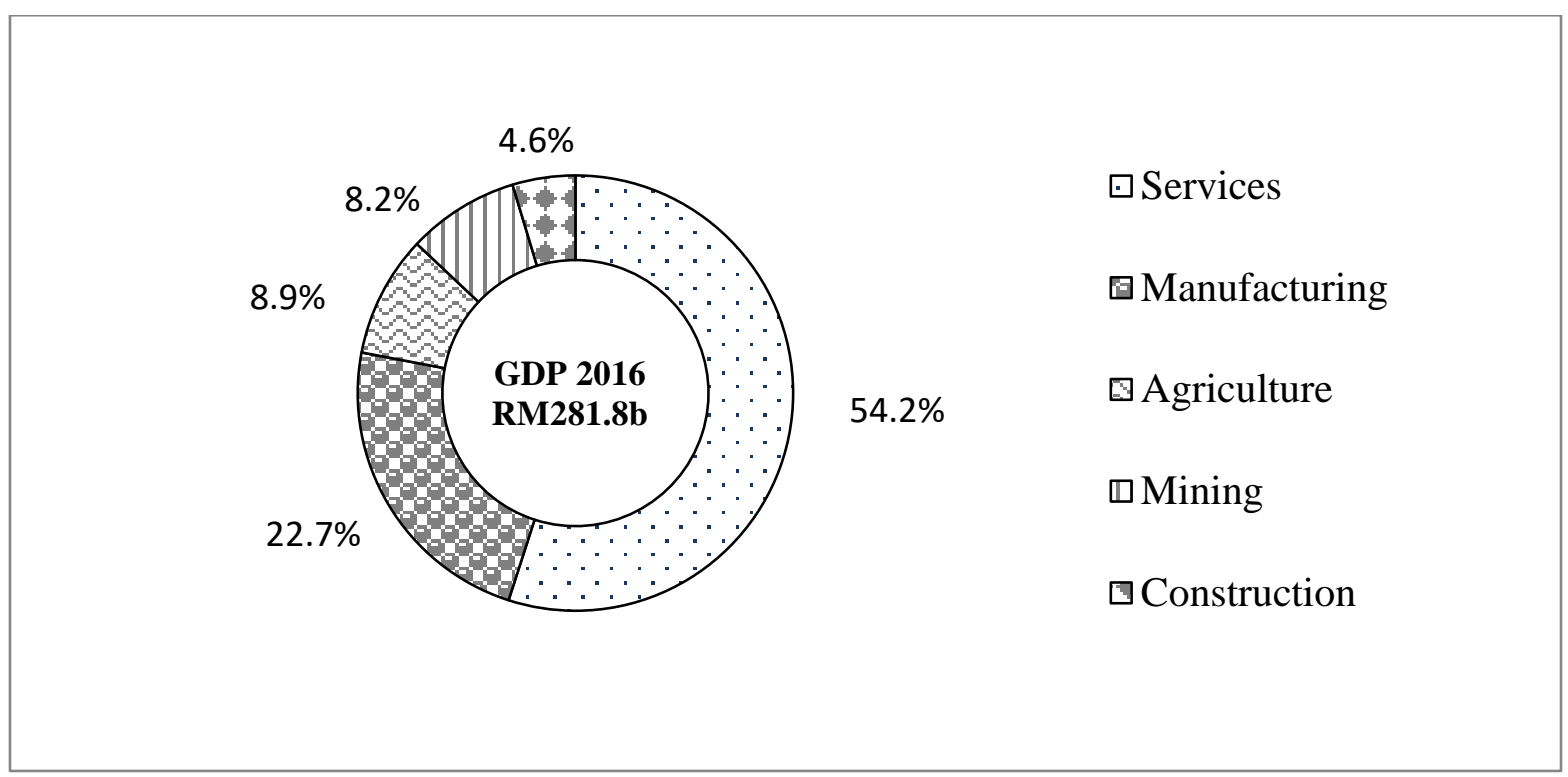

Figure 1.1 Percentage share to GDP at Constant 2010 Price

Note: Exclude import duties. Source: Department of Statistics Malaysia, 2016

Table 1.1: Employment and Agricultural Productivity, 1985- 2010

\begin{tabular}{|c|c|c|c|c|c|}
\hline \multirow[b]{2}{*}{ Year } & \multicolumn{3}{|l|}{ Agriculture } & \multicolumn{2}{|l|}{ Total } \\
\hline & $\begin{array}{c}\text { Employment } \\
\text { ('000) }\end{array}$ & $\begin{array}{c}\% \text { of Total } \\
\text { Employment }\end{array}$ & $\begin{array}{c}\text { Productivity per } \\
\text { Worker } \\
\text { (RM in } 1978 \text { prices) }\end{array}$ & $\begin{array}{c}\text { Employment } \\
\text { ('000) }\end{array}$ & $\begin{array}{c}\text { Productivity per } \\
\text { Worker } \\
\text { (RM in } 1978 \text { prices) }\end{array}$ \\
\hline 1985 & 1,796 & 31.3 & 6,600 & 5,737 & 9,950 \\
\hline 1990 & 1,738 & 26 & 8,530 & 6,685 & 11,870 \\
\hline 1995 & 1,429 & 18 & 11,360 & 7,937 & 15,160 \\
\hline 2000 & 1,280 & 14.1 & 14,450 & 9,066 & 17,460 \\
\hline 2005 & 1,100 & 10.9 & 18,450 & 10,053 & 22,640 \\
\hline 2010 & 930 & 8.4 & 24,730 & 11,099 & 29,060 \\
\hline \multicolumn{6}{|c|}{ Average Annual Growth Rate (\%) } \\
\hline $1985-1995$ & -2.3 & & 5.6 & 3.3 & 4.3 \\
\hline $199-2010$ & -2.8 & & 5.3 & 2.3 & 4.4 \\
\hline
\end{tabular}

Source: Economic Planning Unit, Department of Statistics, Malaysia

The Malaysian agricultural sector can be divided into 3 sub-sectors: industrial crops, food crops, and other miscelllaneous crops. The important crops in terms of land use are industrial crops such as oil palm, rubber, cocoa and tobacco, which mainly serve the export market followed by the food crops such as paddy, coconut, fruits, vegetables and livestocks. The third sub-sector includes, sugarcane, cassava, maize and sweet potato which cater both export and domestic markets. The agricultural land use has shown significant changes over the period 1995-2010. Due to good prospects in palm oil market, oil palm planted area increased from 
2540 thousand hectares in 1995 to 3637 thousand hectares in 2010. Conversely, the planted area for paddy continued to decline to 450 thousand hectares in 2010 compared to 673 thousand hectares in 1995 as a result of conversion of paddy land for other land uses, including urbanisation (Table 1.2).

Interestingly, agricultural value-added grew at 3.0 per cent per annum over 2001-2005 and 5 per cent per annum over the period 2006-2010. In 2005, agricultural value added was RM21.6 billion (in 1987 constant prices) or $8.2 \%$ of the GDP and it increased to RM49.7 billion or $14.2 \%$ of the GDP in 2010 (Olaniyi et al. 2013).

Table 1.2: Agricultural land use in Malaysia and average annual growth rate, 19952010 (in 1000 ha)

\begin{tabular}{lrrrr|rrrr}
\hline \multirow{2}{*}{ Crops } & \multicolumn{5}{c|}{ Year } & \multicolumn{3}{c}{ Average Annual Growth Rate (\%) } \\
\cline { 2 - 9 } & $\mathbf{1 9 9 5}$ & $\mathbf{2 0 0 0}$ & $\mathbf{2 0 0 5}$ & $\mathbf{2 0 1 0}$ & $\mathbf{1 9 9 5}$ & $\mathbf{2 0 0 0}$ & $\mathbf{2 0 0 5}$ & $\mathbf{2 0 1 0}$ \\
\hline Industrial crops & & & & & & & \\
Rubber & 1679 & 1560 & 1395 & 1185 & -1.5 & -2.2 & -3.2 & -2.3 \\
Oil palm & 2540 & 3131 & 3461 & 3637 & 4.3 & 2 & 1 & 2.4 \\
Cocoa & 191 & 164 & 160 & 160 & -3 & -0.5 & 0 & -1.2 \\
Tobacco & 11 & 9 & 8 & 6 & -2.4 & -3.5 & -4.5 & -3.5 \\
Food crops & & & & & & & & \\
Paddy & 673 & 521 & 475 & 450 & -5 & -1.8 & -1.1 & -2.6 \\
Coconut & 249 & 214 & 193 & 176 & -3 & -2 & -1.9 & -2.3 \\
Pepper & 10 & 9 & 9 & 8 & -2 & -1.6 & -1 & -1.5 \\
Vegetables & 42 & 48 & 64 & 86 & 2.7 & 5.7 & 6.2 & 4.9 \\
Fruits & 258 & 292 & 330 & 373 & 2.5 & 2.5 & 2.5 & 2.5 \\
Others & 99 & 106 & 111 & 130 & 1.4 & 0.9 & 3.1 & 1.8 \\
\hline Total & $\mathbf{5 , 7 5 1}$ & $\mathbf{6 , 0 5 5}$ & $\mathbf{6 , 2 0 5}$ & $\mathbf{6 , 2 1 1}$ & $\mathbf{1}$ & $\mathbf{0 . 5}$ & $\mathbf{0}$ & $\mathbf{0 . 5}$ \\
\hline
\end{tabular}

Source: Economic Planning Unit, Ministry of Agriculture, Malaysia

\subsubsection{Significant roles of rice in Malaysian economy}

The agricultural sector has played a significant role in the Malaysian economy and has been considered as the third engine of growth, after services and manufacturing. In fact, the rice sector employs many Malaysians as well as creates food supply, food-sufficiency and income for the farmers.

Rice is grown in all states of Malaysia. In terms of land use, rice farming occupies 8 percent (465 thousand hectares) of the agricultural land of the country, while other food crops, such as coconut, fruits and vegetables share about 10 percent of agricultural land. In 1993, the total 
paddy area which covers both irrigated and non-irrigated was about 600,000 hectares of which rice farming occupied about 322,000 hectares or 48 percent of the total irrigated area while the remaining areas are rainfed. Of the irrigated areas, 290,000 are found in Peninsular Malaysia while the rest are in Borneo (Toriman and Mokhtar, 2012).

In terms of labor force, it is inevitable that rice farming provides a major source of labor supply of the agricultural sector. Presently, there are approximately 1 million farmers in Malaysia; nearly 26 percent of agricultural households or 320,022 households were exclusively paddy farming in 2004 (Ministry of Agriculture, 2009). In addition, more than 20 percent of the agricultural labor force are working in the rural areas. Rice farming provides the main livelihood to these farmers, and the majority of rice farmers are Bumiputera or native Malays, who are mostly poor farmers and manual labourers.

Given the economic predominance of rice and its direct link to global food security, rice production has a significant role in the region's economy. In Malaysia, food security constitutes three main pillars namely to ensure food availability and consistency of food supply, to safeguard accessibility of adequate and nutritious food and to ensure nutrient food provides sufficient nutrition (MOA, 2008). At the household level, the concept of food security is to ensure enough nutritious food and supply without any obstacles; which means households are able and afford to pay for this food. While at the national level, emphasis is on the ability of the country to provide adequate and sufficient food in term of domestic production. Simultaneously, government involvement in food security is to ensure access to sufficient and nutritious food by the households is unrestricted.

Rice is the most economically important staple food crop for a large part of the population, providing two thirds of the caloric intake of more than 3 million people in Malaysia. The total paddy production was 2465 MT in 2010 while the average yield per hectare was 3.48 tonnes in 2010. Rice planted area has shown a stable trend over the period 2000-2010. Approximately, 63 percent were cultivated in the main granary areas in 2010. The main rainfed areas are located in Borneo while the main irrigated areas are located in the Peninsular Malaysia or the central plain. According to the definition of DOA, the major rice planting season varies between regions where the main season normally begins from September to February,while in the off season, the major rice planting season starts from January to July of the following year (Department of Agriculture, 2011). 
Like Japan, Thailand and many other Asian countries, rice farmers and rural communities are perceived as preservers of Malaysian cultural values. Instead of commercial reasons like food exports and tourism, the cultural values associates with the rice farming help to create strong communal bonds, which have been involved in the local beliefs, traditions, ceremonies and religious activities. In Japan, agriculture is commonly considered as a way of life and the autumn festivals as thanksgiving of good harvest and reunion time where family members return to their hometowns to worship their ancestors are still being practiced. Whereas in Thailand, an annual important occasion of the Royal Ploughing Ceremony is held in May at the Royal Field in front of the Grand Palace in Bangkok (TRFRP, 2006). This ceremony gives people, especially rice farmers, the opportunity to collect the rice seeds sowed by 'Phaya Raek Na' which is believed to bring good luck. In Malaysia, The Gawai Day is celebrated every June by the Dayaks (natives of Sarawak state). It is a celebration for giving thanks to God for a good harvest. This is a celebration for tourists as well, where they can partake in the unique agricultural atmosphere. (Chuen-Khee, 2009).

\subsubsection{Rice policy in Malaysia}

Rice is a major staple food and it is one of the major calorie providers for many Malaysians. Given its economic importance in the society and the country, the government has been intervening more in the rice sector than in most others. There are three main obejctives of the different rice policies adopted by the government through the decades; i) to ensure food security; ii) to raise productivity and income of the farmers and iii) to ensure adequate food supply at reasonable costs. The intervention levels through direct or indirect support are mandated under various National Agricultural Plan (NAP). 
Table 1.3 Self-sufficiency level (SSL) of rice in Malaysia

\begin{tabular}{|l|c|c|c|}
\hline \multicolumn{1}{|c|}{ Master Plan } & Period & SSL target (\%) & $\begin{array}{c}\text { SSL achieved } \\
(\%)\end{array}$ \\
\hline First Malaysia Plan & $1966-1970$ & - & 80 \\
\hline Second Malaysia Plan & $1971-1975$ & - & 87 \\
\hline Third Malaysia Plan & $1976-1980$ & 90 & 92 \\
\hline National Agriculture Policy I & $1984-1991$ & 70 & 75.9 \\
\hline Fourth Malaysia Plan & $1981-1985$ & 70 & 76.5 \\
\hline Fifth Malaysia Plan & $1986-1990$ & 70 & 75 \\
\hline Sixth Malaysia Plan & $1991-1995$ & 70 & 76.3 \\
\hline National Agriculture Policy II & $1992-2010$ & 70 & 65 \\
\hline Seventh Malaysia Plan & $1995-2000$ & 65 & 65 \\
\hline National Agriculture Policy III & $1998-2010$ & 65 & 71 \\
\hline Eight Malaysia Plan & $2001-2005$ & 72 & 72 \\
\hline Ninth Malaysia Plan & $2006-2010$ & 90 & - \\
\hline National Agro-food Policy & $2011-2020$ & 70 by 2012 & - \\
\hline $\begin{array}{l}\text { Minister of Agriculture \& } \\
\text { Agro-based Industry }\end{array}$ & & 85 by 2020 & 100 by 2020 \\
\hline
\end{tabular}

Source: MOA, 2012; Fatimah et al, 2010; New Straits Times, 2014

The First Malaysia Plan (1966-1970) was introduced to stimulate the adoption of modern farming practices and crop diversification. Considering the uncertainty of imports which were highly susceptible to natural disasters as well as uncertainty of imports from major exporting countries such as Thailand and China, the objectives of the rice sector during the period were to ensure food security and maintain stable supplies to consumers (Arshad et al, 2000). To achieve this objective, the government made heavy investments in infrastructure and development of new land for agriculture. To assist in the development of the agricultural sector, the government had established various agencies including Malaysian Agricultural Reserach and Development Institute (MARDI) with full responsibility for paddy production research that included, among others, rice breeding, varietal evaluation, agronomic practices and soil management, while The Federal Agricultural Marketing Authority (FAMA) was established to perform marketing functions especially to regulate the marketing scheme in the major granary areas of the Peninsular. 
However, in the early 70s, rice policy in Malaysia had shifted from focusing exclusively on food security, as in the 1960s, to the objectives of self-sufficiency and income distribution between producers and consumers. In the Third Malaysia Plan (1976-1980), the goverment aimed to achieve the self-sufficiency level of 90 percent. These goals were pursued through double cropping on increasing acreage, drainage and irrigation infrastructure expansion, price support, and extension services.

Through the years, the self-sufficiency targets were deliberately lowered because of the government's decision to diversify and intensify agriculture, particularly the production of industrial crops which provide higher earnings than rice. However, in the Third National Agriculture Policy (1998-2010), eight granary areas were designated as permanent rice growing areas responsible for achieving at least 65 percent self-sufficiency. The Eight Malaysia Plan (2001-2005) increased this target to 72 percent, and the Ninth Malaysia Plan (2006-2010) increased it further to 90 percent. However, these targets were not met. In 2014, the Minister of Agriculture and Agro-based Industry announced that Malaysia is determined to achieve its target to end rice imports and be fully self-sufficient by 2020 .

In order to ensure that rice supply is sufficient for the nation various measures have been taken: subsidies, ranging from a fertilizer subsidy and cash assistance to rice farmers; direct intervention of the government in price stabilization; development of irrigation and infrastructure; as well as mechanization projects have been introduced. In terms of production incentives, the government has implemented a Guaranteed Minimum Price (GMP), paddy price subsidy and an input subsidy. This price guarantee is to ensure that the paddy price remains above GMP or at least at GMP level. GMP was first introduced in 1949 at the rate of $248 \mathrm{RM}$ per ton to ensure paddy farmers receive a reasonable minimum farm income. The rate was later revised in 2014 to increase to 1,200 RM per ton, partly due to the increase in input prices and labor costs.

Another form of production incentive is the price subsidy. This scheme was introduced in 1980 at the rate of $165 \mathrm{RM}$ per ton and was then revised and increased to $248.10 \mathrm{RM}$ per ton in 1990. The high poverty prevalance among the rural farmers has directed the intervention by the government to address the situation and raise farmers' income to at least above the poverty line of $300 \mathrm{RM}$ per month. 
Considering the increasing cost of paddy production in the granary areas, the government provided input subsidies to the farmers in the form of fertilizer, and chemical inputs. Since 1974, farmers who owned less than 10 hectares of lands received free fertilizers $(240 \mathrm{~kg}$ per hectare of mixed fertilizer, $80 \mathrm{~kg}$ per hectare of organic fertilizer and $150 \mathrm{~kg}$ (3 bags) of NPK; nitrogen, phosphate and potassium). Along with trying to shield farmers' income from high input costs, the objective of input subsidy is to encourage farmers to use fertilizers efficiently according to the recommendation rate proposed by Department of Agriculture or Malaysian Agriculture Research and Development Institute (MARDI). In addition, farmers also receive a coupon of chemical inputs for purchasing weed and pest controls worth of 200 $\mathrm{RM} / \mathrm{ha}$.

In the mid-1970s, the government had created a specific agency, Padiberas Nasional Berhad (BERNAS) as a rice monopoly to regulate the development of the rice industry and rice marketing. After being privatized in 1996, BERNAS now controls almost all aspects of rice trade, including the normal commercial activities of paddy procurement, rice milling and trading as well as non-commercial activities on behalf of the government, namely management of the national rice stockpile, reimbursement of paddy subsidy payments and procurement of paddy from farmers as the buyer of last resort. To ensure sufficient supply and price stabilization especially during emergency of rice shortages, the government introduced a rice stockpile scheme in 1949. As a policy, BERNAS was obliged to maintain the national stockpile of 292,000 MT, which was intended as a buffer stock during a food crisis and sufficient to sustain the population for at least three months.

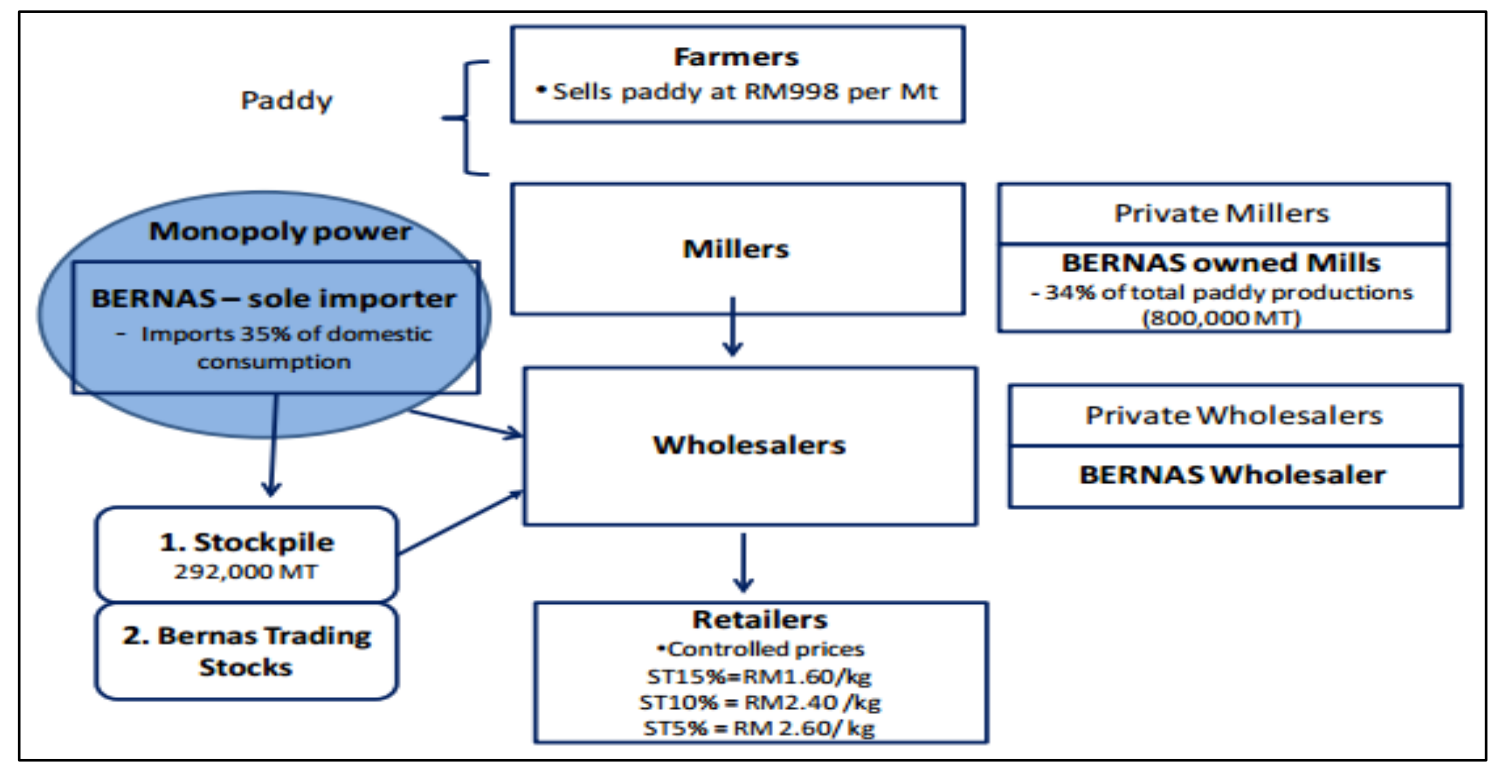

Figure 1.2: Role of BERNAS

Source: Vengedasalam et al. (2011) 
Overall, the Malaysian government allocates about 12.5 percent of its annual national budget to economic services such as infrastructure, industrial agriculture and rural development, where a significant portion goes towards supporting the rice sector (Daño and Samonte, n.d.). In 2009, the incentive scheme cost almost half thousand million US dollars (493.3 millions USD) of the government revenue. The largest component of government subsidies went to the price subsidy (448 millions RM) followed by subsidies of inputs use such as fertilizer (275 millions RM) and pesticides subsidies (173 million RM).

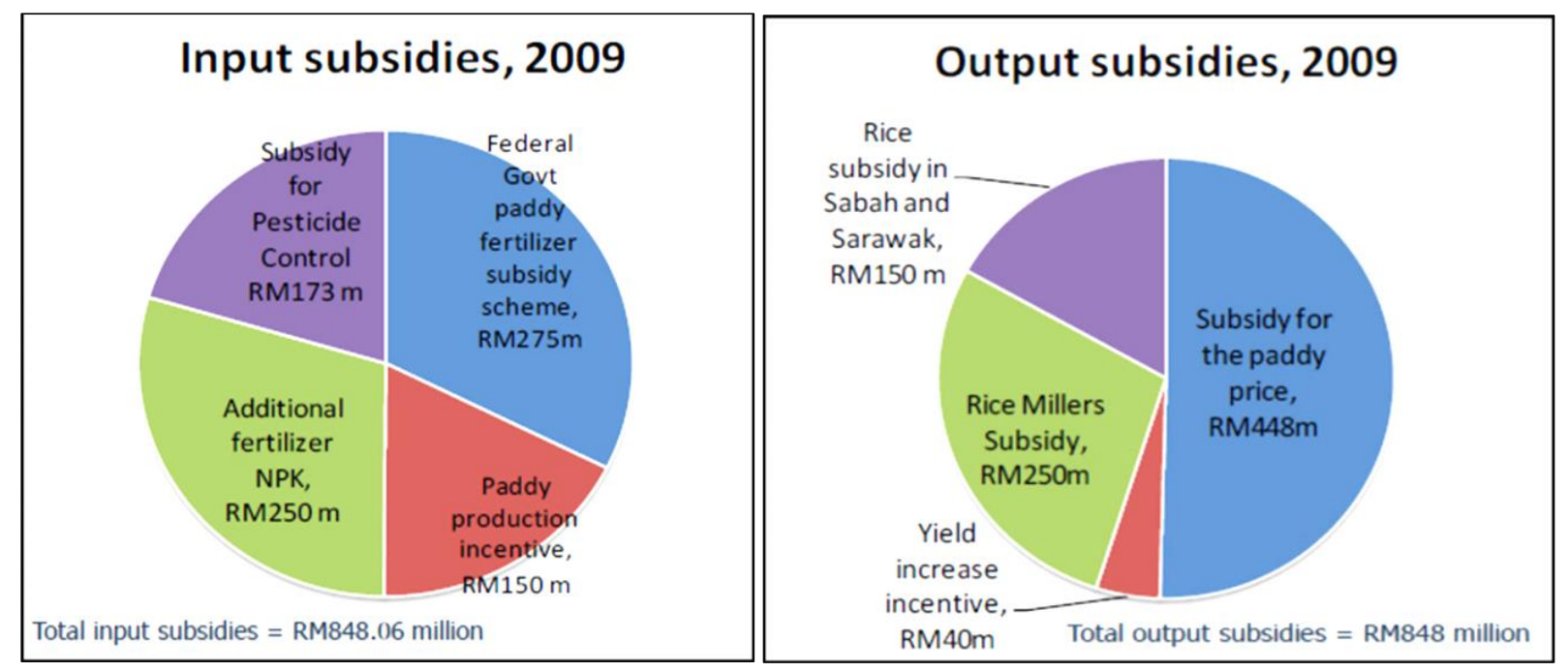

Figure 1.3: Subsidies and incentives in the rice sector, 2009

Source: Department of Agriculture (2010)

Despite of the voluminous incentives provided by the government, the Malaysian rice farms have faced unstable farmer income, high costs of production, natural resources and environment degradation, which have lead to unsustainable development of this sector. In addition, more international and global issues such as international trade agreements and regulations lead the farmers and policy makers to adjust and to change strategies for development and the competitiveness of this sector. 


\subsubsection{Case study site: MADA granary area}

After Independence in 1957, the government made massive public investments, including irrigation infrastructure to supplement rainfall of a single crop. By early 1970, the first phase of rice double cropping was successfully launched through the implementation of a development project for both water resources and irrigation as well as drainage infrastructures (which received irrigation water from the dam for the first time). This project which is known as Muda Irrigation Project has allowed irrigating the rice fields during the dry season and supplementing the supply of water for crop requirements during the end of the wet season (less rainfall). The project has resulted in a massive increase in the cropping intensity of approximately 190\% (Chan and Cho, 2012). Increased investment in irrigation and drainage facilities, together with improved farm road networks and other infrastructures had been instrumental in changing the scenario of rice production in Malaysia.

The success of rice double cropping has been furthered through the development of irrigation infrastructures to eight permanent designated granary areas. Granary Areas are the irrigated areas that refer to major irrigation schemes (areas greater than 4,000 hectares) and recognized by the Government in the National Agricultural Policy as the main paddy producing areas (Department of Agriculture, 2014). There are eight granary areas in Malaysia, namely Muda Agricultural Development Authority (MADA), Kemubu Agricultural Development Authority (KADA), Kemasin Semerak Integrated Agricultural Development Area (IADA KemasinSemerak), Kerian-Sg. Manik Integrated Agricultural Development Area (IADA KSM), Barat Laut Selangor Integrated Agricultural Development Area (IADA BLS), Pulau Pinang Integrated Agricultural Development Area (IADA P. Pinang), Seberang Perak Integrated Agricultural Development Area (IADA Seberang Perak), and Northern Terengganu Integrated Agricultural Development Area (IADA KETARA) (refer to Figure 1.4). These eight granaries have been responsible for scaling up and increasing productivity in the rice farming as well as contributing to at least $65 \%$ of total rice production in the country.

This study was performed in the MADA granary area in Kedah, located in northern Malaysia (Figure 2). MADA is located in the Muda Irrigation Scheme that covers about 130,282 ha of which about 108,581 ha or $84 \%$ of the total irrigated areas are in the north-west of Kedah state and 21,701 ha $(19 \%)$ are located in the southern part of Perlis State. MADA is the largest granary area in Malaysia and contributed $51 \%$ of total granary production in 2013. It 
consistently generates $37 \%$ of Malaysia's total annual rice production on $33 \%$ of the country's rice area.

The average temperature in MADA was $27.4^{\circ} \mathrm{C}$ in 2008 with an average maximum temperature of $33^{\circ} \mathrm{C}$, and average minimum of $22^{\circ}$ (Afroz and $\mathrm{Ba}$, n.d.). The optimum temperature of $34^{\circ} \mathrm{C}$ allows for the high-yielding rice cultivars of MR219, MR220 and MR232 to be grown in this granary area. Annual rainfall averages over 2,500mm; this far exceeds the global annual average of 1,050mm (Chan and Cho 2012). Rainfall is inextricably linked to the seasonal monsoons; the southwest monsoon and the northeast monsoon seasons.The northeast monsoons, which are usually established in early May and end in September, provide a wet season in Kedah, particularly for the MADA granary area in which rice grows. The northeast monsoon of early November until late March provides a dry season that allows the rice fields to dry out and rice to ripen and be harvested. During this dry season, the Muda Irrigation Scheme allows rice fields to be flooded so as to enable double cropping of rice in a more intensive fashion.

Since its establishment in 1970, MADA has been given the responsibility to undertake any agricultural development in the Muda area in Kedah and Perlis. The main function of MADA is to improve the social economics and well-being of the farmers, especially the rural population, and to implement efficient and effective use of irrigation and water resources for irrigated paddy cultivation as well as provide credit and agricultural services to farmers under MADA. 

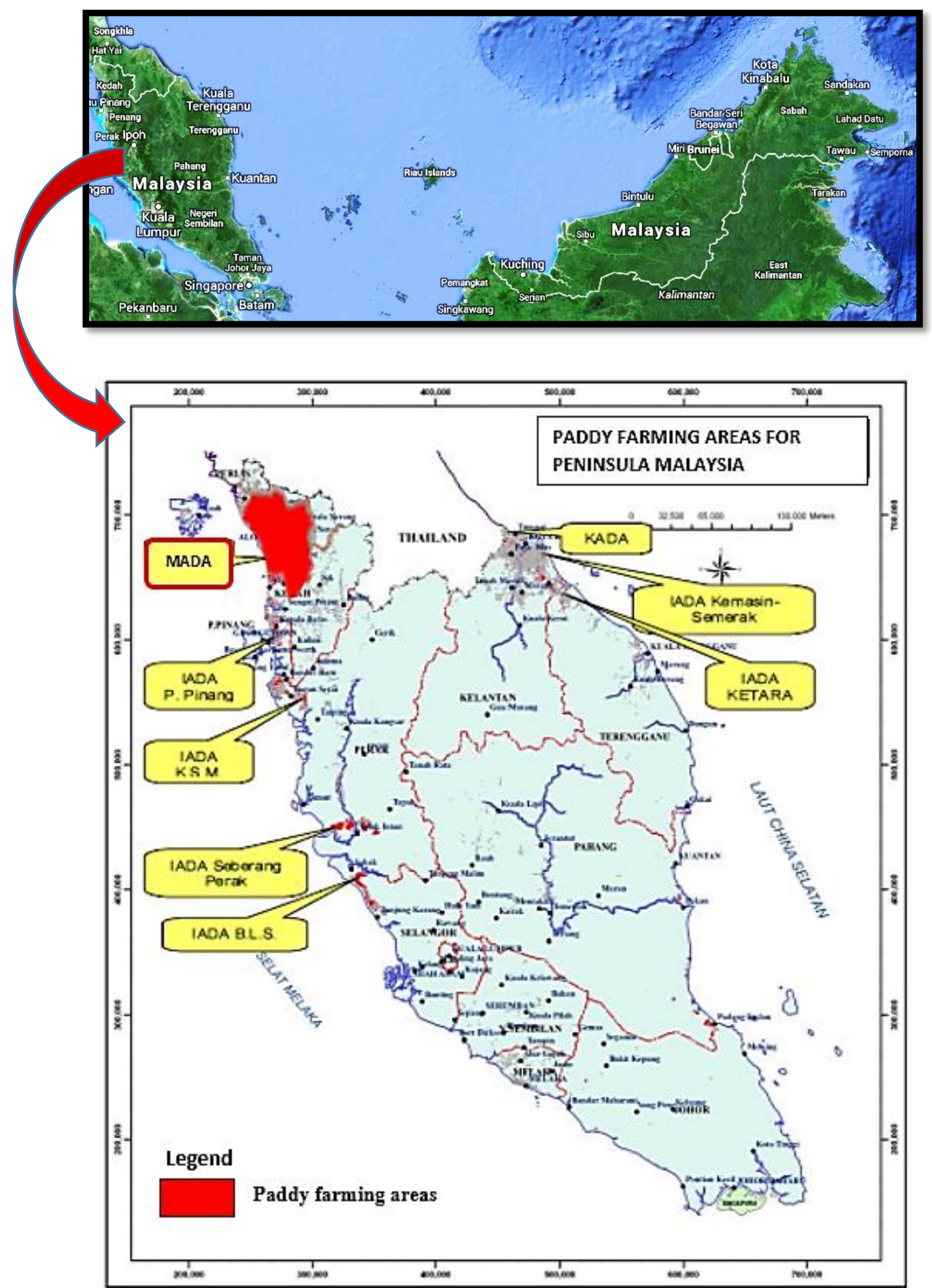

Figure 1.4: Location of MADA granary area in Northern Malaysia (Source: Department of Agriculture Peninsula Malaysia, 2015) 


\subsection{Objectives and research questions}

In correspondence to the previously mentioned problems, the overall objective of this study is to empirically analyze the current effects of policies, and to investigate the level and composition of policy supports and the actual market structure inherent to economic incentives in Malaysia's rice sector. In particular, this study will serve four main purposes:

First, it will present an analysis of the comparative advantages or competitiveness of rice production under different scenarios of existing policies and economic reforms.

Second, it will contribute to the understanding of the forces that drive the competitiveness of rice production in Malaysia.

Third, it will investigate the technical efficiency among the rice farms in Malaysia and determine the factors that influence it.

Fourth, by establishing the linkage between both competitiveness and efficiency, the results of this research will enable the comprehension of this information, the measurements and the characteristics associated with each method and how these details may contribute to explaining competitiveness.

The central research questions addressed in this dissertation are as follows:

i) Is rice sufficiently profitable privately to provide farmers with the incentive to maintain or expand output?

ii) Is rice production in Malaysia socially profitable, and hence, should Malaysia endeavor for self-sufficiency?

iii) Is rice production in Malaysia competitive?

iv) What are the factors that influence competitiveness at the individual farm level?

v) Will a farm that becomes more efficient become competitive as a result?

vi) Are rice farms in Malaysia technically efficient?

vii) Does efficiency enhance competitiveness?

viii)Is there a positive correlation between a farm's comparative/competitive advantage and efficiency?

ix) How are these two types of analysis (competitiveness and efficiency) related? 


\subsection{Overview and outline of the chapters}

To comprehend the remainder of this work, it is essential to have a clear understanding of 'competitiveness'. This section aims to introduce further insights on the term's conceptual foundation as means of achieving clarity for the following chapters.

Most of the questions posed by the relevant economic literature revolve around how to allocate resources in order to ensure social welfare, including the establishment of high living standards and high employment rates. Researchers often rely on the concept of competitiveness as the basis of analysis when they are interested in determining which sector contributes the most to the nation's economic growth. 'Competitiveness' has a broad meaning that has yet to gain universal definition acceptance in economics (Sharples, 1990). The Organization for Economic Cooperation and Development (OECD) succinctly describes competitiveness as "the ability of companies, industries, regions, nations and supranational regions to generate, while being and remaining exposed to international competition, a relatively high factor of income and factor employment levels on a sustainable basis" (Hatzichronologou, 1996). The European Commission (2001) defines competitiveness as "the ability of an economy to provide its population with high and rising standards of living and high rates of employment on a sustainable basis". Others relate this meaning to profitability. Agriculture Canada (1991) defines competitiveness as "the ability to gain profits and maintain market share”.

Given the broad concept and ambiguity present in the literature, competitiveness is a relative measure. Thus, depending on the purpose of the study, the level of analysis, and the commodity in question, several methodologies for estimating competitiveness have been developed (see more in Hatzichronoglou, 1996; Latruffe, 2010; von Cramon-Taubadel and Nivyevskyi, 2008 etc.). Latruffe (2010) classifies measurement into two disciplines: 1) the neoclassical economies that place emphasis on trade and measure competitiveness with comparative advantages, exchange rates and export or import indices and;2) the strategic management that focuses on the firm's structure and strategy, as well as measures the firm's competitiveness based on various cost indicators, including productivity and efficiency. These two measurements of competitiveness are presented in the remaining chapters, which can be categorized into the first stream of the literature on the comparative advantage/ competitiveness described by Monke and Pearson (1989), while the second stream of literature mainly focuses on efficiency. 
Within the context of this work, 'comparative/competitive advantage' is defined as a country's ability to produce a good or service at a lower cost than other countries can. Specifically, this dissertation, whether qualitative or quantitative in nature, serves two fundamental tasks: First, it explores the ability of Malaysian rice farms to gain private and social profits under the current policy scenario and takes into consideration potential external factors that contribute to or hinder this competitiveness; Second, it measures the consequences of public intervention, as well as assesses the consequences of these interventions with respect to the national policy objectives or development of rice production. This information on competitiveness and the factors that influence it is crucial for local policymakers to be conscious of in order to design targeted and efficient policies for agricultural practices.

Among the measures surveyed, the Domestic Resource Cost or DRC is regarded as the true measure of comparative advantage (Singgel, 2006). The DRC compares the domestic resources cost at social prices to the value added measured at social prices ${ }^{1}$. The use of the social price ensures that the DRC measures the true comparative advantage that can be derived from the Ricardian framework.

However, Masters and Winter-Nelson (1995) and Singgel (2006) have demonstrated that the DRC understates the competitiveness of activities relying on a high level of non-tradable inputs. The bias is more pronounced if the activities include very divergent combinations of traded and non-traded inputs. Consequently, Masters and Winter-Nelson (1995) proposed the Social Cost Benefit (SCB), which is analogous to the unit cost ration (UCs) proposed by Singgel (2006). SCB compares total domestic costs at social prices to the total outputs measured at social prices. This concept is regularly cited in economic literature and is also an indicator of comparative advantage, which can be calculated using the Policy Analysis Matrix (PAM) framework (Monke and Pearson, 1989). Since SCB does not include the calculation of the value added in the critical dimension, it is not affected by the classifications of tradable or non-tradable costs.

The second stream of literature is related to efficiency, which is often cited as an indicator of competitiveness. Efficiency can be defined as a farm's ability to use existing technology in

\footnotetext{
${ }^{1}$ The development of the DRC ratio draws back to Bruno (1965) as a project appraisal indicator to evaluate the benefits of new activities.
} 
the best way (Latruffe, 2010). The concept consists of three components: scale efficiency (whether the firm operates at an optimal or sub-optimal rate), technical efficiency (relative to the best possible output in the industry) and allocative efficiency (a farm's ability to use inputs in optimal proportions given their respective prices). Further information on this can be found in Farrell (1957).

Technical efficiency offers the opportunity to measure the degree to which a farmer produces maximum potential output, information that is obtainable from a given set of inputs and a specific technology (Kumbhakar and Lovell, 2000). More importantly, it allows for measuring the shortfall of the observed output to the maximum feasible output, as well as the possible causes of this shortfall. This shortfall is known as technical inefficiency and is attributed to a farm's managerial inefficiency, which refers to aspects that are not under the control of the producers, such as the farmer's age or managerial experience.

Technical efficiency can be estimated using either a parametric approach, such as the Stochastic Frontier Analysis (SFA), or a non-parametric approach, for example, the Data Envelopment Analysis (DEA). Through linear programming, DEA provides a simple way to estimate technical efficiency by conducting a benchmarking assessment of the most efficient farms in the frontier. However, the major drawback of DEA is that all deviations from the production frontier are attributed to technical inefficiencies, and any consideration of random events is ignored (Coelli et al., 2005). On the other hand, SFA distinguishes statistical noise from inefficiency, which is a pragmatic assumption for a real world application.

This dissertation presents four papers on the topic of the competitiveness and efficiency of the rice farms in Malaysia. A brief description of the four core papers is detailed as below:

Paper 1 (Chapter 2): 'Assessing Competitiveness of Rice Production in Malaysia using the Policy Analysis Matrix'. In this paper, we perform an analysis of comparative advantage, or an aggregate competitiveness of the rice production, using the Policy Analysis Matrix (PAM) as the core analytical approach. PAM, as developed by Monke and Pearson (1989), is a straight-forward policy induced transfer analysis that allows policymakers to analyze the impact of current policies and market structures on commodities in question by comparing the private and social structures of incentives to producers. The first perspectives on private incentives are the incentives that motivate the behavior of the individuals actively involved in 
the rice chain business, including the farmers, the processors, the millers and the wholesalers whose questions or aims are primarily profit and income oriented. The second perspectives on the social incentives refer to the nation as a whole and thus the questions focus on economic growth, social wellbeing, or the international comparative advantage of the commodity. In the context of rice production in Malaysia, these incentives aim to enhance rice production levels, secure self-sufficiency by 2020 and maintain food security. Utilizing a PAM model, this study investigated whether the government's interventions make economic sense to be fully selfefficient. In order to arrive at this conclusion, the competitiveness of Malaysia's rice production, particularly in the four granary areas, was analyzed.

In the PAM framework, there are several indicators that can be calculated to measure the protection rate, including the Nominal Protection Coefficient (NPC), the Effective Protection Coefficient (EPC), the Domestic Resources Cost (DRC), and the Social Cost Benefit (SCB). These protection rates were used throughout this study to measure comparative advantages. Among these indicators, the DRC indicator is widely employed as a measure of competitiveness. The DRC compares the cost of domestic resources measured at social prices to value added measured in social prices. $0<\mathrm{DRC}<1$ indicates comparative advantage (the social opportunity cost of domestic resources used is smaller than the corresponding social value added). The opposite is true for the DRC $>1$.

The empirical results show that three out of four granary areas have comparative advantages in the production of rice with Domestic Resource Cost values or DRCs of less than 1. The farms located in these areas produce a net surplus for the country. In the other region, rice farming appears to be marginally competitive and imparts relatively low social profits. As one might expect, such average or representative data might suffer from several significant problems. As described by von Cramon Taubadel and Nivyevskyi (2008; 2009), the results based on aggregated data most certainly conceal relevant variations and the underlying distribution of competitiveness across a set of heterogeneous producers. In other words, the results presented in this paper aggregate very efficient farms that are more competitive than average with less efficient farms that are less competitive than average. This can have great, far-reaching implications for policy conclusions based on the PAM results. Therefore, only cautious conclusions based on average DRCs have been made in this paper and further 
analyses of DRC distributions are required to determine which factors influence a farm's competitiveness.

Paper 2 (Chapter 3): 'Determinants of Rice Farming Competitiveness in Malaysia: An Extension of the Policy Analysis Matrix'. In consideration of the disadvantage of using aggregated data, as outlined in the first paper, and in light of the aforementioned aspects of measuring a farm's competitiveness, this paper provides a disaggregated analysis that allowed us to construct the distributions of SCB scores for rice production and individual rice farms. By considering the distribution of competitiveness, we therefore avoid the shortcomings of working with average or aggregated data. These shortcomings arise since results based on average data ignore the facts that farms are heterogeneous with very few farms might actually resemble the average.

Since DRC understates the competitiveness of activities relying on a high level of nontradable inputs, therefore the Social Cost Benefit Ratio (SCB) indicator is employed in this paper as a measure of competitiveness. SCB compares total costs at social prices to the social value of producing that unit of output in question. The SCB ratio is always greater than 0 , and a SCB greater than 1 indicates that production is uncompetitive, while a SCB ratio of less than 1 indicates that total input costs are less than revenue and that production is competitive. SCB distributions are generated using farm-level data provided by the Muda Agricultural Development Authority (MADA). This dataset is a balanced panel of 6750 rice farms over the period 2010- 2014. For each rice farm, it was possible to generate information on disaggregated input use and output of the rice production. The conversion from private to social prices and costs was based on the available sources of data, as well as interviews with the traders and government-related agencies.

The results demonstrate that many Malaysian rice farms were able to produce rice competitively from 2010 until 2013, but not in 2014. For example, in 2010, 70\% of all farms that produced rice did so competitively. Corresponding shares for rice in 2011 until 2014 were $73 \%, 61 \%, 62 \%$ and $48 \%$ respectively, which point to a sizeable competitive core. These competitive farms account for a disproportionately large share of total rice output; the $73 \%$ of the rice producing farms that were competitive in 2011, for example, accounted for almost $90 \%$ of total rice production in that year. This suggests that competitive rice production takes place mainly on a large scale in Malaysia. 
However, as one might expect, several issues impede the aggregated data on representative farms; the consideration of average SCBs alone conceal important variations among the farms. For example, in 2013, the average ton of paddy was produced at a SCB of 1.02, i.e. not competitive. This result obscures the fact that more than half of the farms $(62 \%)$ in this region were competitive, and that these competitive farms together accounted for about $83 \%$ of the total rice production. Therefore, the analysis conveys there is substantial variation in the competitiveness of farms producing rice in the MADA granary area. This highlights the major pitfall of grounding policy based on the average data and the main advantage of using the distribution analysis as presented in this paper.

In the second stage of analysis, we identified factors that explain this variation and that could be used to improve the competitiveness of individual farms by essentially focusing on the determinants of rice competitiveness in Malaysia. In particular we looked at the impact of the farm's size, its distance from the milling factories, the farmer's access to credit, off-farm income, landownership, cost of hired labor, farmers' organization and subsidies on competitiveness. The analysis draws specific attention to the impact of input and output subsidies on farm-level performance. Subsidies are of considerable interest to policy makers in Malaysia considering the WTO commitments to the reduction of domestic support.

The empirical analysis in the paper employs farm-level survey data on input use, output, farm characteristics and subsidies from 2010 to 2014. We used the System Generalized Methods of Moments (SGMM) estimator. The SGMM includes dynamics in the estimation of farm competitiveness. That is, we could use previous farm competitiveness or the SCB ratio as a regressor and control for potential endogeneity, unobserved heterogeneity and persistency of the series. In this case, the SCB was advantageous because it allowed us to calculate the social profits without government intervention or subsidies.

Our results indicate that participation in the farmers' organization, the farmer's gender and the total farm size are the major determinants of rice competitiveness, while the farm's distance from the rice mills, off-farm income and the cost of hired labor are the main constraints that reduce competitiveness. Finally, our estimates revealed that there are no significant differences between types of policies (input subsidies and bonuses) and competitiveness. 
Paper 3 (Chapter 4): 'Estimating Technical Efficiency and Unobserved Heterogeneity on Rice Farms in Malaysia'. In this paper, we performed an analysis of the farm's performance and its determinants in Malaysian rice farming. In contrast to the second paper introduced above, here we measured performance using efficiency analysis methods. Increasing resource use efficiency has become a critical issue on the policy agenda for enhancing food productivity and food security in Malaysia. Heterogeneous environmental and biophysical characteristics, such as soil condition, rainfall or droughts, as well as managerial characteristics, may influence the input and output of production processes. When such differences are observed and captured by proxies, they can be incorporated into the model so that measured technical efficiency can be determined by these factors. However, when such heterogeneity is neglected or omitted, it leads to biased estimations of the parameters concerning the production frontier and it could induce overstatement of the farm's technical inefficiency. The framework provided in this paper will, therefore, focus on the cases in which managerial characteristics and environmental conditions are not observed, but are assumed to be constant or different for each rice farm. This is crucial considering the panel data collections provided by developing countries are significantly costlier, and, consequently, a long tradition of statistical collection may not exist. This issue is particularly relevant when the data exhibits a missing variable problem where firm heterogeneity is not accounted for in the model due to aggregation or a lack of information.

In view of this lack of information, we applied a Stochastic Frontier model of Chen et al. (2014) that allowed us to distinguish technical inefficiency from individual fixed effects. The advantage of this model specification is that it allows for unmeasured characteristics and the estimation is free of incidental parameters.

The results imply that roughly $60 \%$ of the rice farms experienced improvements in technical efficiency with more efficient farms produce disproportionately more outputs over the period 2010-2014. However, the efficiency fluctuated over this period; mean efficiency was $61 \%$ in 2010, decreased in 2011, and increased steadily for the next two years before it declined again in 2014. A high standard deviation throughout the years is indicative of the large degree of heterogeneity within the rice production system, which means that some farms improved, while some farms did not. The low mean values of TEC further revealing that the frontier is shifting inward and some farms are essentially moving farther from the frontier. However, the potential for increasing individual farm output varies considerably since many farms became 
much better while others became much worse. Government support, such as input and output subsidies, availability of credit facilities and off-farm activities, are identified as important factors causing variations in the level of technical efficiency among rice farmers. This suggests that a serious policy recommendation that facilitates farmers' accessibility to credit, capital, land and other inputs, and improved access to and distribution of input subsidies especially for small farms, must be carefully designed and well-targeted.

Paper 4 (Chapter 5): 'A Note on Farm Competitiveness and Efficiency'. This paper concludes this $\mathrm{PhD}$ dissertation by linking the two strands of analysis on competitiveness measurements. The first strand focuses on the analysis of comparative advantages or competitiveness while the second strand of literature focuses on efficiency where technical efficiency analysis is the main interest. For the purpose of this paper, we developed a simple model that relates competitiveness and technical efficiency and proposed a PCB criterion decomposition that formally relates improvements in efficiency to improvements in PCB ratio.

In particular, we demonstrated that efficiency enhances a farm's competitiveness, thus supporting the common perception of a connection between efficiency and competitiveness. While comparative advantage and efficiency have been long-standing measurements of competitiveness, both analyses used for this research required different data, expertise, computation, framework and calculation. Therefore, to help us clearly define competitiveness and guide the direction of the policy's effects, we briefly contrast these two largely independent methods. Establishing the linkage will help policy makers and others make better use of one or the other measure if they knew how it relates to the other.

PAM has many disadvantages including the common perception on the static nature due to its limitation of the Leontief fixed input-output coefficients which do not take into account the farmer's behavior or reaction to the changes in domestic prices as well as the difficulty in estimating social prices. However, the advantages of PAM go beyond its pure analytic nature in terms of policy analysis. Due to its intuitively comprehensive concept, communicability and easiness, PAM results can serve as an appropriate tool for delivering the information needs of politicians and officials interested in evaluating the impact of policies. It is very intuitive and non-technical; even anybody who can do as simple gross margin calculation can understand the PAM. In contrast, a competent empirical application of efficiency approach 
(i.e SFA) requires a clear understanding of both the production economics and the econometric theory behind the specified model along with adequate programming skills, which can often prove to be a difficult task and challenging. Furthermore, the results of efficiency analysis is quite complex and hardly being applied especially a more sophisticated analysis such as profit function or distance function approach, which makes it relatively difficult to explain particularly for the policy-makers dialog or ministry discussions. In some cases, there might be almost better to use PAM rather than a more sophisticated SFA model as it is easier to communicate, carry out and more intuitive. However, if both methods produce a fairly similar result, it is therefore easier to use PAM method. If so, then it leads to the question; what additional information that we get in return for complexity of SFA estimation? To this end, by linking these two methods, the results will provide us with additional information on understanding competitiveness and how these two approaches are related and applied in a more comprehensive manner.

\section{References}

Afroz, R., and A.B. Ba. "Environmental Efficiency of Rice Production: a Case Study in Kedah Malaysia.” Management (1976):1-11.

Bishwajit, G., S. Sarker, M.A. Kpoghomou, H. Gao, L. Jun, D. Yin, and S. Ghosh. 2013. "Self-sufficiency in rice and food security: a South Asian perspective." Agriculture \& Food Security 2(1):10. Available at: http://www.agricultureandfoodsecurity.com/content/2/1/10.

Bruno, M. 1965. The Optimal Selection of Export-promoting and Import-substituting Projects. Project for Quantitative Research in Economic Development, Center for International Affairs, Harvard University. Available at: https://books.google.de/books/about/The_Optimal_Selection_of_Export_promotin.html? id=ZBzbHgAACAAJ\&pgis=1 [Accessed December 15, 2015].

Chan, C.W., and M.C. Cho. 2012. "Country Report: Malaysia, Asia Pacific Economic Cooperation (APEC), Workshop on Food Security." Available at: http://www.apipapec.com/my/good-practices/1_1/1_1_1/country_report_malaysia.html.

Chen, Y.Y., P. Schmidt, and H.J. Wang. 2014. "Consistent estimation of the fixed effects stochastic frontier model." Journal of Econometrics 181(2):65-76. Available at: http://dx.doi.org/10.1016/j.jeconom.2013.05.009.

Chuen-Khee, P. 2009. "Malaysian Agricultural: Conventional and Extended Thoughts." Journal of Sustainable Development 2(1):80-86. 
Coelli, T.J., D.S.P. Rao, C.J. O’Donnell, and G.E. Battes. 2005. An introduction to efficiency and productivity analysis.

Daño, E.C., and E.D. Samonte. "Public Sector Intervention in the Rice Industry in Malaysia Southeast Asia Regional Initiatives for Community Empowerment (SEARICE)."

Department of Agriculture Peninsular Malaysia. 2011. "Perangkaan Padi Malaysia (Paddy Statistics of Malaysia)." :1-106. Available at: http://nkea.mardi.gov.my/index.php/epppertanian/epp/30-epp9-pengeluaran-beras-wangi-di-kawasan-luar-jelapang-padi.

Department of Agriculture, M. 2014. "Perangkaian Padi Malaysia (Paddy Statistics of Malaysia) 2013.”

Department of Statistics Malaysia, (DOS). 2015. "Labour Force Survey Report, Malaysia, 2014." Available at: https://www.statistics.gov.my/index.php?r=column/ctheme\&menu_id=U3VPMldoYUxz VzFaYmNkWXZteGduZz09\&bul_id=NHUxTlk1czVzMGYwS29mOEc5NUtOQT09.

Department of Statistics Malaysia, (DOS). 2016. "Gross Domestic Product Third Quarter 2016." Available at: https://www.statistics.gov.my/index.php?r=column/cthemeByCat\&cat=100\&bul_id=ellh Q3N0dURzVThUQmtFSkxHRUphQT09\&menu_id=TE5CRUZCblh4ZTZMODZIbmk2 aWRRQT09.

Farrell, M.J. 1957. "The Measurement of Productive Efficiency." Journal of the Royal Statistical Society. Series A (General) 120(3):pp. 253-290. Available at: http://www.jstor.org/stable/2343100.

Kumbhakar, S.C., and C. a. K. Lovell. 2000. "Stochastic frontier analysis." Stochastic frontier analysis 69:680. Available at: http://books.google.com/books?hl=en\&lr=\&id=wrKDztxLWZ8C\&oi=fnd\&pg=PR9\&dq $=$ Stochastic+frontier+analysis\&ots=L1Ptx0MJ21\&sig=k1 yR968QVtd1YCORupspxcLgt Ds.

Latruffe, L. 2010. "Competitiveness, Productivity and Efficiency in the Agricultural and Agri-Food Sectors.” OECD Food, Agriculture and Fisheries Papers 30(30):1-63.

Masters, W.A., and A. Winter-Nelson. 1995. "Measuring the Comparative Advantage of Agricultural Activities: Domestic Resource Costs and the Social Cost-Benefit Ratio." American Journal of Agricultural Economics 77(2):243-250.

Ministry of Agriculture. 2009. Overview of Agriculture Sector in Malaysia. Available at: http://www.slideshare.net/ranzcdadavao/overview-of-agriculture-sector-in-malaysia presentation

Monke, E.A., and S.R. Pearson. 1989. The Policy Analysis Matrix For Agricultural Development. Ithaca, NY: Cornell University Press. Available at: http://web.stanford.edu/group/FRI/indonesia/documents/pambook/pambook.pdf [Accessed December 14, 2015]. 
Nivievskyi, O., S. von Cramon-Taubadel and B. Brummer. 2010. "A Note on Technical Efficiency, Productivity Growth and Competitiveness.” Annual Meeting, July. Available at: http://ageconsearch.umn.edu/bitstream/61759/2/11234 AAEA 2010.pdf.

Olaniyi, A.O., A.M. Abdullah, M.F. Ramli, and A.M. Sood. 2013. "Agricultural Land Use in Malaysia: An Historical Overview and Implications for Food Security." Bulgarian Journal of Agricultural Science 19(1):60-69.

Redfern, S.K., N. Azzu, and J.S. Binamira. 2012. "Rice in Southeast Asia: facing risks and vulnerabilities to respond to climate change." Building resilience for adaptation to climate change in the Agriculture sector (2002):295-314. Available at: http://www.fao.org/fileadmin/templates/agphome/documents/faooecd/oecd_proceedings. pdf\#page $=302$.

Singgel, E. 2006. "International Competitiveness and Comparative Advantage: A Survey and a Proposal for Measurement." Journal of Industry Competition and Trade 6(2):137-159. Available at: https://www.cesifogroup.de/portal/pls/portal/!PORTAL.wwpob_page.show?_docname=956160.PDF [Accessed December 15, 2015].

The Asia Foundation. 2010. "Food Security in Asia and the Changing Role of Rice." No. Occational Paper No. 4, Available at: http://asiafoundation.org/publication/foodsecurity-in-asia-and-the-changing-role-of-rice/.

Toriman, M.E., and M. Mokhtar. 2012. Irrigation: Types, Sources and Problems in Malaysia, Irrigation Systems and Practices in Challenging Environment in Dr. Teang Shui Lee, ed. InTech.

Vengedasalam, D., M. Harris, and G. MacAulay. 2011. "Malaysian Rice Trade and Government Interventions." In 55th Annual Conference of the Australian Agricultural and Resource Economics Society. Available at: http://ageconsearch.umn.edu/bitstream/100726/2/Vengedasalam.pdf [Accessed March $21,2016]$.

von Cramon Taubadel, S., \& Nivyevskyi, O. (2009). Belarus agricultural productivity and competitiveness: impact of state support and market intervention. Retrieved from https://openknowledge.worldbank.org/bitstream/handle/10986/18897/483350ESW0REVI 110FINAL0forOprinting.pdf?sequence $=1 \&$ isAllowed $=\mathrm{y}$

von Cramon-Taubadel, S., \& Nivyevskyi, O. (2008). Ukraine-ag-competitiveness-policy note - final

Warr, P., and A.A. Yusuf. 2014. "Fertilizer subsidies and food self-sufficiency in Indonesia." Agricultural Economics 45(5):571-588. Available at: http://doi.wiley.com/10.1111/agec.12107 [Accessed December 10, 2015]. 


\section{Chapter 2}

\section{Assessing Competitiveness of Malaysian Rice Production Using the Policy Analysis Matrix}

In recent years, the Malaysian rice sector has experienced structural changes to increase its competitiveness within a dynamic environment that is influenced by political, technical, economic and international trade challenges. Malaysia's high dependency on food imports makes the country vulnerable to international market shocks as well as policy disruptions in major rice exporting countries. Using a Policy Analysis Matrix, this paper examines whether Malaysia would have a comparative advantage in rice production under different scenarios of existing policies and economic reforms. The empirical results show that three out of four granary areas have comparative advantages in the production of rice with Domestic Resource Cost values or DRCs of less than one. The farms located in these areas produce a net surplus for the country. In the other region, rice farming appears to be marginally competitive and imparts relatively low social profits. To fully understand the impact of these farms, they must be identified and studied by further research using disaggregated data. This finding suggests that policy should focus on encouraging structural changes capable of enabling the local farms to grow enough to generate a sufficient income from social profits and thus improving overall competitiveness of rice production in the country.

Keywords: policy analysis matrix, self-sufficiency, comparative advantage, rice production, Malaysia 


\subsection{Introduction}

Rice is one of the most important staple foods for a large part of the world's human population and has a large influence on human nutrition, the livelihood and food security of several billion people across the globe. In Asia alone, rice provides about 60 to $70 \%$ of the average inhabitant's daily calorie intake and contributes to 50 to $55 \%$ of the average protein consumption (Bishwajit et al. 2013). The total rice harvested globally in 2010 equated to approximately 154 million hectare. The majority of this amount was harvested in Asia (137 million ha or $88 \%$ of the rice harvested global) of which about 48 million ha or $31 \%$ of the global rice total was harvested in Southeast Asia (Redfern et al, 2012). Given the economic predominance of rice and its direct link to global food security, rice production places a significant role on the region's economy.

Similar to other Asian countries, the rice crop plays an important role in Malaysian society as it fosters agricultural activity and contributes to the nourishment of a rising population. This sector is an important source of employment and constitutes as a significant pillar of the Malaysian agricultural production. However, its contribution to the agricultural economy is relatively small compared to industrial export crops, such as palm oil and rubber. The rice sector's contribution to the agricultural GDP was only 4 percent of the sector's total value in 2010. In 1995, rice farms occupied a mere 6.9 percent of the total agricultural land. In 2005 this share increased slightly to an estimated 9.7 percent. This outcome was partly due to the expansion of rice production in new regions. Industrial export crops, such as rubber and palm oil, dominated the agricultural sector and combined accounted for $77 \%$ of the country's total agricultural land use in 2010 (Perangkaan, Perancangan and Pertanian, 2013).

Malaysia's rice production has fluctuated over the last two decades. However, production has exceeded the long-term trend in recent years (2006- 2013, see Figure 2.1). High yielding varieties and generally favorable growing conditions (Rittgers and Wahab, 2014) have resulted; production area and yields have additionally increased above previous trends. The harvested area increased from 660,000 ha in 2005 to 690,000 ha in 2013. With higher productivity levels leading to an increase in yields, an increasing trend in rice production has been recorded during this period.

However, the country's rice yield is still below the world average and the levels of productivity vary in the country's major producing states. In 2011, the government launched 
the National Agro-Food Policy (2012- 2020) in tandem to increase rice production. A total of RM 19.6 million (US \$6.5 million) was spent in 2012 in order to improve paddy yields and irrigation infrastructure by introducing high yielding rice varieties. Through these measures, the government hopes to enhance rice yields to 4 tons per hectare, compared to the current 2.5 tons per hectare (Cottrell and Hoh, 2011). As part of the policy's goal to boost production, a new planted area was identified in East Malaysia and planted with high yielding paddy. The aim is to plant paddies in an additional area of 5,100 hectares by the year 2020. Apart from improving basic infrastructure, the Malaysian government is also promoting a System of Rice Intensification (SRI) technology in some rice growing states. SRI requires less water and chemical fertilizer to enhance rice productivity under rain fed conditions. These efforts and incentives could explain the recent productivity gains experienced in the country's rice growing states.

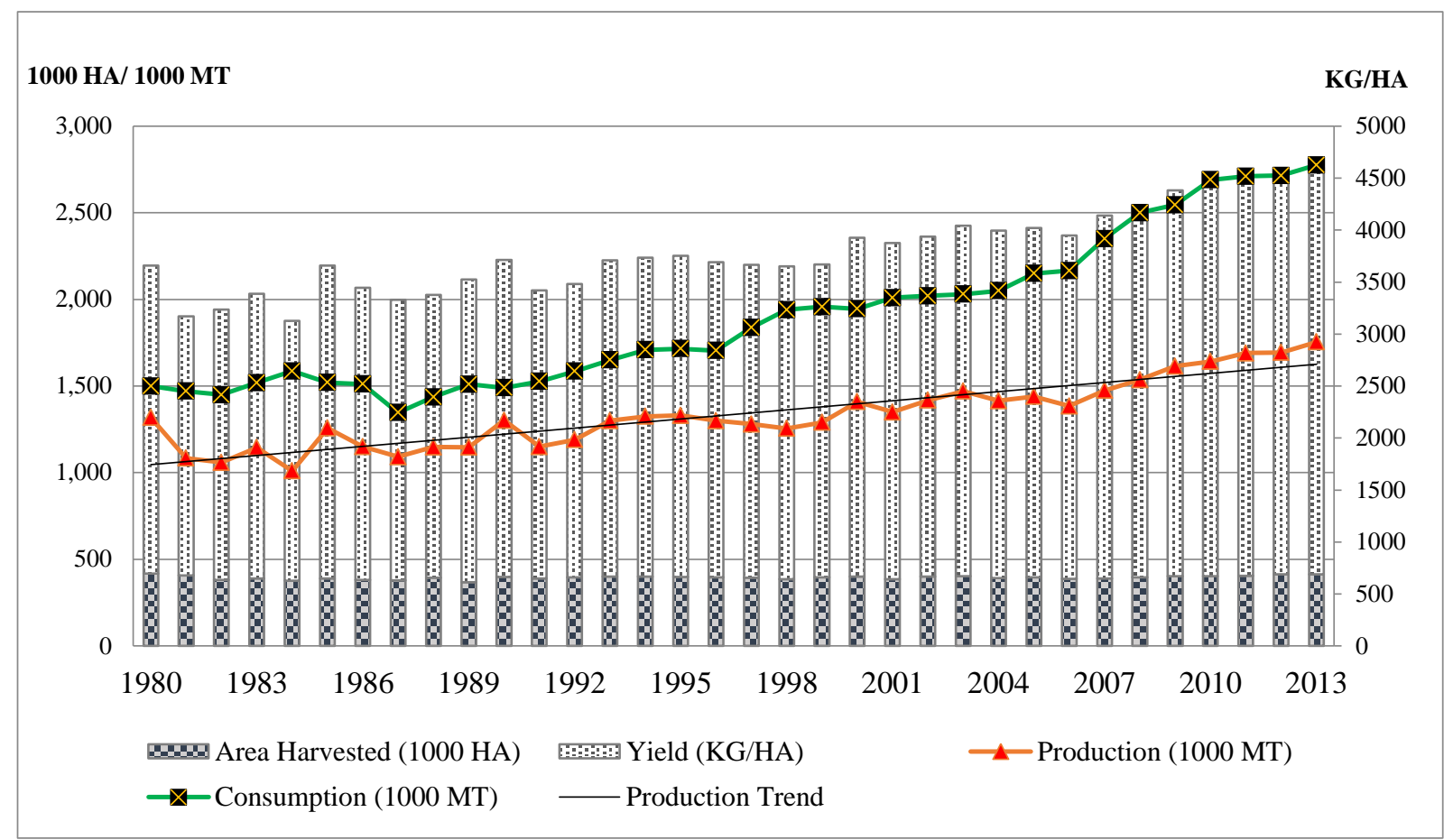

Figure 2.1: Rice Production, Consumption, Yield and Harvested Area in Malaysia (1980- 2013) (Source: FAOSTAT, 2014)

The consumption of rice has increased consistently since the 1980s and had nearly doubled by 2010. It was further predicted to increase slightly in 2014/2015 in accordance with population growth and the increasing number of tourists and immigrant workers coming to Malaysia (Rittgers \& Wahab, 2014). Rice is considered a daily staple food and Malaysians consume between 2.6 million to 2.8 million tons of rice annually. However, the current production is not able to meet the growing demand since Malaysia only produces $70 \%$ of its total rice 
needs. The other $30 \%$ is imported from suppliers such as Thailand, Vietnam and Pakistan. Clearly, as the population increases and rice consumption grows, the gap between demand and the supply of rice will continue to widen. Malaysia's lack of self-sufficiency in rice production results in heavy dependence on rice imports, which cost the country millions of Malaysia Ringgit annually and increasing Malaysia’s trade deficit.

A series of dramatic changes in the rice scenario have occurred globally, which have been precipitated by a hike in the price of petroleum and the unfolding of world food prices, coupled with the rising price the tripling of Thai rice price and other major exporting countries in 2008 (Jamora \& Von Cramon-Taubadel, 2012; Rosegrant et al, 2002). The 2008 food crisis led to an increase in input costs and reduced profits. While the input costs place further financial pressure on farmers, they continue to struggle to maximize profits and make end meets. Like in any other developing countries, Malaysia being a net importer of rice was caught in the tension of the food crisis (Tey and Radam, 2011; Timmer, 2007).

By definition, the concept of food security entails a great emphasis on providing adequate amounts of food in the context of food production (the primary interest at the national level), while simultaneously ensuring that affordable and nutritious food is easily accessible (the primary interest at the household and individual level) (FAO, n.d.). In response to increased efforts to achieve food security, new initiatives have been enacted to ensure citizens have access to sufficient food supplies. Malaysia has more than 100,000 farmers who depend solely on rice production and their employment in the rice industry to live above the poverty level (M.d Wahid et al, 2008). Thus, robust planning and a coherent commitment from all parties are crucial for establishing food security and effectively addressing poverty.

This has prompted Malaysian authorities to readdress the agriculture industry and structurally adjust the local rice policy in order to increase production and become $100 \%$ self-sufficient. Achieving self-sufficiency in rice production is thus an effective way to promote national level food security (Bishwajit et al, 2013). The primary aim of the policy is to increase domestic paddy production by improving yields through the utilization of optimal inputs, new technology and improved farm management. The policy also includes incentives for paddy production, such as price support and a yield increase incentive (Mailena et al, 2014)). In the Third National Agriculture Policy (1998-2010), eight granary areas were designated as permanent rice growing areas responsible for achieving at least $65 \%$ self-sufficiency. The Eight Malaysia Plan (2001-2005) increased this target to 72 percent, and the Ninth Malaysia 
Plan (2006-2010) increased it further to a 90\%. Unfortunately, these targets were not met. Correspondingly, the Minister of Agriculture and the Agro-based Industry announced that Malaysia is determined to achieve its target to end rice imports and become entirely selfsufficient by 2020 (New Straits Times, 2014).

Against this background, several pertinent questions can be raised: Is rice sufficiently profitable privately to provide farmers with the incentive to maintain or expand output? Is rice production in Malaysia socially profitable, and hence should Malaysia endeavor for selfsufficiency? Answers to these questions are essential in order to evaluate the current policy environment. If Malaysia is not adequately competitive in rice production, then the government's plan to become self-sufficient by 2020 will impose costs on the rest of the economy. This might be politically desirable, but if rice is not competitive, then Malaysia would be better off putting its agricultural resources to other uses where they generate higher returns, and using these proceeds to import rice instead. Therefore, a comparative advantage assessment of rice production is required to address the issue of rice's self-sufficiency in the country and to shed light on these questions.

\subsection{Policy measures in the rice industry}

Malaysia is one of the most liberalized trading nations with low tariffs on the majority of commodities and products (Tengku Mohd Ariff and Ariffin, 1999). The concept of low tariffs as an agricultural protection and as a national security measure is intended to: maintain food security and to make it the food available to all consumers at low prices, improve terms of trade, provide a source of government revenue, protect domestic programs, balance trade deficit, enhance national health standards, improve national safety and protect the local environment.

Since rice is considered a strategically important commodity, however, the Malaysian government intervenes more on the rice market than in most others. Policy measures for rice include: a monopoly on imports, controlled prices for milling, wholesale and retail rice, a fertilizer subsidy, price support, provision of drainage and irrigation facilities, spurring innovation, and public investments in research and development (R\&D) support. 
The Malaysian government has been intervening in the rice industry since the country's independence in 1957. Since then, three main goals of rice policy have changed in relative importance over time. The transition from colonial to post independence government resulted in a shift of rice policy towards achieving self-sufficiency, as a strategy to save on the rapidly rising food imports and reduce the country's dependency on essential food supplies coming from overseas. Hence, the goal of achieving independence from food imports by 1963 was adopted by the government (Rudner, 1975). For rice specifically, 65 percent self-sufficiency was targeted in order to ensure rice's availability, especially during a food crisis. Beyond these $65 \%$, the government argued that it is cheaper to import rice from the world market so as to release arable land to more lucrative and profitable industrial crops that yield high-value products and provide more export earnings.

In the 1960s, the government initiated several land development programs, notably related to irrigation and drainage works necessary for double cropping. The Muda Irrigation Scheme in Kedah, the country's largest rice growing state is an example of these programs (Rudner, 1975). Another prominent intervention was the provision of a fertilizer subsidy scheme, which began in the late 1950s. This scheme has remained active over the decades and the continuous increase in global fertilizer prices prompted a more comprehensive fertilizer subsidy program in 2008, which aimed to expand support to paddy producers. The 2008 scheme included the implementation of additional fertilizer, pesticides, lime and yield increase incentives, and cost $\$ 493.3$ million US dollars (Department of Agriculture, 2010). Of the total costs, more than 525 million RM (\$154.4) were allocated to the fertilizer subsidy scheme to benefit the farmers who owned less than 10 hectares of land. As a result of the scheme, farmers received free fertilizers: $240 \mathrm{~kg}$ per hectare of mixed fertilizer, $80 \mathrm{~kg}$ per hectare of organic fertilizer and $150 \mathrm{~kg}$ (3 bags) of NPK (nitrogen, phosphate and potassium).

Middlemen have always played a dominant role in the marketing, milling and purchasing activities of Malaysia's rice market. Consequently, in the mid-1970s, the government created a specific agency called Padiberas Nasional Berhad (BERNAS) to serve as a rice monopoly. The agency's purpose was to regulate the development of the rice industry and rice marketing. After being privatized in 1996, BERNAS controlled nearly every aspect of the rice trade, including the normal commercial activities of paddy procurement, rice milling and trading, as well as non-commercial activities on behalf of the government. Such activities conducted for the government's sake involved namely the management of the national rice 
stockpile, reimbursement of paddy subsidy payments and the procurement of paddy from farmers as the buyer of last resort (Tengku Mohd Ariff and Ariffin, 1999). As a consequence of rice being used as a buffer stock to ensure sufficient supply and price stabilization, BERNAS was obliged to maintain the national stockpile of 92,000 metric tons of rice in 1994. A summary of subsidies and major incentives with the respective allocations in the rice sector is presented in Table 2.1.

Table 2.1: Subsidies and incentives in the rice sector in 2008

\begin{tabular}{|c|c|c|}
\hline Types of subsidies & Descriptions & Allocations (RM mil.) \\
\hline $\begin{array}{l}\text { Federal Government } \\
\text { fertilizer subsidy scheme }\end{array}$ & $\begin{array}{l}\text {-RM240 kg/ hectare mixed fertilizer (12 bags @ } \\
20 \mathrm{~kg} / \mathrm{bag} \text { ) } \\
-80 \mathrm{~kg} / \mathrm{hectare} \text { for organic fertilizer (4bags @ } \\
20 \mathrm{~kg} / \mathrm{bag} \text { ) }\end{array}$ & 275 \\
\hline Price Subsidy Scheme & RM248.10/MT & 448 \\
\hline Paddy production incentive & $\begin{array}{l}\text { RM140/ha/season } \\
\text { Ploughing expenses at a maximum of RM100 }\end{array}$ & 95 \\
\hline Additional fertilizer NPK & 3 bag @ 50kg each bag/hectare & 250 \\
\hline Pesticide Control Subsidy & RM200/ha/season & 173 \\
\hline Lime Application & RM850/ha & 46 \\
\hline Rice Millers Subsidy & $\begin{array}{l}\text { Peninsular Malaysia; RM750/Mt } \\
\text { Sabah \& Sarawak: RM600/Mt } \\
\text { (to encourage domestic millers to produce ST15 } \\
\text { (Peninsular) and SS15 (Sabah \& Sarawak) }\end{array}$ & 250 \\
\hline $\begin{array}{l}\text { Rice Subsidy in Sabah and } \\
\text { Sarawak }\end{array}$ & $\begin{array}{l}\text { Difference between wholesaler price and } \\
\text { purchasing cost of rice import }\end{array}$ & 150 \\
\hline
\end{tabular}

Source: Department of Agriculture (last updated 29 December, 2010).

One of the primary problems regarding sectoral constraints is that rice production has developed in an instable market environment, which has been characterized by price variability and strong fluctuations in product supply and demand (Amaya Montoya, 2011). Therefore, rice farmers are exposed to variable levels of profitability. Furthermore, the Malaysian rice sector consistently encountered difficulties in increasing its competitiveness within a dynamic environment influenced by political, technical, economic and trade challenges. Globalization and international trade have additionally played defining roles in the country's national development, however these factors have equally important implications for Malaysia's rice sector, which must compete with other international producers. 
As a member of the World Trade Organization (WTO), Malaysia is bound by the stipulations of the Uruguay Round Agreement on Agriculture. These include rules and regulations regarding domestic support, export subsidies and market access in agriculture. Regardless of whether or not Malaysian rice production is profitable from a comprehensive economic perspective depends on its comparative advantage, under the conditions of no subsidies or with limited subsidies that have been permitted by the rules for all trading partners. Therefore, an assessment of comparative advantage can be helpful in this respect.

\subsection{Material and Method}

\subsubsection{Policy Analysis Matrix}

The policy analysis matrix (PAM), as developed by Monke and Pearson, (1989) is a double entry bookkeeping analytical framework that helps policymakers to address central issues regarding agricultural policy developments. PAM is widely used for measuring the impact of policies on farm competitiveness and farm level profits. The framework additionally measures the influence public investments have on the agricultural system's efficiency, and the effect agricultural research and development have on economic efficiency and comparative advantages (Masters and Winter-Nelson 1995; Siggel 2006).

PAM takes the influence policies have on the costs and returns of agricultural production and investment projects into account. The principal strength of PAM is that it provides a straightforward policy-induced transfer analysis and allows for varying levels of disaggregation. In addition, PAM results show the net effects under the complex and contradictory policies as well as the individual effects of these policies. However, PAM also has its shortcomings, one of which is the assumption of fixed input-output coefficients, or static nature. Production is described by a string of techniques in which each has a fixed input-output coefficient representing some share of total production, whereas others do not consider the results to be realistic in a dynamic setting (Monke and Pearson 1989; Nelson and Panggabean 2011).

PAM is composed of two cost columns (shown in Table 2.2); one representing tradable inputs and the other domestic factors. Intermediate inputs, which consist of fertilizers, pesticides, compound feed, transportation, electricity, fuel and purchased seeds, are divided into tradable inputs and domestic factor components. This disaggregation process allows for intermediate goods to be separated into four categories: tradable inputs, domestic factors, transfers (taxes 
or subsidies that are disregarded in the social evaluations), and non-tradable inputs (which must be further disaggregated so that all costs will be classified as tradable inputs, domestic factors and transfers).

Table 2.2: Policy Analysis Matrix

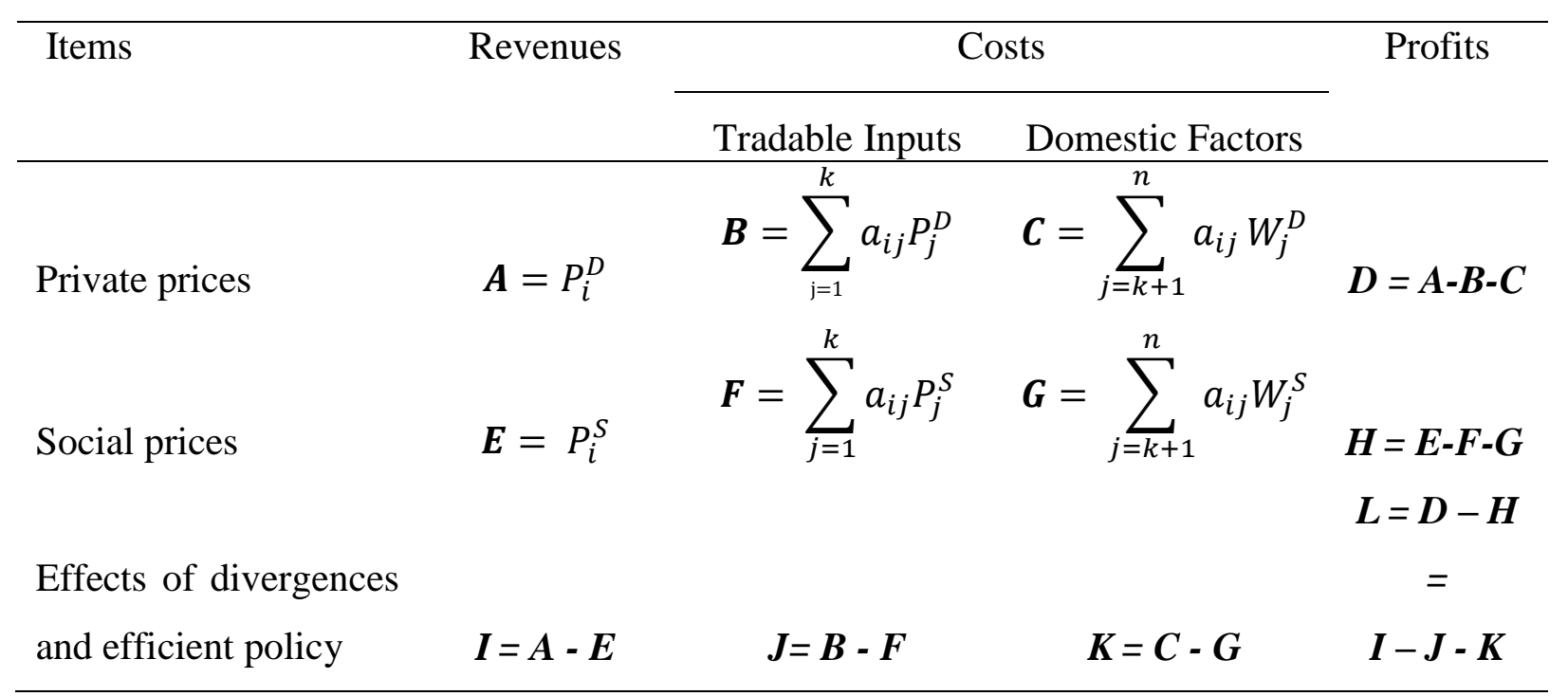

Source: Monke and Pearson (1989)

Note:

The subscript $i$ refers to outputs and the subscript $j$ refers to inputs,

$\mathrm{a}_{i j}$ for $(\mathrm{j}=1$ to $\mathrm{k}$ ) are technical coefficients for traded inputs in the production of $\mathrm{i}$;

$\mathrm{a}_{i j}$ for $(\mathrm{j}=\mathrm{k}+1$ to $\mathrm{n})$ are technical coefficients for domestic inputs in the production of $\mathrm{i}$;

$\mathrm{P}_{i}^{*}$ is the price of output $i$, evaluated privately $(*=D)$ or socially $(*=S)$;

$\mathrm{P}_{j}^{*}$ is the price of traded input $j$, evaluated privately $(*=D)$ or socially $(*=S)$;

$\mathrm{W}_{j}^{*}$ is the price of domestic input $j$, evaluated privately $(*=D)$ or socially $(*=S)$;

$\mathrm{D}(=\mathrm{A}-\mathrm{B}-\mathrm{C})$ measures Private profit;

$\mathrm{H}(=\mathrm{E}-\mathrm{F}-\mathrm{G})$ measures Social profits;

I (= A-E) measures Output transfers;

$\mathrm{J}(=\mathrm{B}-\mathrm{F})$ measures Input transfers;

$\mathrm{K}(=\mathrm{C}-\mathrm{G})$ measures Factor transfers;

$\mathrm{L}(=\mathrm{D}-\mathrm{H}$; or I-J-K) measures Net transfers.

The first row of the matrix provides a measure of private profitability (D), defined as revenue (A) minus total costs $(B+C)$, which assesses the values of all outputs and inputs at private prices, reflecting the actual market or financial prices received by the farmers, processors, or merchants involved in the agricultural system. This private or financial price includes the underlying economic costs and valuation combined with the effects of all policies and market failures. Thus, the private profitability calculations reveal the competitiveness of the agricultural system assuming the use of modern technology, input costs, output values and policy transfers. 
The table's second row measures the social profits $(\mathrm{H})$, which reflect the agricultural system's efficient use of resources and overall comparative advantage. Efficient outcomes are attainable when economy's resources are used to create the highest income and output levels. To determine social profits, social prices are used for the valuation of inputs and outputs. Social values, or prices, demonstrate a policy benchmark for comparisons because they are considered the prevailing prices in a free market in the absence of policy interventions, distortions or market failures (Kanaka and Chinnadurai, 2013; Monke and Pearson, 1989). Social prices reflect the opportunity cost or the value of using a good or service produced by a particular activity in order to achieve the objective of optimizing income and social welfare. Thus, considering that output $(\mathrm{E})$ and input $(\mathrm{F}+\mathrm{G})$ are valued at social prices that reflect the scarcity values or opportunity costs, social profits are an efficiency measure. For output (E) and input (F) traded internationally, world export prices (free on board) are used. The cost of insurance freight prices (CIF) is used to deduce domestic factors, which are not traded in the international market. Social profits indicate that the foreign exchange either cut costs by reducing imports or earned by expanding exports of each unit of production. A positive value indicates that production contributes to national income, while a negative value suggests that the country's national growth would be improved by not producing the commodity. Thus, it is a signal of measuring international comparative advantage (Kanaka and Chinnadurai, 2013).

The second identity located in the third row of the accounting matrix measures divergences, which are defined as the differences between private and social valuations of revenues, costs and profits. Any divergence between private and social prices, which is measured vertically, must be explained by the effects of the policies. The effects of divergences are disaggregated into three categories: distorting policies, market failure and efficient policies. When government enforced market failure correction policies are not in place, distorting policies are the cause of divergences between the private and social prices of tradable outputs and inputs. However, if efficient policies enacted by the government are able to correct or offset market failures and create a greater income, the differences between private and social valuations will be reduced, since efficient policies correct divergences (Masters and Winter-Nelson 1995; Monke and Pearson 1989). The PAM framework also calculates the protection rate generated by different ratios such as the NPC, EPC, DRC, and SCB. These protection rates were used throughout this study to measure comparative advantages. 
The Nominal Protection Coefficient (NPC) is one of the most widely used methods of measuring price distortions (Fang and Beghin 2000; S. Mohanty, Fang, and Chaudhary 2003; Sadoulet and Janvry 1995; S. J. Yao 1997). The NPC is defined as:

$$
\mathrm{NPC}_{i}=P_{i}^{D} / P_{i}^{S}
$$

NPC ratio compares the private and social prices of a commodity. This ratio demonstrates the impact a policy has on the two prices; domestic price compared to the world price that causes a divergence. NPC can be calculated for both inputs (NPCI) and outputs (NPCO). Subsidies on outputs are indicated by NPCO (which is A/E) if its value is larger than one, while input subsidies are represented by NPCI (which is B/F) if its value is smaller than one (Fang and Beghin, 2000). From a strictly theoretical point of view in the context of trade, if NPC $>1$, producers are protected and consumers taxed; this scenario suggests that the production is inefficient and the price is heavily affected by government policies or by other factors of that commodity.

The effective protection coefficient (EPC) is defined as the ratio of distorted tradable value, which has been added at market price to its undistorted value at the border price level. EPC captures the effect of government policies on input as well as on output markets (Hayat and Islam 2005; Javed et al. 2006). EPC is defined as:

$$
\mathrm{EPC}=\left(P_{i}^{D}-\sum_{\mathrm{j}=1}^{k} a_{i j} P_{j}^{D} /\left(P_{i}^{S}-\sum_{j=1}^{k} a_{i j} P_{j}^{S}\right)\right.
$$

Based on the PAM table, EPC is the ratio of the value of added private prices (A-B) to the value of added social prices (E-F). This coefficient indicates the degree of policy transfer from output and tradable input distortions. A value greater (or less) than one indicates a net subsidy (or net tax) to value added (Beghin and Fang, 2002; Monke and Pearson, 1989). Additionally, if EPC $>1$, it suggests that government policies impart positive incentives to producers while $\mathrm{EPC}<1$ indicates that producers are not protected through policy interventions (Mohanty et. al, 2003).

The Domestic Resources Cost (DRC) is widely used to measure comparative advantages or relative efficiency between agricultural commodities (e.g.von Cramon Taubadel and Nivyevskyi, 2008; 2009). DRC was developed simultaneously in the 1960s by Bruno (1965) in Israel and by Krueger (1966) in United States. The DRC is defined as the shadow value of 
non-tradable inputs used in an activity per unit of tradable value added (G/ (E-F)). The formula for DRC is written as;

$$
\mathrm{DRC}=\sum_{j=k+1}^{n} a_{i j} W_{j}^{S} /\left(P_{i}^{S}-\sum_{j=1}^{k} a_{i j} P_{j}^{S}\right)
$$

DRC indicates whether or not the use of domestic factors is socially profitable (DRC $<1)$ (DRC $>1)$. We calculate the DRCs to enable cross-commodity comparisons in each Malaysian state. The commodities can be ranked according to the DRC values and thus can provide indications of comparative advantage or disadvantage within that state. A state is said to have a comparative advantage due to a given crop if the value of the DRC for that crop is lower than the DRC for other crops grown in that state.

The Social Cost Benefit (SCB) is defined as $(\mathrm{F}+\mathrm{G}) / \mathrm{E}$, and provides information similar to the DRC. Finally, the indicators private net return to land (PNRL) and social net return to land (SNRL) were used to measure the return to the fixed factor for this study. Hayat and Islam, (2005) state that the net economic benefit per unit of land is likely to be more relevant when ranking crops, as opposed to calculating domestic resources per unit (or ringgit/domestic currency). The PAM table provides the PNRL, which is defined as A-B-C without the cost of land use and SNRL as E-F-G without the cost of land use. Greater values of PNRL indicate that the crop in question is more desirable for the producer, but not necessarily for society. A higher value of SNRL suggests both a product's stronger competitiveness as well as its desirability for the society (Fang and Beghin, 2000; Yao, 1997).

\subsubsection{Data collection}

In the 1980s, the government enhanced further irrigation developments in order to enable rice double cropping in eight designated granary areas. Of these, four were chosen as the study areas: Muda Agricultural Development Authority (MADA); Kemubu Agricultural Development Authority (KADA); Barat Laut Selangor Integrated Agricultural Development (BLS); and North Terengganu Integrated Agricultural Development (KETARA). The contributions of the four granary areas are presented in Appendix 2.1.

The data employed in this study are collected from various national and international published and unpublished resources. In order to estimate the PAM, a comprehensive set of data including yields, input requirements of the markets, and social prices of inputs and 
outputs were required. The aggregate output and input coefficients for the four granary areas were taken from Terano and Mohamed, (2011), Mohd Rashid and Mohd Dainuri, (2013) and KADA (2014). These authors used a fairly large-scale survey that encompassed different agro ecological zones. The survey focused on generating information related to the production costs of rice for the provinces over the period 2011-2012. These output and input coefficients were then complied according to the land's hectare count.

The output (rice) and input farm gate prices (urea, compound or TSP, NPK and organic fertilizers, pesticides and lime) were taken from nationally and internationally published and unpublished sources. Social prices of tradable commodities are based on import parity prices or export parity prices, depending on the trade status of the commodity in question. Since Malaysia frequently imports rice, an import parity price is used to measure the social price of rice. The CIF price of 25 percent broken rice and the official exchange rate were collected from FAO and the Central Bank Malaysia. CIF prices for fertilizers, including urea (Europe), TSP (US Gulf ports), organic and NPK, were collected from the World Bank, IRRI, and the FAO food outlook. The fuel price was obtained from Domestic Trade and Consumer Affairs Ministry in Malaysia, whereas the data pertaining to lime, pesticides and wages were collected from the Ministry of International Trade and Industry, the Department of Statistics Malaysia and FAOSTAT.

The social price of land is one of the more important and complicated components of domestic factors. With regard to land valuation, Gittinger, (1984) describe the social cost of land, which is considered when determining border prices, as the net value of production forgone when the status of the land changed from 'without land use' to 'with land use'. In a free market, the market price of a piece of land will reflect its economic value. However, Van Schalkwyk and Van Zyl (1994) argue that non-farm related factors, such as policy distortions may get capitalized as market values and thus, land values tend to not reflect its true economic value. In this respect, Monke and Pearson (1989) propose using the rental value instead of market value, because the rental value reflects the relationship between opportunity cost and land use. They further argue that in the absence of both financial cost and rental value that reflect the opportunity cost of a land, its 'potential productive capacity' can be used to access its value in the best alternative use. For example, if oil palm production represents the best alternative to rice production in granary areas, the social costs of land for rice production equals the social profits (excluding land) from the oil palm production. 
In the studied areas, many farmers preferred sharecropping or producing oil palm as a substitute commodity for rice (Terano and Mohamed 2011). Hence, in estimating social prices for land, we used the average net income of palm oil in each granary area. Due to the challenges inherent to estimating the social profits of oil palm production, these figures are based on primary data provided by an agricultural officer and a land value officer in Selangor, Malaysia. Other data pertaining to the conversion of private to social prices are presented in Appendix 2.2 and 2.3.

\subsection{Result and Discussion}

\subsubsection{Policy analysis matrix in the context of import parity price of rice}

In this section, the results of the policy analysis matrix and sensitivity analysis are discussed sequentially and with necessary interpretations. The main results of the protection and comparative advantage coefficients for the four observed granary areas are shown in Table 2.3. Domestic Resource Cost (DRC) and Social Cost Benefit (SCB) were estimated in order to measure the competitiveness of Malaysia's rice sector. DRC compares the domestic costs of resources measured at the corresponding social price with the value added measured in the social prices. The use of the social prices in DRC measure allows us to test whether the employment of scarce domestic inputs in the production of rice generates positive returns for Malaysia.

The empirical analysis presented in this paper demonstrates that three of four study areas (BLS, MADA and KADA) had comparative advantages in the production of rice $(\mathrm{DRC}<1)$ between 2011 and 2012. However, the results indicate no comparative advantage for rice production in the KETARA area because the DRC was greater than one. It is more advantageous for the nation to produce rice in the three granary areas and to expand its production considering the added social value is greater than the cost of importing rice. However, the estimated DRCs are closer to unity, indicating that there may be some competing demand on resources for production of other crops. Moreover, the closer the DRC value is to one, the more impact a small change in prices can have. With the estimated DRC of rice grown in KETARA observed to be greater than one under the circumstances of import parity prices, no comparative advantage is detected. As a result, the emphasis on the attainment of self-sufficiency in rice production appears to be uneconomically justified and remains debatable. 
Table 2.3: Summary results of different indicators of protection and comparative advantage

\begin{tabular}{|c|c|c|c|c|c|c|c|c|c|c|c|c|}
\hline \multirow{2}{*}{ Areas } & \multicolumn{6}{|c|}{2011} & \multicolumn{6}{|c|}{2012} \\
\hline & DRC & SCB & $\mathrm{PC}$ & SRP & PNRL & SNRL & DRC & SCB & $\mathrm{PC}$ & SRP & PNRL & SNRL \\
\hline $\mathrm{KADA}$ & 0.92 & 0.95 & 12.51 & 0.62 & 3432 & 274 & 0.90 & 0.93 & 8.15 & 0.47 & 2842 & 349 \\
\hline MADA & 0.97 & 0.98 & 31.36 & 0.62 & 3262 & 104 & 0.84 & 0.88 & 5.11 & 0.48 & 3380 & 661 \\
\hline KETARA & 1.19 & 1.11 & -6.93 & 0.88 & 2874 & -415 & 1.13 & 1.08 & -6.84 & 0.60 & 2101 & -307 \\
\hline BLS & 0.86 & 0.91 & 10.89 & 0.88 & 5703 & 524 & 0.78 & 0.85 & 4.76 & 0.56 & 4239 & 891 \\
\hline
\end{tabular}

Source: Own estimation

Nevertheless, the average DRC results presented in this paper should be interpreted with caution. These results are based on aggregated data that most certainly conceals relevant variation and the underlying distribution of competitiveness across a set of heterogeneous producers (von Cramon Taubadel and Nivyevskyi, 2008). In other words, the results presented here aggregate very efficient farms that are more competitive than average with less efficient farms that are less competitive than average. This can have great far-reaching implications for policy conclusions based on the PAM results. For example, support based on the average competitiveness will over-support some farms and under-support others. Therefore, only cautious conclusions based on average DRCs have been made and further analyses of DRC distributions is required to determine which factors influence a farm's competitiveness.

Another indicator of competitiveness is the Social Cost Benefit (SCB) ratio. The estimated SCB values used for this research are consistent with the DRC calculations discussed above. The calculated SCB ratios, which are less than 1, indicate the profitability of rice farming in each granary area except for in KETARA. With an estimated SCB ratio exceeding unity, the KETARA granary area hardly displays a comparative advantage in rice production.

The measure of net transfer is further demonstrated by the Profitability Coefficient (PC), which determines the predominant effects of all policies, including output, tradable and nontradable input policies that may not be included in NPC and EPC estimates (Monke and Pearson, 1989). Each of the PC values for the three granary areas, excluding KETARA, is negative in both years. The results indicate that there is a net transfer from social to private 
profits, except in KETARA. The other ratio indicator measuring net transfer is the Subsidy Ratio to producers (SRP), which indicates the influence of incentives or disincentives on divergences. The average values of SRP range between 0.47 and 0.59 in 2012. This value conveys that the divergences, which are almost entirely due to distortive policies in the case of this study, have nearly doubled in gross revenue.

Further analyses were conducted to measure the private net return to land (PNRL) and social net return to land (SNRL), which were used to estimate the returns to the fixed factor: land. Both PNRL and SNRL values are positive for three of the areas, except for KETARA. This implies that it is desirable for average rice producers in the granary areas KADA, MADA and BLS to grow rice.

The results in Table 2.4 show the divergences between private and social profits, or in other words, the effect of different policy transfers, such as output, input, factor and net policy transfers. The values of the output transfers (private revenues less social revenues) are positive, while the values for input transfers (the difference between the private and social prices of tradable inputs) and the factor transfers (the difference between the private and social prices of non-tradable inputs or domestic factors) are all negative. The positive values of output transfers point to the system receiving protection, i.e. the government protective policies affect the system positively, resulting in a price subsidy scheme of RM240.1/mt. The negative values of the input transfers indicate that the producers buy inputs at a lower price than the world market price due to the subsidy policy on fertilizers, lime and pesticides. The same is true for the factor transfer values that demonstrate that the costs of non-tradable inputs are lower than their social prices. This can be attributed to the primary factors of production, which is mainly land, since the social and private values of land are determined by the land's alternative uses. 
Table 2.4: PAM results of rice production in major granary areas in Malaysia in 2011$\mathbf{2 0 1 2}^{2}$

\begin{tabular}{|c|c|c|c|c|c|c|c|}
\hline $\begin{array}{c}\text { Granary } \\
\text { Area }\end{array}$ & Year & $\begin{array}{l}\text { Output } \\
\text { Transfers } \\
\text { (RM/ha) }\end{array}$ & $\begin{array}{l}\text { Tradable } \\
\text { Input } \\
\text { Transfers } \\
\text { (RM/ha) }\end{array}$ & $\begin{array}{l}\text { Domestic } \\
\text { Factor } \\
\text { Transfers } \\
(\mathrm{RM} / \mathrm{ha}) \\
\end{array}$ & $\begin{array}{c}\text { Private } \\
\text { Profitability } \\
(\mathrm{RM} / \mathrm{ha})\end{array}$ & $\begin{array}{c}\text { Social } \\
\text { Profitability } \\
(\mathrm{RM} / \mathrm{ha})\end{array}$ & $\begin{array}{c}\text { Net } \\
\text { Policy } \\
\text { Effects } \\
\text { (RM/ha) }\end{array}$ \\
\hline \multirow[t]{2}{*}{ KADA } & 2011 & 1772.95 & -284.38 & -1100 & 3431.60 & 274.27 & 3157.33 \\
\hline & 2012 & 1252.35 & -140.6 & -1100 & 2841.60 & 348.65 & 2492.95 \\
\hline \multirow[t]{2}{*}{ MADA } & 2011 & 1571.15 & -204.76 & -1200 & 3324.64 & 348.73 & 2975.91 \\
\hline & 2012 & 996.03 & -122.66 & -1600 & 3379.73 & 661.04 & 2718.69 \\
\hline \multirow[t]{2}{*}{ KETARA } & 2011 & 1315.57 & -204.66 & -1100 & 1921.84 & -698.39 & 2620.23 \\
\hline & 2012 & 1161.45 & -46.44 & -1200 & 2100.95 & -306.94 & 2407.89 \\
\hline \multirow[t]{2}{*}{ BLS } & 2011 & 2284.75 & -194.44 & -1100 & 4165.28 & 586.09 & 3579.19 \\
\hline & 2012 & 2064.27 & -84.08 & -1200 & 4239.07 & 890.72 & 3348.35 \\
\hline
\end{tabular}

Source: Own estimation

Overall, the net transfer policy for all regions is positive. The net transfer is the sum of output transfer, the tradable input transfer and factor transfer. The net transfer is the difference between private profits and social profits. Due to the fact that social profits are positive in each granary area, except in the KETARA area, the systems could operate profitably without any policy transfers. The results also show variations in profitability across regions, both in private and social terms. Based on the research conducted for this paper, the private profits per hectare of rice production in all granary areas are greater than zero. This is demonstrated by normal returns and possible expansions to each area's production, unless, of course, a farming area could not be expanded or the substitute crops were more lucrative at private prices. Moreover, the social profits are positive in all areas that have DRCs less than one, indicating that the rice producers in these areas are efficiently using scarce resources. Conversely, a negative social profit value in KETARA reveals that the rice system is dependent on government assistance. The result of private profits clearly indicates that rice production is highly profitable in some granary areas at private prices. However, at social prices, profitability is decreased.

2. Exchange rate: US $\$ 1=$ RM3.05 and EUR€1= RM4.25 (Oct 31, 2011); US $\$ 1=$ RM3.06 and EUR $€ 1=$ RM4 .27 (Oct 31, 2012); US\$1= RM2.96 and EUR€1=RM4.21 (Nov 30, 2014) ${ }^{2}$ 


\subsubsection{Sensitivity analysis}

It may be worthwhile to examine the degree to which the comparative advantage of rice production in Malaysia, under a set of baseline assumptions, is affected by the changes in key parameter values. Morris et al. (1990) postulates that a sensitivity analysis would be applicable for two reasons. Firstly, the profitability analysis is conducted on the basis of certain simplifying assumptions of production technologies, as indicated by the output-input coefficients, government policies and prices. Secondly, the DRC framework gauges an area's comparative advantage, which is static as it represents a snapshot taken at a fixed point in time. However, in practice, actual efficiency is dynamic (it adjusts according to changes in production technologies, prices and government policies). Therefore, it is crucial to determine the effect changes in the parameters have on the results.

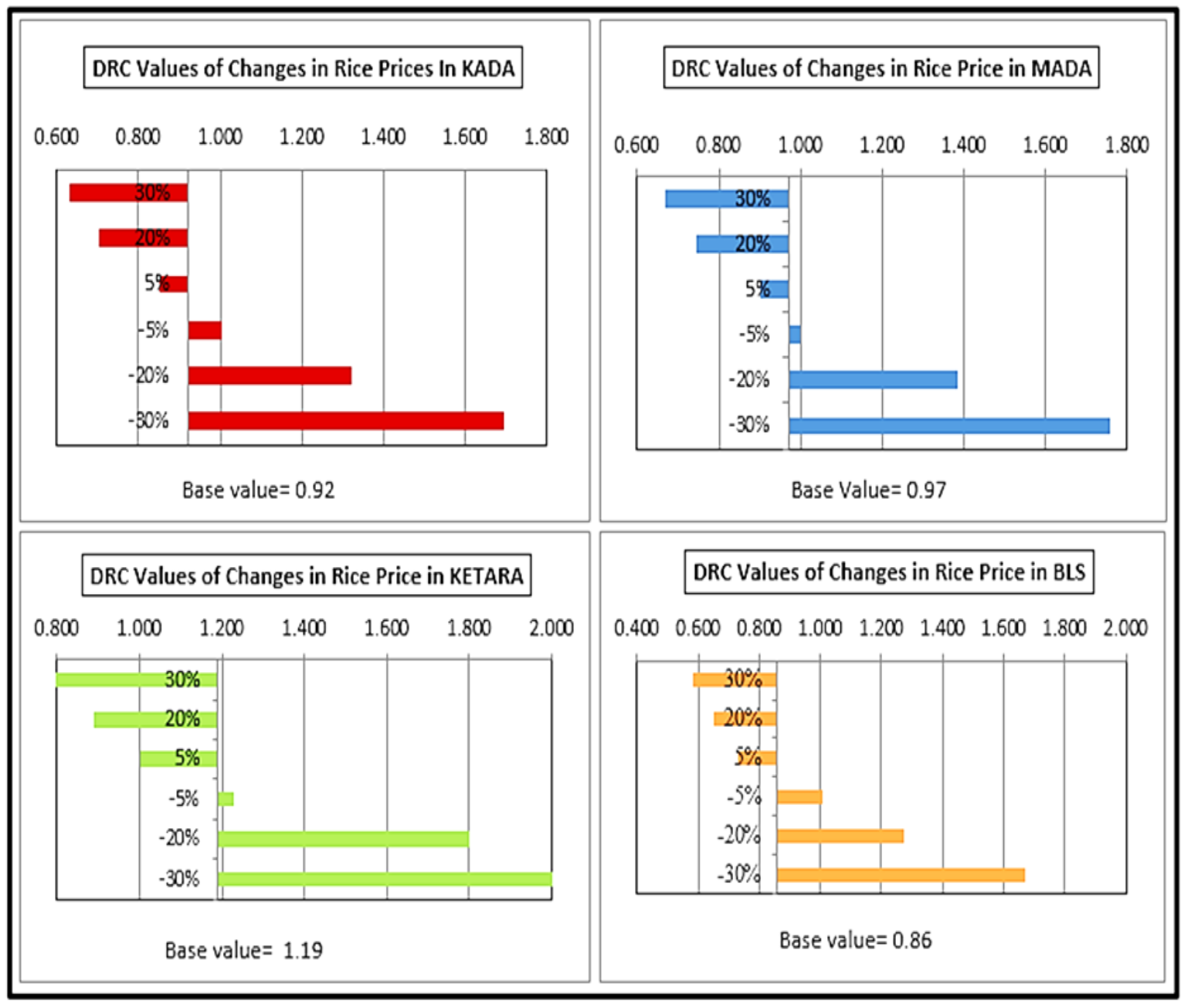

Figure 2.2: Change of Domestic resource cost (DRC) in the import rice prices in Malaysia 
The subsequent graphs summarize the results of the sensitivity analysis on the comparative advantages of rice production in Malaysia in 2011, with special emphasis on the individual impact of relevant determining factors. Figure 2.2 demonstrates that the estimated DRCs in rice production in each granary area are quite sensitive to changes in the international (reference) price of rice. An increase of 20 percent in the international price would make the domestic production of rice in all areas socially profitable, with DRC values of less than one.

Table 2.5: Change in selected tradable input prices

\begin{tabular}{llccccccc}
\hline $\begin{array}{l}\text { Tradable } \\
\text { inputs }\end{array}$ & $\begin{array}{l}\text { Granary } \\
\text { area }\end{array}$ & $\begin{array}{c}\text { DRC } \\
\text { Base } \\
\text { value }\end{array}$ & $\mathbf{1 0 \%}$ & $\mathbf{2 5 \%}$ & $\mathbf{4 5 \%}$ & $\mathbf{- 1 0 \%}$ & $\mathbf{- 2 5 \%}$ & $\mathbf{- 4 5 \%}$ \\
\hline Fertilizer & KADA & 0.92 & 0.949 & 1.000 & 1.076 & 0.889 & 0.849 & 0.824 \\
& MADA & 0.97 & 1.001 & 1.053 & 1.131 & 0.940 & 0.898 & 0.873 \\
& KETARA & 1.19 & 1.236 & 1.313 & 1.433 & 1.146 & 1.086 & 1.050 \\
& BLS & 0.86 & 0.891 & 0.939 & 1.001 & 0.835 & 0.796 & 0.773 \\
\hline Seed & KADA & 0.92 & 0.921 & 0.926 & 0.932 & 0.915 & 0.910 & 0.907 \\
& MADA & 0.97 & 0.974 & 0.980 & 0.988 & 0.966 & 0.960 & 0.956 \\
& KETARA & 1.19 & 1.196 & 1.206 & 1.220 & 1.182 & 1.172 & 1.166 \\
& BLS & 0.86 & 0.867 & 0.875 & 0.885 & 0.857 & 0.850 & 0.845 \\
\hline Pesticides & KADA & 0.92 & 0.923 & 0.931 & 0.942 & 0.913 & 0.905 & 0.900 \\
& MADA & 0.97 & 0.974 & 0.981 & 0.991 & 0.965 & 0.958 & 0.954 \\
& KETARA & 1.19 & 1.193 & 1.199 & 1.206 & 1.185 & 1.180 & 1.176 \\
& BLS & 0.86 & 0.864 & 0.868 & 0.872 & 0.860 & 0.857 & 0.854 \\
\hline Fuel & KADA & 0.92 & 0.919 & 0.922 & 0.925 & 0.916 & 0.914 & 0.912 \\
& MADA & 0.97 & 0.971 & 0.972 & 0.974 & 0.969 & 0.967 & 0.966 \\
& KETARA & 1.19 & 1.191 & 1.194 & 1.198 & 1.187 & 1.184 & 1.182 \\
& BLS & 0.86 & 0.864 & 0.866 & 0.870 & 0.860 & 0.858 & 0.856 \\
\hline
\end{tabular}

Source: Own estimation

The impact of changes in other single factors namely traded inputs; imported fertilizer prices, seed, pesticides, and fuel prices, are presented in Table 2.5. As the country progresses towards trade liberalization, the costs of these inputs are expected to rise, resulting in a reduction of comparative advantages for rice farming in all major granary areas. It is evident that if the costs of tradable inputs increase, the values of DRC will also grow, but fertilizer is the most susceptible to changes. The high share of fertilizer used in rice production in all the granary areas, has negatively affected the comparative advantage in Malaysia. As the price of fertilizer increases by 25 percent in KADA, or by 10 percent in MADA, the social profits will minimize. However, profitability remains quite robust for the other inputs. 
The sensitivity analysis of increasing or decreasing the costs of imported rice, fertilizer, seed, pesticides and fuel shows that the coefficients have similar patterns of competitiveness. Under certain unfavorable economic conditions, average Malaysian rice producers could lose their comparative advantages. For example, in the event of higher input costs, with particular emphasis on fertilizer costs or the deterioration of the international market's price of rice, a rice producer's comparative advantage could diminish.

\subsection{Conclusion}

The challenges presented by trade liberalization have created tougher competition and unfavorable conditions for Malaysia to strengthen its economic growth. The country's rice sector, which is an important part of the economy because of its production value and the source of employment it provides, also faces these challenges. More than 100,000 farmers are involved in rice farming. In an effort to increase paddy production, the government has provided a great degree of support to paddy producers, most of whom live in poverty. These incentives aim to enhance rice production levels, secure self-sufficiency by 2020 and maintain food security. Utilizing a PAM model, this study investigated whether the government's interventions make economic sense to be fully self-efficient. In order to arrive at this conclusion, the competitiveness of Malaysia's rice production, particularly in the KADA, MADA, KETARA and BLS granary areas, was analyzed.

The results indicate that three out of four granary areas have comparative advantages in rice production with Domestic Resource Cost values, or DRCs, of less than one. Conversely, the results indicated no comparative advantage for rice production in the KETARA area, as the DRC is greater than one. Similarly, Social Cost Benefit or SCB values in these areas are less than one indicating that the comparative advantages in rice production are noteworthy.

Therefore, social profitability appears in three of the four areas, although there are farms that generate a net surplus for the country. To fully understand the impact of these farms, they must be identified and studied by further research using disaggregated data. These farms may generate social profits, but they might depend on financial government support to provide for their families. In this case, policies should focus on encouraging structural changes, which enable these farms to grow enough to generate a sufficient income from social profits alone, i.e. without (or with much less) subsidy. This way the government could encourage selfsufficiency and spend less money. In the other region, the average farm does not yield a social 
profit. However, it is likely that this area also has farms that are socially profitable. In all four regions (and especially in the KETARA region there must be many farms that are not producing a social profit. Thus, further research with disaggregated data is required to determine why this is the case, and how the situation can be improved.

\section{Additional Notes:}

The empirical analysis presented in Appendix 2.2 and 2.3 is based on secondary data provided by R.Terano et al (2013), Rabu and Mohd Shah (2013) and KADA (2014). The data were then crosschecked with a local expert from BERNAS to ensure reliability and validity. Each calculation was conducted on a hectare basis and in Malaysia currency, the Malaysian Ringgit (RM). As means of determining the PAM, the authors of this text classified input items into tradable and non-tradable inputs categories. In the context of rice farms, tradable inputs include fertilizers, chemicals, seeds and fuel, while the other inputs, such as labor, capital and land rent were categorized as non-tradable inputs. The social price (shadow price) of all the inputs and the output (rice) was subsequently estimated, and finally, the commodity and system budget tables were configured to the PAM table and relevant policy parameters were derived.

The conversion of private to social prices is based on several data and assumptions:

i. Rice is an imported good; therefore, the social price for rice is the import parity price of rice equivalents at the farm gate.

ii. As for the tradable inputs, the social prices of fertilizers, pesticides, seeds, fuel and lime are the respective import parity prices at the farm gate.

iii. Social costs of transplanting packages are also assumed to equal the private costs considering that the owners determine the value of these packages and services.

iv. Domestic inputs, such as land, for which no international prices exist is valued at local opportunity costs. Hence, the rental values of land per hectare for different granary areas were obtained from an agricultural officer and a land value officer in Selangor. Based on the information provided, it is clear that all approaches used to determine the value of agricultural land are subject to criticism. In this regard, one can argue that this is due to the extreme difficulty of assigning a price to land. 
v. Social costs are assumed to equal private costs for labor.

vi. The need to determine the shadow exchange rate is important when conducting an economic analysis, especially because it affects all the social values of tradable components and output. Thus, the shadow exchange rate is used instead of the official exchange rate to convert the international prices in US dollars to Malaysia's currency. In 2011, the official exchange rate was \$1/3.05 Malaysia Ringgit, but the shadow exchange rate was estimated at $\$ 1 / 3.061$ Malaysia Ringgit. In 2012, the shadow exchange rate was estimated at $\$ 1 / 3.076$ (as the official exchange rate was $\$ 1 / 3.06$ ). Malaysia is an open economy where the disparity between the official and shadow exchange is minimal.

Appendix 2.1: Rice Production in Major Granary Areas, Malaysia (2008- 2010)

\begin{tabular}{|c|c|c|c|c|c|c|c|c|}
\hline \multirow{2}{*}{ Granary Area } & \multirow{2}{*}{ Area $(\mathrm{Ha})$} & \multirow{2}{*}{$\%$ Area } & \multicolumn{6}{|c|}{ Contribution to National Production (Metric ton and \%) } \\
\hline & & & 2008 & $\%$ & 2009 & $\%$ & 2010 & $\%$ \\
\hline MADA & 96,558 & 23.22 & 887,992 & 37.74 & 976,192 & 38.33 & 912,321 & 37.01 \\
\hline KADA & 32,167 & 7.74 & 179,048 & 7.61 & 209.950 & 8.36 & 201,135 & 8.16 \\
\hline IADA K.S MANIK & 27,829 & 6.69 & 169,753 & 7.21 & 187,117 & 7.45 & 184,563 & 7.08 \\
\hline IADA BLS & 18,814 & 4.52 & 174,247 & 7.41 & 202,633 & 8.07 & 210 & 8.53 \\
\hline IADA P. PINANG & 10,305 & 2.46 & 98,436 & 4.16 & 107,285 & 4.27 & 115,189 & 4.67 \\
\hline IADA S.PERAK & 8,529 & 2.05 & 62,076 & 2.64 & 70,294 & 2.8 & 70,814 & 2.87 \\
\hline $\begin{array}{l}\text { IADA KETARA } \\
\text { IADA }\end{array}$ & 5,156 & 1.24 & 46,097 & 1.96 & 49,082 & 1.95 & 52,711 & 2.14 \\
\hline K.SEMERAK & 5,220 & 1.26 & 14,757 & 0.63 & 16,853 & 0.67 & 20,550 & 0.83 \\
\hline $\begin{array}{l}\text { TOTAL } \\
\text { GRANARY }\end{array}$ & 204,578 & 49.20 & $1,632,406$ & 69.38 & $1,609,666$ & 72.46 & $1,557,493$ & 71.31 \\
\hline $\begin{array}{ll}\text { TOTAL } & \text { NON } \\
\text { GRANARY } & \end{array}$ & 211,213 & 50.82 & 720,626 & 30.63 & 691,637 & 27.54 & 707,256 & 28.71 \\
\hline MALAYSIA & 415,791 & 100 & $2,353,032$ & 100 & $2,301,303$ & 100 & $2,264,749$ & 100 \\
\hline
\end{tabular}


Appendix 2.2: Private and social costs calculations for the rice farms in KADA, MADA, KETARA and BLS granary areas in Malaysia (RM/ha) in 2011

\begin{tabular}{|c|c|c|c|c|c|c|c|c|c|c|c|c|c|c|}
\hline \multirow{2}{*}{$\begin{array}{c}\text { Granary } \\
\text { area }\end{array}$} & \multirow[b]{2}{*}{ Items } & \multicolumn{11}{|c|}{ Costs } & \multirow{2}{*}{ Revenue } & \multirow{2}{*}{$\begin{array}{c}\text { Cost- } \\
\text { benefit } \\
\text { ratio }\end{array}$} \\
\hline & & Seed & NPK & Urea & Compound & Organic & Pesticides & Lime & Transplanting & Fuel & Labor & Land & & \\
\hline \multirow[t]{2}{*}{ KADA } & Private & 200 & 378 & 138 & 325 & 132 & 230 & 248 & 0 & 76 & 1120 & 900 & 6589 & 1.76 \\
\hline & Social & 213 & 340 & 142 & 373 & 138 & 244 & 322 & 0 & 96 & 1120 & 1150 & 5336 & 1.07 \\
\hline \multirow[t]{2}{*}{ MADA } & Private & 136 & 336 & 104 & 312 & 110 & 184 & 240 & 0 & 42 & 760 & 1000 & 6603 & 2.05 \\
\hline & Social & 145 & 302 & 106 & 358 & 115 & 195 & 312 & 0 & 53 & 760 & 2600 & 5607 & 1.13 \\
\hline \multirow[t]{2}{*}{ KETARA } & Private & 140 & 315 & 92 & 312 & 110 & 138 & 0 & 450 & 29 & 580 & 900 & 5166 & 1.69 \\
\hline & Social & 149 & 284 & 94 & 358 & 115 & 146 & 0 & 450 & 36 & 580 & 2100 & 4005 & 0.93 \\
\hline \multirow[t]{2}{*}{ BLS } & Private & 160 & 420 & 115 & 325 & 121 & 184 & 0 & 530 & 53 & 980 & 900 & 8027 & 2.12 \\
\hline & Social & 168 & 394 & 122 & 390 & 134 & 187 & 0 & 530 & 67 & 980 & 2100 & 5963 & 1.18 \\
\hline
\end{tabular}

Appendix 2.3: Private and social costs calculations for the rice farms in KADA, MADA, KETARA and BLS granary areas in Malaysia (RM/ha) in 2012

\begin{tabular}{|c|c|c|c|c|c|c|c|c|c|c|c|c|c|c|}
\hline \multirow{2}{*}{$\begin{array}{c}\text { Granary } \\
\text { area }\end{array}$} & \multirow[b]{2}{*}{ Items } & \multicolumn{11}{|c|}{ Costs } & \multirow{2}{*}{ Revenue } & \multirow{2}{*}{$\begin{array}{c}\text { Cost- } \\
\text { benefit } \\
\text { ratio }\end{array}$} \\
\hline & & Seed & NPK & Urea & Compound & Organic & Pesticides & Lime & Transplanting & Fuel & Labor & Land & & \\
\hline \multirow[t]{2}{*}{ KADA } & Private & 200 & 378 & 138 & 325 & 132 & 230 & 248 & 0 & 76 & 1120 & 900 & 6589 & 1.76 \\
\hline & Social & 213 & 340 & 142 & 373 & 138 & 244 & 322 & 0 & 96 & 1120 & 1150 & 5336 & 1.07 \\
\hline \multirow[t]{2}{*}{ MADA } & Private & 136 & 336 & 104 & 312 & 110 & 184 & 240 & 0 & 42 & 760 & 1000 & 6603 & 2.05 \\
\hline & Social & 145 & 302 & 106 & 358 & 115 & 195 & 312 & 0 & 53 & 760 & 2600 & 5607 & 1.13 \\
\hline \multirow[t]{2}{*}{ KETARA } & Private & 140 & 315 & 92 & 312 & 110 & 138 & 0 & 450 & 29 & 580 & 900 & 5166 & 1.69 \\
\hline & Social & 149 & 284 & 94 & 358 & 115 & 146 & 0 & 450 & 36 & 580 & 2100 & 4005 & 0.93 \\
\hline \multirow[t]{2}{*}{ BLS } & Private & 160 & 420 & 115 & 325 & 121 & 184 & 0 & 530 & 53 & 980 & 900 & 8027 & 2.12 \\
\hline & Social & 168 & 394 & 122 & 390 & 134 & 187 & 0 & 530 & 67 & 980 & 2100 & 5963 & 1.18 \\
\hline
\end{tabular}




\section{References}

Amaya Montoya, J.D. (2011). The Colombian rice sector scenarios and strategic options for increasing the competitiveness considering international free trade agreements: Master Thesis. Wageningen University, Management Studies.

Bishwajit, G., Sarker, S., Kpoghomou, M.-A., Gao, H., Jun, L., Yin, D., \& Ghosh, S. (2013). Self-sufficiency in rice and food security: a South Asian perspective. Agriculture \& Food Security, 2(1), 10. http://doi.org/10.1186/2048-7010-2-10

Department of Agriculture. (2010). Subsidi, Bantuan dan Insebtif Pertanian. http://pmr.penerangan.gov.my/index.php/penstrukturan-subsidi/9893-subsidi-bantuandan-insentif-pertanian.html

Fang, C., \& Beghin, J. C. (2000). Self-sufficiency, Comparative Advantages, and Agricultural Trade: A Policy Analysis Matrix for Chinese Agriculture. Retrieved from http://down.cenet.org.cn/upfile/52/20062232278169.pdf

FAO. Food and Agriculture Organization of the United Nations, (n.d.). The State of Food Insecurity in the World. Retrieved December 6, 2015, from http://www.fao.org/docrep/014/i2330e/i2330e.pdf

Gittinger, J.P. (1982). Economic Analysis of Agricultural Projects, 2nd ed. Baltimore MD: The Johns Hopkins University Press, London

Hayat, A., \& Islam, S. (2005). Protection and comparative advantage of rice production in Bangladesh: A policy analysis matrix. https://ejournals.unm.edu/index.php/nsc/article/view/626

Jamora, N., \& von Cramon-Taubadel, S. (2012). RTG 1666 GlobalFood Discussion Papers. RTG 1666 GlobalFood.Transformation of Global Agri-Food Systems: Trends, Driving Forces, and Implications for Developing Countries.

Javed, S., Hassan, S., Adil, S. A., Ghafoor, A., Bakhsh, K., \& Siddique, A. (2006). Comparative Advantage of Cotton Production and Its Policy, 43, 193-196.

Kanaka, D. S., \& Chinnadurai, M. (2013). The Policy Analysis of Rice Cultivation in India. European Journal of Physical and Agricultural Sciences, 1(1). Retrieved from http://www.idpublications.org/wp-content/uploads/2013/11/the-policy-analysis-matrixof-rice-cultivation-in-india.pdf

Krueger, A.O. (1966). Some economic costs of exchange control: the Turkish case. Journal of Political Economy. 74, 466-480. 
M.d Wahid, M., Nik Hashim, N. M., \& Chamhuri, S. (2008). Review of Malaysian Agricultural Policies with Regards to Sustainability. American Journal of Environmental Sciences, 4(6), 608-614. Retrieved from http://thescipub.com/PDF/ajessp.2008.608.614.pdf

Mailena, L., Shamsudin, M. N., Radam, A., \& Latief, I. (2014). Rice farms efficiency and factors affecting the efficiency in MADA Malaysia. Journal of Applied Sciences. http://doi.org/10.3923/jas.2014.2177.2182

Masters, W. A., \& Winter-Nelson, A. (1995). Measuring the Comparative Advantage of Agricultural Activities: Domestic Resource Costs and the Social Cost-Benefit Ratio. American Journal of Agricultural Economics, 77(2), 243-250. http://doi.org/10.2307/1243534

Mohanty, S., Fang, C., \& Chaudhary, J. (2003). Assessing the Competitiveness of Indian Cotton Production: A Policy Analysis Matrix Approach. Journal of Cotton Science, 7(3). $\quad$ Retrieved from http://www.support.aaec.ttu.edu/CERI/NewPolicy/Publications/WorkingPapers/Assessi ng the Competitiveness of Indian Cotton Production.pdf

Mohd Rashid, R., \& Mohd Dainuri, M. S. (2013). Food and livelihood security of the Malaysian paddy farmers. Economic and Technology Management Review, 8, 59-69.

Monke, E. A., \& Pearson, S. R. (1989). The Policy Analysis Matrix for Agricultural Development. Ithaca, NY: Cornell University Press. Retrieved from http://web.stanford.edu/group/FRI/indonesia/documents/pambook/pambook.pdf

Morris, M.L. (1990). Determining Comparative Advantage Through DRC Analysis: Guidelines Emerging from CIMMYT's Experience. CIMMYT Economics Paper NO.1. Mexico, D.F.: CIMMYT.

Nelson, G. C., \& Panggabean, M. (2011). Matrix Policy : Approach Analysis, 73(3), 703-712.

Perangkaan, Perancangan, \& Pertanian, (2013). Sub Sektor Tanaman Makanan. Booklet Statistik Tanaman, 1-114.

Redfern, S. K., Azzu, N., \& Binamira, J. S. (2012). Rice in Southeast Asia: facing risks and vulnerabilities to respond to climate change. Building Resilience for Adaptation to Climate Change in the Agriculture Sector, (2002), 295-314. Retrieved from http://www.fao.org/fileadmin/templates/agphome/documents/faooecd/oecd_proceedings .pdf\#page $=302$

Rittgers, C., \& Wahab, A. G. (2014). Malaysia Grain and Feed Annual. GAIN Report, 1-5. 
Rosegrant, M. W., \& Sulser, T. (2002). Rice Price Crisis : Causes , Impacts , and Solutions. Asian Journal of Agriculture and Development, Vol. 7, No. 2, 7(2), 1-15.

Rudner, M. (1975). The State and Peasant Innovation in Rural Development: The Case of Malaysian Rubber in D.Lim (ed), Readings on Malaysian Economic Development. Oxford University Press, Kuala Lumpur.

Sadoulet, E., \& Janvry, A. de. (1995). Quantitative Development Policy Analysis. The Johns Hopkins University Press, Baltimore and London. Retrieved from http://caoye.lzu.edu.cn/upload/news/N20141106111536.pdf

Siggel, E. (2006). International competitiveness and comparative advantage: A survey and a proposal for measurement. Journal of Industry, Competition and Trade, 6(2), 137-159. http://doi.org/10.1007/s10842-006-8430-x

Tengku Mohd Ariff, T. A., \& Ariffin, T. (1999). Effect of Trade Liberalization on Agriculture in Malaysia: Commodity Aspects (The CGPRT Center Working Paper Series no. 46.). Retrieved from http://ageconsearch.umn.edu/bitstream/32694/1/wp990046.pdf

Terano, R., \& Mohamed, Z. (2011). Household Income Structure Among Paddy Farmers in the Granary Areas of Malaysia. International Conference on Innovation, Management and Service, IPEDR, 14, 160-165.

Tey, (John) Yeong-Sheng, \& Radam, A. (2011). Demand patterns of rice imports in Malaysia: Implications for food security. Food Security, 3(2), 253-261. http://doi.org/10.1007/s12571-011-0128-1

Timmer, C. P. (2007). Structural Transformation, the Changing Role of Rice, and Food Security in Asia: Small Farmers and Modern Supply Chains. Asian Journal of Agriculture and Development, 9(1), 21-35. Retrieved from http://ageconsearch.umn.edu/bitstream/204258/2/AJAD_2011_9_1_2Timmer.pdf

von Cramon Taubadel, S., \& Nivyevskyi, O. (2009). Belarus Agricultural Productivity and Competitiveness: Impact of State Support and Market Intervention. Retrieved from https://openknowledge.worldbank.org/bitstream/handle/10986/18897/483350ESW0RE VI110FINAL0for0printing.pdf?sequence $=1 \&$ is Allowed $=\mathrm{y}$

von Cramon-Taubadel, S., \& Nivyevskyi, O. (2008). Ukraine-Ag-Competitiveness-Policy Note - Final.

Yao, S. (1997). Comparative Advantages and Crop Diversification: A Policy Analysis Matrix for Thai Agriculture. Journal of Agricultural Economics, 48(1-3), 211-222. http://doi.org/10.1111/j.1477-9552.1997.tb01146.x 
Assessing Competitiveness of Malaysian Rice Production

Yao, S. J. (1997). Rice production in Thailand seen through a policy analysis matrix. Food Policy, 22(6), 547-560. http://doi.org/10.1016/S0306-9192(98)00007-4 


\section{Chapter 3}

\section{Determinants of Rice Farming Competitiveness in Malaysia : An Extension of the Policy Analysis Matrix}

The advent of free trade agreements, including the Asean Free Trade agreement (AFTA) and WTO accession, hampers the Malaysian rice sector as the sector must compete with low-cost exporting countries. This implies that structural changes in trade and adjustments at the farm level are needed to improve competitiveness. In this paper we aim to understand the driving forces behind competitive rice production in Malaysia; to do so, an extension of the Policy Analysis Matrix proposed by Monke and Pearson (1989) is applied. This extension allows us to take farm-level heterogeneity into account and derive competitiveness score distributions for each rice farm. In a second step of analysis, we use dynamic panel regression methods to examine factors influencing rice competitiveness. Our results demonstrate that considering the aggregate data or average Social Cost Benefit alone may conceal important variations across the farms. Many farmers are shown to be competitive; however these competitive farms account for a disproportionately large share of rice production when using disaggregate data. We concluded participation in the farmers' organization, gender and farm size are the major determinants of rice competitiveness, while the increasing distance to rice mills, offfarm income and the use of hired labor may reduce competitiveness.

Keywords: policy analysis matrix, competitiveness, self-sufficiency, comparative advantage, rice production, Malaysia 


\subsection{Introduction}

Agriculture is an important sector of Malaysia's economy as it provides employment and is the main source of income for the population, as well as it alleviates poverty in rural areas. Rice is a major staple food in Malaysia and the industry provides employment for 11.6 million Malaysian rice farmers (12\% of the national workforce), and contributes about $7.7 \%$ to the national GDP (Chan and Cho, 2012).

Since rice is a strategically important staple commodity, the government intervenes more in this sector than in others. Rice is highly protected due to food security concerns and the critical role it plays in supporting farmers' incomes. However, the liberalization of rice trade fostered by the World Trade Organization (WTO), the Uruguay Round Agreement on Agriculture, and regional trade agreements such as the ASEAN Free Trade Area (AFTA), has bound Malaysia to commitments in the areas of domestic support, export subsidies and market access to agriculture. The key factors that affect the global rice trade are import tariffs, tariff rate quotas in major importing countries and price supports in major exporting countries (Wailes, 2005).

The recent dramatic changes on the international rice scenario precipitated by the price increase in petroleum, high prices of agricultural inputs and the spike in world food prices, have had considerable effects on rice farmers and rice production (Timmer and Dawe, 2007; Jamora and von Cramon-Taubadel, 2012). The world food price crisis of 2008 placed a particularly heavy burden on the balance of trade in many developing countries, especially Malaysia, which has been a large net importer of rice for centuries. Rice imports account for a larger share of GDP in Malaysia than in other countries. Malaysia's high dependency on rice imports makes the country vulnerable to international market shocks and disruptions in major rice exporting countries.

For these reasons rice production will continue to receive significant attention from policymakers. The Malaysian government has provided considerable support to rice producers, and some economic analysts argue that without this support rice production could not compete internationally (Arshad et al. 2011; Umar et al. 2014; Tengku Mohd Ariff and Ariffin 1999). Some of these analysts find that the price support scheme has increased rice outputs and the income generated from them by more than $50 \%$, and that repealing this policy would render the rice sector uncompetitive. However, other analyses indicate that rice 
production in Malaysia is competitive. The study conducted by Busayo Rashidat et al. (2013) determined the relevant costs and benefits of various incentive schemes before and after the food crisis for rice production in selected regions of Malaysia (so-called granary areas). The authors assert that there is no significant difference in Domestic Resource Costs (DRC) between 2007 and 2008, which leads them to conclude that rice cultivation is socially profitable for all paddy farmers. Correspondingly, a recent study conducted by Abdul Fatah and von Cramon Taubadel (2015) demonstrates that on average three out four granary areas in Malaysia have comparative advantages in rice production between 2011 and 2012. However, regional averages can hide considerable variation among farms, which has not been considered in the literature to date.

Is rice production in Malaysia competitive? We generate new evidence using an extension of the Policy Analysis Matrix approach proposed by Monke and Pearson (1989). This extension allows us to take farm-level heterogeneity into account and study the distribution of competitiveness scores for each rice farm. In a second step of our analysis, we use panel regression methods to study the factors that influence competitiveness at the individual farm level.

\subsection{Rice production and policies in Malaysia}

Rice production represents $13 \%$ of the total area harvested in the country and $30 \%$ of the area devoted to seasonal crops. Furthermore, rice production represents $6 \%$ of the value of agricultural production and $11 \%$ of Malaysia's agricultural activity (Chan and Cho, 2012). The majority of rice is produced by small predominantly subsistence farmers with an average farm size of 2.5 hectares (Mohd Rashid and Mohd Dainuri, 2013). On average, rice production in Malaysia yielded 3.7 t/ha during the years 2010-2013, which lies between yields in Thailand (3.0 t/ha) and in Vietnam (5.6 t/ha). 


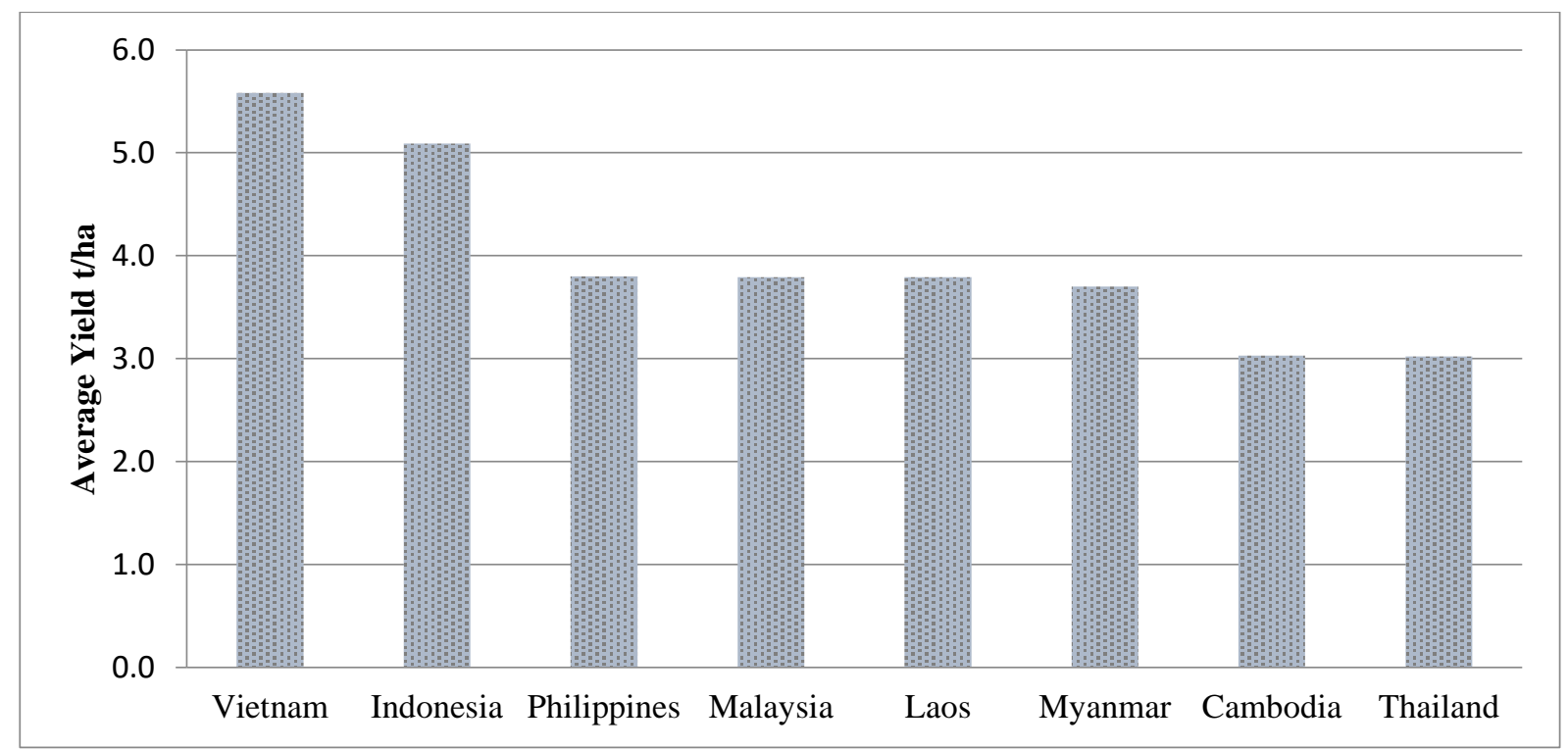

Figure 3.1: Average rice yields, ASEAN countries for 2010-2013. (Source: FAOSTAT, 2016).

Rice is a staple food, and Malaysians consume nearly 2.2 million tons of rice annually, $70 \%$ of which is produced domestically and the rest of which is imported from major rice exporting countries such as Vietnam and Thailand. During the period 2000-2005, the country imported 515 thousand metric tons of rice, making Malaysia the third largest Asian rice importer after the Philippines and Indonesia (FAOSTAT, 2016). During this time, the government argued that it was cheaper to import rice from other countries so as to release arable lands for other cash crops that have the potential to produce higher earnings and yield more profits. However, the world food crisis in 2008 led to an increased emphasis on selfsufficiency, and in 2012 the Malaysian government increased price support measures in the form of a guaranteed minimum price (GMP), and paddy bonus payments to stimulate supply. This output support was supplemented by input subsidies, particularly through the provision of fertilizer, low cost credit and irrigation facilities. In addition, to stabilize consumer prices, the government allowed the national rice company Padiberas Nasional Berhad (BERNAS) to import rice at low or zero tariffs.

These types of programs are common in most developing countries. In Asia, countries such as India, Bangladesh, Indonesia and Pakistan implement food price stabilization programs and input subsidies (Dorosh, 2009; Timmer and Dawe, 2007; Warr and Yusuf, 2014). However, simultaneously protecting both producers and consumers is very costly (Warr and Yusuf, 2014) and has become one of Malaysia's most politically contentious issues. 
According to Malaysia's WTO trade report review (2014), the total support given to agriculture consisted of reduction commitments amounting to 1 billion RM. Of this, approximately $74 \%$ was related to Green Box assistance, mainly in the form of income support for farmers while others involved the fertilizer subsidy scheme. In 2013, price support (incentives or bonus payments for paddy rice production) remained the largest part of expenditures (480 million RM) followed by the fertilizer subsidy (465 million RM).

In addition, the Malaysian government has announced the goal of becoming $100 \%$ selfsufficient in rice by the year 2020. Since preliminary evidence (Abdul Fatah and von Cramon, 2015) indicates that much of Malaysia's rice production is competitive at both private and social prices, producer support measures might be unnecessary. The goal of this paper is to generate more detailed evidence on the competitiveness of rice production in Malaysia.

\subsection{Measuring the competitiveness of rice production}

The Social Cost Benefit (SCB) ratio is one of the indicators that can be calculated to measure competitiveness using the Policy Analysis Matrix (PAM) framework developed by Monke and Pearson (1989). The PAM is described in Appendix 3.2.

It is defined as:

$$
\mathrm{SCB}=\left[\sum_{j=1}^{k} a_{i j} P_{j}^{S}+\sum_{j=k+1}^{n} a_{i j} W_{j}^{S}\right] / P_{i}^{S}
$$

where $P_{i}$ is the price of the output $i$, the $P_{j}$ are the prices of the $k$ tradeable inputs, the $W_{j}$ are the prices of the $n-k$ non-tradeable inputs, and the $\alpha_{i j}$ are technical coefficients which measure the amount of input $j$ that is required to produce one unit of output $i$. Throughout, the superscript $S$ indicates that social rather than private prices are employed. Hence, the SCB is simply the ratio of the social cost of producing one unit of an output, such as rice, to the social value of that unit of output. An SCB value between zero and one indicates that the activity in question is competitive, while a value greater than one indicates that social cost exceeds social value and the activity is not competitive. ${ }^{3}$

\footnotetext{
${ }^{3}$ Another PAM-based indicator that is commonly used is the Domestic Resource Cost (DRC) ratio. However, as Frohberg and Hartmann (1997), Masters and Winter-Nelson (1995) and von CramonTaubadel and Nivyevskyi (2008) discuss, the DRC suffers from several weaknesses. In particular, it is sensitive to the classification of inputs into tradable and non-tradable, which can be difficult in applied work (Monke and Pearson, 1989), and it has a discontinuity at zero, which makes the interpretation of DRC distributions difficult. We therefore consider only the SCB ratio.
} 
The PAM approach and associated indicators, such as the SCB, have been used by analysts working in many developing countries where price distortions are often substantial (Yao 1997; Reig-Martínez et al. 2008; Erenstein 2010; Zheng et al. 2015). However, one major drawback of almost all applied PAM analysis to date is that it is carried out with aggregate data, for example for average or representative farms. This will provide an incomplete picture of sectoral competitiveness since results based on average data may conceal important variations in competitiveness among heterogeneous producers (Nivievskyi et al 2010; von Cramon-Taubadel and Nivyevskyi 2008). To improve the usefulness of indicators based on the PAM, Morrison and Balcombe (2002) suggest resampling data using the bootstrapping method. This method can generate distributional properties of the indicators and thus allow the calculation of standard deviations and confidence intervals for PAM indicators. von Cramon Taubadel and Nivyevskyi (2009) propose the calculation of the distributions of PAM indicators using farm-level survey data. Using kernel methods, they estimate SCB distributions for different agricultural products (e.g. wheat) over a large sample of farms in Ukraine. Using these distributions they estimate the proportion of farms that produces competitively for each product and the proportion of the total production of that product that is produced competitively.

We adapt the methods proposed by von Cramon-Taubadel and Nivyevskyi $(2008,2009)$ to calculate SCB distributions for rice production in Malaysia using panel data during 20102014 period. The calculation of SCB distributions is purely a descriptive technique; however its use here is motivated by the hypothesis that Malaysia has the potential to grow more rice if analysis can identify those farms that are currently competitive and the reasons for their superior performance, thus providing benchmarks for other, currently less competitive farms.

\subsection{Data and assumptions}

In Malaysia, the rice-cropping season is categorized into main and off-seasons. The main season usually begins in September and runs through December, while the off-season runs from February to May. During the off-season the amount and frequency of precipitation is lower than it is during the main season. Therefore, the off-season crop relies heavily on the irrigation system. 
In the Third National Agriculture Policy (1998-2010), eight granary areas ${ }^{4}$ were designated as permanent rice granary areas responsible for scaling up and increasing productivity in the rice farming industry. The eight granaries contribute about $75 \%$ of the national rice production. The data used in this analysis are from the Muda Agricultural Development Authority (MADA), which is the largest granary area and contributed $51 \%$ of total granary production in 2013 and consistently generates 37\% of Malaysia's total annual rice production on $33 \%$ of the country's rice area (Appendix 3.1). The farm level data is collected twice a year and each survey period includes a balanced sample of 675 farming households. The panel is composed of ten cross-sections, covering main and off- seasons over the five-year period from 2010 to 2014. This data set provides comprehensive information, including input use, output and corresponding prices.

The farm-level panel data described above allows us to estimate the financial costs (profits) and social costs (profits) of rice production for each farm in each of the ten seasons. The result is a panel of 6750 PAMs one for each farm and season. To complete these PAMs (Appendix table 3.2), we first need to classify and decompose input items into tradable and non-tradable input categories. In Malaysian rice farming, the tradable inputs are fertilizers, seeds and agro-chemicals including pesticides, herbicides, rat and golden snail control, while other inputs such as labor, capital and land rent are categorized as non-tradable. Using the available data we complete the row of each PAM that describes costs and revenues at private prices. Second, we estimate the social prices (shadow price) of all the inputs and of the output (rice) and complete the row of the PAM that describes costs and revenues at social prices. Finally, we calculate the SCB ratio for each farm and season and derive the distribution of the SCB across farms for each season.

Social prices of output and tradable inputs are based on import or export parity prices, depending on the trade status of the commodity in question. Since Malaysia is a net importer of rice, an import parity is used to measure the social price of rice. The major rice imports are 25 percent broken rice mainly from Vietnam, followed by milled rice and glutinous rice (Department of Agriculture, 2014). We use the CIF price of $25 \%$ broken rice as the reference price (social price), obtained from the International Rice Reserch Institute (IRRI). To

\footnotetext{
${ }^{4}$ Granary Areas refer to major irrigation schemes (areas greater than 4,000 hectares) and recognized by the Government in the National Agricultural Policy as the main paddy producing areas. There are eight granary areas in Malaysia, namely MADA, KADA, IADA KERIAN, IADA BLS, IADA P. Pinang, IADA Seberang Perak, IADA KETARA and IADA Kemasin Semerak (Appendix 2).
} 
calculate the farm gate equivalent of this CIF price ${ }^{5}$, we use information regarding costs of handling, transportation, freight and insurance based on an interview with an officer from BERNAS. For the tradable inputs, the social prices are also import parity prices converted to the farm gate price. CIF prices for fertilizers, including urea (Europe), TSP (US Gulf ports), organic and NPK are provided by the World Bank, IRRI, and various issues of the FAO food outlook. The costs of moving these inputs from the port of entrance to the farm gate are based on information provided by traders.

For the non-tradeable input of land we assume a social price of zero. This is because of the impossibility of growing alternative crops on the land presently devoted to harvesting rice, both for legal reasons derived from land regulations and for physical reasons connected to the condition of the soil and the risk of seasonal flooding of the cultivation plots.

In some countries where the labor market is imperfect or there are macroeconomic imbalances, current wages may be a distorted indicator of the social cost of labor. In such cases, the current wages are corrected by using conversion factors to compute social wages (European Commission, 2014). However, in the case of a small country, such as Malaysia, where the unemployment rate is low, the social wage for labor can be assumed to be equal to the market wage. Therefore, we set conversion factor used to convert private into social wages equal to one.

The costs of machinery services hired for harvesting, transplanting and threshing were included in the capital account. However, payment for these services includes tradable components such as machine depreciation, fuel and oil, and non-tradable components such as labor for maintenance and the administration of rental operations. Therefore, we decompose machinery services into tradable and non-tradable components.

\subsection{Results and discussion}

\subsubsection{The profile of rice farming}

Rice farming in the MADA region is dominated by a small landholding size ranging between 1.70 to 2.17 hectares (Table 3.1). Investments in tertiary irrigation development have

\footnotetext{
${ }^{5}$ The conversion factors of paddy to rice are based on percentages of paddy recovery rates at 0.65 .
} 
considerably increased the production in the MADA area. Average gross paddy yields over 10 seasons are roughly 6 tons per hectare.

Table 3.1 summarizes household incomes generated in the main and off-seasons from 2010 to 2014. For the average MADA farm, the monthly gross margin for both seasons constantly increased during this period. The average full-time paddy farmer has reached the minimum income objective of $960 \mathrm{RM}$ per month, the equivalent of about 8.50 USD per day, which meets the government's aims of raising rice farmers' income above the poverty line. The survey data also shows that non-agricultural income contributes only a small percentage to total household income. The use of double cropping has reduced the availability of family labor for other income activities and thus increased the number of full-time farmers who participate exclusively in rice farming. A summary of calculations for each cost element based on private and social valuations for the main season and the off-season, calculated in Ringgit Malaysia (RM) currency is presented in Appendix 3.4

Table 3.1: Comparison of household income between main season and off-season, 20102014

\begin{tabular}{|c|c|c|c|c|c|c|c|c|c|c|}
\hline \multirow{2}{*}{ Variable } & \multicolumn{2}{|c|}{2010} & \multicolumn{2}{|c|}{2011} & \multicolumn{2}{|c|}{2012} & \multicolumn{2}{|c|}{2013} & \multicolumn{2}{|c|}{2014} \\
\hline & Main & Off & Main & Off & Main & Off & Main & Off & Main & Off \\
\hline \multicolumn{11}{|l|}{ Agricultural Income (RM)*: } \\
\hline \multirow[t]{2}{*}{ Gross income from paddy } & 3907 & 4035 & 4200 & 3205 & 3971 & 3613 & 5136 & 4267 & 6770 & 4901 \\
\hline & $(2,385)$ & $(2,803)$ & $(2,893)$ & $(2,077)$ & $(2,578)$ & $(2,393)$ & $(16,021)$ & $(2,705)$ & $(4,259)$ & $(2,928)$ \\
\hline \multirow[t]{2}{*}{ Total subsidy } & 1293 & 1335 & 1399 & 1060 & 1314 & 1184 & 1499 & 1412 & 1400 & 1013 \\
\hline & (789) & $(927)$ & (959) & (687) & $(853)$ & (757) & $(960)$ & $(895)$ & $(880)$ & $(605)$ \\
\hline \multirow[t]{2}{*}{ Price support or bonus } & 1723 & 1738 & 1813 & 1415 & 1780 & 1586 & 1991 & 1876 & 0 & 0 \\
\hline & $(1,043)$ & $(1,171)$ & $(1,258)$ & (944) & $(1,292)$ & $(1,023)$ & $(1,270)$ & $(1,197)$ & - & - \\
\hline \multirow[t]{2}{*}{ Income from other agriculture } & 2062 & 2181 & 2171 & 1839 & 2294 & 1729 & 2006 & 2033 & 2227 & 1460 \\
\hline & $(1,555)$ & $(2,148)$ & $(2,064)$ & $(1,798)$ & $(2,925)$ & $(1,242)$ & $(1,601)$ & $(1,617)$ & $(1,708)$ & $(1,076)$ \\
\hline \multirow[t]{2}{*}{ Cost of production } & 1708 & 2213 & 1886 & 1924 & 1971 & 1999 & 2028 & 2230 & 2402 & 2571 \\
\hline & $(305)$ & $(673)$ & (366) & (440) & $(393)$ & (439) & (406) & $(465)$ & $(408)$ & $(475)$ \\
\hline \multirow[t]{2}{*}{ Net income from agriculture } & 7276 & 7156 & 7697 & 5545 & 7388 & 6091 & 8603 & 7435 & 7995 & 4803 \\
\hline & $(5,032)$ & $(6,156)$ & $(6,167)$ & $(4,476)$ & $(6,130)$ & $(4,756)$ & $(16,837)$ & $(5,610)$ & $(6,051)$ & $(4,098)$ \\
\hline \multirow[t]{2}{*}{ Non-agricultural income } & 165 & 195 & 201 & 180 & 159 & 151 & 123 & 102 & 145 & 119 \\
\hline & $(434)$ & $(516)$ & (540) & (460) & (438) & (428) & $(415)$ & (408) & (713) & (364) \\
\hline \multirow[t]{2}{*}{ Total household income } & 7441 & 7351 & 7898 & 5725 & 7547 & 6242 & 8726 & 7537 & 8141 & 4922 \\
\hline & $(5,024)$ & $(6,131)$ & $(6,163)$ & $(4,429)$ & $(6,095)$ & $(4,747)$ & $(16,836)$ & $(5,580)$ & $(6,019)$ & $(4,068)$ \\
\hline $\begin{array}{l}\text { Nonagricultural income as \% } \\
\text { of total household income }\end{array}$ & 0.02 & 0.03 & 0.03 & 0.03 & 0.02 & 0.02 & 0.01 & 0.01 & 0.02 & 0.02 \\
\hline Farm size (ha) & $\begin{array}{r}1.94 \\
(1.56)\end{array}$ & $\begin{array}{r}2.17 \\
(2.01)\end{array}$ & $\begin{array}{r}2.08 \\
(1.91)\end{array}$ & $\begin{array}{r}2.02 \\
(2.00)\end{array}$ & $\begin{array}{r}1.96 \\
(1.93)\end{array}$ & $\begin{array}{r}1.79 \\
(1.29)\end{array}$ & $\begin{array}{r}1.75 \\
(1.25)\end{array}$ & $\begin{array}{c}1.72 \\
1.22\end{array}$ & $\begin{array}{r}1.77 \\
(1.26)\end{array}$ & $\begin{array}{r}1.70 \\
(1.39)\end{array}$ \\
\hline Gross yield (kg) & $\begin{array}{c}6,338 \\
(3,865)\end{array}$ & $\begin{array}{c}6,536 \\
(4,530)\end{array}$ & $\begin{array}{c}6,817 \\
(4,678)\end{array}$ & $\begin{array}{c}5,175 \\
(3,360)\end{array}$ & $\begin{array}{c}6,402 \\
(4,140)\end{array}$ & $\begin{array}{c}5,783 \\
(3,687)\end{array}$ & $\begin{array}{c}7,303 \\
(4,624)\end{array}$ & $\begin{array}{c}6,876 \\
(4,355)\end{array}$ & $\begin{array}{c}7,039 \\
(4,426)\end{array}$ & $\begin{array}{c}5,134 \\
(3,059)\end{array}$ \\
\hline Sample size (n) & 675 & 675 & 675 & 675 & 675 & 675 & 675 & 675 & 675 & 675 \\
\hline
\end{tabular}

Figures in parentheses are standard deviations. *Exchange rate: US\$1= RM3.08 and EUR€1=RM4.32 (Oct 31, 2010); US\$1=RM3.07 and EUR€1=4.30 (Oct 31, 2011); US\$1=RM3.06 and EUR€1=RM3.96 (Oct 31, 2012); US\$1=RM3.16 EUR€1=RM4.33 (Oct 31, 2013) and US\$1= RM3.29 and EUR€1=RM4.14 (Oct 31, 2014). 


\subsubsection{The competitiveness of rice production}

Results from the SCB analysis of rice production between 2010 and 2014 are presented in Figure 2 and summarized in Table 3.2. The results reveal that more than $50 \%$ of the farms produced rice competitively in each year with the exception of the 2014 , when only $48 \%$ of the farms were competitive. Overall, a high share of individual farms and a high share of total production are competitive in all years. The competitive farms produce a disproportionate share of the total rice in MADA. For example, in 2011 approximately two-thirds of the individual farms (73\%) were competitive and altogether, they produced a disproportionately large amount of the total rice production (90\%). This suggests that a large number of individual farms in the major granary area are competitive in producing rice.

Table 3.2: Summary of SCB results by share of individual farms and total rice production, 2010- 2014

\begin{tabular}{|c|c|c|c|}
\hline Year & Distribution by & $\begin{array}{c}\text { Competitive } \\
(\mathrm{SCB}<1)\end{array}$ & $\begin{array}{c}\text { Uncompetitive } \\
(\mathrm{SCB}>\mathbf{1})\end{array}$ \\
\hline \multirow{3}{*}{2010} & \multirow{3}{*}{$\begin{array}{l}\text { Weighted average SCB } \\
\text { Share of the individual farms in the sample }(\%) \\
\text { Share of the total production volume in the } \\
\text { sample }(\%)\end{array}$} & 0.65 & 2.33 \\
\hline & & 69.19 & 30.81 \\
\hline & & 86.14 & 13.86 \\
\hline \multirow{3}{*}{2011} & \multirow{3}{*}{$\begin{array}{l}\text { Weighted average SCB } \\
\text { Share of the individual farms in the sample }(\%) \\
\text { Share of the total production volume in the } \\
\text { sample }(\%)\end{array}$} & 0.61 & 2.30 \\
\hline & & 73.04 & 26.96 \\
\hline & & 89.89 & 10.11 \\
\hline \multirow{3}{*}{2012} & \multirow{3}{*}{$\begin{array}{l}\text { Weighted average SCB } \\
\text { Share of the individual farms in the sample }(\%) \\
\text { Share of the total production volume in the } \\
\text { sample }(\%)\end{array}$} & 0.66 & 2.66 \\
\hline & & 60.74 & 39.26 \\
\hline & & 81.83 & 18.17 \\
\hline \multirow{3}{*}{2013} & \multirow{3}{*}{$\begin{array}{l}\text { Weighted average SCB } \\
\text { Share of the individual farms in the sample }(\%) \\
\text { Share of the total production volume in the } \\
\text { sample }(\%)\end{array}$} & 0.67 & 2.28 \\
\hline & & 62.37 & 37.63 \\
\hline & & 83.49 & 16.51 \\
\hline \multirow{3}{*}{2014} & \multirow{3}{*}{$\begin{array}{l}\text { Weighted average SCB } \\
\text { Share of the individual farms in the sample }(\%) \\
\text { Share of the total production volume in the } \\
\text { sample }(\%)\end{array}$} & 0.67 & 2.28 \\
\hline & & 47.70 & 52.30 \\
\hline & & 71.13 & 28.87 \\
\hline
\end{tabular}

Source: Own calculations

Overall, the results confirm that many Malaysian rice farmers are able to produce rice competitively. Note that consideration of average SCBs alone would conceal important variations among the farms. For example, in 2013, the average ton of paddy was produced at 
a SCB of 1.02, i.e. not competitive (Figure 3.2). This result obscures the fact that more than half of the farms $(62 \%)$ in this region were competitive, and that these competitive farms together accounted for $83 \%$ of the total rice production. Therefore, the analysis presented here demonstrates there is substantial variation in competitiveness between farms that produce rice in the MADA granary.

In the following section we attempt to identify factors that explain this variation and that could be used to improve the competitiveness of individual farms; thus shifting SCB distributions to the left and increasing the overall competitiveness of Malaysian rice production.
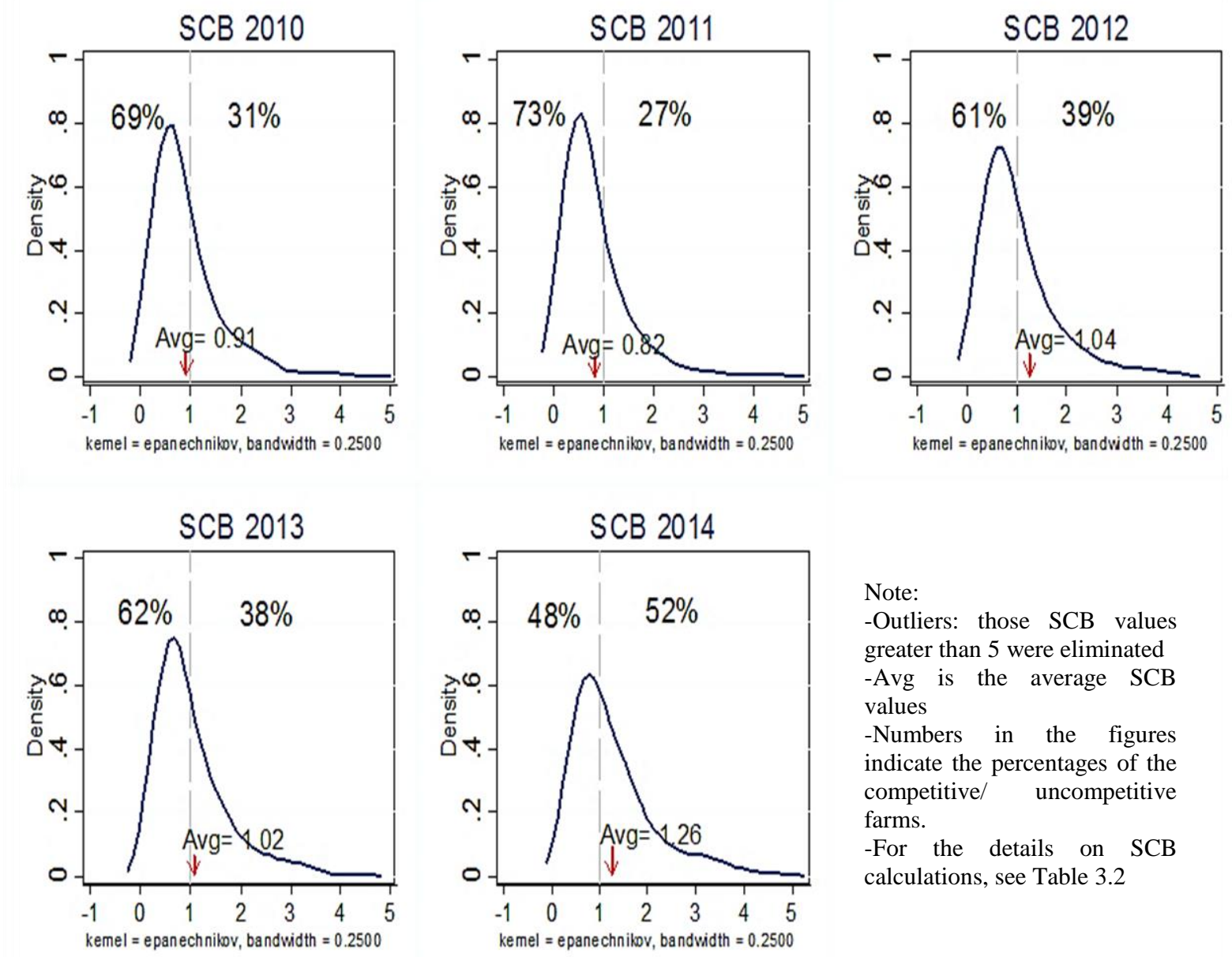

Note:

-Outliers: those SCB values greater than 5 were eliminated -Avg is the average SCB values

-Numbers in the figures indicate the percentages of the competitive/ uncompetitive farms.

-For the details on SCB calculations, see Table 3.2

Figure 3.2: Distribution of competitiveness scores (SCB) for the rice farms, 2010-2014 (Source: Own calculations) 


\subsubsection{The determinants of rice competitiveness}

To explain differences in competitiveness among farms we use the following dynamic panel data model:

$$
Y_{i t}=\beta_{1} Y_{i t-1}+\beta_{2} X_{i t-1}+\alpha_{i}+\varepsilon_{i t}
$$

where $Y_{i t}$ is farm $i$ 's SCB score in period $t, X_{i t-1}$ is a vector of exogenous explanatory variables (farm size, distance to milling factories, access to credit, off-farm income, landownership, hired cost labor, farmers' organization, land ownership and a time trend), and $\alpha_{i}$ and $\varepsilon_{i t}$ are error terms $\left(\alpha_{i}\right.$ captures unobserved and time constant farm specific effects and $\varepsilon_{i t}$ is an idiosyncratic error term).

Since the lagged dependent variable in equation (2) can be correlated with the error term $(\varepsilon)$, it violates the assumption of exogeneity. Furthermore, the unobserved farm specific effects $(\alpha)$ can be correlated with explanatory variables in X. To account for these problems, Anderson \& Hsiao (1981) propose a difference generalized method of moments (DGMM) estimator to obtain unbiased estimates. The model is specified using a system of equations, one per period, and uses all available lags of the dependent variable as instruments for each first-difference equation (Bond et al, 2001). However, if the parameter $\beta_{1}$ is close to a random walk, then the lagged levels are weak instruments for differences, because, in this case, past levels of SCB scores do not convey much information about present changes. A more suitable alternative is to use the system generalized method of moments (SGMM) proposed by Arellano and Bover (1995) and Blundell and Bond (1998) that estimates the model in levels, as well as in differences, by using the lagged instruments for the level equations.

We employ the SGMM and perform several tests to determine the most appropriate model specification. The Arellano-Bond test is executed to determine serial correlation on the residuals, under the hypothesis of no first (AR1) or second (AR2) order serial correlation of the residuals (Roodman, 2009a). In order to check for endogeneity bias and potential problems of specification in the model estimation we use the Hansen test of over-identifying restrictions (Bond, Hoeffler, and Temple 2001). In addition, we use the difference-in-Hansen test statistic to test the validity of specific subsets of instruments.

Where valid instruments are usually scant, the Arellano Bond estimation procedure is useful since any lagged level is a valid instrument. To avoid the proliferation of instruments, 
Roodman (2009b) suggests that the instrument matrix be collapsed by only constructing instruments for each additional lag, rather than constructing an instrument for each lag in each period. He further suggests excluding longer lags as instruments so that the number of lags used as instruments in any period is capped. There are no clear guidelines on how to select the optimal instruments, but in any case they should not exceed the number of observations (Roodman, 2009b).

We choose the explanatory variables in the vector $\mathrm{X}$ based on theoretical considerations and data availability. These variables include characteristics of the farm (e.g. size, distance from the rice mill) and the farmer (whether he/she is a member of the farmers' organization, whether he/she owns or rents the farm, gender, off-farm income, access to credit), and the amounts of government support received by the farm. Descriptive statistics are presented in Table 3.3. Estimation is carried out with the full balanced panel of 6750 SCB ratios presented in the previous section; one ratio for each of $i=675$ farms in each of $t=10$ seasons (two seasons in each of five years).

Table 3.3: Definitions of variables and summary statistics during the period 2010-2014

\begin{tabular}{|c|c|c|c|c|c|c|}
\hline Variable & Unit & Definition & Mean & SD & Min & Max \\
\hline \multicolumn{7}{|c|}{ Dependent variable } \\
\hline SCB & $\%$ & Social cost benefit ratio & 1.05 & 0.91 & 0.00 & 10.13 \\
\hline \multicolumn{7}{|c|}{ Explanatory variables } \\
\hline $\begin{array}{l}\text { Hired cost } \\
\text { labor }\end{array}$ & $\mathrm{RM} / \mathrm{ha}$ & $\begin{array}{l}\text { Gross salary paid based on each } \\
\text { activities on the farm }\end{array}$ & 424 & 341 & 14 & 4108 \\
\hline $\begin{array}{l}\text { Distance to } \\
\text { milling }\end{array}$ & $\mathrm{Km}$ & $\begin{array}{l}\text { Distance from the paddy field to the } \\
\text { rice mill }\end{array}$ & 3.06 & 2.39 & 0.02 & 28.02 \\
\hline Credit & RM & Dummy $=1$ if the farmer gets credit & 0.08 & 0.27 & 0.00 & 1.00 \\
\hline Landowner & $0 / 1$ & $\begin{array}{l}\text { Dummy }=1 \text { if the farmer owns the } \\
\text { farm }\end{array}$ & 0.78 & 0.41 & 0.00 & 1.00 \\
\hline Off income & RM & $\begin{array}{l}\text { Income from non-agricultural } \\
\text { activities }\end{array}$ & 154 & 482 & 0.00 & 15000 \\
\hline PPK & $0 / 1$ & $\begin{array}{l}\text { Dummy }=1 \text { if the farmer is a member } \\
\text { of a farmers' organization }\end{array}$ & 0.98 & 0.13 & 0.00 & 1.00 \\
\hline Gender & $0 / 1$ & Dummy $=1$ if the farmer is a male & 0.90 & 0.29 & 0.00 & 1.00 \\
\hline Farm size & $\mathrm{Ha}$ & Rice farming area, owned and rented & 1.89 & 1.62 & 0.12 & 27.54 \\
\hline Subsidy & RM & $\begin{array}{l}\text { Total input subsidies received by the } \\
\text { farmers }\end{array}$ & 1291 & 852 & 57 & 8545 \\
\hline Bonus & RM & $\begin{array}{l}\text { Bonus payment or output subsidies } \\
\text { received by the farmers who sells the } \\
\text { rice to the government rice mill }\end{array}$ & 1392 & 1255 & 0 & 11815 \\
\hline $\begin{array}{l}\text { Years } \\
\text { Season }\end{array}$ & $\begin{array}{l}\text { Years } \\
0 / 1\end{array}$ & $\begin{array}{l}\text { Vector of years dummies } \\
\text { Dummy }=1 \text { if main season }\end{array}$ & & & & \\
\hline
\end{tabular}

Source: Own calculations 


\subsection{Results and Discussion}

Table 3.4 presents the results of the econometric model using the SGMM approach. The difference-in-Hansen test statistics indicate that the null hypothesis of no serial correlation between instruments and error terms cannot be rejected, indicating that the over-identifying restrictions are valid. The Arellano-Bond test for AR(1) provides strong evidence that the residuals are negatively correlated which corresponds to the first-differencing process inherent in the SGMM method. In addition, the null hypothesis of zero autocorrelation in the first differenced at order 2 (AR2) is not rejected, which is a required assumption for consistent results.

Table 3.4: SGMM estimates for rice competitiveness

\section{Dependent variable: SCB score}

\begin{tabular}{|c|c|c|}
\hline Explanatory variables & Coefficient & Standard errors \\
\hline $\mathrm{SCB}_{i t-1}$ & -0.294 & 0.400 \\
\hline Hired cost labor & 4.e-04*** & $6 . e-05$ \\
\hline Distance to the rice mill & $\mathbf{0 . 0 7 7} * *$ & 0.025 \\
\hline Access to credit & 2.e-05 & 1.e-05 \\
\hline Landowner & 0.038 & 0.035 \\
\hline PPK member & $-0.354 * *$ & 0.159 \\
\hline Male & $-0.077 *$ & 0.046 \\
\hline Off income & 5.e-05* & 3.e-05 \\
\hline Farm size & $-0.081 * * *$ & 0.011 \\
\hline Input subsidies $_{i t-1}$ & $-2 . e-04$ & 0.001 \\
\hline Bonus payment $_{i t-1}$ & $-4 . e-04$ & 0.001 \\
\hline Main season & $-0.268 * * *$ & 0.055 \\
\hline Observations & 5400 & \\
\hline Number instruments & 29 & \\
\hline Year and system control & Yes & \\
\hline Arellano-Bond test AR(1) & -1.84 & {$[0.065]$} \\
\hline Arellano-Bond test AR(2) & -0.74 & [0.459] \\
\hline $\begin{array}{l}\text { Difference-in-Hansen tests of exogeneity } \\
\text { of instrument subsets }\end{array}$ & 2.61 & {$[0.855]$} \\
\hline \multicolumn{3}{|c|}{$\begin{array}{l}\text { Note: } * * * \text { Significant at the } 1 \% \text { level; ** Significant at the } 5 \% \text { level; * Significant at the } 10 \% \text { level. } \\
\text { P-values in square brackets. Results were generated using xtabond2 from Roodman }(2003) .\end{array}$} \\
\hline \multicolumn{3}{|c|}{$\begin{array}{l}\text { Since the greater values of the } \mathrm{SCB} \text { score }(\mathrm{SCB}>1) \text { indicate less competitiveness, a positive } \\
\text { estimated coefficient indicates that the explanatory variable in question increases the SCB and } \\
\text { therefore has a negative influence on competitiveness. The result demonstrates that the } \\
\text { estimated coefficient of hired labor cost variable is significant at the } 1 \% \text { level. Each additional }\end{array}$} \\
\hline
\end{tabular}


intensive. Much of the labor requirements for the nursery, land preparation, fertilizer application, pest control, as well as postharvest activities are mainly completed by farmers with the help of hired labors, for whom wages are high, particularly during weeding and harvesting periods. For example, for 2013, the average daily wage rate is 38 RM (equivalent to 8.5 EUR) (Department of Agriculture, 2014). If a 3 ha farm hires a half-time labor, then the SCB scores will fall by 0.04 .

The variable "distance to milling" has a statistically strong effect on competitiveness at the $5 \%$ level. The farther a farm is located from the closest milling factory, the lower its competitiveness. The delayed drying of a paddy can cause severe losses of moisture due to high transpiration rates and microorganisms, especially during the dry season (off-season). To avoid high post-harvest losses, farmers have to sell paddy immediately after harvest. To proceed with this, farmers have the option of selling a paddy directly to a local miller or allowing the paddy to be collected by local traders. Most farmers prefer to wait for collection because they do not own trucks to load their harvest. Thus, farmers must bear the transaction costs, which increase as the distance to the rice mills increases.

It appears that growers who engage collectively in a farmer's organization (PPK) are accessing social and economic benefits greater than non-collective action participants. The results are consistent with the predicted function of agricultural cooperatives in improving the performance of their members in the market by providing easy access to productive inputs and technical and management services, such as training, information and extension on input application (Addai et al, 2014). Many governments establish farmer-based cooperation groups to improve rural service delivery and access to the market, as well as reduce transaction costs and achieve competitiveness.

Male farmers are observed to be operating at a higher level of profitability than their female counterparts. It implies that male farmers earned more social profits from rice production and are more competitive than the female farmers. This could be due to the limited access the female farmers usually have to resources of production in comparison with the male farmers. This corroborates the results of many previous studies on the role of gender in agricultural production. The study by Siriwardana and Jayawardena (2014) in Sri Lanka found male household heads to be more productive than female household heads in mechanized farms. Koirala et al. (2015) found female heads of households to be less productive than men in rice 
production in a study in the Philippines, a fact that the authors attributed to culture, access to land and economic factors.

Another important finding is that involvement in off-farm activities appears to reduce competitiveness. The increasing importance of off-farm work implies less labor effort and time spent on the farm. The coefficient suggests that off-farm income tends to increase the SCB ratio by $5 \times 10^{-4}$. Such an effect, though small, is statistically significant at the $10 \%$ level. Our result confirms the finding made by Goodwin and Ashok (2004) who noted that increased reliance on off-farm work may have implied less attention paid to the on-farm productivity issues such as adoption of best management practices and technologies, and in turn decreases competitiveness.

We used the farm size variable to test whether competitiveness increases with the scale of operation. Our result indicates that increasing the farm size per hectare reduces the SCB of rice production by 0.081 . This finding suggests that the consolidation of small farms in the MADA granary area will lead to the realization of economies of scale in rice production. Other variables such as access to credit and landownership have no significant effect on competitiveness.

We turned our attention to the rice policies and different mechanisms affecting competitiveness. To avoid the effects of heterogeneity on total subsidies, we disaggregated subsidies into input subsidies and bonus payments. The whole idea of the SCB is that we calculated the social profits without government intervention or subsidies. To determine whether these subsidies would improve SCBs, we tested the hypothesis in a dynamic setting; do past subsidies affect current competitiveness or are the farms that previously received more subsidies more competitive today? We hypothesize that input subsidies, by encouraging input use, might lead farms to produce in more efficient, more beneficial ways when evaluated at social prices. Additionally, if the bonus payments are more coupled from intensity and production decisions, they might not have a negative effect on competitiveness. In fact, they may lead to a wealth effect which can reduce farmers' aversion to risks and facilitate investment and thus increase outputs. The various mechanism through which decoupled payment and inputs subsidies may affect production are well discussed in the literature (see Goodwin and Ashok 2005; Femenia et al. 2010; Sunding and Zilberman 2000). 
Our SGMM results, however, indicate no significant difference between these types of policies and competitiveness scores. The general evidence seems to be that input subsidies and bonuses are, if anything, increasing competitiveness. Subsidies, by encouraging input use, may indeed be increasing production and making it more competitive. Since the evidence shows no strong effects of subsidies and bonus payments, then the policy implications are that the policies are not having a strong effect on competitiveness, and the money in question could perhaps be better spent in other ways. At best, the subsidies are a form of social policy that simply increases farm incomes, but then the question arises as to why larger farms, that are presumably not poor, should also receive these payments. So current spending is poorly targeted as social policy, and ineffective as an economic policy to boost competitiveness.

\subsection{Conclusion and recommendations}

The Malaysian rice market has been characterized in the past decade by pervasive government interventions for various purposes, such as to alleviate poverty and increase self-sufficiency levels. Since rice is a staple food, the government intervenes more in the rice market than in most others. These interventions include support for producers through subsidies on fertilizers, lime and pesticides on the input side and a subsidized guaranteed minimum price coupled with price bonuses on the output side. However, the successful completion of WTO negotiations together with Asean Free Trade Agreement (AFTA) negotiations would imply that significant structural changes must be made not only to the trade regime, but also to the rice sector and adjustments at the farm level are needed in order for greater efficiency and competitiveness to be achieved.

Previous literature had discussed the impact of policies on agricultural competitiveness using the Policy Analysis Matrix (PAM) in many developing countries. However, one major drawback of almost all applied PAM analysis to date is that it is carried out with aggregate data, for example for average or representative farms. This will provide an incomplete picture of sectoral competitiveness since results based on average data may conceal important variations in competitiveness among heterogeneous producers. We have addressed this shortcoming, using a unique, farm level survey data from rice farmers in the major granary area in Malaysia over the period 2010 to 2014. Our contribution to the existing literature is twofold. First, we provide new evidence on rice competitveness using an extension to the Policy Analysis Matrix approach proposed by (Monke and Pearson (1989). This extension allows us to take farm-level heterogeneity into account and derive competitiveness score 
distributions for each rice farm. To improve the usefulness of SCB indicator, we use a kernelbased estimate to demonstrate the distribution of competitiveness scores and determine the proportion of farms that are producing competitively and the proportion of total production/output value of the product that is produced competitively. Second, we develop a panel regression model to examine the factors that influence rice competitiveness at the individual farm level. This approach may also be useful for other evaluation in other contexts, thus contributing to the broader research direction on agricultural competitiveness.

The empirical results reveal that more than $50 \%$ of farmers produce rice competitively from 2010 until 2013 and altogether, they produce a disproportionately large number of the total rice production $(80 \%)$. This suggests that a large number of individual farms in the granary area are competitive in producing rice. Additionally, we briefly note the contrast between the distributions of using disaggregate SCB and average SCB that would result from the use of aggregated data.

Our dynamic SGMM estimates revealed that participation in a farmer's organization, gender and total farm size are the major determinants of rice competitiveness, while the distance to the rice mills, off-farm income and the use of hired labor are the main constraints that reduce competitiveness. Additionally, there are no signicant differences between the types of policies employed (input subsidies and bonuses) and competitiveness. The estimates produced for this paper have the potential to influence on-going debates on federal budget reduction, as well as add to the discussion on the agricultural subsidy reform policy.

Policies for rice farmers need to vary depending on the context. This statement is bolstered by our empirical analysis, which reveals that the types of supports do not have significant effects on competitiveness and the money in question could be spent in other ways. Bonus payments and input subsidies in their current form are not as efficient as they seem to be considering that essentially only large farms and high-income groups benefit from them. The existing set of programs was designed to address situations that are now out-of-date and, as a consequence, may no longer be relevant.

If the government decides to preserve small and marginal farms, assistance measures should be directed towards these specific groups to prevent such problematic outcomes. For instance, improving infrastructure that links farmers to millers would help improve competitiveness. In 
addition, offering support in the form of providing technical assistance through farmers' organization so that farmers can receive a better share of market prices could improve competitiveness. If this were the case for the policy agenda, such support could become a social safety net for the poor and could facilitate a comfortable exit from farming for small farmers through job provision or income support programs. The replacement of the fertilizer subsidy by direct income support programs would be tantamount to income support without any waste and lack of efficient distribution associated with the fertilizer and input subsidy scheme.

In other cases, policy-makers must consider whether there are social reasons to support large farms. The empirical evidence reveals that farmers are fully aware of the utility of subsidies; considering the fact that the previous provision of input subsidies does not improve current competitiveness. If profits generated by farming activities were to be ensured by the government, the incentive to adopt innovate practices and technology would diminish.

Similarly, the incorporation of the paddy bonus into the guaranteed minimum price is justified on the grounds of increasing rice prices and cost control. Efforts to direct paddy bonus payments to poor and small farms by incorporating the access to farm size and production deliveries seem achievable. However, regardless of whether the farms are small or large, paddy bonuses are given to all farmers. It is important to note that not all paddy growers are poor; some support goes to larger farms where profits are already substantial. The drawback implies that the support may be biased towards larger farms and is not well-targeted. Therefore, a combination of both subsidy schemes is not completely necessary and improvement would result in a more efficient use of public money.

Given the fact that the sample in this study constitutes only a dataset of individual rice farms selected from one granary area of the country, our findings and policy recommendations cannot be generalized to the national level. These results are situation specific and thus cannot be extrapolated to other granary areas with different conditions. The SGMM provides an appropriate framework to analyse the determinants of rice competitiveness, however data limitation prevents the consideration of all aspects in the analysis. We suggest for future research to determine the characteristics of farms (bio-physical conditions such as soil types and climate variability) and different agro-ecological regions, as well as other farmer's characteristics such as age, education and human capital. Extending this research topic would 
not only supplement the contribution of this study but also can shed light on the variations and differences in competitiveness level among rice farms and region specific priorities. Additionally, further research will lead to the policies that would enhance farmers income, shifting from less efficient to more efficient farms and allowing them to better contribute to the national goal of food self-sufficiency. 


\section{APPENDIX}

Appendix 3.1: Contribution of MADA to the total granary areas and National Production, 2010- 2013

\begin{tabular}{|c|c|c|c|c|c|c|c|c|c|c|}
\hline \multirow[b]{2}{*}{ GRANARY AREA } & \multirow{2}{*}{$\begin{array}{c}{ }^{*} \text { RICE } \\
\text { AREA } \\
\text { (HA) }\end{array}$} & \multirow{2}{*}{$\begin{array}{c}\% \text { RICE } \\
\text { AREA }\end{array}$} & \multicolumn{8}{|c|}{ CONTRIBUTION TO NATIONAL PRODUCTION (TONS \& \%) } \\
\hline & & & 2010 & $\%$ & 2011 & $\%$ & 2012 & $\%$ & 2013 & $\%$ \\
\hline MADA & 96,558 & 33.31 & 912,321 & 37.99 & 956,417 & 38.02 & 929,070 & 36.60 & 941,889 & 37.05 \\
\hline KADA & 29,450 & 10.16 & 201,135 & 8.37 & 217,210 & 8.63 & 192,399 & 7.58 & 159,800 & 6.29 \\
\hline IADA KERIAN & 21,108 & 7.28 & 174,563 & 7.27 & 196,051 & 7.79 & 232,963 & 9.18 & 188,586 & 7.42 \\
\hline $\begin{array}{l}\text { IADA BARAT LAUT } \\
\text { SELANGOR }\end{array}$ & 19,021 & 6.56 & 210,292 & 8.76 & 221,295 & 8.80 & 226,580 & 8.93 & 237,594 & 9.34 \\
\hline IADA PULAU PINANG & 10,305 & 3.55 & 115,189 & 4.80 & 118,050 & 4.69 & 115,839 & 4.56 & 120,383 & 4.73 \\
\hline $\begin{array}{l}\text { IADA SEBERANG } \\
\text { PERAK }\end{array}$ & 14,140 & 4.88 & 70,814 & 2.95 & 75,612 & 3.01 & 81,461 & 3.21 & 126,027 & 4.96 \\
\hline IADA KETARA & 4,876 & 1.68 & 52,711 & 2.19 & 57,163 & 2.27 & 54,910 & 2.16 & 54,114 & 2.13 \\
\hline $\begin{array}{l}\text { IADA KEMASIN } \\
\text { SEMERAK }\end{array}$ & 5,047 & 1.74 & 20,550 & 0.86 & 17,560 & 0.70 & 23,381 & 0.92 & 18,815 & 0.74 \\
\hline TOTAL GRANARY & 200,505 & 69.17 & $1,757,575$ & 73.18 & $1,859,358$ & 73.91 & $1,856,602$ & 73.14 & $1,847,208$ & 72.65 \\
\hline $\begin{array}{ll}\text { TOTAL } & \text { NON- } \\
\text { GRANARY } & \end{array}$ & 89,377 & 30.83 & 644,090 & 26.82 & 656,331 & 26.09 & 681,972 & 26.86 & 695,309 & 27.35 \\
\hline TOTAL MALAYSIA & 289,882 & 100.00 & $2,401,665$ & 100.00 & $2,515,689$ & 100.00 & $2,538,574$ & 100.00 & $2,542,517$ & 100.00 \\
\hline
\end{tabular}

Source: Paddy Production Survey Report 2014, Department of Agriculture, Malaysia , Putrajaya.

* Total parcel excluding Sabah and Sarawak. Land and rice fields in Sabah and Sarawak have not been gazetted and are still using traditional lands 
Appendix 3.2: Policy Analysis Matrix

\begin{tabular}{|c|c|c|c|c|}
\hline \multirow[t]{2}{*}{ Items } & \multirow[t]{2}{*}{ Revenues } & \multicolumn{2}{|c|}{ Costs } & \multirow[t]{2}{*}{ Profits } \\
\hline & & Tradable Inputs & Domestic Factors & \\
\hline Private prices & $\boldsymbol{A}=P_{i}^{D}$ & $\boldsymbol{B}=\sum_{\mathrm{j}=1}^{k} a_{i j} P_{j}^{D}$ & $\begin{array}{l}\boldsymbol{C} \\
=\sum_{j=k+1}^{n} a_{i j} W_{j}^{D}\end{array}$ & $D=A-B-C$ \\
\hline Social prices & $\boldsymbol{E}=P_{i}^{S}$ & $\boldsymbol{F}=\sum_{j=1}^{k} a_{i j} P_{j}^{S}$ & $\begin{array}{l}\boldsymbol{G} \\
=\sum_{j=k+1}^{n} a_{i j} W_{j}^{S}\end{array}$ & $H=E-F-G$ \\
\hline $\begin{array}{l}\text { Effects of } \\
\text { divergences } \\
\text { and efficient } \\
\text { policy }\end{array}$ & $I=A-E$ & $J=B-F$ & $K=C-G$ & $\begin{array}{c}L=D-H= \\
I-J-K\end{array}$ \\
\hline
\end{tabular}

Source: Monke and Pearson (1989)

Note:

The subscript $i$ refers to outputs and the subscript $j$ refers to inputs,

$a_{i j}$ for $(j=1$ to $k)$ are technical coefficients for traded inputs in the production of $i$;

$\mathrm{a}_{i j}$ for $(\mathrm{j}=\mathrm{k}+1$ to $\mathrm{n})$ are technical coefficients for domestic inputs in the production of $\mathrm{i}$;

$\mathrm{P}_{i}^{*}$ is the price of output $i$, evaluated privately $(*=D)$ or socially $(*=S)$;

$\mathrm{P}_{j}^{*}$ is the price of traded input $j$, evaluated privately $(*=D)$ or socially $(*=S)$;

$\mathrm{W}_{j}^{*}$ is the price of domestic input $j$, evaluated privately $(*=D)$ or socially $(*=S)$;

$\mathrm{D}(=\mathrm{A}-\mathrm{B}-\mathrm{C})$ measures Private profit;

$\mathrm{H}(=\mathrm{E}-\mathrm{F}-\mathrm{G})$ measures Social profits;

$\mathrm{I}(=\mathrm{A}-\mathrm{E})$ measures Output transfers;

$\mathrm{J}(=\mathrm{B}-\mathrm{F})$ measures Input transfers;

$\mathrm{K}(=\mathrm{C}-\mathrm{G})$ measures Factor transfers;

L (= D-H; or I-J-K) measures Net transfers.

Conversion from private to social prices is based on several data and assumptions;

i. Since rice is an imported good, the social price for rice is the import parity price of rice ( $25 \%$ broken) equivalent at the farm gate. Appendix 3.3 displays the calculations for the import parity of rice based on the world market price $(25 \%$ broken Vietnam rice) (source from an interview with BERNAS officer).

ii. As for the tradable inputs, the social prices for fertilizers, pesticides, herbicides, and seeds are the respective import parity prices at the farm gate. 
Appendix 3.3: Scheme of Import Parity Price Calculations for Rice, Malaysia

\begin{tabular}{|c|c|}
\hline \multicolumn{2}{|l|}{ A) PURCHASE PRICE } \\
\hline Purchase Price (FOB) & $\mathrm{USD} / \mathrm{t}$ \\
\hline Exchange Rate & $\mathrm{RM} / \mathrm{t}$ \\
\hline Less $10 \%$ quality discount & $\mathrm{RM} / \mathrm{t}$ \\
\hline \multicolumn{2}{|l|}{ B) IMPORT COST } \\
\hline 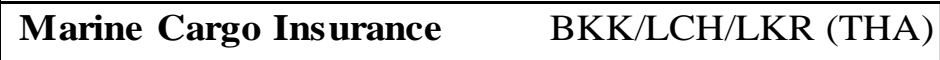 & Rate $(\mathrm{PP} * 120 \% \mathrm{x} .1 \%) / \mathrm{t}$ \\
\hline Land Transportation & Rate/Port \\
\hline Port Handling & \\
\hline Carpenter/EMC/Custom Exam & Selected Port (Container Only) \\
\hline Government Inspection & Selected Port (Container Only) \\
\hline Forwarding/Coordination & Service Agrmt. \\
\hline Terminal Handling Charges (THC) & Rate/Port (Container Only) \\
\hline Documentation Fee & Conv. Only \\
\hline EDI & Selected Port \\
\hline Port Charges/Surcharge & Selected Port \\
\hline Port Weighbridge & Selected Port \\
\hline \multicolumn{2}{|l|}{ Storage (Penalties/Delay/EMC/Detention) } \\
\hline Surveyor Fees & Contract Rate \\
\hline Others & Rate/Port \\
\hline SGN (HCM) & Rate/Port \\
\hline $\begin{array}{l}\text { Warehouse Handling } \\
\text { Ocean Freight }\end{array}$ & $\begin{array}{l}\text { In }+ \text { Out + Stck Mgt } \\
\text { Rate/Port }\end{array}$ \\
\hline \multicolumn{2}{|l|}{ Total Import Cost per MT } \\
\hline \multicolumn{2}{|l|}{ C) WAREHOUSE COST (BASED ON SALES VOLUME) } \\
\hline Labour Charges (Handling) & $\mathrm{RM} / \mathrm{t}$ \\
\hline Gassing & $\mathrm{RM} / \mathrm{t}$ \\
\hline Spraying/Fogging & $\mathrm{RM} / \mathrm{t}$ \\
\hline Warehouse Rental & $\mathrm{RM} / \mathrm{t}$ \\
\hline Security & $\mathrm{RM} / \mathrm{t}$ \\
\hline Cleaning & $\mathrm{RM} / \mathrm{t}$ \\
\hline Forklift Rental & $\mathrm{RM} / \mathrm{t}$ \\
\hline Weighbridge & $\mathrm{RM} / \mathrm{t}$ \\
\hline Warehouse Service/Maintenance & $\mathrm{RM} / \mathrm{t}$ \\
\hline Utilities & $\mathrm{RM} / \mathrm{t}$ \\
\hline Insurance & $\mathrm{RM} / \mathrm{t}$ \\
\hline Staff Salary & $\mathrm{RM} / \mathrm{t}$ \\
\hline Total Ware house Cost & $\mathrm{RM} / \mathrm{t}$ \\
\hline Import Parity Price of Rice per MT $(A+B+C)$ & $\mathrm{RM} / \mathrm{t}$ \\
\hline - Processing costs & $\mathrm{RM} / \mathrm{t}$ \\
\hline Border Price of Rice & $\mathrm{RM} / \mathrm{t}$ \\
\hline Border Price of Paddy & \\
\hline $\mathrm{x}$ Conversion factor and milling rate & 0.65 \\
\hline$=$ Price of paddy & $\mathrm{RM} / \mathrm{t}$ \\
\hline + Trans portation farm -> Dis trict area & $\mathrm{RM} / \mathrm{t} / \mathrm{km}$ \\
\hline Import Parity Price at farm gate & $\mathrm{RM} / \mathrm{t}$ \\
\hline
\end{tabular}


iii. The need to determine the shadow exchange rate is important for an economic analysis. The shadow exchange rate affects all the social values of tradable inputs and output. This is the point when various opportunities for alternative investment present themselves to a nation and they must be properly evaluated and then the same foreign exchange premium must be used in the economic analysis for each alternative. Thus, instead of the official exchange rate, the shadow exchange rate is used to convert international prices from US dollars to Malaysia's currency. Malaysia is a small open trading nation where such discrepancy between official exchange rate and shadow exchange rate is quite small.

iv. Domestic inputs such as land for which no international prices exist is valued at local opportunity costs. However, in this view the rental values of land per hectare for granary area at social prices are assumed to be zero since the conversion of paddy fields to other crops is unfeasible due to its soil condition and flooding area suitable for only rice cropping. In addition Malaysian government has already officially recognized the field as the permanent rice growing areas responsible for achieving the minimum level of self-sufficiency under the National Agriculture Policy (1984).

v. Social costs are assumed to equal private costs for labor. Distortions in the labor market are minimal since minimum wage is not enforced in agriculture and has limited impact on the Malaysian economy. Therefore, the private wage rate for rural labor is a good approximation of the social wage and thus, the conversion factor for the labor is assumed to be equal to 1 .

vi. Some of the taxes, including land tax and water tax, are viewed as pure transfers from one agent to another within the society, which does not create economic value or induce an economic impact (European Commission, 2008). In this case, all prices of input and output should be a net of VAT or other indirect taxes and should be omitted from revenues under economic analysis. Therefore, the conversion factor for the taxes is assumed to be 0 .

vii. The following table provides a summary of calculations for each cost element based on private and social valuations for the main season and the off-season, calculated in Ringgit Malaysia (RM) currency. 
Appendix 3.4: Private and social valuations of inputs in rice production, 2010- 2014

\begin{tabular}{|c|c|c|c|c|c|}
\hline Variable & 2010 & 2011 & 2012 & 2013 & 2014 \\
\hline \multicolumn{6}{|c|}{ Main Season } \\
\hline private inputs & 471 & 411 & 406 & 486 & 648 \\
\hline social inputs & 426 & 410 & 493 & 440 & 645 \\
\hline private labor & 292 & 348 & 341 & 433 & 505 \\
\hline social labor & 292 & 348 & 341 & 433 & 505 \\
\hline private capital & 990 & 1129 & 1137 & 1155 & 1251 \\
\hline social capital & 1248 & 1422 & 1433 & 1456 & 1577 \\
\hline private land & 306 & 300 & 315 & 318 & 325 \\
\hline social land & 0 & 0 & 0 & 0 & 0 \\
\hline private others & 19 & 20 & 21 & 21 & 21 \\
\hline social others & 0 & 0 & 0 & 0 & 0 \\
\hline \multicolumn{6}{|c|}{ Off Season } \\
\hline private inputs & 454 & 381 & 459 & 624 & 790 \\
\hline social inputs & 395 & 452 & 503 & 568 & 723 \\
\hline private labor & 640 & 369 & 408 & 374 & 528 \\
\hline social labor & 640 & 369 & 408 & 374 & 528 \\
\hline private capital & 1098 & 1153 & 1111 & 1211 & 1230 \\
\hline social capital & 1384 & 1452 & 1400 & 1525 & 1550 \\
\hline private land & 305 & 322 & 326 & 340 & 288 \\
\hline social land & 0 & 0 & 0 & 0 & 0 \\
\hline private others & 20 & 20 & 21 & 21 & 23 \\
\hline social others & 0 & 0 & 0 & 0 & 0 \\
\hline
\end{tabular}

Source: Own calculations

Note: Exchange rate: US\$1= RM3.08 and EUR€1=RM4.32 (Oct 31, 2010); US $\$ 1=$ RM3.07 and EUR€1=4.30 (Oct 31, 2011); US $\$ 1=$ RM3.06 and EUR€1=RM3.96 (Oct 31, 2012); US\$1= RM3.16 EUR€1=RM4.33 (Oct 31, 2013) and US\$1= RM3.29 and EUR€1=RM4.14 (Oct 31, 2014). 
Appendix 3.5: Distribution of competitiveness scores (SCB) for the rice farms, 20102014

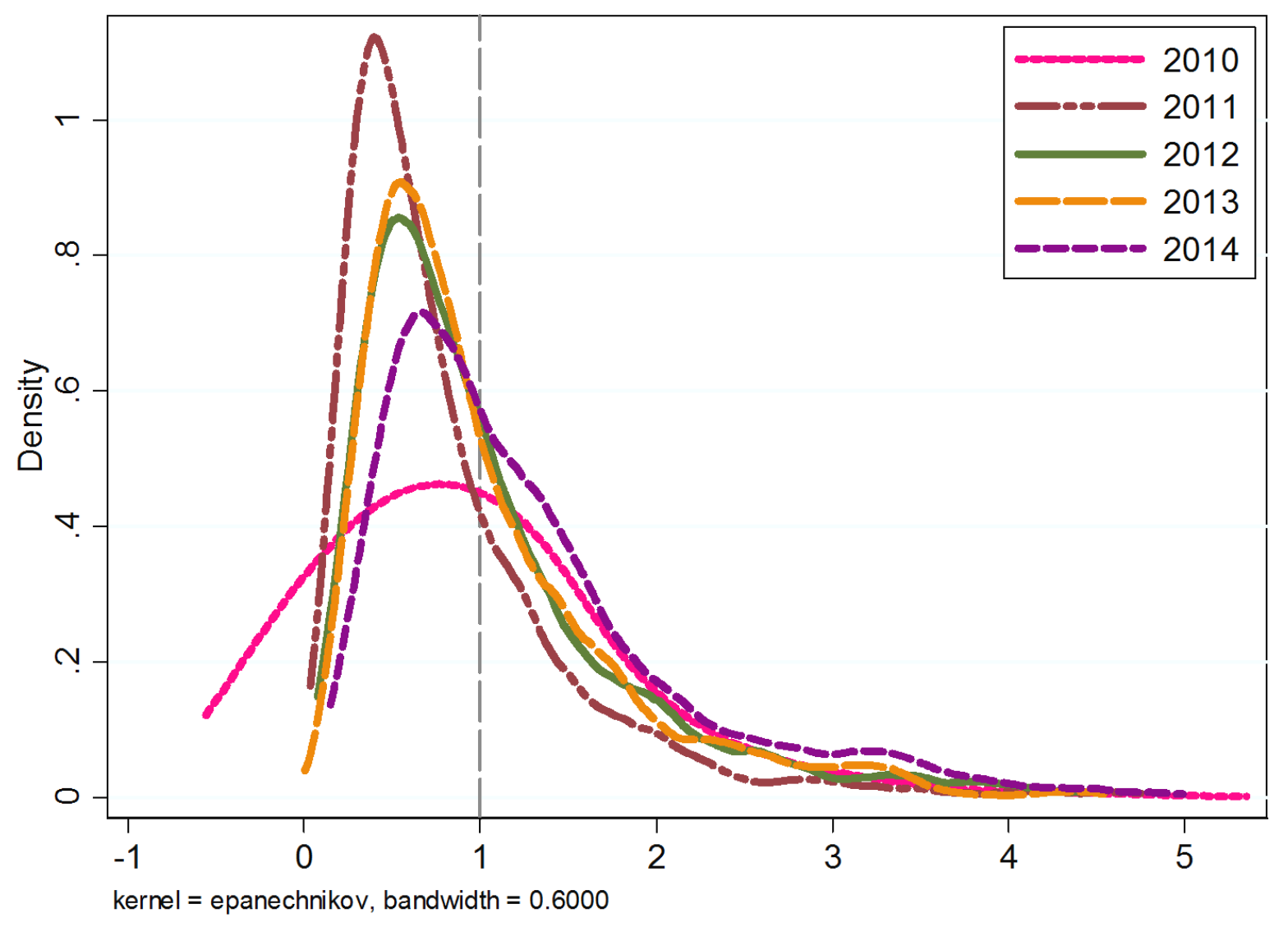

Source: Own calculations 


\section{References}

Abdul Fatah, F., \& von Cramon Taubadel, S. (2015). The policy analysis matrix of profitability and competitiveness of rice farming in Malaysia. In 29th International Conference of Agricultural Economists, Milan, Italy. Retrieved from http://ageconsearch.umn.edu/bitstream/210872/2/Abdul Fatah-The Policy Analysis Matrix of Profitability and Competitiveness of Rice Farming-896.pdf

Addai, K. N., Owusu, V., \& Danso-Abbeam, G. (2014). Effects of farmer - basedorganization on the technical efficiency of maize farmers across various agro - ecological zones of Ghana. Journal of Economics and Development Studies, 2(1), 141-161. Retrieved from http://jedsnet.com/journals/jeds/Vol_2_No_1_March_2014/7.pdf

Anderson, T. W., \& Hsiao, C. (1981). Estimation of dynamic models with error components. Journal of the American Statistical Association, 76(375), 598.

Arellano, M., \& Bover, O. (1995). Another look at the instrumental variable estimation of error-components models. Journal of Econometrics, 68, 29-51. Retrieved from http://www.cemfi.es/ arellano/arellano-bover-1995.pdf

Arshad, F. M., Alias, E. F., Noh, K. M., \& Muhammad, T. (2011). Food security: selfsufficiency of rice in Malaysia. International Journal of Management Studies, 18(2), 83100. Retrieved from http://www.ijms.uum.edu.my/images/pdf/18no2ijms/ijms1825.pdf

Blundell, R., \& Bond, S. (1998). Initial conditions and moment restrictions in dynamic panel data models. Journal of Econometrics, 87, 115-143. Retrieved from http://www.ucl.ac.uk/ uctp39a/Blundell-Bond-1998.pdf

Bond, S. R., Hoeffler, A., \& Temple, J. (2001). GMM estimation of empirical growth models. Discussion Paper No. 3048. Retrieved from https://www.nuffield.ox.ac.uk/users/bond/CEPR-DP3048.PDF

Busayo Rashidat, Y., Mohd Mansor, I., \& Nolila Mohd, N. (2013). Comparative study of two incentive schemes in Malaysian paddy production. Institute of Agricultural and Food Policy Studies, Putra Infoport, 23, http://doi.org/10.5829/idosi.wasj.2013.23.eemcge.2206

Chan, C.-W., \& Cho, M.-C. (2012). Country report: Malaysia, Asia Pacific Economic Cooperation (APEC). Workshop on Food Security. Retrieved from http://www.apipapec.com/my/good-practices/1_1/1_1_1/country_report_malaysia.html

Department of Agriculture, M. (2014). Perangkaaan padi Malaysia (paddy statistics of Malaysia 2013). Putrajaya, Malaysia. 
Dorosh, P. A. (2009). Price stabilization, international trade and national cereal stocks: world price shocks and policy response in South Asia. Food Security, 1(2), 137-149. http://doi.org/10.1007/s12571-009-0013-3

Erenstein, O. (2010). A comparative analysis of rice-wheat systems in Indian Haryana and Pakistan Punjab. Land Use Policy, 27(3), 869-879. http://doi.org/10.1016/j.landusepol.2009.12.001

European Commission. (2014). Guide to Cost-benefit Analysis of Investment Projects Economic appraisal tool for Cohesion Policy 2014-2020. Retrieved from http://ec.europa.eu/regional_policy/sources/docgener/studies/pdf/cba_guide.pdf

FAOSTAT. (2016). Food and Agriculture Organization of the United Nations statistics division. Retrieved January 4, 2016, from http://faostat3.fao.org/download/Q/QC/E

Femenia, F., Gohin, A., \& Carpentier, A. (2010). The decoupling of farm programs: Revisiting the wealth effect. American Journal of Agricultural Economics, 92(3), 836848. http://doi.org/10.1093/ajae/aap029

Frohberg, K., \& Hartmann, M. (1997). Comparing measures of competitiveness. Discussion paper No. 2. Institute of Agricultural Development in Central and Eastern Europe. Retrieved from http://www.econstor.eu/bitstream/10419/28566/1/241163463.pdf

Goodwin, B. K., \& Ashok, K. M. (2004). Farming efficiency and the determinants of multiple job handling by farm operators. American Journal of Agricultural Economics, 86(3), $722-729$.

Retrieved from http://pubag.nal.usda.gov/pubag/downloadPDF.xhtml?id=38670\&content=PDF

Goodwin, B. K., \& Ashok, K. M. (2005). Another look at decoupling: additional evidence on the production effects of direct payments. American Journal of Agricultural Economics, 87(5), 1200-1210. Retrieved from http://pubag.nal.usda.gov/pubag/downloadPDF.xhtml?id=6842\&content=PDF

Jamora, N., \& Von Cramon-Taubadel, S. (2012). What world price? GlobalFood Discussion Paper. Georg-August-Universitaet Goettingen. ISSN 2192-3248. Retrieved from file://C:/Users/userdell/Downloads/GlobalFood_DP17\%20(2).pdf

Kanaka, D. S., \& Chinnadurai, M. (2013). The policy analysis of rice cultivation in India. European Journal of Physical and Agricultural Sciences, 1(1). Retrieved from http://www.idpublications.org/wp-content/uploads/2013/11/the-policy-analysis-matrixof-rice-cultivation-in-india.pdf 
Koirala, K. H., Ashok, K. M., \& Mohanty, S. (2015). The role of gender in agricultural productivity in the Philippines: the average treatment effect. In Southern Agricultural Economics Association's 2015 Annual Meeting, Atlanta, Georgia. Retrieved from http://ageconsearch.umn.edu/bitstream/195705/2/ATT_SAEA_2015 (1).pdf

Masters, W. A., \& Winter-Nelson, A. (1995). Measuring the comparative advantage of agricultural activities: domestic resource costs and the social cost-benefit ratio. American Journal of Agricultural Economics, 77(2), 243-250. http://doi.org/10.2307/1243534

Mohd Rashid, R., \& Mohd Dainuri, M. S. (2013). Food and livelihood security of the Malaysian paddy farmers. Economic and Technology Management Review, 8, 59-69.

Monke, E. A., \& Pearson, S. R. (1989). The policy analysis matrix for agricultural development. Ithaca, NY: Cornell University Press. Retrieved from http://web.stanford.edu/group/FRI/indonesia/documents/pambook/pambook.pdf

Morrison, J., \& Balcombe, K. (2002). Policy analysis matrices: beyond simple sensitivity analysis. Journal of International Development, 14(4), 459-471. http://doi.org/10.1002/jid.887

Nivievskyi, O., von Cramon-Taubadel, S., \& Brummer, B. (2010). A note on technical efficiency, productivity growth and competitiveness. Annual Meeting, July. Retrieved from http://ageconsearch.umn.edu/bitstream/61759/2/11234 AAEA 2010.pdf

Reig-Martínez, E., Picazo-Tadeo, A. J., \& Estruch, V. (2008). The policy analysis matrix with profit-efficient data: evaluating profitability in rice cultivation. Spanish Journal of Agricultural Research, 6(3), 309-319. Retrieved from file:///C:/Users/userdell/Downloads/324-324-1-PB.pdf

Roodman, D. (2009a). A note on the theme of too many instruments. Oxford Bulletin of Economics and Statistics, 71(1), 135-158. Retrieved from http://www.cgdev.org/files/14256_file_Instruments.pdf

Roodman, D. (2009b). How to do xtabond2: An introduction to difference and system GMM in Stata. Stata Journal, 9(1), 86-136. http://doi.org/The Stata Journal

Siriwardana, A. N., \& Jayawardena, L. N. A. C. (2014). Socio-demographic factors contributing to the productivity in paddy farming: a case study. Tropical Agricultural Research, 25(3), 437-444. $\quad$ Retrieved from http://www.pgia.ac.lk/files/Annual_congress/journel/v25/Journal-No 3/Poster/14. siriwardana $20 \mathrm{ok}$ final - OK.pdf 
Sunding, D., \& Zilberman, D. (2000). The agricultural innovation process : research and technology adoption in a changing agricultural sector. Handbook of Agricultural Economics, 1-105. http://doi.org/10.1016/S1574-0072(01)10007-1

Tengku Mohd Ariff, T. A., \& Ariffin, T. (1999). Effect of trade liberalization on agriculture in Malaysia: commodity aspects. The CGPRT Center Working Paper Series no. 46. Retrieved from http://ageconsearch.umn.edu/bitstream/32694/1/wp990046.pdf

Timmer, C. P. (2005). Food security and economic growth: an Asian perspective. Working Paper No. 50, December 2004 (Revised December 2005).

Timmer, C. P., \& Dawe, D. (2007). Managing food price instability in Asia: A macro food security perspective. Asian Economic Journal, 21(1), 1-18. http://doi.org/10.1111/j.14678381.2007.00244.x

Umar, S. H., Abdullah, A. M., Shamsudin, M. N., \& Mohamed, Z. A. (2014). Effects of paddy price support withdrawal on Malaysian rice sector: time series econometric approach. Asian Journal of Agriculture and Rural Development, 4(7), 401-413. Retrieved from http://www.aessweb.com/pdf-files/3-484-AJARD-4(7)2014-401-413.pdf

von Cramon Taubadel, S., \& Nivyevskyi, O. (2009). Belarus agricultural productivity and competitiveness: impact of state support and market intervention. Retrieved from https://openknowledge.worldbank.org/bitstream/handle/10986/18897/483350ESW0REVI 110FINAL0for0printing.pdf?sequence $=1 \&$ isAllowed $=\mathrm{y}$

von Cramon-Taubadel, S., \& Nivyevskyi, O. (2008). Ukraine-ag-competitiveness-policy note - final.

Wailes, E. J. (2005). Rice: Global trade, protectionist policies, and the impact of trade liberalization. M. Ataman Aksoy and John C. Beghin, 2(576), 177.

Warr, P., \& Yusuf, A. A. (2014). Fertilizer subsidies and food self-sufficiency in Indonesia. Agricultural Economics, 45(5), 571-588. http://doi.org/10.1111/agec.12107

World Trade Organization. (2014). Trade Policy Review Malaysia: World Trade Organization (Vol. $\mathrm{WT} / \mathrm{TPR} / \mathrm{S} / 2$ ). Retrieved from https://www.wto.org/english/tratop_e/tpr_e/tp392_e.htm

Yao, S. (1997). Rice production in Thailand seen through a policy analysis matrix. Food Policy, 22(6), 547-560. http://doi.org/10.1016/S0306-9192(98)00007-4

Zheng, S., Lambert, D., Wang, S., \& Wang, Z. (2015). Effects of agricultural subsidy policies on comparative advantage and production protection in China: An Application with a Policy Analysis Matrix Model. The Chinese Economy, 46(1), 20-37. Retrieved from 
http://web.a.ebscohost.com.ezaccess.library.uitm.edu.my/ehost/pdfviewer/pdfviewer?sid $=355 \mathrm{ac} 440-\mathrm{f} 279-4 \mathrm{~b} 04-\mathrm{b} 575-17 \mathrm{~b} 9212254 \mathrm{a} 2 \% 40$ sessionmgr $4005 \& \mathrm{vid}=2 \& \mathrm{hid}=4101$

\section{Chapter 4}

\section{Estimating Technical Efficiency and Unobserved Heterogeneity On Rice Farms in Malaysia}

Changes and trends in farm efficiency have been of considerable interest to many Asian governments due to a strong link between food security and rice production. We use farm level data to gain insights on the technical efficiency of the Malaysia's rice farming. Although panel data are available, some important descriptive attributes are scarce. As a result, we take unobserved heterogeneity into account and use the recent fixed effect model implemented by Chen et al (2014). During the period of 2010-2014, technical efficiency was found to be fluctuating, with an average mean value of 60 percent. The low mean values of technical efficiency change further revealing that the frontier is shifting inward and some farms are essentially moving farther from the frontier. In a second stage of analysis, we examine the factors that account for the variations in inefficiencies across the farms as well as their potential to improve efficiency and resource use using a fixed effect model regression. Our empirical results indicate that access to credit, non-farm income, distance to the rice mill, farm size and hired labor are the major determinants of technical efficiency. Additionally, government input subsidies are found to have a positive impact on farm technical efficiency and thus support the argument that agricultural subsidies may create incentives for farmers to improve their efficiency. Overall, the results indicate that rice production can be improved by continuously increasing a farm's resources and technical efficiency. This suggests that a serious policy recommendation that facilitates farmers' accessibility to credit, capital, land and other inputs, especially for small farms, must be carefully designed and well-targeted. Improved access to and distribution of input subsidies must also occur.

Keywords: rice, technical efficiency, fixed effect, panel data, unobserved heterogeneity 


\subsection{Introduction}

The efficiency of the rice production sector has been the subject of considerable interest and policy focus for many Asian governments due to the strong relationship between food security and rice production (Timmer and Dawe 2007). The global rice market crisis of 20072008 led to sudden spikes in rice prices, which further marginalized poor populations in many developing countries and hindered their access to sufficient basic food supplies (Dawe, 2010). Rice is a primary food staple for a large part of the world's human population and has a large influence on the livelihood of farmers. For this reason, policymakers have become particularly concerned with the efficiency of rice production. Reliable research results on the efficiency of rice production can contribute to policies that increase agricultural production, promote adequate food supplies, and boost incomes and food security for low income farmers.

Research on production efficiency can also contribute to the debate on whether it is necessary to support rice production, for example with price support or input subsidies. Many countries in Southeast Asia, including Malaysia, protect and support domestic rice producers. Since the inception of the ASEAN free trade agreement (AFTA), rice tariffs have been reduced to 0-5\% for all trading partners in the region. However, in the major rice importing countries, such as Malaysia, rice is considered a key to food security and, therefore, is subject to tariffs up to $20 \%$. Both the volumes of the input subsidies and price support have increased remarkably over the years. This support, however, has been the subject of a long-standing debate (Hoang and Meyers, 2015). Some argue that deviations from production and international trade based on comparative advantage will result in allocative inefficiencies and rent-seeking behavior. Policy makers counter that support is required to boost domestic self-sufficiency and to protect farmers from the effects of what is perceived to be unfair competition. Research can inform this debate by providing facts on whether and which rice producers are efficient, and the factors that contribute to differences in productivity and efficiency among producers.

Malaysia has the potential to grow more rice if analysis can identify efficient farms and the causes of their superior performance, thus, providing benchmarks for less efficient farms. The study of the rice markets in Malaysia is somehow unique in the region as it exhibits some exceptional features and is worth investigating for several reasons. First, Malaysia lies entirely in the equatorial zone with uniform temperature, high humidity and rainfall that are 
favorable for the development and growth of the tropical rice crop. The copious rainfall provides important water sources for successful cultivation of rice. However, despite of its natural endowments, the country's topography leaves limited arable land to expand rice production (Arshad et al. 2011). Second, the average yield in Malaysia from 2010- 2013 was 4.60 tons paddy per hectare, compared to just 3.44 tons paddy per hectare in the major rice exporters in Southeast Asia (Mutert and Fairhurst, 2002). Yet, the evidence indicates that the average potential rice yield in the country is 10 tons per hectare (Siwar et al. 2014). The yield gap between potential and actual yield levels in Malaysia is nearly twice that of the current yield which requires further improvement in efficiency in order to close the gap. Third, the $2 \%$ national population growth rate is resulting in a demand that outpaces the production growth. At the same time, there is little scope to extend the crop land frontier: rice land availability in Malaysia has declined by 10,600 ha (0.30\%) from 1990-1995 (Daño and Samonte, n.d.). Consequently, Malaysia needs to produce more rice, while at the same time increase the efficiency of the scarce resource, which is largely possible by increasing the adoption rate of high-yielding rice varieties in all seasons to up to 90 per cent of total rice area (Abiola et al. 2016). This implies that Malaysian farmers need to increase their efficiency by utilising the scarce resources efficiently. Therefore, studying the potential of inefficiencies in farm performance is important not only from the policy standpoint but also from a global context.

However, literature on the efficiency of Malaysian rice production has typically used crosssectional data (Thiam et al. 2001). To the best of our knowledge, the technical efficiency of Malaysian rice farms, and its evolution over time, have not been studied using representative farm panel data. This study is an attempt to narrow this gap. For this purpose, we conduct an empirical technical efficiency analysis with unobserved heterogeneity and employ an implementation by Chen et al (2014) of a fixed effect model. We study data from a panel of 6,570 rice farms covering the years 2010-2014. These data provide a unique opportunity to analyze the changes in farm level efficiency over time for rice farms in Malaysia and to gain insights into the factors that determine differences in efficiency between farms.

The rest of this paper is structured as follows. In section 4.2 we present the panel data model of technical efficiency that we employ. Section 4.3 describes the data that we use. In section 4.4 we present and discuss results, and Section 4.5 concludes. 


\subsection{Methods to measure efficiency using panel data}

Since the seminal work conducted by Aigner et al. (1977), the Stochastic Frontier (SF) model has been widely use to estimate the technical efficiency in applied economic research. Extensive research in this field has resulted in a growing arsenal of methods and econometrics techniques pertaining to specifications, estimation and testing issue. Despite that, when productivity or efficiency is analyzed at the farm level, the problem arises that not all relevant factor can be observed or measured adequately. Therefore, some environmental, such as soil condition, weather, rainfall or droughts, and managerial characteristics are often omitted from the model specifications because of unavailable or missing information. This information is referred to as unobserved heterogeneity (Álvarez et al, 2009). As a result, inference based on the output comparison could be biased and is often criticized because farms are heterogeneous and operate under different production and environmental conditions (Abdulai and Tietje, 2007).

To overcome the challenge of unobserved heterogeneity, the standard stochastic frontier models, such as the fixed-effects or random-effects model, can be employed (Pitt and Lee 1981; Schmidt and Sickles 1984). A frequent case in most classical stochastic frontier occurs when the information that accounts for unobserved heterogeneity not included in the model is considered time-invariant and these specifications interpret time-invariant unobserved heterogeneity as inefficiency, thus do not provide any mechanism to disentangle the former from the latter. The consideration on how heterogeneity is treated has induced several extensions of the standard stochastic frontier model (see Greene (2008) for a recent survey). These extensions distinguish between the aforementioned latent components by separating the inefficiency from the time invariant unobserved heterogeneity that are unrelated with the production process but affect the output (Kumbhakar and Hjalmarsson, 1995; Greene, 2005a,b; Wang and Ho, 2010; Chen et al. 2014).

In the dataset that we employ, managerial characteristics and environmental conditions are not directly observed and can be interpreted as unobserved farm heterogeneity. Consider the following specification of the fixed-effect stochastic production frontier model for panel data $^{6}$ :

$$
\begin{gathered}
y_{i t}=\alpha_{i}+\beta^{\prime} x_{i t}+v_{i t}-u_{i t} \\
\varepsilon_{i t}=v_{i t}-u_{i t}
\end{gathered}
$$

\footnotetext{
${ }^{6}$ In the following method, i draw heavily on the following sources; Belotti and Giuseppe (2012) and Holtkamp (2015).
} 
where $y_{i t}$ is the vector of the output of firm $i(i=1, \ldots, N)$ in period $t(t=1, \ldots, T) ; \quad x_{i t}$ is a set of inputs that produce output $y_{i t} ; \alpha_{i}$ is the unit fixed-effect; $\beta$ is the associated vector that describes technology parameters to be estimated. The composite error term $\varepsilon_{i t}$ is the difference between the idiosyncratic error that captures noise $v_{i t}$, and the one-sided disturbance $u_{i t}$ which represents inefficiency. Under the frequently used normal-half normal model, the distributional assumptions are $v_{i t} \sim N\left(0, \sigma_{v}^{2}\right)$ and $u_{i t} \sim N^{+}\left(0, \sigma_{u}^{2}\right)$. However, as mentioned previously whether or not to separate $\alpha_{i}$ from $u_{i t}$ has been the subject of much debate in the stochastic frontier literature. A major limitation of the model in equation (1) is related to an identification problem which arises when the inefficiency term is time-variant. It is not likely that a constant level of inefficiency would extend over long periods of time; i.e. process of learning or managerial ability. In this case, it is difficult to disentangle the unobserved farm-specific heterogeneity from inefficiency (Greene, 2005).

Greene (2005) proposed a "true fixed effects" or TFE model that includes a maximum likelihood dummy variables estimator (MLDVE), in which the unit-specific intercepts are estimated with structural parameters. The TFE model places unobserved heterogeneity as fixed effects in the stochastic frontier model (equation 1) and generates a neutral shift of the function specific to each farm (Porcelli, 2009) while allowing for time-varying inefficiency (Belotti and Giuseppe, 2012). This approach is frequently applied, however it leads to inconsistent variance parameter estimates due to the incidental parameters problem especially in the short panel because the number of parameters depends on the sample size (there are firm effects $\alpha_{i}$; and the number of parameters, $\mathrm{N}$ which increases with the sample size). Hence, the estimated error variance, and the parameter $\sigma_{u}^{2}$ is inconsistent.

To account for this limitation, Chen et al. (2014) propose a consistent estimator for the TFE normal-half normal model based on the within transformed model where the fixed effects have been removed. This procedure is commonly used in the panel data:

$$
\bar{z}_{i t}=z_{i t}-\bar{z}_{i}
$$

For any corresponding variable $(z)$ in each panel $i$, the individual mean $\left(\bar{z}_{i}\right)$ is subtracted from the observed value in period $\mathrm{t}\left(z_{i t}\right)$. Correspondingly, the model can be represented by using 
the deviations from means $\left(\bar{z}_{i}\right)$ so that the transformed model is free from incidental parameters problem $\left(\alpha_{i}\right)$ :

$$
\bar{y}_{i t}=\beta^{\prime} \bar{x}_{i t}+\bar{v}_{i t}-\bar{u}_{i t}
$$

As outlined by (Holtkamp, 2015) the model in equation (4) has the following features: first, the incidental parameters problem is removed by a within-transformation; second, it produces a consistent estimator of the error variance since the relevant likelihood function is derived from $T-1$ deviations; and third, this approach, which is based on a more general distributional theory, allows for the maintenance of the firm-specific and time varying inefficiency $u_{i t}$.

The distribution of the composed error, $\epsilon_{i t}$ is defined by the Closed Skew Normal (CSN) distribution in the stochastic frontier context (Chen et al. 2014). The CSN is a generalization of the skew normal distribution (González-Farías et al. 2004), which is itself a generalization of the normal distribution. Therefore, the CSN family preserves some properties of the normal distribution (Chen et al. 2014). With panel data, the distribution of the composed error can be written as:

$$
\epsilon_{i} \sim \operatorname{CSN}_{1,1}\left(0, \sigma^{2},-\frac{\lambda}{\sigma}, 0, I\right)
$$

where the density of a CSN distribution includes a p-dimensional pdf and a q-dimensional cdf of a normal distribution; parameters in the bracket describe location $(0)$, scale $\left(\sigma^{2}\right)$, skewness $\left(\frac{\lambda}{\sigma}\right)$, as well as the mean vector $(0)$ and covariance matrix in the cdf $(I)$. In the panel data, the vector $\left(\varepsilon_{i}=\varepsilon_{i 1}, \varepsilon_{i 2} \ldots \ldots \epsilon_{i T}\right)^{\prime}$ is distributed as:

$$
\epsilon_{i t} \sim \operatorname{CSN}_{T, T}\left(0_{T}, \sigma^{2} I_{T},-\frac{\lambda}{\sigma} I_{T}, 0_{T}, I_{T}\right)
$$

where $I$ is the identity matrix and the vector is divided into a linear combination; its mean is represented by $\bar{\varepsilon}_{i}$ and its first T-1 deviations as $\bar{\varepsilon}_{i}^{*}=\left(\bar{\varepsilon}_{i 1}, \bar{\varepsilon}_{i 2} \ldots \ldots, \bar{\varepsilon}_{i, T-1}\right)^{\prime}$; and within MLE, which is defined by the maximization of the within likelihood with respect to $\beta, \lambda$ and $\sigma^{2}$, which is not subject to the incidental parameters problem, (where $\beta=$ within estimator, $\lambda=\frac{\sigma_{u}}{\sigma_{v}}$ and $\left.\sigma^{2}=\sigma_{u}^{2}+\sigma_{v}^{2}\right)$. 
The point estimator of Battese and Coelli (1988) can be used to assess technical effciency. Therefore, the composed error has to be recovered:

$$
\varepsilon_{i t}=y_{i t}-\hat{y}_{i t}=y_{i t}-\beta^{\prime} x_{i t}-\hat{\alpha}_{i}
$$

The estimate $\hat{\alpha}_{i}$, can be obtained by mean-adjusting the usual estimator for the fixed effects linear model. In this model if $\hat{\beta}$ is the within estimator, then the fixed effects estimates of individual effects are; $\widehat{\alpha}_{i}=\bar{y}_{i}-\bar{x}_{I} \hat{\beta}$. However, in the stochastic frontier model, since the $\bar{\varepsilon}_{i}$ is not zero because $-E\left(u_{i t}\right)=\sqrt{\frac{2}{\pi}} \sigma_{u}$, the estimator needs to be modified and $\widehat{\alpha}_{i}$ can be calculated as the mean-adjusted estimate by (Chen et al. 2014):

$$
\hat{\alpha}_{I}^{M}=\bar{y}_{i}-\hat{\beta}^{\prime} \bar{x}_{i}+\sqrt{\frac{2}{\pi}} \hat{\sigma}_{u}
$$

where $\hat{\beta}$ and $\hat{\sigma}_{u}$ are the within MLE estimates.

\subsection{Data and empirical definitions of the variables}

We estimate the stochastic frontier model outlined above using farm-level survey data over the period 2010-2014. These farms are located in Muda Agricultural Kemubu Authority (MADA), Kedah, which is the largest granary area in Malaysia and located in north Malaysia. Granary Areas ${ }^{7}$ are acknowledged by the Government in the National Agricultural Policy as the main paddy producing areas. These eight areas are irrigated according to large irrigation schemes (areas greater than 4,000 hectares) (Department of Agriculture, 2014).

The output variable is defined as the total output of rice production in kilograms $(\mathrm{kg})$. The consideration of the gross output of rice in $\mathrm{kg}$ has the advantage of taking quality differences into account. The actual purchasing price that farmers normally receive from the processors or the rice millers depends on the grain's purity, quality and moisture content. Corresponding to the standards enforced by the local and government millers, the acceptable moisture content of paddies in Malaysia is $14 \%$. If the moisture in a sample of paddy surpasses this limit, the per $\mathrm{kg}$ price of this rice is adjusted accordingly. The vector $\mathrm{X}$ includes five inputs: land (in

\footnotetext{
${ }^{7}$ There are eight granary areas in Malaysia, namely MADA, KADA, IADA KERIAN, IADA BLS, IADA P. Pinang, IADA Seberang Perak, IADA KETARA and IADA Kemasin Semerak.
} 
ha), labor, is approximated by the wage expenditure per day in Ringgit Malaysia (RM), capital costs, also in RM (which include the costs of machinery services hired for harvesting, transplanting, seedling and threshing), quantity of seeds used (in $\mathrm{kg}$ ), and the value of agricultural chemicals in RM.

These variables are transformed and scaled to their respective means before taking logarithms. With this transformation, the elasticities of the output regarding the inputs are the first-order coefficients of the inputs in a translog function (evaluated at the means of the variables).

Prior to further analysis, we remove outliers from the balanced panel data of 6,750 rice farms for the period 2010-2014. Here, all observations were detected as outliers if $99 \%$ of the variable of interest (output, capital, labor and seed) lied outside \pm 3 standard deviations from the mean. To account for zero usage of agricultural chemicals, the values of this variable are added to the amount of pesticides subsidies of 200 RM per hectare. Additionally, many data sets are incomplete or indicate obvious errors. As a consequence, the remaining panel is unbalanced with 6,570 and we continued working with the unbalanced panel data for the rice farms in Malaysia.

We use a translog functional form which includes a time trend, $t$ as an additional input in order to allow for non-neutral technical change. The model specification is therefore:

$$
\begin{aligned}
& \ln y_{i t}=\alpha_{i}+\sum_{j=1}^{5} \beta_{j} \ln x_{j i t}+\frac{1}{2} \sum_{j=1}^{5} \sum_{l=1}^{5} \beta_{j l} \ln x_{j i t} \ln x_{l i t} \\
& +\beta_{t} t+\frac{1}{2} \beta_{t t} t^{2}+\sum_{j=1}^{5} \beta_{t j} \ln x_{j i t} t+v_{i t}-u_{i t}
\end{aligned}
$$

In this equation, $\alpha_{i}$ is the unobserved heterogeneity which is treated as fixed; $x_{i t}$ is a set of inputs that produce output $y_{i t} ; \quad v_{i t}$ is the statistical error; and the non-negative random variable $u_{i t}$ is the technical inefficiency.

Both output and input exhibit substantial variation over time. For example, the average output increased from $5,359 \mathrm{~kg}$ in 2010 to $6,316 \mathrm{~kg}$ in 2013 , but then decreased strongly to $4947 \mathrm{~kg}$ in 2014. Individual inputs such as seed, agricultural chemicals and capital costs also vary considerably over time. The standard deviations indicate a higher degree of heterogeneity among the rice producers in the dataset, even though they are all located in the same granary 
area. This heterogeneity is presumably due to farm-level variation in factors which are not captured in the dataset, including biophysical conditions (e.g. climate, irrigation, soil condition), farmer characteristics (e.g. age, education, experience, household size), and managerial skills. The CFE model described above allows us to account for this farm-level heterogeneity when estimating efficiency.

In a second step, we use a fixed effect panel regression to analyze the determinants of technical efficiency. Exogenous variables that we hypothesize will affect technical efficiency include farm characteristics (e.g. size, distance from the rice mill), farmer characteristics (whether he/she is a member of the farmers' organization, whether he/she owns or rents the farm, gender, off-farm income, access to credit), and the amount of government support received by the farm. This support includes subsidies on input use such as fertlizer, lime and chemical inputs. Since 1974, farmers who owned less than 10 hectares of lands received free fertilizers of $240 \mathrm{~kg}$ per hectare of mixed fertilizer, $80 \mathrm{~kg}$ per hectare of organic fertilizer and $150 \mathrm{~kg}$ (3 bags) of NPK (nitrogen, phosphate and potassium). In addition, all farmers receive a coupon of agricultural chemical inputs for purchasing weeds and pest controls worth of 200 $\mathrm{RM} / \mathrm{ha}$. Another form of support is the price subsidy. This scheme was introduced in 1980 at the rate of $165 \mathrm{RM}$ per ton and was then revised and increased to $248.10 \mathrm{RM}$ per ton in 1990.A list of these variables and descriptive statistics are provided in Table 4.1.

The relationship between off-farm income and technical efficiency is complex and ambiguous. Kumbhakar and Lien, (2010) and Abdulai and Eberlin (2001) postulated higher production inefficiency is associated with the involvement of households in off-farm activities. Farmers who have various sources of income may devote more time to off-farm activities and, hence, pay less attention and effort to farm activities, such as agronomical practices. However, off-farm income might also have a beneficial effect on technical efficiency. Fernandez-Cornejo et al. (2007) argue that off farm income increases the adoption of agricultural innovations through managerial time. Additionally, an increase in nonfarm employment reduces financial constraints, especially for resource constrained farmers who may require the additional income to purchase productivity enhancing inputs (Huffman, 1980).

Access to formal credit may relieve financial constraints otherwise hindering farmers from investing in efficiency enhancing inputs (Abdulai and Eberlin, 2001; Brummer and Loy, 
2000; von Cramon-Taubadel and Saldias, 2014). In this case, credit could therefore increase the net revenue obtained from fixed inputs, market conditions and individual characteristics. On the other hand, a credit constrained farmer will be less efficient if credit shortage adversely affects access to input and limits the adoption of high yielding varieties and the acquisition of information relevant for increasing productivity (Wozniak, 1993). Credit can also be worrisome if default costs are seen to be minor and a credit is therefore used as a welfare support measure by the household (Binswanger and Deininger, 1997).

Other variables representing characteristics of the farmers include gender, participation in a farmer's organization and land ownership. The household head, whether male or female, is assumed to be the primary decision maker for that household and therefore contributes to efficiency. Farmers who participate in a farmers' organization might be more efficient due to easier access to productive inputs and technical and management services, such as training, information and extension on input application (Addai et al, 2014). Economic theory suggests that lack land ownership negatively affects a farmer's access to credit designated to improve land-based practices. Therefore, land ownership reduces uncertainty which helps farmers to make investment decisions on land, adopt the best cropping system, use the land as collateral for credit and thus improves efficiency (Koirala et al, 2016).

Two variables that represent farm characteristics employed in the analysis of the determinants of technical inefficiency include land and distance to the rice mill. The relationship between farm size and efficiency has gain much attention in the literature. In most developed countries, farm size is found to increase consistently in the last decades. Some authors hypothesize that larger farms benefited from higher efficiency than smaller farms (Olson and Vu 2009; Masterson, 2007). However, other authors, particularly in the developing countries studies argue that smaller farms are more productive because they make use of the land more intensively (Johnson and Ruttan,1994; Binswanger and Elgin, 1998; Bhatt and Bhat, 2014). We hypothesize that smaller farms are more technically efficient than the larger farm, considering a relatively small farm with limited access to resources may use the combined resources (use labor more intensively, use more of available land for land improvement) in a diligent manner in order to survive. Additionally, our hypothesis is that distance to the rice mills reduces technical inefficiency. With greater access to the market and better roads and transport infrastructure, farmers are able to reduce the risk and uncertainty of postharvest losses as well as achieve greater information on market prices. 
The effect of subsidies is ambiguous and remains a controversial issue. The arguments for a negative impact of subsidies on technical efficiency point to the weakening of the managerial efforts and unfairly undermining poor farmers, reducing incentives for producers to boost efficiency and shifting their focus from crops to farming subsidies (Martin and Page 1983; Serra et al, 2008). On the other hand, explanations for a positive relationship between subsidies and efficiency include the incentives to adopt technologies or practices that are not common for the farmers and subsidization may help them to overcome financial constraints (Kumbhakar and Lien 2010; Zhu and Lansink 2010). 
Table 4.1: Summary of rice production data and descriptive statistics, MADA granary area, 2010-2014.

\begin{tabular}{|c|c|c|c|c|c|c|c|c|c|c|c|c|c|}
\hline \multirow{2}{*}{ Variable } & \multirow{2}{*}{ Unit } & \multicolumn{2}{|c|}{2010} & \multicolumn{2}{|c|}{2011} & \multicolumn{2}{|c|}{2012} & \multicolumn{2}{|c|}{2013} & \multicolumn{2}{|c|}{2014} & \multicolumn{2}{|c|}{ All } \\
\hline & & Mean & $\mathrm{SD}$ & Mean & $\mathrm{SD}$ & Mean & SD & Mean & SD & Mean & SD & Mean & SD \\
\hline Rice output & $\mathrm{kg}$ & 5359 & 3480 & 4983 & 3431 & 5039 & 3242 & 6316 & 15436 & 4947 & 3139 & 5331 & 7567 \\
\hline Land & hectare & 2.1 & 1.8 & 2.0 & 1.9 & 1.8 & 1.5 & 1.7 & 1.2 & 1.8 & 1.3 & 1.9 & 1.6 \\
\hline Labor & $\mathrm{RM}$ & 78 & 80 & 69 & 65 & 80 & 69 & 88 & 76 & 114 & 91 & 86 & 78 \\
\hline Cost of capital & $\mathrm{RM}$ & 818 & 167 & 881 & 198 & 875 & 191 & 926 & 169 & 947 & 187 & 889 & 188 \\
\hline Seed & $\mathrm{kg}$ & 330 & 265 & 318 & 278 & 298 & 239 & 296 & 245 & 272 & 211 & 303 & 249 \\
\hline Cost of agriculture chemicals & $\mathrm{RM}$ & 360 & 66 & 305 & 93 & 344 & 192 & 470 & 243 & 571 & 208 & 589 & 368 \\
\hline \multicolumn{14}{|l|}{ Exogeneous variable } \\
\hline Input subsidy & $\mathrm{RM}$ & 1330 & 863 & 1241 & 853 & 1249 & 805 & 1465 & 929 & 1227 & 779 & 1303 & 852 \\
\hline Price support (bonus payment) & $\mathrm{RM}$ & 1753 & 1112 & 1631 & 1134 & 1685 & 1167 & 1947 & 1235 & 0 & 0 & 1403 & 1259 \\
\hline $\begin{array}{l}\text { Off income (income from non- } \\
\text { farm activities) }\end{array}$ & $\mathrm{RM}$ & 174 & 474 & 189 & 504 & 157 & 437 & 105 & 388 & 128 & 559 & 150 & 476 \\
\hline $\begin{array}{l}\mathrm{PPK}(=1 \text { if farmer is a member of a } \\
\text { farmers' organization) }\end{array}$ & Dummy & 1.0 & 0.2 & 1.0 & 0.1 & 1.0 & 0.1 & 1.0 & 0.1 & 1.0 & 0.1 & 1.0 & 0.1 \\
\hline Distance to the rice mills & $\mathrm{km}$ & 3.1 & 2.2 & 2.9 & 2.4 & 3.1 & 2.3 & 2.9 & 2.5 & 3.1 & 2.3 & 3.0 & 2.4 \\
\hline Gender $(=1$ if farmer is a male $)$ & Dummy & 0.9 & 0.3 & 0.9 & 0.3 & 0.9 & 0.3 & 0.9 & 0.2 & 0.9 & 0.3 & 0.9 & 0.3 \\
\hline Owner (=1 if farmer owns the land) & Dummy & 0.8 & 0.4 & 0.8 & 0.4 & 0.8 & 0.4 & 0.8 & 0.4 & 0.8 & 0.4 & 0.8 & 0.4 \\
\hline Credit ( $=1$ If farmer get access to credit) & Dummy & 0.1 & 0.3 & 0.1 & 0.3 & 0.1 & 0.3 & 0.1 & 0.3 & 0.0 & 0.2 & 0.1 & 0.3 \\
\hline Time trend (Year $1=2010,5=2014)$ & & 1 & 0 & 2 & 0 & 3 & 0 & 4 & 0 & 5 & 0 & 3 & 1 \\
\hline No. of observations & & \multicolumn{2}{|c|}{1298} & \multicolumn{2}{|c|}{1307} & \multicolumn{2}{|c|}{1321} & \multicolumn{2}{|c|}{1329} & \multicolumn{2}{|c|}{1315} & \multicolumn{2}{|c|}{6570} \\
\hline
\end{tabular}




\subsection{Results and discussions}

In this analysis, the use of the farm effects framework to deal with unobserved heterogeneity necessitates a check for a random or fixed effects approach. A Hausman test of null hypothesis was conducted in the translog production function in the corresponding FGLS and LSDV specifications. The test revealed that individual or unobserved effects have no correlation with explanatory variables ${ }^{8}$. Thus, we reject the null hypothesis that suggests specifications that do not account for these correlations (firm-specific effects and explanatory variables) may produce inconsistent and biased results. Therefore, the random effects are rejected in favor of the fixed effects model.

Table 4.2 presents the results of CFE model. At first, we compare CFE model with LSDV model (see Appendix 4.1). CFE has a considerably smaller AIC than the LSDV model, which suggests that it provides a better trade-off between goodness of fit and complexity. Furthermore, the fact that $\sigma_{u}^{2}$ in the CFE specification is significant confirms that firmspecific variation in output is also attributable to inefficiency, which makes our study of inefficiency highly relevant. In the following we therefore focus on the CFE results. Note that a Likelihood Ratio test indicates that the simplification of the Cobb-Douglas to a translog form is rejected. ${ }^{9}$ In general, the model features the desired assumptions and restrictions to ensure the accuracy of the estimation. We find only modest violations of the monotonicity in inputs at the individual point estimate; $27 \%$ of the observations violate monotonicity for land while violations of monotonicity for the other factors are; labour (35\%), capital $(0.05 \%)$, seed (16\%) and agricultural chemical (50\%).

The estimated coefficients can be interpreted as the output elasticities since the variables are normalized at their respective mean. The estimation results indicate that increases in land, labor, capital, seed and agrichemical inputs increase rice output. The high productivity, as indicated by the land elasticity, reflects the condition of the land's structure in the granary area. The results also demonstrate that capital and seed have higher elasticities than other inputs. The capital allocated to production, which is measured in machinery services such as

\footnotetext{
${ }^{8}$ The result yielded a value of $\chi_{26}^{2}=[99.11],(p=0.000)$.

${ }^{9}$ The null hypothesis of simplication of the Cobb- Douglas model is rejected $\mathrm{H}_{0}: \beta_{\mathrm{ij}}=0, \chi^{2}=[350.5]$ $>\chi_{(21,0.01)}^{2}=[38.9]$.
} 
trucks and tractors, is particularly important during harvesting and post-harvest period.The availability of such capital can improve output by reducing the risks of postharvest losses and diseases that would result from the prolonged delivery of the outputs to the rice mills. The significant positive coefficient of seed implies that the use of higher-quality seeds can boost output by increasing crop emergence, reducing replanting, and encouraging more vigorous early crop growth or crop intensity due to a shorter growth duration. The majority of labor requirements, especially during postharvest, manuring, nursery, land preparation, pest control and harvesting activities, require more time and labor in rice production. Additional hours in this system may increase harvesting activity and reduce post-harvest losses leading to higher overall output. Additionally, the use of agricultural chemicals in the rice farming is essential in reducing weed problems, pests and diseases. However, this variable is not significant. Surprisingly, the coefficient of the time trend variable is -0.02 and is statistically significant at the $1 \%$ level, indicating a slightly negative technological change over the study period. This observation might possibly be due to the low adoption rate of improved seed technologies to the farmers in the granary area especially the new improvement in the hybrid rice which is expected to increase yield by $20-30 \%$ (Jamal et al. 2013). Direct seeding is the primary production practice in Malaysia, covering over 80 percent of the rice area planted (Kuyek, 2000). Direct seeding requires large amounts of seed. However, hybrid seed is very expensive which makes it impractical to commercialize.

At the sample mean, we reject the hypothesis of constant return to scale. ${ }^{10}$ The summing up of all plausible point elasticities of the estimation, land, labor, capital, seed and agri-chemical provided us with a measure of scale elasticities of 1.49. The scale elasticity indicates increasing returns to the scale of the rice production, which reacts to proportional increases in input use with more than proportional increases in output.

\footnotetext{
${ }^{10}$ The hypothesis of constant return to scale is rejected, $\left(\chi_{5}^{2}=[138.8], \mathrm{p}=(0.000)\right.$.
} 
Table 4.2: Estimation results of the CFE Model

\begin{tabular}{|c|c|c|c|}
\hline Variable & Coefficient & Std.Error & p-value \\
\hline logland & 0.1490 & 0.0477 & 0.0020 \\
\hline loglabor & 0.0567 & 0.0157 & 0.0000 \\
\hline logcapital & 0.8741 & 0.0484 & 0.0000 \\
\hline logseed & 0.4168 & 0.0339 & 0.0000 \\
\hline logagrichemical & 0.0023 & 0.0316 & 0.9410 \\
\hline time trend & -0.0228 & 0.0066 & 0.0010 \\
\hline $0.5^{*}(\log l a n d)^{2}$ & -0.1137 & 0.1342 & 0.3970 \\
\hline $0.5^{*}{\text { (labor })^{2}}^{2}$ & 0.0462 & 0.0123 & 0.0000 \\
\hline $0.5 *(\log \text { capital })^{2}$ & 0.3979 & 0.0604 & 0.0000 \\
\hline $0.5^{*}(\operatorname{logseed})^{2}$ & 0.8060 & 0.0803 & 0.0000 \\
\hline $0.5^{*}(\text { logagrichemical })^{2}$ & 0.4252 & 0.1017 & 0.0000 \\
\hline $0.5^{*}(\text { time trend })^{2}$ & 0.0057 & 0.0079 & 0.4680 \\
\hline logland*labor & 0.0518 & 0.0338 & 0.1250 \\
\hline logland*logcapital & 0.1601 & 0.1025 & 0.1180 \\
\hline logland*logseed & -0.3361 & 0.0795 & 0.0000 \\
\hline logland*logagrichemical & -0.1840 & 0.0924 & 0.0470 \\
\hline logland $*$ time trend & 0.0071 & 0.0250 & 0.7770 \\
\hline loglabor*logcapital & 0.0790 & 0.0263 & 0.0030 \\
\hline loglabor*logseed & 0.0315 & 0.0259 & 0.2250 \\
\hline loglabor*logagrichemical & -0.0077 & 0.0205 & 0.7070 \\
\hline loglabor*time trend & -0.0012 & 0.0060 & 0.8430 \\
\hline logcapital*logseed & 0.0076 & 0.0809 & 0.9250 \\
\hline logcapital*logagrichemical & 0.0103 & 0.0717 & 0.8860 \\
\hline logcapital*time trend & 0.0098 & 0.0232 & 0.6730 \\
\hline logseed*logagrichemical & -0.0799 & 0.0598 & 0.1820 \\
\hline logseed $*$ time trend & 0.0216 & 0.0190 & 0.2550 \\
\hline logagrichemical*time trend & -0.0270 & 0.0172 & 0.1170 \\
\hline $\ln \{\backslash$ sigma_v^2\} & -2.9389 & 0.1753 & 0.0000 \\
\hline $\ln \left\{\backslash\right.$ sigma_u $\left.\mathrm{u}^{\wedge} 2\right\}$ & -0.5721 & 0.0602 & 0.0000 \\
\hline$\sigma_{\mathrm{v}}$ & 0.0529 & & \\
\hline$\sigma_{\mathrm{u}}$ & 0.5644 & & \\
\hline Log likelihood & -2667 & & \\
\hline AIC & 5393 & & \\
\hline Observation & 6570 & & \\
\hline
\end{tabular}

The technical efficiency, calculated as a static score for each individual farm for each year from 2010 to 2014 is depicted in Figure 4.1, while Table 4.3 provides the descriptive statistics of the mean efficiency level. The technical efficiency distribution generated by the CFE 
model shows the observations of technical efficiency vary over time in many rice farms in the MADA granary area. In the period from 2010 to 2014, roughly $60 \%$ of the rice farms experienced improvements in technical efficiency with more efficient farms produce disproportionately more outputs. However, the efficiency fluctuated over this period, as illustrated by the TE scores for the upper quartiles that become systematically smaller/ larger or improvement/depletion in average TE scores. Results indicate that the mean efficiency was $61 \%$ in 2010 , decreased in 2011, and increased steadily for the next two years before it declined again in 2014. A high standard deviation throughout the years is indicative of the large degree of heterogeneity within the rice production system, which means that some farms improved, while some farms did not. The overall estimate of technical efficiency is lower and quite dispersed, in particular for farms operating in 2011. In contrast, many farms were rated substantially better than the average in 2013.
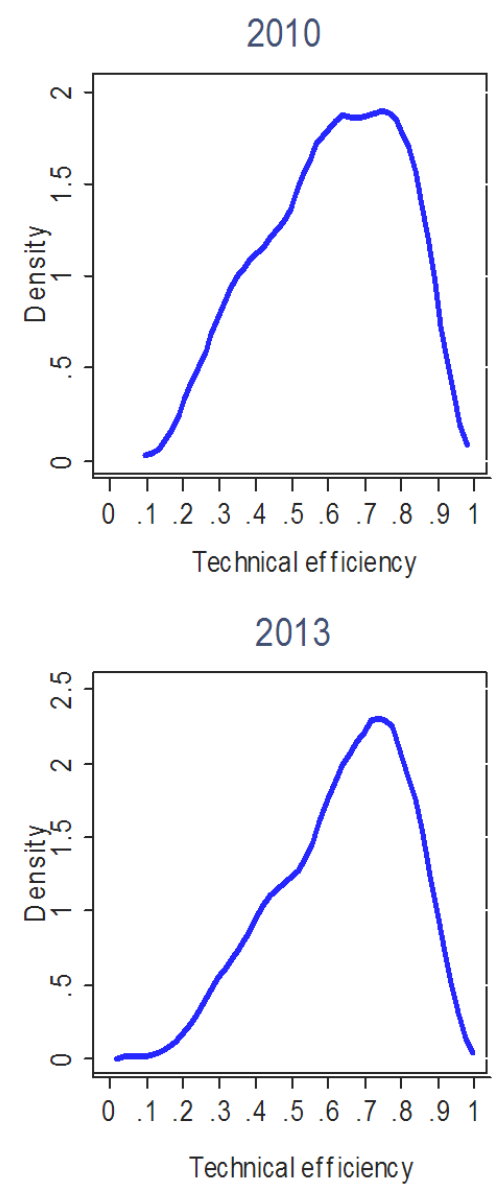

2011

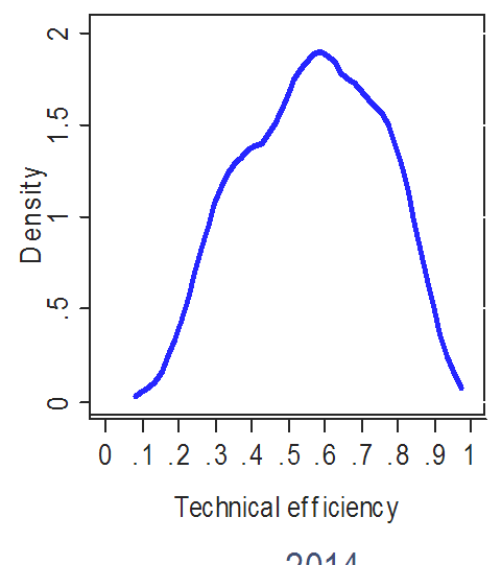

2014

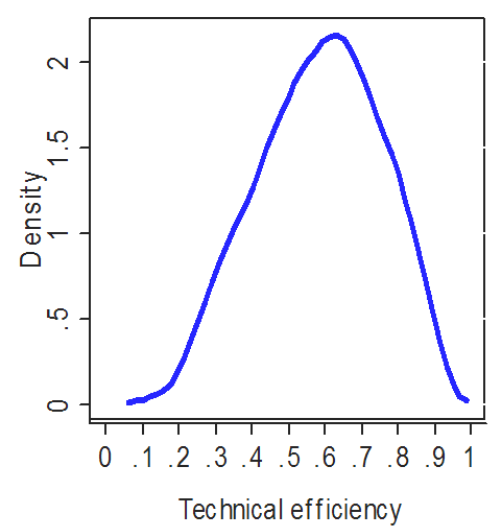

2012
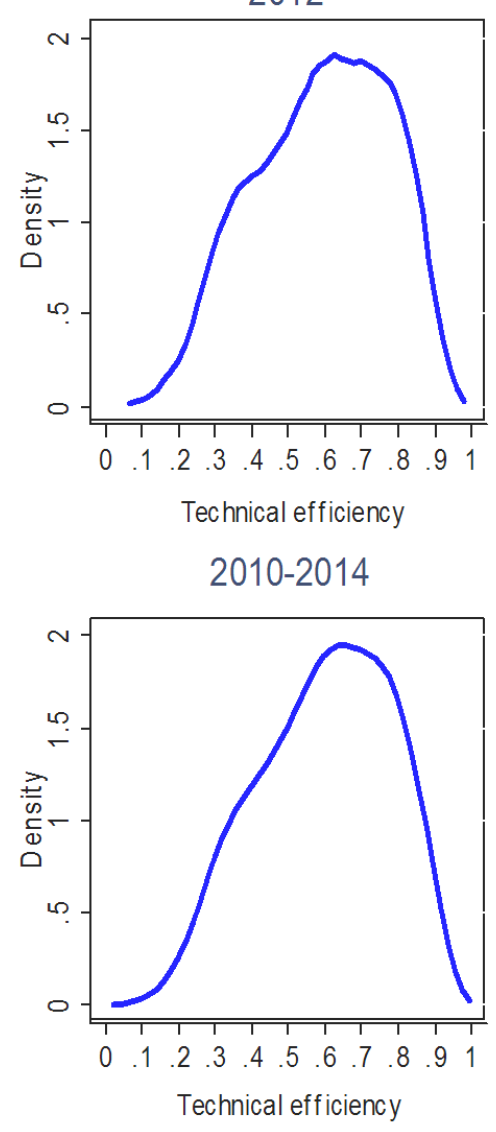

Figure 4.1: Distribution of the TE of rice farms, 2010-2014 
Table 4.3: Technical efficiency (TE) and technical efficiency change (TEC) of rice farms

\begin{tabular}{lcccccccc}
\hline & \multicolumn{7}{c}{ TE } & TEC \\
\cline { 2 - 7 } \cline { 5 - 7 } & Mean & SD & Min & Max & $\begin{array}{l}25 \% \\
\text { quantile }\end{array}$ & $\begin{array}{l}75 \% \\
\text { quantile }\end{array}$ & \\
\hline 2010 & 0.61 & 0.19 & 0.14 & 0.94 & 0.47 & 0.76 & - \\
2011 & 0.56 & 0.18 & 0.12 & 0.93 & 0.42 & 0.71 & -0.0697 \\
2012 & 0.59 & 0.18 & 0.10 & 0.94 & 0.45 & 0.74 & 0.0431 \\
2013 & 0.64 & 0.17 & 0.06 & 0.96 & 0.52 & 0.77 & 0.0828 \\
2014 & 0.58 & 0.17 & 0.10 & 0.95 & 0.47 & 0.71 & -0.0818 \\
\hline Overall & 0.60 & 0.18 & 0.10 & 0.95 & 0.46 & 0.739 & -0.0064 \\
\hline \hline
\end{tabular}

Source: Own estimation

Our result reinforces several observations made based on the technical efficiency distribution provided in Table 3. Specifically, the mean values are around $50-60 \%$ which indicates many farms are far from the frontier. Increasing overall efficiency is a question of either getting the less efficient ones to become more efficient, or getting them to exit so that their resources can be used by other, more efficient, producers. This trend is reflected by technical efficiency change or TEC that varies over the period. The low mean values of TEC further revealing that the frontier was shifting inward and some farms were essentially moving farther from the frontier. This finding therefore necessitates a more detailed analysis to determine which factors influence a farm's efficiency.

In the second stage of the analysis, we examine the factors that account for the variations in inefficiencies across the farms as well as their potential to improve efficiency and resources using fixed effect model. In Table 4.4 the determinants of technical inefficiency are shown. The estimated parameters shows the influence of the variables have on technical inefficiency level; a positive parameter indicates that a variable has increased technical inefficiency level, otherwise identified as a negative effect on technical efficiency. 
Table 4.4: Determinants of technical inefficiency

\begin{tabular}{lrrr}
\hline \multicolumn{4}{c}{ Dependent variable: Inefficiency } \\
\hline Variable & $\begin{array}{r}\text { Estimated } \\
\text { coefficient }\end{array}$ & $\begin{array}{r}\text { Standard } \\
\text { error }\end{array}$ & t-value \\
\hline Input subsidy & -0.0003 & $8 . \mathrm{E}-06$ & -41.230 \\
Price support & $-4 . \mathrm{E}-06$ & $6 . \mathrm{E}-06$ & -0.760 \\
Off-income & $-4 . \mathrm{E}-05$ & $9 . \mathrm{E}-06$ & -4.920 \\
PPK [dummy, farmer's organization] & 0.0484 & 0.0333 & 1.450 \\
Distance to rice mill & 0.0087 & 0.0019 & 4.650 \\
Male & 0.0062 & 0.0139 & 0.450 \\
Ownership [dummy, landowner] & -0.0092 & 0.0102 & -0.900 \\
Access to credit & -0.0735 & 0.0150 & -4.910 \\
Land & 0.0724 & 0.0027 & 26.620 \\
Cost of labor & 0.0001 & $1 . \mathrm{E}-05$ & 3.820 \\
Time trend & -0.0052 & 0.0031 & -1.670 \\
Constant & 0.8257 & 0.0382 & 21.600 \\
\hline & & & \\
No. of observation & 6570 & & \\
R-squared & 0.4996 & & \\
\hline \hline
\end{tabular}

The results show that off-farm income, land ownership, access to credit and government supports reduce technical inefficiency while participation in farmer's organization, gender, distance to the rice mill, farm size and cost of hired labor increase inefficiency. Ceteris paribus, landowners are found to be $0.9 \%$ more efficient than tenant operators while participation in a farmer's organization increases inefficiency by $4.8 \%$. However, male are found to be $0.6 \%$ less efficient than their female counterparts. The farther a farm is located from the closest milling factory, the higher its inefficiency. A farm that is $5 \mathrm{~km}$ away from the nearest rice mill is $0.9 \%$ less efficient.

Examining the contribution of the subsidy-related variables to a farm's technical inefficiency provides an overview of the influence government support had on the farmers' performances between 2010 and 2014. The estimated model suggested that all support received had a significant and positive effect on technical efficiency. All other things being equal, a farm that receives more subsidies is closer to the frontier. For additional $250 \mathrm{RM}$ of input subsidies received will make the farm $10 \%$ more efficient. Correspondingly, our results demonstrate that input use is an important factor in improving agricultural production in Malaysia in such 
a way that an increase in input subsidy reduces technical inefficiency. Our results corroborate the findings made by Tian (2000) on Chinese rice farms and Zhu et al, (2012).

The coefficient of the price support indicates that the provision of price support would have a negative impact on technical inefficiency. The result indicates that $1000 \mathrm{RM}$ of subsidies will make farm $10 \%$ more efficient. A possible explanation could be that when these supports are available, they help less efficient farms make investments required to make them more competitive.

Farmers who were engaged in off-farm activities, depicted by a negative and significant coefficient for off-farm income, tend to exhibit lower inefficiency. Ceteris paribus, a farm with 4,000 RM more off-farm income will be $10 \%$ more efficient. This positive relationship is expected because as the households move towards spending more time off of the farm, they will require time and management saving technologies (like herbicide-tolerant crops) to maintain production. In addition, they are less likely to adopt management-intensive technologies, such as integrated pest manage and agricultural machinery, which corroborates the finding made by Ji et al. (2012). Additionally, Takahashi and Otsuka (2009) propose that increased nonfarm income may assist in accessing credit; therefore adding to the long-term financial investment among rice farmers in the Central Luzon, Philippines.

Similarly, our results show that access to credit has a negative and statistically significant relationship with technical inefficiency. All other things being equal, a farm with $200 \mathrm{RM}$ more credit volume is $10 \%$ more efficient. These results confirm the previously stated assumption that by overcoming financial constraint, credit availability helps farmers attain higher levels of efficiency through the purchase of higher quality farm inputs, such as fertilizers, new technologies and high-yielding varieties of rice seeds.

As expected, technical efficiency decreases with the increasing use of land and it is significant at the $1 \%$ level. Results imply that large farms are $7.2 \%$ more technically inefficient, which confirms our expectations. It is often recognized that in the land market especially in Malaysia where labor use intensities on small farms are high, smaller farms face higher effective purchase prices for land. More land alone does not make a farm more efficient, but more land coupled with equivalent increases in other inputs will lead to increased productivity 
(higher frontier). Therefore, small farms engage in more intensive use of resources; they use labor more intensively and use more of available land for land improvement in a diligent manner and thereby are more technically efficient.

Additionally, we find that the use of hired labor has a positive effect on technical inefficiency, implying family labor is more crucial than hired labor for higher efficiency. Small farmers, predominantly are taking advantage of the fact that household labor has very low opportunity costs which make their production is more efficient.

\subsection{Conclusions}

The rice sector is one of the major sectors of Malaysian agriculture. However, there are few studies of the efficiency of rice production in Malaysia. We used farm level data to gain insights on the technical efficiency of the country's rice farming. Although panel data were available, some important descriptive attributes were scarce. As a result we took unobserved heterogeneity into account. In this framework, we applied the recent fixed effect Stochastic Frontier model of Chen et al. (2014), which allows for unmeasured characteristics while simultaneously the model estimation is free of incidental parameters.

In the observation period from 2010 to 2014, technical efficiency appeared to be fluctuate in rice production. Our results indicate that the mean efficiency was $61 \%$ in 2010; it decreased in 2011 and increased steadily for the next two years, before it declined again in 2014. However, technical efficiency change has been quite low during the period.

The potential for increasing individual farm output varies considerably since many farms became much better while others became much worse. Government support such as input subsidies, credit facilities and off-farm activities are identified as important factors contributing to the improvement in the level of technical efficiency among rice farmers. Our empirical result points to a significant relationship between efficiency and access to credit. Overcoming financial constraints with better credit availability helps farmers attain higher levels of efficiency through the purchase of higher quality farm inputs such as fertilizers, new technologies and high-yielding varieties of rice seeds. The positive impact of nonfarm income on technical efficiency is another reason for the continued and sizeable contribution of 
nonfarm sources of farm household income. Subsidies seem to be an important component of increasing rice production. Our main result indicates that input subsidies have a positive, significant influence on the technical efficiency of the Malaysian rice farms. Subsidies can improve the technical efficiency if they encourage them to be innovative, to improve the implementation of the existing technologies, to increase ability of the farms to adjust their behavior and thereby operate more efficiently. Therefore, the direction of subsidies and supports affecting farm performance is crucial and the results of this study will help policymakers to identify the positive and negative effects and better target public intervention to improve farm efficiency.

However, public support provided to the small farmers mainly for political reasons will most likely not be enough for these farmers to become efficient. This effort must come to be realized through a combination of access to land and capital since poor farmers with small landholdings usually need capital in almost all economies (Abdulai and Eberlin 2001). Our result supports this notion since the technical efficiency increases with the decreasing use of land. A redistribution of land to small farmers with an adequate provision of finance could increase technical efficiency.

Overall, the results indicate that rice production can be improved by continuously increasing a farm's resources and technical efficiency. This can only be achieved if agricultural development and the policies facilitating farmers' accessibility to credit, capital, land and offfarm activities, especially for small farms, are carefully designed and well-targeted. Improved access to and distribution of input subsidies must also occur. 
Appendix 4.1: Estimation results of CFE Model and LSDV Model

\begin{tabular}{|c|c|c|c|c|c|c|}
\hline \multirow{2}{*}{ Variable } & \multicolumn{3}{|c|}{ CFE } & \multicolumn{3}{|c|}{ LSDV } \\
\hline & Coefficient & Std.Error & $\mathrm{p}$-value & Coefficient & Std.Error & $\mathrm{p}$-value \\
\hline logland & 0.1490 & 0.0477 & 0.0020 & -0.0245 & 0.0471 & 0.6030 \\
\hline loglabor & 0.0567 & 0.0157 & 0.0000 & 0.0652 & 0.0168 & 0.0000 \\
\hline logcapital & 0.8741 & 0.0484 & 0.0000 & 1.0603 & 0.0464 & 0.0000 \\
\hline logseed & 0.4168 & 0.0339 & 0.0000 & 0.5200 & 0.0334 & 0.0000 \\
\hline logagrichemical & 0.0023 & 0.0316 & 0.9410 & -0.0131 & 0.0340 & 0.7000 \\
\hline time trend & -0.0228 & 0.0066 & 0.0010 & -0.0178 & 0.0071 & 0.0120 \\
\hline $0.5^{*}(\operatorname{logland})^{2}$ & -0.1137 & 0.1342 & 0.3970 & -0.1382 & 0.1428 & 0.3330 \\
\hline $0.5^{*}(\text { labor })^{2}$ & 0.0462 & 0.0123 & 0.0000 & 0.0551 & 0.0129 & 0.0000 \\
\hline $0.5^{*}$ (logcapital $^{2}$ & 0.3979 & 0.0604 & 0.0000 & 0.4392 & 0.0730 & 0.0000 \\
\hline $0.5^{*}(\text { logseed })^{2}$ & 0.8060 & 0.0803 & 0.0000 & 0.7595 & 0.0798 & 0.0000 \\
\hline $0.5^{*}{\text { (logagrichemical })^{2}}^{2}$ & 0.4252 & 0.1017 & 0.0000 & 0.3835 & 0.1087 & 0.0000 \\
\hline $0.5^{*}(\text { time trend })^{2}$ & 0.0057 & 0.0079 & 0.4680 & 0.0101 & 0.0084 & 0.2300 \\
\hline logland*labor & 0.0518 & 0.0338 & 0.1250 & 0.0499 & 0.0369 & 0.1770 \\
\hline logland*logcapital & 0.1601 & 0.1025 & 0.1180 & 0.0231 & 0.1110 & 0.8350 \\
\hline logland*logseed & -0.3361 & 0.0795 & 0.0000 & -0.2982 & 0.0806 & 0.0000 \\
\hline logland*logagrichemical & -0.1840 & 0.0924 & 0.0470 & -0.1754 & 0.0993 & 0.0770 \\
\hline logland*time trend & 0.0071 & 0.0250 & 0.7770 & 0.0046 & 0.0266 & 0.8610 \\
\hline loglabor*logcapital & 0.0790 & 0.0263 & 0.0030 & 0.0839 & 0.0282 & 0.0030 \\
\hline loglabor*logseed & 0.0315 & 0.0259 & 0.2250 & 0.0314 & 0.0285 & 0.2710 \\
\hline loglabor*logagrichemical & -0.0077 & 0.0205 & 0.7070 & 0.0000 & 0.0221 & 1.0000 \\
\hline loglabor*time trend & -0.0012 & 0.0060 & 0.8430 & 0.0047 & 0.0065 & 0.4640 \\
\hline logcapital*logseed & 0.0076 & 0.0809 & 0.9250 & 0.1672 & 0.0904 & 0.0650 \\
\hline logcapital*logagrichemical & 0.0103 & 0.0717 & 0.8860 & -0.0718 & 0.0747 & 0.3360 \\
\hline logcapital*time trend & 0.0098 & 0.0232 & 0.6730 & 0.0129 & 0.0238 & 0.5880 \\
\hline logseed*logagrichemical & -0.0799 & 0.0598 & 0.1820 & -0.0465 & 0.0632 & 0.4620 \\
\hline logseed*time trend & 0.0216 & 0.0190 & 0.2550 & 0.0207 & 0.0205 & 0.3130 \\
\hline logagrichemical*time trend & -0.0270 & 0.0172 & 0.1170 & -0.0117 & 0.0178 & 0.5110 \\
\hline $\ln \left\{\backslash\right.$ sigma_v^$\left.v^{\wedge}\right\}$ & -2.9389 & 0.1753 & 0.0000 & & & \\
\hline $\ln \left\{\backslash \operatorname{sigma} \mathbf{u}^{\wedge} 2\right\}$ & -0.5721 & 0.0602 & 0.0000 & & & \\
\hline$\sigma_{\mathrm{v}}$ & 0.0529 & & & & & \\
\hline$\sigma_{\mathrm{u}}$ & 0.5644 & & & & & \\
\hline Log likelihood & -2667 & & & -4042 & & \\
\hline $\mathrm{AIC}$ & 5393 & & & 8139 & & \\
\hline Observation & 6570 & & & 6570 & & \\
\hline
\end{tabular}




\section{Additional notes:}

The data employed in this study are based on the panel of 6750 rice farms in MADA granary area. The farm level data is collected twice a year and each survey period includes a balanced sample of 675 farming households. The panel is composed of ten cross-sections, covering main and off- seasons over the five-year period from 2010 to 2014. This data set provides comprehensive information, including input use, output and corresponding prices.

However, despite of the rich dataset provided, the data suffers from ambiguous values and substantial zero users of variable inputs, particularly agricultural chemicals. For example, the standard deviation for the output is 7486 , while for the input variables such as agricultural chemical and seed, the standard deviations are approximately 217 and 241 respectively, which indicate large variations in output and inputs. Additionally, many data sets are not complete or show noticeable errors. We found 1,208 zero values in agrichemicals, 45 in seed, 21 in cost capital, 113 in labor and 1 in output. To account for these extreme values, we use a rule of thumb of 3 standard deviations from the mean to detect outliers or if $99 \%$ of the variable of interest lied outside \pm 3 standard deviations from the mean. Since all farmers received pesticides subsidies in a form of coupon worth $200 \mathrm{RM}$, we therefore use this value to account for zero usage of agricultural chemicals, by adding this amount to the agricultural chemical values. Other implausible values were also detected in capital, seed as well as agricultural chemicals. These values were then properly adjusted according to the normal standard rate proposed by MADA. As a consequence, the remaining panel is unbalanced with 6,570 out of 6,750 observations were used for the estimation. All the monetary values have been deflated by the 2010 consumer price index. Finally, to avoid data inaccuracy or bias, the dataset were then crosschecked by MADA officers.

Details on the data treatment are summarized in the following Appendix 4.2; 
Appendix 4.2: Data treatment for outliers, missing values and errors

\begin{tabular}{|c|c|c|c|c|c|}
\hline Variable & $\begin{array}{l}\text { Original } \\
\text { data }\end{array}$ & $\begin{array}{l}\text { Change data } \\
\text { due to outliers }\end{array}$ & $\begin{array}{l}\text { Standard } \\
\text { deviation }\end{array}$ & $\begin{array}{l}\text { Change data due to } \\
\text { missing values and } \\
\text { errors }\end{array}$ & $\begin{array}{l}\text { Standard } \\
\text { deviation }\end{array}$ \\
\hline Seed & 6750 & $\begin{array}{l}45 \\
\text { observations } \\
\text { are omitted }\end{array}$ & 240.58 & $\begin{array}{l}457 \text { observations are } \\
\text { adjusted according to } \\
\text { the standard } \\
\text { application rate of the } \\
\text { seed use }\end{array}$ & 248.98 \\
\hline Labor & 6750 & $\begin{array}{l}113 \\
\text { observations } \\
\text { are omitted }\end{array}$ & 115.83 & - & 78.368 \\
\hline Capital & 6750 & $\begin{array}{l}21 \\
\text { observations } \\
\text { are omitted }\end{array}$ & 176.33 & $\begin{array}{l}585 \text { observations are } \\
\text { adjusted according to } \\
\text { the average rate of } \\
\text { machinery services }\end{array}$ & 188.01 \\
\hline $\begin{array}{l}\text { Agricultural } \\
\text { chemicals }\end{array}$ & 6750 & - & 217.00 & $\begin{array}{l}1208 \text { missing values } \\
\text { are replaced with the } \\
\text { values of pesticides } \\
\text { subsidies of } 200 \mathrm{RM}\end{array}$ & 367.76 \\
\hline Output & 6750 & $\begin{array}{l}1 \text { observation } \\
\text { is omitted }\end{array}$ & 7486.00 & - & 7566.57 \\
\hline Total & 6750 & 180 & & 2250 & \\
\hline
\end{tabular}




\section{References}

Abdulai, A., and H. Tietje. 2007. "Estimating technical efficiency under unobserved heterogeneity with stochastic frontier models: Application to northern German dairy farms." European Review of Agricultural Economics 34(3):393-416.

Abdulai, A., and R. Eberlin. 2001. "Technical efficiency during economic reform in Nicaragua: Evidence from farm household survey data." Economic Systems 25(2):113125.

Abiola, O.A., S. Mad Nasir, R. Alias, and A. Ismail. 2016. "Effect of Improved High Yielding Rice Variety on Farmers Productivity in Mada, Malaysia." International Journal of Agricultural Sciences and Veterinary Medicine 4(1):38-52.

Addai, K.N., V. Owusu, and G. Danso-Abbeam. 2014. "Effects of Farmer - BasedOrganization on the Technical efficiency of Maize Farmers across Various Agro Ecological Zones of Ghana." Journal of Economics and Development Studies 2(1):141161. Available at: http://jedsnet.com/journals/jeds/Vol_2_No_1_March_2014/7.pdf [Accessed April 14, 2016].

Aigner DJ, Lovell CAK, Schmidt P. 1977. "Formulation and estimation of stochastic frontier production function models". J Econ 6:21-37.

Álvarez, A., J. Del Corral, And A. Fernández. 2009. "Modeling Regional Heterogeneity With Panel Data: With Application To Spanish Provinces." Uclm.Es (May). Available at: http://www3.uclm.es/profesorado/jcorral/Trabajando/6f10da_Efi_Regions_12.pdf.

Arshad, F.M., E.F. Alias, K.M. Noh, and T. Muhammad. 2011. "Food Security: SelfSufficiency of Rice in Malaysia." International Journal of Management Studies 18(2):83-100. Available

at: http://www.ijms.uum.edu.my/images/pdf/18no2ijms/ijms1825.pdf [Accessed March 21, 2016].

Assunção, J.J., and M. Ghatak. 2003. "Can unobserved heterogeneity in farmer ability explain the inverse relationship between farm size and productivity?" Economics Letters 80(2):189-194.

Belotti, F., and I. Giuseppe. 2012. "Consistent estimation of the 'true' fixed-effects stochastic frontier model." 5 No. 231,

Bhatt, M.S., and S.A. Bhat. 2014. "Technical Efficiency and Farm Size Productivity - Micro Level Evidence From Jammu \& Kashmir." International Journal of Food and Agricultural Economics 2(4):27-49. Available at: http://www.foodandagriculturejournal.com/vol2.no4.pp27.pdf.

Binswanger, H. and Elgin M. 1998. "Reflections on land reform and farm size." In: Eicher, C.,Staatz, J. (Eds.), International Agricultural Development, third ed. Johns Hopkin, Baltimore, pp. 316-328.

Binswanger, H.P. and K. Deininger. 2005. "Explaining Agricultural and Agrarian Policies in Developing Countries." Journal of Economic Literature. XXXV(Dec. 1997):19582005. 
Brummer, B., and J. Loy. 2000. "The Technical Efficiency Impact of Farm Credit Programmes: A Case Study of Northern Germany." Journal of Agricultural Economics 51(3):405-418.

Chakrabarty, T., S. Akter, a S.M. Saifullah, S. Sheikh, and A.C. Bhowmick. 2014. "Use of Fertilizer and Pesticide for Crop Production in Agrarian Area of Tangail District, Bangladesh." Environment and Ecology Research 2(6):253-260.

Chen, Y.Y., P. Schmidt, and H.J. Wang. 2014. "Consistent estimation of the fixed effects stochastic frontier model." Journal of Econometrics 181(2):65-76. Available at: http://dx.doi.org/10.1016/j.jeconom.2013.05.009.

Daño, E.C., and E.D. Samonte. "Public Sector Intervention in the Rice Industry in Malaysia. Southeast Asia Regional Initiatives for Community Empowerment (SEARICE)."

Dawe, D. 2010. The Rice Crisis: Markets, Policies and Food Security. The Food and Agriculture Organization of the United Nations and Earthscan. Available at: http://www.fao.org/3/a-an794e.pdf [Accessed December 6, 2015].

Department of Agriculture, M. 2014. "Perangkaian Padi Malaysia (Paddy Statistics of Malaysia) 2013.”

Diaz, C., M. Hossain, S. Merca, and T. Mew. 1998. "Seed Quality and Effect on Rice Yields: Findings from Farmer Participatory Experiments in Central Luzon, Philippines." Philippines Journal Crop Science 23(2):111-119.

Elbehri, A., and A. Sarris. 2009. "Farm Support Policies That Minimize Global Distortionary Effects." In FAO Expert Meeting on "How to Feed the World in 2050." Available at: http://www.fao.org/wsfs/forum2050/wsfs-forum/en/.

Fernandez-Cornejo, J., M. Ashok, R. Nehring, C. Hendricks, M. Southern, and a Gregory. 2007. "Off-farm income, technology adoption, and farm economic performance." Economic Research Report - Economic Research Service, USDA (36):53 pp. Available at: <Go to ISI $>$ ://CABI:20073230903.

Gianessi, L.P. 2014. "Importance of Pesticides for Growing Rice in South and South East Asia." CropLife Foundation (International Pesticide Benefit Case Study 108):30-33.

González-Farías, G., A. Domínguez-Molina, and A.K. Gupta. 2004. "Additive properties of skew normal random vectors." Journal of Statistical Planning and Inference 126(2):521534.

Greene, W. 2005. "Reconsidering heterogeneity in panel data estimators of the stochastic frontier model.” Journal of Econometrics 126(2):269-303.

Greene, W. 2008. "The econometric approach to efficiency analysis". In H. O. Fried, C. A. K. Lovell, \& S. S. Schmidt (Eds.), The Measurement of Productive Efficiency and Productivity Change chapter 2. (pp. 92-250). Oxford University Press. New York.

Heshmati, A., S.C. Kumbhakar, and L. Hjalmarsson. 1995. "Efficiency of the Swedish pork industry: A farm level study using rotating panel data 1976-1988." European Journal of Operational Research 80(3):519-533. 
Hoang, H.K., and W.H. Meyers. 2015. "Price stabilization and impacts of trade liberalization in the Southeast Asian rice market." Food Policy 57:26-39. Available at: http://dx.doi.org/10.1016/j.foodpol.2015.07.009.

Holtkamp, J. 2015. "Unobserved heterogeneity in productivity analysis of panel data: Applications to meat chain firms and global growth in agriculture." Available at: http://hdl.handle.net/11858/00-1735-0000-0022-5DE0-E.

Hsiao, C. 2007. "Panel data analysis - Advantages and Challenges." Sociedad de Estadística e Investigación Operativa 00(0):1-63. Available at: http://www.springerlink.com/index/10.1007/s11749-007-0046x\nhttp://www.springerlink.com/index/9870132756017386.pdf.

Huffman, W.E. "Farm and Off-Farm Work Decisions: the Role of Human Capital," Review of Economics and Statistics 62(1)(1980): 14-23.

International Rice Research Institute (IRRI). 2002. Available at: http://www.irri.org.

Jamal, K., N.H. Kamarulzaman, A.M. Abdullah, M.M. Ismail, and M. Hashim. 2013. "Farmer's acceptance towards fragrant rice farming: The case of non-granary areas in the East Coast, Malaysia.” International Food Research Journal 20(5):2895-2899.

Ji, Y., X. Yu, and F. Zhong. 2012. "Machinery investment decision and off-farm employment in rural China." China Economic Review 23(1):71-80. Available at: http://dx.doi.org/10.1016/j.chieco.2011.08.001.

Johnson, N., Ruttan, V. 1994. Why are farms so small? World Development 5, 691-706.

Koirala, K.H., A. Mishra, and S. Mohanty. 2016. "Impact of land ownership on productivity and efficiency of rice farmers: The case of the Philippines." Land Use Policy 50:371378. Available at: http://ac.els-cdn.com/S0264837715002987/1-s2.0S0264837715002987-main.pdf?_tid=232317b2-98f2-11e5-b3d100000aacb361\&acdnat=1449060324_bb4fbf2206458aa6ee59de4d75848197.

Kumbhakar, S.C., and G. Lien. 2010. "Impact of Subsidies on Farm Productivity and Efficiency." In The Economic Impact of Public Support to Agriculture. New York, NY: Springer New York, pp. 109-124. Available at: http://link.springer.com/10.1007/978-14419-6385-7_6 [Accessed November 13, 2016].

Kuyek, D. 2000. "Hybrid Rice in Asia: An Unfolding Threat." March, 2000. Available at file://C:/Users/userdell/Downloads/grain-34-hybrid-rice-in-asia-an-unfoldingthreat\%20(2).pdf

Martin, J.P., and J.M. Page. 1983. "The Impact of Subsidies on X-Efficiency in LDC Industry: Theory and an Empirical Test." The Review of Economics and Statistics 65(4):608. Available at: http://www.jstor.org/stable/1935929?origin=crossref [Accessed November 13, 2016].

Masterson, T. 2007. "Productivity, Technical Efficiency, and Farm Size in Paraguayan Agriculture by Keywords : Farm Size, Productivity, Technical Efficiency, Paraguay." Working Paper (490):37. Available at: http://ssrn.com/abstract=964722. 
Mundlak, Y. 1978. "On the Pooling of Time Series and Cross Section Data." Econometrica 46(1):69-85.

Mutert, E., and T.H. Fairhurst. 2002. "Southeast Asia Developments in Rice Production in Southeast Asia." Better Crops International, 15.

Olson, K., and L. Vu. 2009. "Productivity growth, Technical Efficiency and Technical Change on Minnesota farms Productivity growth, Technical Efficiency and Technical Change on Minnesota farms.” In Agricultural \& Applied Economics Association's 2009 AAEA \& ACCI Joint Annual Meeting, Milwaukee, WI, July 26-28.

Pitt, M.M., and L. Lee. 1981. "The Measurement and Sources of Technical Inefficiency In The Indonesian Weaving Industry." Journal of Development Economics 9:43-64.

Porcelli, F. 2009. "Measurement of Technical Efficiency. A brief survey on parametric and non-parametric techniques." Retrieved February (January):1-27. Available at: http://citeseerx.ist.psu.edu/viewdoc/download?doi=10.1.1.232.4843\&rep=rep1\&type=pd f.

Schmidt, P., and R.C. Sickles. 1984. "Production frontiers and panel data." Journal of Business and Economic Statistics 2(4):367-374.

Serra, T., D. Zilberman, and J.M. Gil. 2008. "Farms' technical inefficiencies in the presence of government programs." The Australian Journal of Agricultural and Resource Economics 52(1):57-76. Available at: http://doi.wiley.com/10.1111/j.14678489.2008.00412.x [Accessed November 13, 2016].

Siwar, C., D.M. Idris, M. Yasar, and G. Morshed. 2014. "Issues and Challenges Facing Rice Production and Food Security in the Granary Areas in the East Coast Economic Region (ECER), Malaysia.” Research Journal of Applied Sciences, Engineering and Technology 7(4):711-722.

Takahashi, K., and K. Otsuka. 2009. "The increasing importance of nonfarm income and the changing use of labor and capital in rice farming: the case of Central Luzon, 1979-2003." Agricultural Economics 40(2):231-242. Available at: http://doi.wiley.com/10.1111/j.1574-0862.2009.00372.x [Accessed November 3, 2016].

Tetteh Anang, B., and J. Amikuzuno. 2015. "Factors Influencing Pesticide Use in Smallholder Rice Production in Northern Ghana." Agriculture, Forestry and Fisheries 4(2):77. Available at: http://www.sciencepublishinggroup.com/journal/paperinfo.aspx?journalid=119\&doi=10. 11648/j.aff.20150402.19.

Thiam, A., B.E. Bravo-Ureta, and T.E. Rivas. 2001. "Technical efficiency in developing country agriculture: a meta-analysis." Agricultural Economics 25:235-243. Available at: http://citeseerx.ist.psu.edu/viewdoc/download?doi=10.1.1.336.2197\&rep=rep1\&type=pd f [Accessed December 14, 2015].

Tian, W. 2000. "Technical Efficiency and Its Determinants in China's Grain Production." Journal of Productivity Analysis 13:159-174. 
Timmer, C.P., and D. Dawe. 2007. "Managing food price instability in Asia: A macro food security perspective." Asian Economic Journal 21(1):1-18.

von Cramon-Taubadel, S., and R. Saldias. 2014. "Access to credit and determinants of technical inefficiency of specialized smallholder farmers in Chile." Chilean journal of agricultural research 74(4):413-420.

Available at: http://www.scielo.cl/scielo.php?script=sci_arttext\&pid=S0718$\underline{58392014000400006 \& \operatorname{lng}=\mathrm{en} \& n \mathrm{~nm}=\mathrm{iso} \& \ln \mathrm{l}=\mathrm{en}}$.

Wozniack, G.D. “Joint Information Acquisition and New Technology Adoption: Late Versus Early Adoption,” The Review of Economics and Statistics 75(1993): 438-445.

Zhu, X., and A.O. Lansink. 2010. "Impact of CAP Subsidies on Technical Efficiency of Crop Farms in Germany, the Netherlands and Sweden." Journal of Agricultural Economics 61(3):545-564. Available at: http://doi.wiley.com/10.1111/j.1477-9552.2010.00254.x [Accessed November 13, 2016].

Zhu, X., R.M. Demeter, and A.O. Lansink. 2012. "Technical efficiency and productivity differentials of dairy farms in three EU countries: the role of CAP subsidies." Agricultural Economics Review 13(1):66-92. 


\section{Chapter 5}

\section{A Note on Farm Competitiveness and Efficiency}

\subsection{Introduction}

The concept of competitiveness permeates the economic literature in several areas, including: the microeconomic level, where competitiveness is measured at a single firm/farm level; the meso-economic level, where it is measured at commodity or sector level; and finally at the macroeconomic level, where competitiveness is measured at an aggregate or country level (Latruffe, 2010). 'Competitiveness' has a broad meaning, which has yet to gain universal definition acceptance in economics (Ahearn et al 1990; Sharples 1990). The ambiguity associated with the term allows researchers to apply their own definition based on different ways and perspectives they put forward in the literature. The Organisation for Economic Cooperation and Development (OECD) succinctly describes competitiveness as "the ability of companies, industries, regions, nations and supranational regions to generate, while being and remaining exposed to international competition, a relatively high factor of income and factor employment levels on a sustainable basis" (Hatzichronologou, 1996). The European Commission (2001) defines competitiveness as: "the ability of an economy to provide its population with high and rising standards of living and high rates of employment on a sustainable basis". However, given the evolution of the concept over time, this term was redefined by the Aiginger et al, (2013) as "the ability of a country (region, location) to deliver the beyond-GDP goals for its citizens". Others relate this meaning with profitability. Agriculture Canada (1991) defines "competitiveness as the ability to gain profits and maintain market share". Latruffe (2010) clarifies competitiveness as "the ability to successfully face and engage with the competition, either domestically or internationally". Subsequently, competitiveness equates to the ability to sell the products that satisfy the demand while simultaneously securing profits over time.

Despite the vast research efforts dedicated to this subject during the last two decades, considerable misunderstandings exist and interminable debates over the precise meaning of ‘competitiveness' and its scope have occurred (Sarker and Ratnasena, 2014). Thus, depending 
on the purpose of the study, the level of analysis, and the commodity in question, a large number of measures of competitiveness have been developed. Latruffe (2010) classifies measurement into two disciplines; 1) the neoclassical economies which places emphasis on trade and measure competitiveness with comparative advantages, exchange rate and export or import indices and; 2) the strategic management which focuses on the firm's structure and strategy, as well as measures the firm's competitiveness based on various cost indicators, including productivity and efficiency.

The first strand of literature suggests that a nation's competitiveness is based on comparative advantage. Comparative advantage, as conceptualised by the Ricardian and Hecksher-Ohlin models for two inputs in a two country case ${ }^{11}$, postulates that differences in production costs among countries have resulted in trade flows and that the country with a cost advantage will specialize in the production of that good. Such a concept is widely used when comparing the international competitiveness between countries. However, a large number of measures for determining comparative advantage have been developed due to uncertainty on the precise meaning of the comparative/competitive advantage. Singgel (2006) and Latruffe (2010) provide a comprehensive survey and discussion on these measures and concepts. Among the measures surveyed, the Domestic Resource Cost or DRC is regarded as the true measure of comparative advantage (Singgel, 2006). The DRC compares the domestic resources cost at social prices to the value added measured at social prices ${ }^{12}$. The use of the social price ensures that the DRC measures the true comparative advantage that can be derived from the Ricardian framework. The DRC is a widely applied concept used in economic literature that is also an indicator of comparative advantage which can be calculated from the Policy Analysis Matrix (PAM) framework (Monke and Pearson, 1989).

Despite the wide use and acceptance of the DRC as an indicator of comparative advantage in PAM, it is criticized for yielding potential inaccuracies in the ranking of activities. Masters and Winter-Nelson (1995) and Singgel (2006) have demonstrated that the DRC understates the competitiveness of activities relying on a high level of non-tradable inputs. The bias is

\footnotetext{
${ }^{11}$ Findlay and Grubert (1959) who were among the first to use a two country, two good, two factor model to consider the effects of Ricardian productivity and factor abundance in jointly determining factor prices and production patterns.

${ }^{12}$ The development of the DRC ratio draws back to Bruno (1965) as a project appraisal indicator to evaluate the benefits of new activities.
} 
more pronounced if the activities include very divergent combinations of traded and nontraded inputs. Consequently, Masters and Winter-Nelson (1995) proposed the Social Cost Benefit (SCB), which is analogous to the unit cost ratio (UCs) proposed by Singgel (2006). SCB compares total domestic costs at social prices to the total outputs measured at social prices. Since SCB does not include the calculation of the value added in the critical dimension, it is not affected by the classifications of tradable or non-tradable costs.

The second strand of literature focuses on the efficiency and productivity analysis as the measurement of competitiveness where technical efficiency and Total Factor Productivity (TFP) have been the main long-term interest. Productivity analysis has been heavily applied on the micro level. Furthermore, a profusion of studies have been conducted to investigate technical efficiency and to a lesser extent, the allocative efficiency of farms in various countries (Bhatt and Bhat 2014; Brummer and Loy 2000; Kumbhakar 1987; Masterson 2007; Yao and Gerald 2007; Abdulai and Huffman 1998). The theoretical elements of these concepts are empirically constructed and the practical applications of modeling these functions, as well as the measurements using parametric and non-parametric methods, are extensive. The competitiveness or the comparative advantage is determined by the Decision Making Unit (DMU) and its distance to the best-practice frontier, which is based on relative rates of TFP change (Nishimizu and Page, 1986).

Although authors have been prolific in exploring the connection between competitiveness/comparative advantage and efficiency, the theoretical treatment does not offer any ready conclusions. The SCB approach works with social prices in measuring international competitiveness. Efficiency measurement simply compares DMUs with one another - the frontier is defined by the best. But whether the best are good enough (whether they are actually competitive) is never answered directly by efficiency analysis. It could be that even the best are not competitive, but they are surviving due to subsidies or protection. There should nevertheless be a relationship - the DMUs that are closest to the frontier should have better SCBs, but they might still have 'bad' SCBs overall: in other words they might be relatively efficient but nonetheless not competitive. Recently, researchers have started to produce PAM results with disaggregated data and others use the same types to efficiency analysis, this leads to the natural question, how are these two types of analysis related? 
Establishing the linkage will help policy makers and others make better use of one or the other measure if they knew how it relates to the other.

To motivate our empirical analysis, we develop a simple model that relates competitiveness and technical efficiency, and propose a PCB criterion decomposition that formally relates improvements in efficiency to improvements in PCB ratio. To date, no empirical work on this link has been published, therefore we aim to fill that gap. Our paper makes several contributions to the literature. Firstly, our research offers a novel approach for determining the relationship between competitiveness and efficiency. Secondly, in addition to introducing a theoretical link between the two strands, our analysis provides a foundation for understanding the information, the measurements, and the characteristics associated with each method and how these links may contribute to explaining competitiveness.

The rest of the paper proceeds as follows: Section 5.2 provides an overview of the strengths and weakness of each approach to measuring competitiveness. Section 5.3 outlines the SCB and PCB calculations using the Policy Analysis Matrix framework; Section 5.4 provides the model estimations using both CFE and primal system of profit maximization; Section 5.5 provides a decomposition of static competitiveness, distinguished into technical efficiency and allocative efficiency; Section 6 describes the empirical illustration we used to test the relationship; and the final section concludes the paper.

\subsection{Strength and weaknesses of the PAM and SFA approaches}

In this paper, we showed two alternative tools or methods that can be used to explain competitiveness and efficiency. In doing so, we proposed a simple decomposition of competitiveness into technical efficiency. The proposed technique provides a clear analytical link between two largely separate methodologies for assessing economic performance, costbenefit indicators based on the international price rule and efficiency analysis, and thus, facilitates a more detailed understanding of the definition of competitiveness.

Despite the acknowledged methodological reservations, SCB or Private Cost Benefit (PCB) measurements as described by the PAM framework have proved to be highly useful policy tools when market and shadow prices diverge. Activities with the lowest SCB ratios are normally assumed to exhibit the greatest potential for expansion as exports or efficient substitutes for imports and, defined in this way, the greatest comparative advantage. 
Additionally, PAM is a straightforward policy analysis that provides a quantitative estimate of the impact of policies and market structure of the commodity by comparing the private and social structure of incentives on the microeconomic level (i.e. incentives to producers, processors, and marketing agents). Moreover, it potentially serves as an information baseline used for evaluating agricultural and trade policy analysis, as well as to support policy planning or project appraisal needs. PAM is a purely descriptive analysis and its results are relatively easy to estimate, however, the advantages of PAM go beyond its pure analytic nature in terms of policy analysis. Due to its intuitively comprehensive concept, PAM results can serve as an appropriate tool for delivering the information needs of politicians and officials interested in evaluating the impact of policies. PAM's ability to inform provides critical information to the best-positioned individuals who are then able to effectively allocate funds or budgets for investment and research pathways. It can also inform policy makers about the weaknesses and strengths of environments specific to the country. Furthermore, PAM's analysis and results are more relaxed and easy to present; the main users of competitiveness indicators are the ministry or government departments designing policies, consulting and negotiating trade agreements or writing development plans, as well as private sector agents, like banks and industrial corporations.

A major drawback of PAM, however, is that it does not provide an understanding of the historical forces of the current pattern of measured comparative advantage, nor does it expand much on the notion of dynamic. Since PAM's assessment of differences between private and social incentives is carried out based on a static approach, or in other words, it is based on Leontief fixed-input-output coefficients. This is important, because when we use the observed coefficients, that are observed under conditions of private prices, and then assume that these coefficients would be the same under social prices, we could be making a mistake. If social input price ratios differ from private input price ratios, for example, then farmers would use a different input mix under social prices than they do under private prices - they would reallocate (also on the output side). Therefore in the longer run, and if there are large gaps between private and social prices, SCB measures are likely to be inaccurate. Efficiency analysis that is based on flexible functional forms does not suffer from this limitation. It does not take the reactions of the producers' change in domestic prices into account. Additionally, PAM's assessment of differences delivers less insight into the direction of future changes to 
SCB. Therefore, its applicability to long-term projections is limited and inferences of SCB must be interpreted as short-term or as a current incentive structure.

Historical analyses of economic performance have also tended to focus on the measurement of efficiency. Efficiency improvement has been regarded as one of the most important goals or analyses for many social and economic policies and reforms. Efficiency measurement compares the actual performance with the optimal performance located on the relevant frontier. However, an empirical approximation is needed since the true frontier is unobserved. This approximation is frequently referred as a "best-practice frontier". The economic theory of production is based on the production (cost or profit) frontiers and efficiency relative to those frontiers; where emphasis is often placed on optimizing behavior subject to constraint. However, estimation of efficiency relative to the constructed frontiers using econometric approach or mathematical programming are both analytically rigorous benchmarking assessment to measure efficiency (profit) relative to a frontier. A competent empirical application of parametric approach (i.e Stochastic Frontier Analysis) requires a clear understanding of both the production economics and the econometric theory behind the specified model along with adequate programming skills. Where econometric approach is parametric and efficiency analysis is to be taken seriously, producer performance evaluation must be robust to both statistical noise and specification error. Obtaining efficient and unbiased estimates of production structures can often prove to be a difficult task and challenging.

Despite of its prominence measurement of competitiveness, efficiency studies or analyses are costly, due to their complexity. The literature relevant to this wider purpose is not surveyed here, but Latruffe (2010) provide such a survey, as far as trade policy analysis is concerned. Efficiency models are sufficiently detailed, given their comprehensive nature, and they are fully reliable, due to the simplifying assumptions on which they rely. Additionally, efficiency studies, whether of using parametric or non-parametric methods, are normally based on the domestic prices. Inferences drawn on the comparative advantage are normally grounded in terms of technical efficiency change between countries or competing industries or sectors. In highly distorted economies, efficiency studies however do not provide information regarding the domestic costs relative to international competitors. On the other hand, competitive and comparative advantage indicators as described by PAM framework are more manageable and 
less costly, while permitting the analyst to monitor the impact of policy changes on the competitive environment, the cost structure of industries and the resulting market structure.

\subsection{Policy Analysis Matrix (PAM)}

The policy analysis matrix (PAM), as developed by Monke \& Pearson, (1989) is a double entry bookkeeping analytical framework that helps policymakers to address central issues regarding agricultural policy developments. PAM is widely used for measuring the impact of policies on farm competitiveness and farm level profits. The framework additionally measures the influence public investments have on the agricultural system's efficiency, and the effect agricultural research and development have on economic efficiency and comparative advantages (Masters and Winter-Nelson 1995; Siggel 2006).

PAM is composed of two cost columns (shown in Table 5.1); one representing tradable inputs and the other domestic factors. Intermediate inputs, which consist of fertilizers, pesticides, compound feed, transportation, electricity, fuel and purchased seeds, are divided into tradable inputs and domestic factor components. This disaggregation process allows for intermediate goods to be separated into four categories: tradable inputs, domestic factors, transfers (taxes or subsidies that are disregarded in the social evaluations), and non-tradable inputs (which must be further disaggregated so that all costs will be classified as tradable inputs, domestic factors and transfers).

The first row of the matrix provides a measure of private profitability (D), defined as revenue (A) minus total costs $(B+C)$, which assesses the values of all outputs and inputs at private prices, reflecting the actual market or financial prices received by the farmers, processors, or merchants involved in the agricultural system. This private or financial price includes the underlying economic costs and valuation combined with the effects of all policies and market failures. Thus, the private profitability calculations reveal the competitiveness of the agricultural system assuming the use of modern technology, input costs, output values and policy transfers.

The second row of PAM table measures the social profits $(\mathrm{H})$, which reflect the agricultural system's efficient use of resources and overall comparative advantage. Efficient outcomes are attainable when economy's resources are used to create the highest income and output levels. 
To determine social profits, social prices are used for the valuation of inputs and outputs. Social values, or prices, demonstrate a policy benchmark for comparisons because they are considered the prevailing prices in a free market in the absence of policy interventions, distortions or market failures (Kanaka and Chinnadurai, 2013; Monke and Pearson, 1989).

The second identity located in the third row of the accounting matrix measures divergences, which are defined as the differences between private and social valuations of revenues, costs and profits. Any divergence between private and social prices, which is measured vertically, must be explained by the effects of the policies which are disaggregated into three categories: distorting policies, market failure and efficient policies. When government enforced market failure correction policies are not in place, distorting policies are the cause of divergences between the private and social prices of tradable outputs and inputs. However, if efficient policies enacted by the government are able to correct or offset market failures and create a greater income, the differences between private and social valuations will be reduced, since efficient policies correct divergences (Monke and Pearson 1989; Masters and Winter-Nelson 1995). 
Table 5.1: Policy Analysis Matrix

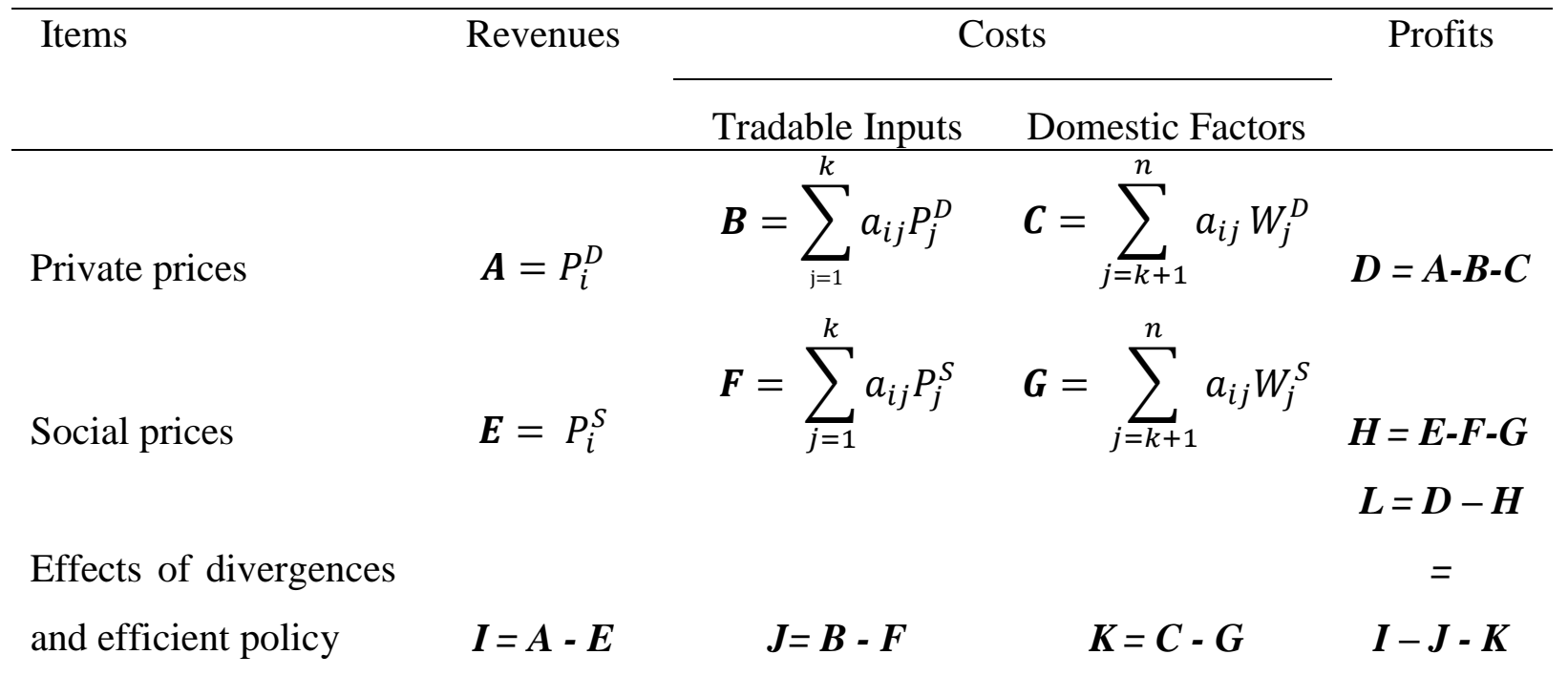

Source: Monke and Pearson (1989)

Note:

The subscript $i$ refers to outputs and the subscript $j$ refers to inputs,

$\mathrm{a}_{i j}$ for $(\mathrm{j}=1$ to $\mathrm{k}$ ) are technical coefficients for traded inputs in the production of $\mathrm{i}$;

$\mathrm{a}_{i j}$ for $(\mathrm{j}=\mathrm{k}+1$ to $\mathrm{n})$ are technical coefficients for domestic inputs in the production of $\mathrm{i}$;

$\mathrm{P}_{i}^{*}$ is the price of output $i$, evaluated privately $(*=D)$ or socially $(*=S)$;

$\mathrm{P}_{j}^{*}$ is the price of traded input $j$, evaluated privately $(*=D)$ or socially $(*=S)$;

$\mathrm{W}_{j}^{*}$ is the price of domestic input $j$, evaluated privately $(*=D)$ or socially $(*=S)$;

$\mathrm{D}(=\mathrm{A}-\mathrm{B}-\mathrm{C})$ measures Private profit;

$\mathrm{H}(=\mathrm{E}-\mathrm{F}-\mathrm{G})$ measures Social profits;

I (= A-E) measures Output transfers;

$\mathrm{J}(=\mathrm{B}-\mathrm{F})$ measures Input transfers;

$\mathrm{K}(=\mathrm{C}-\mathrm{G})$ measures Factor transfers;

L ( $=$ D-H; or I-J-K) measures Net transfers.

The Social Cost Benefit (SCB) ratio is one of the indicators that can be calculated to measure competitiveness using the PAM framework. It is defined as:

$$
S C B=\frac{\sum_{j=1}^{k} a_{i j} P_{j}^{S}+\sum_{j=k+1}^{n} a_{i j} W_{j}^{S}}{P_{i}^{S}}
$$

where $P_{i}$ is the price of the output $i$, the $P_{j}$ are the prices of the $k$ tradable inputs, the $W_{j}$ are the prices of the $n-k$ non-tradable inputs, and the $\alpha_{i j}$ are technical coefficients which measure the amount of input $j$ that is required to produce one unit of output $i$. Throughout, the superscript $S$ indicates that social rather than private prices are employed. Hence, the SCB is simply the ratio of the social cost of producing one unit of an output, to the social value of that unit of output. An SCB value between zero and one indicates that the activity in question is competitive, while a value greater than one indicates that social cost exceeds social value and the activity is not competitive. 
Another indicator which is closely related to SCB is the private cost benefit (PCB). It is defined as:

$$
P C B=\frac{\sum_{j=k+1}^{n} a_{i j} W_{j}^{D}}{P_{i}^{D}-\sum_{\mathrm{j}=1}^{k} a_{i j} P_{j}^{D}}
$$

where $P_{i}$ is the price of the output $i$, the $P_{j}$ are the prices of the $k$ tradable inputs, the $W_{j}$ are the prices of the $n-k$ non-tradable inputs, and the $\alpha_{i j}$ are technical coefficients which measure the amount of input $j$ that is required to produce one unit of output $i$. Here, the superscript D indicates private prices are employed throughout the system, reflecting the actual market or financial prices. Hence, PCB is the ratio of private costs of domestic factor use to the private value added. Similar to SCB, PCB is an indicator of comparative competitiveness. It shows how much the production system affords to pay for the domestic factors and still remain competitive (break even after earning normal profits which is defined as $(A-B-C)=D=0$. In this case, excess profits are attainable if the private costs are less than their value added in private prices. This can be achieved by holding down factor and tradable inputs costs so that it can minimize the private cost and hence maximize excess profit. Therefore, a PCB value between zero and one indicates that the commodity is competitive while a value greater than one indicates that the commodity in question is uncompetitive.

\subsection{Stochastic Frontier Analysis (SFA) approach}

\subsubsection{Fixed effect panel model using CFE estimation}

Since the seminal work conducted by Aigner et al. (1977), the Stochastic Frontier (SF) model has been widely use to estimate the technical efficiency in applied economic research. Extensive research in this field has resulted in a growing arsenal of methods and econometrics techniques pertaining to specifications, estimation and testing issue. Despite that, when productivity and efficiency are analyzed at the farm level, the problem arises that not all relevant factor can be observed or measured adequately. Heterogeneous environmental and biophysical characteristics, such as soil condition, rainfall or droughts, as well as managerial characteristics, are often omitted from the model specifications due to a lack of information available for many of these variables. This information is referred to as unobserved heterogeneity (Álvarez et al, 2009). As a result, inference based on the output comparison could be biased and is often criticized because farms are heterogeneous and operate under different production and environmental conditions (Abdulai and Tietje, 2007). To overcome 
the challenge of unobserved heterogeneity, we apply the recent fixed effect model implemented by Chen et al. (2014). Consider the following specification of the stochastic production frontier model for panel data:

$$
\begin{gathered}
y_{i t}=\alpha_{i}+\beta^{\prime} x_{i t}+v_{i t}-u_{i t} \\
\varepsilon_{i t}=v_{i t}-u_{i t}
\end{gathered}
$$

where $y_{i t}$ is the vector of the output of firm $i(i=1, \ldots, N)$ in period $t(t=1, \ldots, T) ; \quad x_{i t}$ is a set of inputs that produce output $y_{i t} ; \beta$ is the associated vector that describes technology parameters to be estimated. The composite error term $\varepsilon_{i t}$ is the difference between the idiosyncratic error that captures noise $v_{i t}$, and the one-sided disturbance $u_{i t}$ which represents inefficiency. Under the frequently used normal-half normal model, the distributional assumptions are $v_{i t} \sim N\left(0, \sigma_{v}^{2}\right)$ and $u_{i t} \sim N^{+}\left(0, \sigma_{u}^{2}\right)$. Time-invariant unobserved heterogeneity is captured by the vector of incidental parameter, $\alpha_{i}$ which is the number of individual intercepts that equal to the number of farms. However, whether or not to separate $\alpha_{i}$ from $u_{i t}$ has been the subject of much debate in the stochastic frontier literature. A major limitation of the model in equation (4) is related to an identification problem which arises when the inefficiency term is time-variant. In many situations, a constant level of inefficiency does not likely to prevail over longer period due to several reasons (i.e. process of learning). In this case, it is difficult to disentangle the unobserved farm-specific heterogeneity from inefficiency (Greene 2005).

Greene (2005) proposed a "true fixed effects" or TFE model that includes a maximum likelihood dummy variables estimator (MLDVE), in which the unit-specific intercepts are estimated with structural parameters. The TFE model places unobserved heterogeneity as fixed effects in the stochastic frontier model (equation 3) and generates a neutral shift of the function specific to each farm (Porcelli 2009) while allowing for time-varying inefficiency (Belotti and Giuseppe 2012). This approach is frequently applied, however it leads to inconsistent variance parameter estimates due to the incidental parameters problem especially in the short panel because the number of parameters depends on the sample size (there are firm effects $\alpha_{i}$; and the number of parameters, $\mathrm{N}$ which increases with the sample size). Hence, the estimated error variance, and the parameter $\sigma_{u}^{2}$ is inconsistent. 
To account for this limitation, Chen et al. (2014) propose a consistent estimator for the TFE normal-half normal model based on the within transformed model where the fixed effects have been removed. This procedure is commonly used in the panel data:

$$
\bar{z}_{i t}=z_{i t}-\bar{z}_{i}
$$

For any corresponding variable $(z)$ in each panel $i$, the individual mean $\left(\bar{z}_{i}\right)$ is subtracted from the observed value in period $t\left(z_{i t}\right)$. Correspondingly, the model can be represented by using the deviations from means $\left(\bar{z}_{i}\right)$ so that the transformed model is free from incidental parameters problem $\left(\alpha_{i}\right)$ :

$$
\bar{y}_{i t}=\beta^{\prime} \bar{x}_{i t}+\bar{v}_{i t}-\bar{u}_{i t}
$$

As outlined by (Holtkamp, 2015) the model in equation (6) has the following features: first, the incidental parameters problem is removed by a within-transformation; second, it produces a consistent estimator of the error variance since the relevant likelihood function is derived from $T-1$ deviations; and third, this approach, which is based on a more general distributional theory, allows for the maintenance of the firm-specific and time varying inefficiency $u_{i t}$.

\subsubsection{A primal system of Profit Maximization}

The standard microeconomic theory of producer behavior is almost entirely based on the neoclassical approach which assumes that firms are efficient both technically and allocatively. There is, however, an extensive literature on the measurement of productive efficiency which extended the basic neoclassical approach by allowing firms to make mistakes in the production of outputs and use of inputs (Kumbhakar, 1987).

Allocative inefficiency as defined by Schmidt and Lovell (1979) is a failure to allocate right proportions of inputs given the input prices. Under the production process that has allocative inefficiency, the marginal revenue product is not equal to the marginal resource cost. Technical inefficiency occurs when producers fail to maximize the output for a given set of inputs. Under the behavioral assumption of profit maximization, we assume that farms maximize their profits in making their decision on inputs use and production of outputs. That 
is, we can consider non-optimal allocation of inputs and output where farms can be both allocatively inefficient and technically inefficient.

However, estimation that accounts both technical and allocative inefficiency with the profit function approach is not straightforward and complex. In most of the cases, the estimation requires large variations in the price variables in order to get precise parameter estimates, which may not usually occur in practice especially when we work with a cross-section in which most farms have probably faced quite similar prices. Details on the model and estimation issues are discussed comprehensively in Kumbhakar (2001) and Kumbhakar and Wang (2006). Alternatively, Kumbhakar et.al, (2015) proposed other modeling strategy which is the primal system approach by using transcendental logarithmic functional form of the stochastic frontier. The authors argue that if the input endogeneity is considered during the implementation of the econometric problem, then the output-oriented or input-oriented technical inefficiencies are the same. The primal system technique is algebraically equivalent to the profit system for self-dual production function. The advantage of the primal system is that it solves the problem of insufficient price variability. Furthermore, the model is based on the production function, therefore there is no need to take log of profit, which could be an issue when profit is negative for some observations.

The production function (Aigner et.al, 1977) for a typical producer (i) can be written as;

$$
\mathrm{y}_{\mathrm{i}}=\mathrm{f}\left(\mathrm{x}_{\mathrm{i}}\right) \exp (\mathrm{v}-\mathrm{u}), \quad \mathrm{i}=1,2, \ldots . \mathrm{n}
$$

where $f($.$) is the production frontier; x$ is the vector of inputs, $v$ is production uncertainty or noise and $\mathrm{u}$ is technical inefficiency. The profit maximization problem for a producer (omitting the subscript $i$ ) can be represented as:

$$
\begin{gathered}
\max _{y, x} \Pi=\mathrm{py}-\mathrm{wx} \quad \text { s.t } \quad \mathrm{y}=\mathrm{f}(\mathrm{x}) \exp (\mathrm{v}-\mathrm{u}), \mathrm{u} \geq 0 \\
\Rightarrow \max _{x} \Pi=p f(x) \exp (v-u)-w x \\
\Rightarrow \max _{x} \Pi=p f *(x)-w x
\end{gathered}
$$

where $p$ is a vector of output prices; $y$ is the level of production; $w$ is the vector of input prices; $x$ is the vector of inputs; $v$ is the random error and $u$ is the output-oriented technical 
inefficiency. Note that we substitute $\mathrm{y} \cdot \exp (\mathrm{v}-\mathrm{u})$ by $\mathrm{f}^{*}$ to follow the standard neoclassical maximization problem analytics.

The first-order conditions of a profit-maximization problem can be implicitly formulated as:

$$
p f_{j}^{*}=w_{j} \exp \left(\eta_{1}\right), \quad \eta_{j} \gtreqless 0, j=1, \ldots . J
$$

The first-order condition indicates that the value of the marginal product of input $\mathrm{i}$ can be expanded until it equals price of the input or marginal cost. It can therefore be expressed as:

$$
\begin{gathered}
\frac{f_{j}^{*}}{f_{1}^{*}}=\frac{w_{j}}{w_{1}} \exp \left(\xi_{j}\right), j=2,3, \ldots . J, \\
p f_{j}^{*}=w_{1} \exp \left(\eta_{1}\right), \\
\text { where, } \xi=\eta_{j}-\eta_{1}
\end{gathered}
$$

where $f_{j}$ and $f_{1}$ are the marginal products of input $j$ and input 1 , respectively; $w_{j}$ and $w_{1}$ are prices of input $j$ and input 1, respectively; and $\xi$ is allocative inefficiency for the input pair ( $j$, 1). The use of allocative inefficiency in equation 12 which is defined by Schmidt and Lovell, (1979) is appropriate, because a producer is said to be allocatively inefficient if he fails to allocate input in a way that the ratio of input prices equates the marginal rate of substitution (MRTS).

Using the result $s_{j} \equiv \frac{\partial \ln f^{*}}{\partial \ln x_{j}}=\left(\frac{\partial f^{*}}{\partial x_{j}}\right)\left(\frac{x_{j}}{f^{*}}\right)$, where $s_{j}$ are cost shares of the input $x_{j}$ given the input price $w_{j}$, we obtain the following equations:

$$
\begin{gathered}
\frac{s_{j}}{s_{1}}=\frac{w_{j}}{w_{1}} \frac{x_{j}}{x_{1}} \exp \left(\xi_{j}\right), \quad j=2,3, \ldots \ldots . J, \\
p s_{1} \frac{y}{x_{1}}=w_{1} \exp \left(\eta_{1}\right)
\end{gathered}
$$

Finally the primal system to be estimated can be obtained by taking logarithms of equations (15) and (16):

$$
\begin{gathered}
\ln s_{j}-\ln s_{1}=\ln \left(\frac{w_{j}}{w_{1}}\right)+\ln \left(\frac{x_{j}}{x_{1}}\right)+\xi_{j}, \quad j=2, \ldots \ldots \ldots J \\
\ln p+\ln s_{1}+\ln y-\ln x_{1}-\ln w_{1}=\eta_{1}
\end{gathered}
$$


Econometric estimation of the primal system can be performed by considering a translog production function:

$$
\begin{aligned}
& \ln y=\alpha_{0}+\sum_{j} \alpha_{j} \ln x_{j}+\frac{1}{2} \sum_{j} \sum_{k} \alpha_{j k} \ln x_{j} \ln x_{k}+v-u \\
& \ln s_{j}=\ln s_{1}-\ln \left(\frac{w_{j}}{w_{1}}\right)-\ln \left(\frac{x_{j}}{x_{1}}\right)=\xi_{j}, \quad j=2,3, \ldots \ldots \ldots, J \\
& \ln s_{1}=\ln \left(\frac{w_{1}}{p}\right)+\ln x_{1}-\ln y+\eta_{1}
\end{aligned}
$$

Econometric estimation of the primal system described by equation (19) can be performed under the assumption that the error components have the following distributions:

$$
\begin{gathered}
v \sim N\left(0, \sigma_{V}^{2}\right) \\
u \sim N^{+}\left(0, \sigma_{V}^{2}\right) \\
\left(\xi^{\prime}, \eta_{1}\right)^{\prime} \sim M V N(0, \Sigma) \\
\eta_{j} \text { are indepedent of } v \text { and } u
\end{gathered}
$$

where $v$ is a vector of normally distributed random noises that capture specific heterogeneities of farmers; $u$ is the vector of technical inefficiencies half-normally distributed; $\eta$ is the vector of allocative inefficiencies; and the final assumption of $\eta_{j}$ is assumed to be independent for simplicity. We assume normal distributions on allocative errors since $\xi j$ can take both positive and negative values (meaning that inputs can be over- or underused) as suggested by Kumbhakar and Wang (2006).

The likelihood function for the system is:

$$
L=f(v-u) \cdot g\left(\xi^{\prime}, \eta_{1}\right) \cdot|J|
$$

where $|\mathrm{J}|$ is the determinant of the Jacobian matrix:

$$
|J|=\mid\left(\frac{\partial\left(v-u, \xi_{2}, \xi_{3}, \ldots, \xi_{J}, \eta_{1}\right)}{\partial\left(\ln y, \ln x_{1}, \ln x_{2}, \ldots \ldots, \ln x_{J}\right)} \mid\right.
$$

The production parameters of the above model $\alpha_{j}$ can be obtained by maximizing the above likelihood function. After estimation, the technical inefficiency, $u$, can be estimated using the Jondrow et al. (1982) formula that is $\hat{u}=E(u \mid v-u)$ while the allocative inefficieny $\xi_{j}$ can 
be obtained from the residuals of the first-order condition in equation (19). Alternatively, one can estimate technical efficiency from $\widehat{T E}=E(\exp (-u \mid v-u)$.

\subsection{Static decomposition of competitiveness}

\subsubsection{Decomposition of $\mathrm{PCB}$}

By linking both PAM and SFA methods, we can therefore derive the static decomposition of competitiveness or PCB into technical efficiency (TE). We use PCB as an indicator of competitiveness since it is calculated at the private prices which can be possibly comparable to efficiency estimates (i.e efficiency ultimately based on farm behavior in the face of private prices).

The measurement of the technical efficiency as introduced by Farrell's (1957) method measures each firm's technical efficiency relative to the achieved frontier. The frontier represents a minimum input quantities per unit of output given the existing technology. Assume that we use two inputs to produce a unit of output, Farrell's efficiency criterion can therefore be defined as;

$$
\frac{r K+w L}{Q}
$$

where $\mathrm{r}$ is the rental cost of capital; $\mathrm{w}$ is the wage rate; $\mathrm{K}$ is the capital input; $\mathrm{L}$ is the labor input; and Q is the volume of output. Here, firms may also focus on the maximization of the value added at the market prices of a given input of domestic resources allocated to the production of traded goods. The unit isoquant according to Farrell (1957) can be constructed in the value added at market prices and efficiency criterion expresses as:

$$
\frac{r K+w L}{P_{d} Q-\sum_{i} A_{i} P_{d i}}
$$

where A is quantity of input $i$ in the production of of output $\mathrm{Q} ; P_{d i}$ is the market price of intermediate input $i$; and $P_{d}$ is the market price of output. This expression is the familiar of 
Private Cost Benefit or $\mathrm{PCB}^{13}$ that we have described earlier in Section 5.3. By assuming the relative market price of labour has declined, then in this case, firm would exhibit the minimum Private Resource Cost ratio. Minimizing the PCB in traded goods activities is equivalent to maximizing value added at market price per unit of domestic resource employed. Firms that have minimum private cost ratios have the highest levels of overall efficiency according to the Farrell criterion. The relationship between technical efficiency and PCB is thus can be straightforward. We can re-write equation (28) as;

$$
\begin{aligned}
& P C B=\frac{r K+w L}{P_{d} Q-\sum_{i} A_{i} P_{d i}} \\
& P C B=r C_{K}+w C_{L}
\end{aligned}
$$

where

$$
\begin{gathered}
C_{K}=\frac{K}{\left(P_{d} Q-\sum_{i} A_{i} P_{d i}\right)} \\
C_{L}=\frac{L}{\left(P_{d} Q-\sum_{i} A_{i} P_{d i}\right)}
\end{gathered}
$$

$C_{K}$ and $C_{L}$ indicate the value added at market prices of the two input-output coefficients for capital and labor respectively. Taking the total differential of the equations above (29-32), the proportionate change in $\mathrm{PCB}$ can be expressed as:

$$
\begin{aligned}
& \frac{d P C B}{P C B}=\frac{r\left[\left(\frac{\partial C_{K}}{\partial k}\right) d k+\left(\left(\frac{\partial C_{K}}{\partial m}\right) d m\right]+w\left[\left(\frac{\partial C_{L}}{\partial k}\right) d k+\left(\left(\frac{\partial C_{L}}{\partial m}\right) d m\right]\right.\right.}{\frac{(r K+w L)}{\left(P_{d} Q-\sum_{i} A_{i} P_{d i}\right)}} \\
& \frac{d P C B}{P C B}=\left(\frac{r K}{r K+w L}\right)\left(\frac{1}{C_{K}}\right)\left(\frac{\partial C_{K}}{\partial k}\right) d k+\left(\frac{r K}{r K+w L}\right)\left(\frac{1}{C_{K}}\right)\left(\frac{\partial C_{K}}{\partial m}\right) d m \\
& +\left(\frac{w L}{r K+w L}\right)\left(\frac{1}{C_{L}}\right)\left(\frac{\partial C_{L}}{\partial k}\right) d k+\left(\frac{w L}{r K+w L}\right)\left(\frac{1}{C_{L}}\right)\left(\frac{\partial C_{L}}{\partial m}\right) d m
\end{aligned}
$$

\footnotetext{
${ }^{13}$. The only different in Farrell (1957) is that under the distortions of output market and intermediate inputs, Farrell illustrates the measurement of social efficiency and focus on the maximization of the value added at the international prices which is analogously to the Domestic Resource Cost.
} 
Hence, equation (34) can be re-written and transformed into:

$$
\widehat{P C B}=\theta_{K} \hat{A}_{K}+\theta_{L} \hat{A}_{L}+\theta_{K} \hat{B}_{K}+\theta_{L} \hat{B}_{L}
$$

where $\widehat{P C B}=d P C B / P C B$ is the proportionate change in the private resource cost ratio; $\theta_{K}=r K /(r K+w L)$ is the share of capital costs in total factor private costs; and $\theta_{L}=$ $w L /(r K+w L)$ is the share of labor costs in total factor private costs; $\hat{A}_{K}=\left(\frac{1}{C_{K}}\right) /\left(\frac{\partial C_{K}}{\partial_{k}}\right) d_{k}$ and $\hat{A}_{L}=\left(\frac{1}{C_{L}}\right) /\left(\frac{\partial C_{L}}{\partial_{k}}\right) d_{k}$ are the proportionate changes in the coefficients of capital and labor arising from a change in capital-labor ratio; while $k$ is the partial derivative notation that indicate technical efficiency is held constant. Additionally, $\hat{B}_{i}=\left(\frac{1}{C_{i}}\right)\left(\frac{\partial C_{i}}{\partial_{m}}\right) d m$ are the proportional changes in the output- input coefficients arising from technical efficiency (TE) improvements, $m$.

The proportionate change in $\mathrm{PCB}$ is equal to the sum of of the proportionate changes in output-input coefficients of capital and labor weighted by their shares in total domestic private costs. Equation (35) will then reduce to the weighted sum of the proportionate changes in the output-input coefficients arising from technical efficiency improvements if relative factor proportions are held constant, i.e $d_{k}=0$. Therefore, a PCB value between zero and one indicates that a firm is efficient since the private opportunity cost of total factor inputs is less than contribution to the value added at market prices while a value greater than one indicates that a firm is inefficient.

\subsubsection{Decomposition of SCB}

By linking both SCB method which has been described in Section 5.3 and the profit maximization in Section 5.4.2, we can therefore derive the static decomposition of competitiveness which can be distinguished into technical and allocative efficiencies. Assume that $n$ farms operate in the sector in question are index by $\mathrm{i}=(1,2, \ldots . n)$. Each farm $\mathrm{i}$ uses $\mathrm{L}$ inputs, $\mathrm{x}^{\mathrm{i}}=\left(x_{1}^{i}, \ldots . x_{L}^{i}\right)^{\prime} \in R_{+}^{L}$, to produce $\mathrm{J}$ outputs, $\mathrm{y}^{\mathrm{i}}=\left(y_{1}^{i}, \ldots \ldots, y_{J}^{i}\right)^{\prime} \in R$. The SCB is simply the ratio of the social cost of producing one unit of an output, such as rice, to the social value of that unit of output:

$$
S C B=\frac{w x}{p y}
$$


where $p$ is a vector of output prices; $y$ is the level of production; $w$ is the vector of input prices; $x$ is the vector of inputs. An SCB value between zero and one indicates that the activity in question is competitive, while a value greater than one indicates that social cost exceeds social value and the activity is not competitive.

Assume that the production technology is defined by an output set $Y(x)$, representing the vector of outputs $R_{+}^{J}$ that can be produced by an input vector $R_{+}^{L}$ and that all farms $n$ have access to the same technology $T$ that is $T \equiv\{(x, y)$ : can produce $y\}$. Following Fare and Grosskopf (1997) the profit function defined as:

$$
\pi(p, w)=\sup \{p y-w x:(x, y) \in T\}
$$

that gives the 'maximal' profit given prices $(\mathrm{p}, \mathrm{w})$ and technology. With a suitable choice of direction for the classical technology distance functions, we can derive both output- and input-based Farrell decompositions of profit efficiency, respectively. We begin with the Shepard (1970) output distance function which can be defined as:

$$
D_{O}(x, y)=\inf \left\{\theta>0:\left(x, \frac{y}{\theta}\right) \in T\right\}
$$

and input distance function:

$$
D_{i}(x, y)=\sup \left\{\lambda>0:\left(\frac{x}{\lambda}, y\right) \epsilon T\right\}
$$

where the scalars $\theta$ and $\lambda$ are the corresponding level of efficiency. The output distance function $D_{O}(x, y)$ seeks the largest proportional increase in the observed output vector $\mathrm{y}$ provided that the expanded vector $(\mathrm{y} / \theta)$ is still an element of the original output set (Grosskopf et al. 1995). Similarly, the input distance function $D_{i}(x, y)$ seeks the radial contraction of inputs the farm should achieve to put on the frontier or to be considered as being input-efficient. If the farm is fully efficient, so that it is on the frontier, then $D_{O}(x, y)=$ 1 or $D_{i}(x, y)=1$ whereas $D_{O}(x, y)<1$ or $D_{i}(x, y)>1$ indicates the farm is inefficient.

The reciprocal of the Shepard distance function is equivalent to a Farrell output-based technical efficiency measure which can be defined as:

$$
T E_{o}(x, y)=\frac{1}{D_{O}(x, y)}
$$


and input-based technical efficiency:

$$
T E_{i}(x, y)=\frac{1}{D_{i}(x, y)}
$$

Given the profit frontier as expressed in (37) and the Shepard (1970) output and input distance function, the profit efficiency inequality as described by Farrell becomes:

$$
\frac{\pi(p, w)+w x}{p y} \geq \frac{1}{D_{O}(x, y)}
$$

and

$$
\frac{\pi(p, w)-p y}{w x} \geq-\frac{1}{D_{O}(x, y)}
$$

Combining expressions in (37), (40) or (41) and Farrell output-based or input-based revenue efficiency decomposition (42 or 43), we obtain:

$$
\frac{\pi(p, w)}{p y}+S C B \geq T E_{0}(x, y)
$$

or

$$
\frac{1}{S C B}-\frac{\pi(p, w)}{w x} \geq T E_{i}(x, y)
$$

where SCB is a measure of competitiveness as defined in Section 5.3. Following Färe and Grosskopf (1997), these two equations gives Farrell output-based revenue efficiency decomposition and can be modified by introducing allocative efficiency (AE), rendering it an equality;

$$
\frac{\pi(p, w)}{p y}+S C B=T E_{0}(x, y) \cdot A E_{0}
$$

and

$$
\frac{1}{S C B}-\frac{\pi(p, w)}{w x}=T E_{i}(x, y) \cdot A E_{i}
$$

Note that $A E_{0}\left(A E_{I}\right)$ should be greater (less) or equal one. Equation 46 represents the profit efficiency which is the product of technical and allocative efficiencies in which we have presented in Section 5.4.2. Finally, by isolating SCB in (46 and 47) we obtain the following decompositions; 


$$
S C B=T E_{0}(x, y) \cdot A E_{0}-\frac{\pi(p, w)}{p y}
$$

and

$$
\frac{1}{S C B}=T E_{i}(x, y) \cdot A E_{i}+\frac{\pi(p, w)}{w x}
$$

\subsection{Empirical Illustration}

This section applies our competitive analysis-based methodology and technical efficiency with both CFE and primal profit maximization estimates. The data was collected between 2010 and 2014 from Malaysian rice farms, which consist of a representative farm panel of 6570 rice farms in Malaysia's largest granary area ${ }^{14}$.

Our decomposition provides some insights into the origins of the Malaysian rice industry's comparative advantage and efficiency. Figure 5.1 shows the average mean values of the PCB and SCB distributions that were collected during the given period.
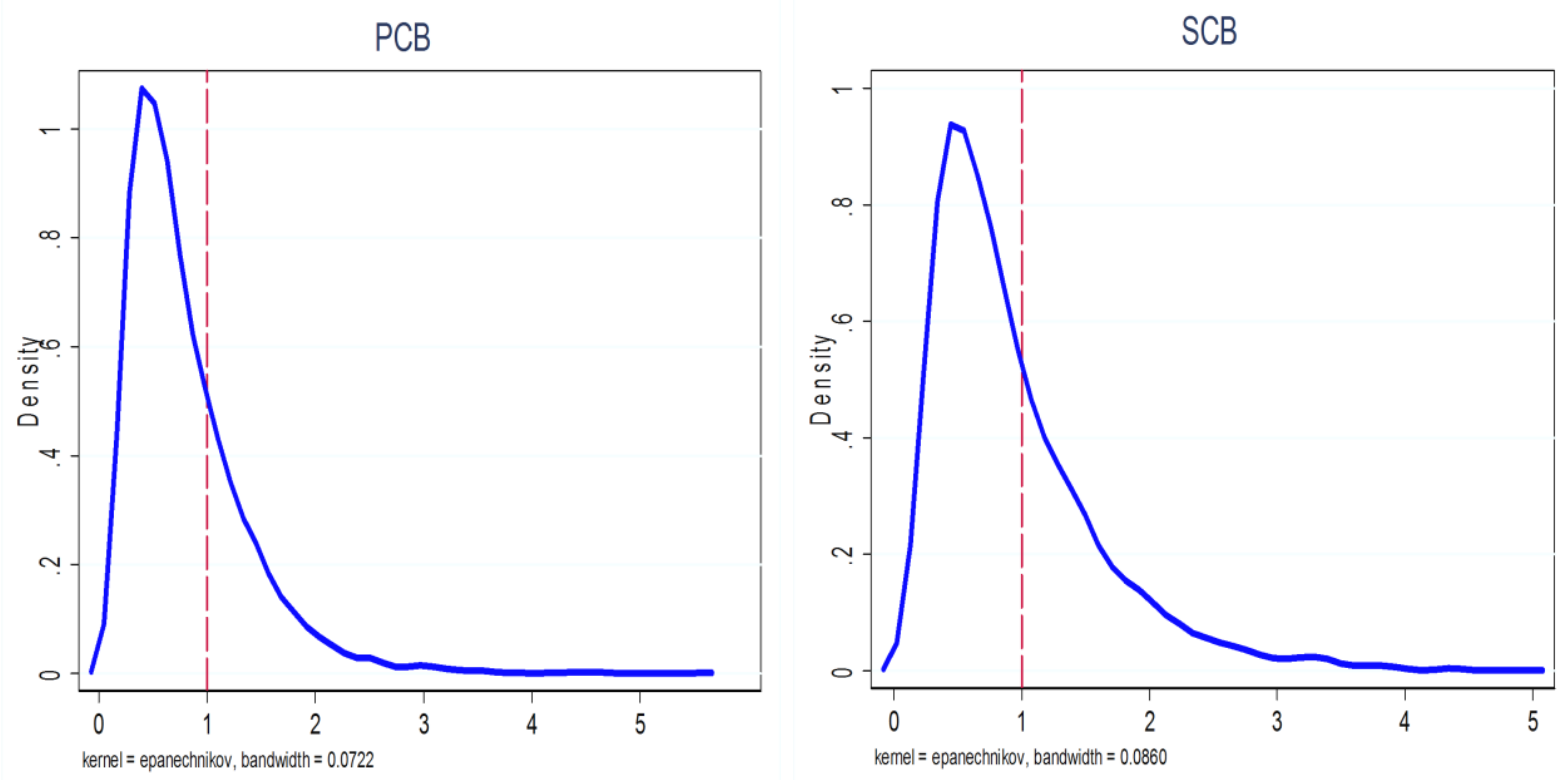

Figure 5.1: Distribution of rice farms' competitiveness scores (PCB and SCB)

\footnotetext{
${ }^{14}$ Granary areas are the irrigated areas which refer to major irrigation schemes (areas greater than 4,000 hectares) and recognized by the Government in the National Agricultural Policy as the main paddy producing areas (Department of Agriculture, 2014).
} 
During the expressed time period, the average PCB value was 0.94 , indicating that rice production was competitive during the period. This implies that, on average, many more competitive farms disproportionately produced more rice outputs at private prices. However, at social prices, the average SCB value was 1.05 , implying that rice production was slightly uncompetitive during the studied period.

Additionally, the technical efficiency distribution generated by the CFE model shows that roughly $53 \%$ of the rice farms made improvements to their technical efficiency while more efficient farms disproportionately produced more outputs.

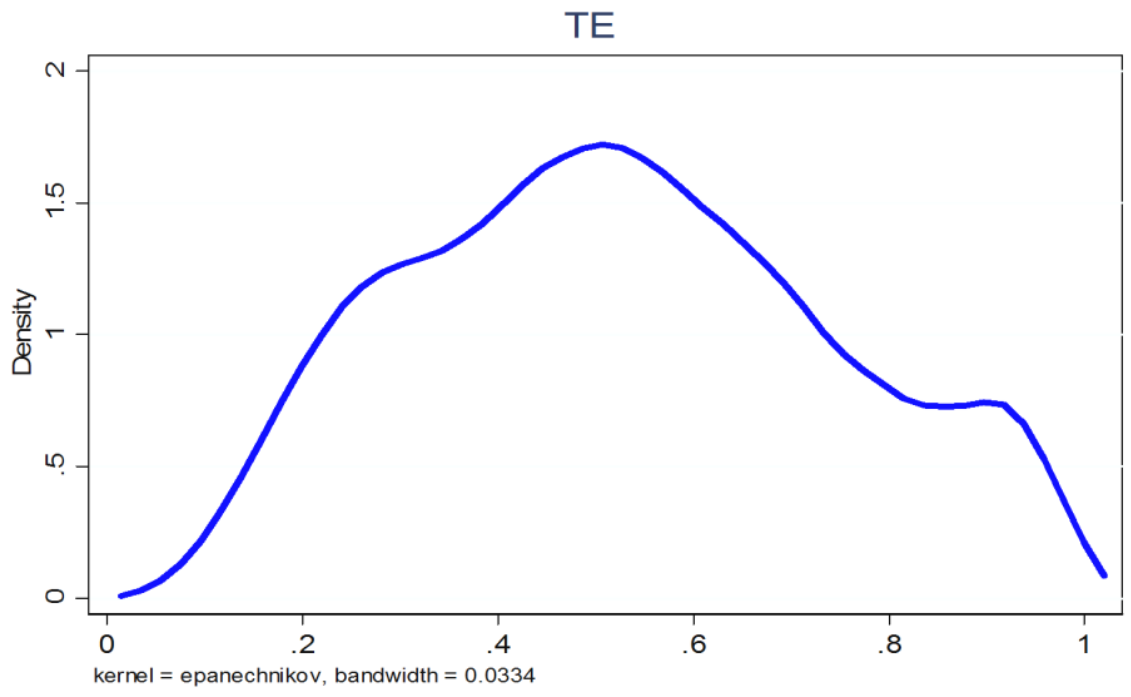

Figure 5.2: Distribution rice farms' technical efficiency, 2010-2014

By linking the PCB method, as demonstrated in Section 5.3, and technical efficiency using the SFA method, shown in Section 5.4, and by interpreting the information derived from this decomposition, it is possible to comprehend both relationships to explore the extent to which variation in the level of technical efficiency affects the performance of a farm's competitiveness, i.e. PCB.

We used Spearman's correlation to assess the relationship between PCB and TE. There is a negative correlation between these two variables, which is statistically significant, $\left[r_{\mathrm{s}}=-\right.$ $0.5969],(p=0.000)$.

The decomposition subplot portrayed in Figure 5.3 displays a scatter plot of PCB versus technical efficiency (TE). It demonstrates that competitive/comparative advantage $(\mathrm{PCB}<1)$ 
has a positive relationship with the level of technical efficiency. This implies that many farms with similar technical efficiency scores display high competitiveness, while very few farms nevertheless display a lower degree of competitiveness. In other words, farms that are closest to the frontier have better PCBs, but they still might have 'bad' PCBs relatively speaking: in other words they might be relatively efficient, but nonetheless not competitive.

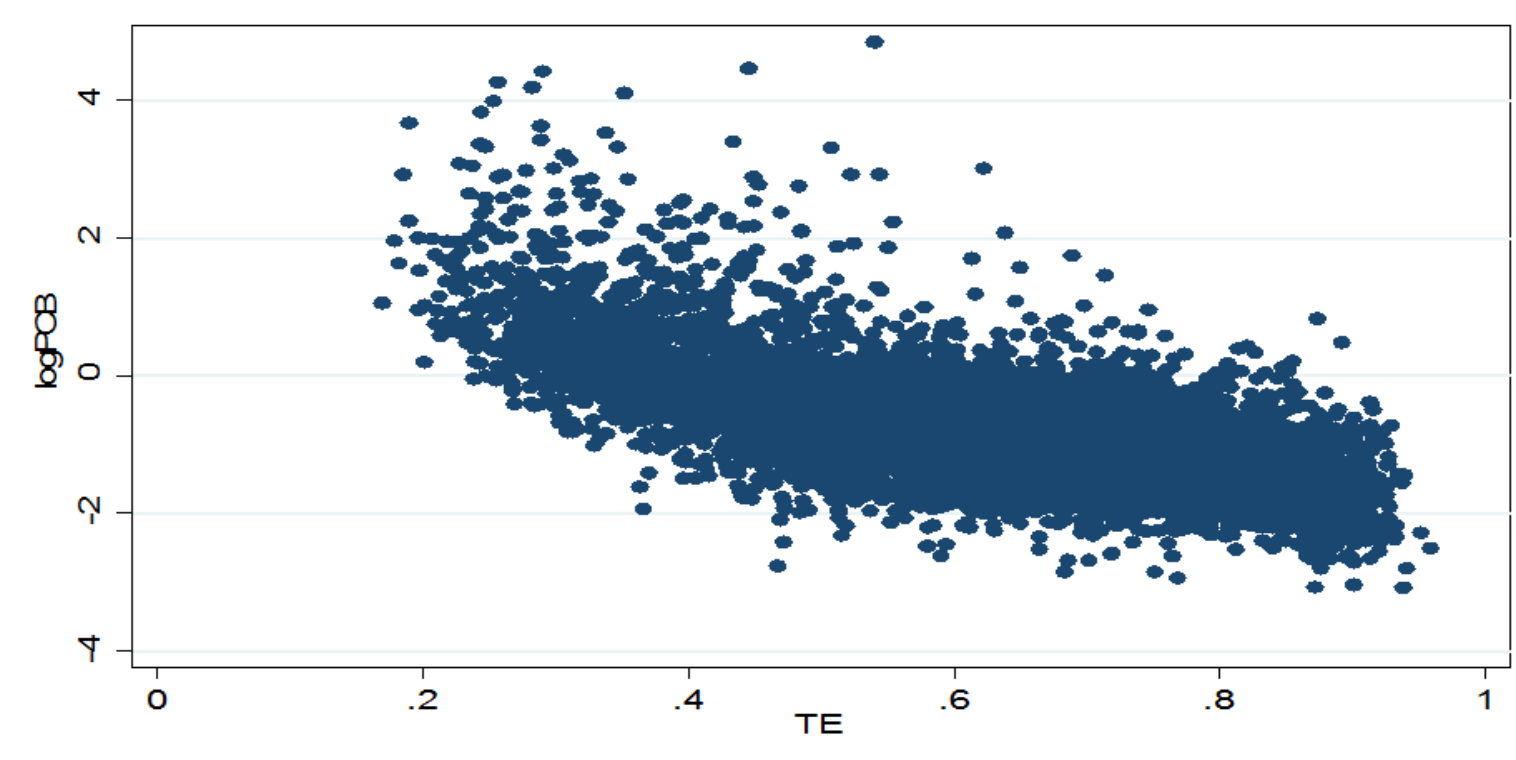

Figure 5.3: Demonstration of decomposition of competitiveness level (logPCB versus TE)

Additionally, our decomposition provides some insights into the origins of the Malaysian rice industry's comparative advantage and efficiency. The two dominant components of the decomposition of SCB are technical efficiency and allocative efficiency. The profit frontier is defined by input and output prices and available technology. That is, a farm can increase its profit through improvements in technical efficiency and through an optimal mix of inputs. However, instead of examining whether profits can be achieved and by how much, the farm can consider what drives the loss of profit- is technical inefficiency or is the problem primarily allocative inefficiency, as expressed by equation (48) or (49). In this analysis, the loss of profit due to technical and allocative inefficiencies experienced by Malaysian rice farms is demonstrated in Figure 5.4. The profit loss due to technical inefficiency is about 50\% while $169 \%$ of potential profit loss is due to allocative inefficiency (Table 5.2). 

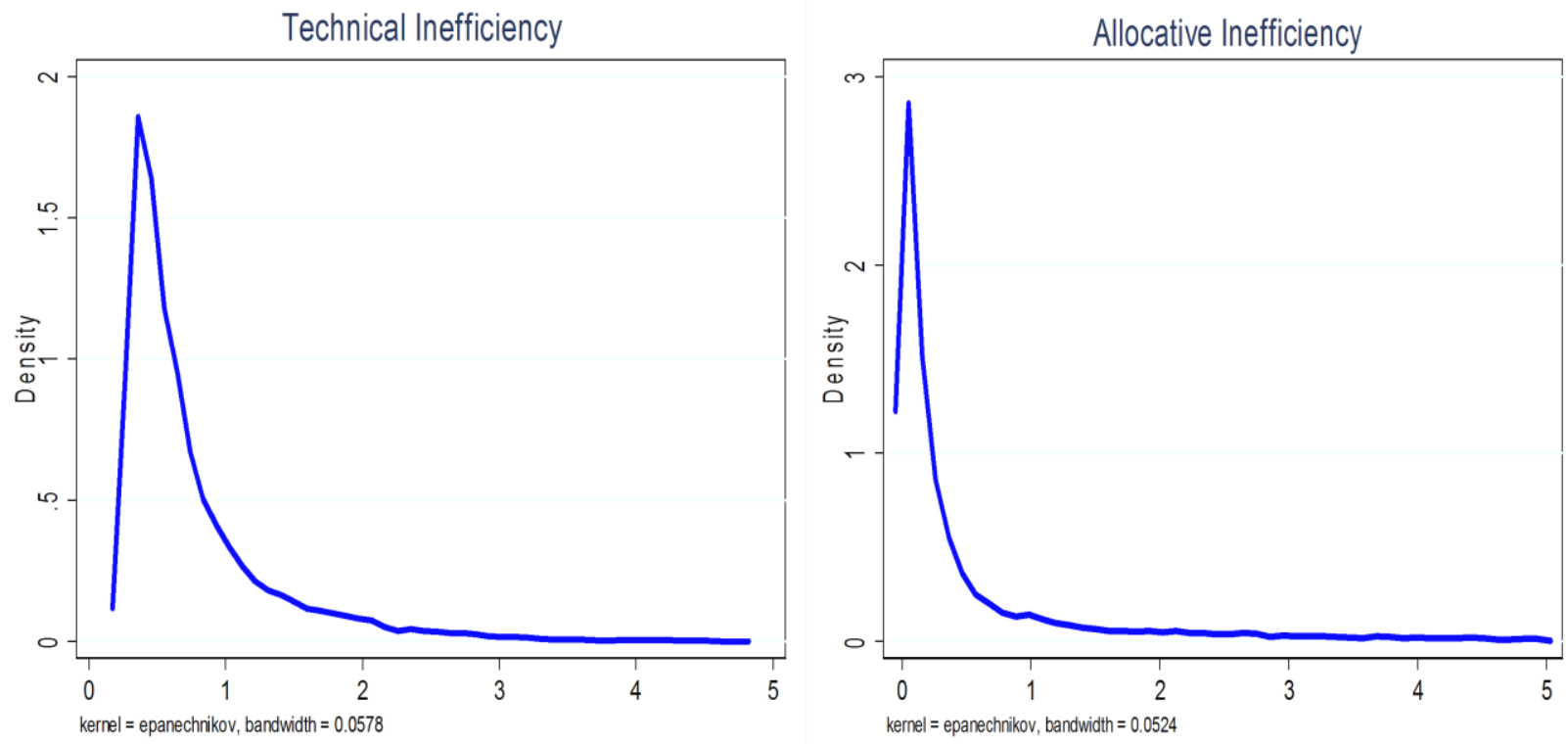

Figure 5.4: Distributions of Technical Inefficiency (TI) and Allocative Inefficiency (AI) Source: Own estimation

Table 5.2: Profit loss due to technical inefficiency, allocative inefficiency or both

\begin{tabular}{|c|c|c|c|c|c|c|}
\hline & \multicolumn{2}{|c|}{ Technical inefficiency } & \multicolumn{2}{|c|}{ Allocative inefficiency } & \multicolumn{2}{|c|}{$\begin{array}{c}\text { Technical and } \\
\text { allocative } \\
\text { inefficiencies }\end{array}$} \\
\hline & Percentiles & Smallest & Percentiles & Smallest & Percentiles & Smallest \\
\hline $1 \%$ & 0.19 & 0.05 & 0.00 & 0.00 & 0.26 & 0.23 \\
\hline $5 \%$ & 0.22 & 0.13 & 0.01 & 0.00 & 0.30 & 0.23 \\
\hline $10 \%$ & 0.25 & 0.13 & 0.01 & 0.00 & 0.33 & 0.23 \\
\hline $25 \%$ & 0.33 & 0.14 & 0.04 & 0.00 & 0.39 & 0.24 \\
\hline \multirow[t]{2}{*}{$50 \%$} & 0.47 & & 0.17 & & 0.57 & \\
\hline & & Largest & & Largest & & Largest \\
\hline $75 \%$ & 0.65 & 0.99 & 0.72 & 168.69 & 0.96 & 19.05 \\
\hline $90 \%$ & 0.80 & 0.99 & 3.20 & 171.07 & 1.77 & 19.70 \\
\hline $95 \%$ & 0.86 & 0.99 & 6.95 & 266.94 & 2.64 & 22.28 \\
\hline \multirow[t]{3}{*}{$99 \%$} & 0.94 & 0.99 & 25.48 & 353.62 & 5.48 & 27.26 \\
\hline & Mean & 0.50 & Mean & 1.69 & Mean & 0.92 \\
\hline & Std. Dev. & 0.20 & Std. Dev. & 8.65 & Std. Dev. & 1.18 \\
\hline
\end{tabular}


To further illustrate a static relationship, we developed a simple model based on fixed effect panel model. For this purpose, we used PCB as the dependent variable since this is the actual market price that farmers actually received while participating in the system and the reference for the comparison between different farms (their individual PCB and efficiency scores) is the current domestic competition within Malaysia. The model can be defined as;

$$
\log Y_{i t}=\alpha_{i}+\beta_{j} X_{j i t}+\varepsilon_{i t}
$$

$Y_{i t}$ is farm $i$ 's PCB in period $t ; X_{i t}$ is a vector of exogenous explanatory variables (technical efficiency, farm size, hired cost labor, distance to milling factories and a time trend); $\alpha_{i}$ captures unobserved and time constant farm specific effects; and $\varepsilon_{i t}$ is an idiosyncratic error term. The estimated fixed effect equations yield the following results;

Table 5.3: Results of static decompositions of competitiveness

\begin{tabular}{|c|c|c|}
\hline \multirow[t]{2}{*}{ Dependent } & \multicolumn{2}{|c|}{$\log (\mathbf{P C B})$} \\
\hline & Model 1 & Model 2 \\
\hline Constant & $\begin{array}{c}1.6390 * * * \\
(0.0288)\end{array}$ & $\begin{array}{c}1.4473 * * * \\
(0.0436)\end{array}$ \\
\hline $\mathrm{TE}$ & $\begin{array}{c}-3.8061 * * * \\
(0.0472)\end{array}$ & $\begin{array}{c}-3.7351 * * * \\
(0.0465)\end{array}$ \\
\hline Farm size & & $\begin{array}{c}-0.0561 * * * \\
(0.0135)\end{array}$ \\
\hline Cost of labor & & $\begin{array}{c}0.0004 * * * \\
(2 . \mathrm{E}-05)\end{array}$ \\
\hline Distance & & $\begin{array}{c}0.0239 * * * \\
(0.0044)\end{array}$ \\
\hline Trend & & $\begin{array}{c}-0.0851 * * * \\
(0.0040)\end{array}$ \\
\hline R-square & 0.6488 & 0.6915 \\
\hline sigma_u & 0.3841 & 0.3527 \\
\hline sigma_e & 0.4960 & 0.3769 \\
\hline
\end{tabular}

Since the greater values of the PCB scores (PCB > 1) indicate less competitiveness, a positive estimated coefficient indicates that explanatory variables in question increase PCB scores and therefore have a negative influence on competitiveness. The results show that the estimated coefficients of technical efficiency in both models are negative and strongly significant at the 
$1 \%$ level. The TE coefficient indicates that a $1 \%$ increase in technical efficiency will lead to a $38 \%$ decrease in the PCB unit, assuming that all other variables remain constant. This outcome implies a relationship between high levels of efficiency and lower scores of PCB and indicates a higher competitiveness, thus confirming our prior hypothesis on static decomposition. We anticipated this relationship and it goes in the predicted direction, however, other factors also influence the PCB.

Although, beyond the application of simple regression, if we are interested in identifying competitive farms we can do PAM analysis that gives the ranking and by simply performing the rank correlation of technical efficiency, we can identify the farms that are in the top $10 \%$ tier of competitiveness are also generally in the top $10 \%$ of technical efficiency. However, what other factors beyond a farm's technical efficiency can explain its competitiveness? Technical efficiency should be able to explain this relationship; if farms are not technically efficient, then they are not receiving the most possible output for a given number of inputs, therefore not receiving the most possible revenue for the given cost, and thus such farms cannot be profitable if they are not technically efficient. Nevertheless, if the regression shows that profitability is $70 \%$ accounted for by technical efficiency, the question is, where is the remaining $30 \%$ ? This could be due to some other variations or factors that influence competitiveness. Farms that are technically inefficient could still be profitable by compensating and excelling in other areas. This possibility is something that we cannot directly measure; it could also be the outcome of unexplained variations or the result of the measured factors, such as scale efficiency or allocative efficiency. This can be achieved with the use of the Stochastic Frontier Analysis, which allows for the more efficient use of inputs and identifies additional information on the factors that cause variation.

\subsection{Conclusion}

In this paper we have demonstrated how one can use two alternative methods or tools to explain comeptitiveness, i.e PAM analysis as well as a more sophisticated SFA method. By linking both approaches, we have proposed a method for a static decomposition of competitiveness measured by the Private Cost Benefit (PCB) into technical efficiency (TE). 
Our motivation was a belief that technical efficiency positively contributes to competitiveness.

Our empirical application of the technique to the rice sector in Malaysia for the period 20102014 provides an illustration of the utility of the methods. The results broadly indicate that a change in the level of technical efficiency is the major source of change in competitiveness and account for a relatively lower PCB ratio. Technical efficiency displays a negative and significant effect on PCB, which implies higher efficiencies lead to lower PCB values and thus increases in overall competitiveness. The results of the preceding analysis suggest that the level of comparative/competitive advantage may be an equally important determinant of technical efficiency in rice production in Malaysia, which is explained by $65 \%$ of the technical efficiency. However, the other $35 \%$ of profitability or competitiveness might be explained by the other factors such as scale or allocative efficiency.

It is evident that these two methods are not substitutes, but they are complements. Whether or not a farm is technically efficient does affect PCB; however that's not all. There are some other variations or factors that could explain the remaining profitability or competitiveness. We could use PAM or PCB to explain competitiveness in certain settings; however we would have to conduct SFA ahead to get additional information on the other factors that might be influencing PCB or competitiveness.

Each of these approaches is characterized by important strengths and weaknesses. The main advantage of PAM is that it is simple and intuitively easy to use and to explain to the lay people than to technical or scientists which are commonly attached to a more sophisticated SFA method. The result of PAM is easily communicable and the intuitiveness of the results and its applicability contribute to its consideration in fulfilling the information needs especially for consulting and policy makers' dialogues. In some cases, then it might be almost better to use PAM rather than sophisticated SFA modeling. However, instead of its simple conception, PAM also suffers from the limitation of the Leontief fixed input-output coefficients which do not take into account the changes in domestic prices as well as the difficulty in estimating social prices. On the other hand, the more sophisticated analytical approach such as profit or distance function approach is hardly being applied and relatively 
difficult to understand and explain due to its complexity and rigorously mathematical programming or calculations.

Our discussions on these two approaches and how they are linked may help policy makers and others make better use of one or the other measure. Although they reveal important differences between the two sets of estimates, both approaches point to a fairly similar result or conclusion on the competitiveness. Therefore, it is suggested that further efforts should be made to combine the advantages of existing methodologies and to improve the collection, precision and consistency of data. 


\section{Appendices}

Appendix 5.1: Demonstration of decomposition of PCB, 2010-2014
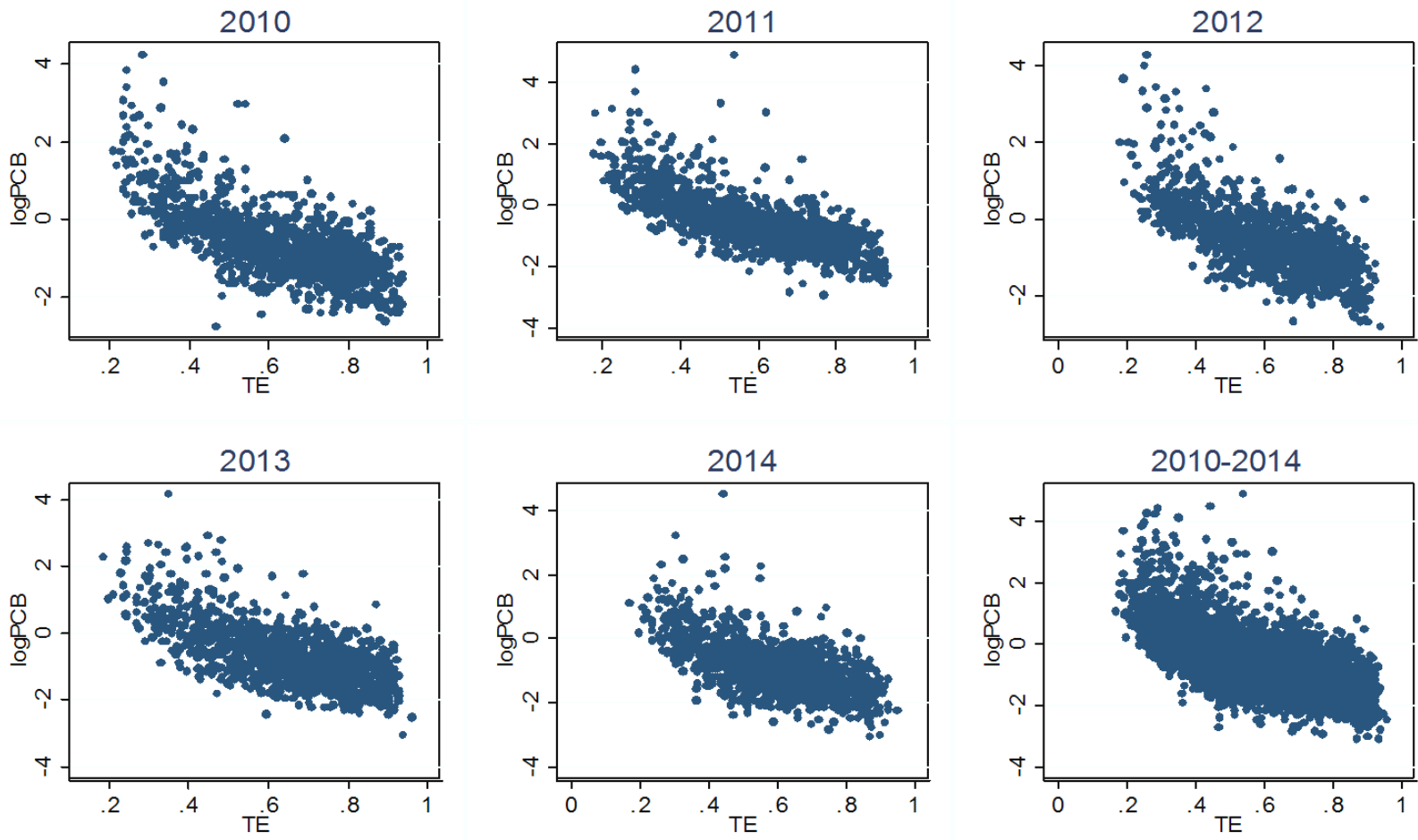

Appendix 5.2: Demonstration of decomposition of SCB, 2010- 2014
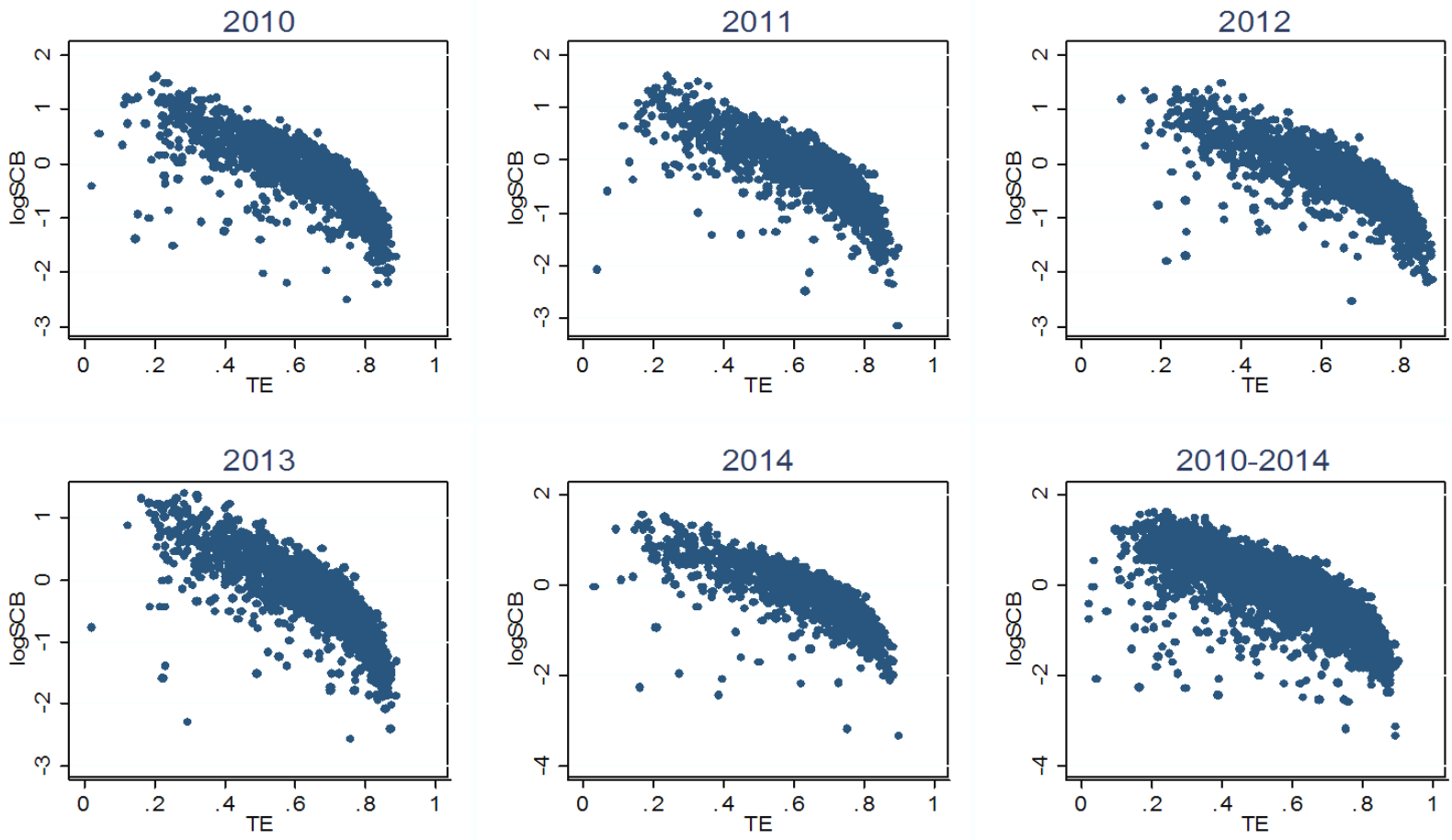


\section{References}

Abdulai, A., and H. Tietje. 2007. "Estimating technical efficiency under unobserved heterogeneity with stochastic frontier models: Application to northern German dairy farms." European Review of Agricultural Economics 34(3):393-416.

Abdulai, A., and W.E. Huffman. 1998. "An Examination of Profit Inefficiency of Rice Farmers in Northern Ghana An Examination of Profit Inefficiency of Rice farmers in Northern Ghana." Staff Paper No. 296. (January):1-27.

Agriculture Canada. 1990. "Report to the Minister of Agriculture of the Task Force on Competitiveness in the Agri-Food Industry." Ottawa, Ontario, June.

Aiginger, K., S. Bärenthaler-sieber, and J. Vogel. 2013. "Competitiveness under New Perspectives." Working Paper No. 44. October 2013. Available at: http://www.foreurope.eu/.

Aigner, D.J., Lovell, C.A.K., and Schmidt, P., 1977. "Formulation and estimation of stochastic frontier production function models." J. Econometrics 6, 21-37.

Álvarez, A., J. Del Corral, and A. Fernández. 2009. "Modeling Regional Heterogeneity with Panel Data: With Application to Spanish Provinces." Uclm.Es (May). Available at: http://www3.uclm.es/profesorado/jcorral/Trabajando/6f10da_Efi_Regions_12.pdf.

Belotti, F., and I. Giuseppe. 2012. "Consistent estimation of the 'true' fixed-effects stochastic frontier model." 5 No. 231, American Journal of Agricultural Economics 83(1):1-19

Bhatt, M.S., and S.A. Bhat. 2014. "Technical Efficiency and Farm Size Productivity - Micro Level Evidence from Jammu \& Kashmir.” International Journal of Food and Agricultural Economics 2(4):27-49. Available at: http://www.foodandagriculturejournal.com/vol2.no4.pp27.pdf.

Brummer, B., and J. Loy. 2000. "The Technical Efficiency Impact of Farm Credit Programmes: A Case Study of Northern Germany." Journal of Agricultural Economics 51(3):405-418.

Bruno, M. 1965. "The Optimal Selection of Export-promoting and Import-substituting Projects." Project for Quantitative Research in Economic Development, Center for International Affairs, Harvard University. Available at: https://books.google.de/books/about/The_Optimal_Selection_of_Export_promotin.html? id=ZBzbHgAACAAJ\&pgis=1 [Accessed December 15, 2015].

Department of Agriculture, Malaysia. 2014. Perangkaian Padi Malaysia (Paddy Statistics of Malaysia) 2013. 
European Commission. 2009. "European Competitiveness Report 2008." European Commission, Brussels.

Färe, R., and S. Grosskopf.(1997). "Profit Efficiency, Farrell Decompositions and the Mahler Inequality." Economics Letters, 283-287. Available at: http://www.sciencedirect.com/science/article/pii/S0165176597002346.

Findlay, Ronald, and Harry Grubert. 1959. "Factor intensities, technological progress, and the terms of trade." Oxford Economic Papers 11, no. 1: 111-21.

Frohberg, Klaus, and Hartmann, Monika. 1997. "Comparing measures of competitiveness." Discussion Paper, Institute of Agricultural Development in Central and Eastern Europe, No. 2, http://nbn-resolving.de/urn:nbn:de:gbv:3:2-22616

Greene, W. 2005. "Reconsidering heterogeneity in panel data estimators of the stochastic frontier model." Journal of Econometrics 126(2):269-303.

Hatzichronoglou, T. 1996. "Globalisation and Competitiveness: Relevant Indicators." OECD Science, Technology and Industry Working Papers, 1996/5, OECD Publishing, Organisation for Economic Co-operation and Development, Paris, France.

Holtkamp, J. 2015. "Unobserved heterogeneity in productivity analysis of panel data: Applications to meat chain firms and global growth in agriculture." :90. Available at: http://hdl.handle.net/11858/00-1735-0000-0022-5DE0-E.

Jondrow, J., C. A. K. Lovell, I. S. Materov and P. Schmidt, On the estimation of technical inefficiency in the stochastic frontier production functions model, Journal of Econometrics, 1982, 19, pp.233-238.

Kanaka, D.S., and M. Chinnadurai. 2013. "The Policy Analysis of Rice Cultivation in India." European Journal of Physical and Agricultural Sciences 1(1). Available at: http://www.idpublications.org/wp-content/uploads/2013/11/The-Policy-Analysis-Matrixof-Rice-Cultivation-In-India.pdf [Accessed March 21, 2016].

Kumbhakar, S.C. 1987. "The specification of technical and allocative inefficiency in stochastic production and profit frontiers." Journal of Econometrics 34(3):335-348.

Kumbhakar, S. 2001. "Estimation of Profit Functions When Profit Is Not Maximum". American Journal of Agricultural Economics, 83(1), 1-19. Retrieved from http://www.jstor.org/stable/1244296

Kumbhakar, S.C., H.J. Wang and A. P. Horncastle. 2015. A Practitioner's Guide to Stochastic Frontier Analysis. 1st edition. Cambridge University Press.

Kumbhakar, S.C., and H.J. Wang. 2006. "Estimation of technical and allocative inefficiencya primal system approach". Journal of Econometrics, 134(2), 419-440. 
Latruffe, L. 2010. "Competitiveness, Productivity and Efficiency in the Agricultural and Agri-Food Sectors.” OECD Food, Agriculture and Fisheries Papers 30(30):1-63.

Masters, W.A., and A. Winter-Nelson. 1995. "Measuring the Comparative Advantage of Agricultural Activities: Domestic Resource Costs and the Social Cost-Benefit Ratio." American Journal of Agricultural Economics 77(2):243-250.

Masterson, T. 2007. "Productivity, Technical Efficiency, and Farm Size in Paraguayan Agriculture.” Working Paper (490):37. Available at: http://ssrn.com/abstract=964722.

Monke, E.A., and S.R. Pearson. 1989. "The Policy Analysis Matrix for Agricultural Development." Ithaca, NY: Cornell University Press. Available at: http://web.stanford.edu/group/FRI/indonesia/documents/pambook/pambook.pdf [Accessed December 14, 2015].

Nishimizu, M., and J.M. Page. 1986. "Productivity Change and Dynamic Comparative." The Review of Economics and Statistics 68(2) (May ,1986), pp . 241-247 Published by: The MIT Press Stable URL: http://www.jstor.org/stable/1925503 com." The Review of Economics and Statistics 68(2):241-247.

Nivievskyi, O., B. Brummer, and S. von Cramon-Taubadel. 2010. "A Note on Technical Efficiency, Productivity Growth and Competitiveness." Annual Meeting, July. Available at: http://ageconsearch.umn.edu/bitstream/61759/2/11234 AAEA 2010.pdf.

Porcelli, F. 2009. "Measurement of Technical Efficiency. A brief survey on parametric and non-parametric techniques." Retrieved February (January):1-27. Available at: http://citeseerx.ist.psu.edu/viewdoc/download?doi=10.1.1.232.4843\&rep=rep1\&type=pdf

Sarker, R., and S. Ratnasena. 2014. "Revealed Comparative Advantage and Half-a-Century Competitiveness of Canadian Agriculture: A Case Study of Wheat, Beef, and Pork Sectors." Canadian Journal of Agricultural Economics/Revue canadienne d'agroeconomie 62(4):519-544. Available at: http://doi.wiley.com/10.1111/cjag.12057.

Schmidt, P. and Lovell, C.A.K. (1979). Estimating Technical and Allocative Inefficiency Relative to Stochastic Production and Cost Frontiers. Journal of Econometrics, 9: 343366.

Shephard, R. W. (1970), Theory of Cost and Production Functions. Princeton: Princeton University Press.

Singgel, E. 2006. "International Competitiveness and Comparative Advantage: A Survey and a Proposal for Measurement.” Journal of Industry Competition and Trade 6(2):137-159. Available at: https://www.cesifogroup.de/portal/pls/portal/!PORTAL.wwpob_page.show?_docname=956160.PDF [Accessed December 15, 2015]. 
von Cramon-Taubadel, S., and O. Nivyevskyi. 2008. "Ukraine-Ag-Competitiveness-Policy Note - Final."

von Cramon-Taubadel, S., and O. Nivyevskyi. 2009. "Belarus Agricultural Productivity and Competitiveness: Impact of State Support and Market Intervention." Available at: https://openknowledge.worldbank.org/bitstream/handle/10986/18897/483350ESW0REV I110FINAL0for0printing.pdf?sequence=1\&isAllowed=y [Accessed April 18, 2016].

Yao, R.T., and E.S. Gerald. 2007. "Technical Change and Productive Efficiency: Irrigated Rice in the Philippines." Asian Economic Journal 21(2):155-168. Available at: http://web.a.ebscohost.com/ehost/pdfviewer/pdfviewer?sid=146d041d-9cfe-4315-95df2c88f34b2f56\%40sessionmgr4005\&vid=1\&hid=4114 [Accessed January 23, 2016]. 


\section{Chapter 6}

\section{Concluding Remarks}

This dissertation presents four selected studies on the topic of the "competitiveness and efficiency of rice production in Malaysia". Chapter 2 analyses the profitability and competitiveness of the rice sector using the Policy Analysis Matrix (PAM) developed by Monke and Pearson (1989) and aggregated data. Chapter 3 extends the PAM method by performing a disaggregated competitiveness analysis and analysing the determinants of competitiveness. Chapter 4 examines the performance of a rice farm using an efficiency analysis. Finally, Chapter 5 concludes the dissertation by linking both competitiveness and efficiency analyses using a static decomposition of competitiveness. In this section, we present a summary of the main results and their implications, discuss the limitations and challenges of the estimations, and present recommendations for future work.

\subsection{Key contributions and summary}

Rice is the most important source of livelihood and is a major source of employment for more than 100,000 farmers and agricultural workers in Malaysia. It accounts for about $9 \%$ of the country's gross value added in agriculture and is grown on approximately 1.8 million hectares of arable land (FAO, 2001). Rice is also the main source of caloric intake for many Malaysians, contributing to nearly half of the average Malaysian's total caloric intake per day. Malaysia's agro-climatic and geographical location provides the basis for the country's potential in agricultural production. The tropical climate and suitable soil conditions are favorable for the development and growth of the tropical rice crop. The country lies entirely in the equatorial zone with uniform temperatures, high humidity and a long wet season. The copious rainfall is an important water source necessary for the successful cultivation of rice. Hence, the rice sector plays a notable role in the society and government's agricultural policies and interventions aim to achieve "several, often conflicting, objectives", including the augmentation of farmers' incomes, delivering quality products at low prices to consumers, maintaining price stabilization, and an attainment of self-sufficiency. 
However, despite its high dependency on the importation of rice, the country continues its aggresive pursuit of rice self-sufficiency, which involves the commitment to end rice imports and become $100 \%$ self-sufficient in terms of rice production by the year 2020 . The most impeding constraint to Malaysia's competitiveness is that the country's endowment of natural advantage and agro-climatic conditions do not automatically yield sufficient qualities of complementary efforts, including a coherent policy framework, facilities and transport infrastructures, as well information and marketing systems, all of which are essential to the establishment of a competitive rice sector.

The recent free trade agreements, including the ASEAN Free Trade Agreement (AFTA) and the World Trade Organization (WTO) accession, offer attractive opportunities, but also pose challenges for the Malaysian rice sector as it must compete with other low-cost exporting countries. This implies that not only structural changes in trade, but also adjustments at the farm-level are needed to improve the sector's efficiency and competitiveness. Further developments in the rice sector will, therefore, depend on the availability of adequate supplies of relatively low-cost and high-quality rice, or in other words, on the competitiveness of rice production. This dissertation offers an analytical work to provide new insights into this issue and the opportunities for improvement as well as the determinants of Malaysia's rice competitiveness.

In the first paper, the Domestic Resource Cost (DRC) indicator using aggregate data is employed to shed light on the competitiveness of Malaysia's rice sector. The main conclusion is that rice production demonstrates modest international competitiveness. The empirical results show that three out of four granary areas have comparative advantages in the production of rice with Domestic Resource Cost values, or DRCs, of less than one. The farms located in these areas produce a net surplus for the entire country. In the remaining region, rice farming appears to be marginally competitive and imparts relatively low social profits.

For the second paper, we essentially continued the analysis performed in the first paper and focused on a disaggregated competitiveness analysis and the determinants of rice competitiveness in Malaysia. The weakness of the DRC method is that it is based on average, or representative, farms. The conclusions that can be drawn from the average indicator might 
be misleading as the variations across heterogeneous producers grow. For this reason, we employed the Social Benefit Cost (SCB) indicator using farm-level survey data to generate SCB distributions that demonstrate the competitiveness of rice production in Malaysia. The results of the SCB analysis reveal that a large proportion of farms are able to produce rice competitively; more than $60 \%$ of rice farmers produced rice competitively over the period from 2010 to 2013 and these competitive farms produced a disproportionately large number of the total rice production ( $80 \%$ ) each year. The only exception was in 2014 , where $48 \%$ of the farms that were identified as competitive accounted for $71 \%$ of the total rice production. From 2012 to 2014, the SCB scores based on average revenue and cost data were greater than 1. This indicates that social revenue was not enough to cover the social value added, suggesting these farms are losing their international competitiveness, in other words they are uncompetitive. However, the SCB distributions based on disaggregated data revealed that many farms were competitive and these competitive farms accounted for a disproportionately large share of rice production during that period. Hence, the competitive farms, on average, tend to produce more rice than non-competitive farms. This information highlights the primary advantage of using disaggregated SCB distributions and avoids the pitfalls working with the average data. In the second stage of the analysis, we further analysed the factors that might influence a farm's degree of competitiveness. The available evidence suggests that participation in the farmers' organization, gender and farm size are the major determinants of rice competitiveness, while the increasing travel distance to rice mills, off-farm income and the use of hired labour may reduce competitiveness.

For the third paper, we performed an efficiency analysis method to measure the technical efficiency of the performance of Malaysia's rice farms. The framework provided in the paper took unobserved heterogeneity into account using the recent fixed effect model (Chen et al, 2014); the cases in which managerial characteristics and environmental conditions are not observed are assumed to be constant or different for each rice farm. This is crucial considering the panel data collections provided by developing countries are significantly costlier and some important attributes may not exist. Therefore, the model allows for unobserved heterogeneity and the estimation is free of incidental parameters. In the observation period from 2010 to 2014, technical efficiency appearead to be fluctuate in rice production. Our results indicate that the mean efficiency was $61 \%$ in 2010 , it decreased in 
2011 and increased steadily for the next two years, before it declined again in 2014. However, the low mean values of technical efficiency change (TEC) further revealing that the frontier is shifting inward and some farms are essentially moving farther from the frontier.

In the second stage of the analysis, we examine the factors that account for the variations in inefficiencies across the farms as well as their potential to improve efficiency and resources using an a fixed effect panel regression. Our empirical results indicate that access to credit, non-farm income, farm size and hired labor are the major determinants of technical efficiency. The potential for increasing individual farm output varies considerably since many farms became much better while others became much worse. Government support such as input subsidies, credit facilities, distance to the rice mills and off-farm activities are identified as important factors causing variations in the level of technical efficiency among rice farmers. Furthermore, the scale elasticity of 1.49 indicates a strong economy of scale; in which outputs can be increased with more than proportionate increases in inputs. This is imperative considering that rice production in Malaysia is small and most of the farmers might depend on capital and other inputs which necessitates a serious policy recommendation. It is possible to achieve more if the provisions of inputs particularly mechanization and transport facilities as well as improvement in high-yielding rice variety are further well distributed and reinforced in the future so that it will help to increase the overall efficiency of rice production in Malaysia.

Finally, the fourth paper links the two strands of analysis on competitiveness. The first strand of the literature focuses on the analysis of comparative advantages/competitiveness, while the second strand emphasizes the efficiency analysis where the concept of technical efficiency is of prime interest. To demonstrate this relationship, we proposed a static decomposition of the PCB into technical efficiency. Our result demonstrates that technical efficiency positively contributes to competitiveness, thus confirming the common perception of the static decomposition. By comparing PCB and TE, our result reveals a clear relationship between competitiveness and efficiency, however higher technical efficiency alone does not translated into higher competitiveness. The low R-square indicates that other unexplained variations may exist or perhaps other factors may affect this relationship such as scale efficiency, allocative efficiency and other few relations; an evidence in which is demonstrated by the 
fixed effect panel regression. This leads us to conclude that both approaches (PAM analysis and SFA method) are not substituted but they are rather complementing. We use PCB to explain competitiveness in certain settings; however we would have to conduct SFA ahead to get additional information on the other factors that might be influencing PCB or competitiveness.

\subsection{Policy implications and options}

Factors like a lack of coherent policy action, poor transportation and infrastructure, low availability of credit and marketing, and information asymmetries exacerbate the underlying barriers to achieving rice competitiveness that are listed in Section 6.1. These barriers can be diminished or even eliminated with better political leadership capable of setting a new frontier and priorities with the past misallocation as well as working hand-in-hand with partners (i.e., international institutions) and various stakeholders to balance their priorities and provide insightful information and funding, while simultaneously minimizing the repercussions of the development of agricultural competitiveness in Malaysia.

Since the inception of the AFTA, in compilation with the trade liberalization fostered by the WTO, rice tariffs have been reduced to $0-5 \%$ for all trading partners in the region. Regardless, in the major rice importing countries, such as Malaysia, rice is considered highly vulnerable to food security and, therefore, is subject to up to $20 \%$ tariffs. Both the WTO accession and on-going negotiations on a free trade agreement with ASEAN countries will require further improvements in productivity and competitiveness at the farm-level. In particular, the conditions of Malaysia's accession to the WTO include the commitment to reducing trade distortions and interventions on agricultural markets, a strategy which policymakers have employed in the rice sector in recent years. Consequently, import barriers such as seeds, agrichemicals and agricultural machineries which make imports are expensive and lessens competitiveness should be reduced.

According to Malaysia's WTO Trade Report Review (2014), the total support given to agriculture consisted of reduction commitments amounting to 1 billion Ringgit Malaysia (RM). Of this, approximately $74 \%$ was related to Green Box assistance, mainly in the form of income support for farmers while others involved the fertilizer subsidy scheme. In 2013, price 
support (incentives or bonus payments for paddy rice production) remained the largest part of expenditures (480 million RM) followed by the fertilizer subsidy (465 million RM). This form of agricultural support has cost Malaysian agriculture billions of RM in revenue. Since our preliminary evidence indicates that many rice farmers are socially competitive, the subsidization and price support of rice production, which are poorly targeted and distort incentives, should be phased out. This could be replaced with targeted, direct income support and income stabilisation measures.

Further efforts are required to reduce marketing margins and farm gate prices that may reduce competitiveness; this could be accomplished by upgrading local storage facilities, transportation infrastructure and the logistics associated with the rice delivery system and marketing chain. Postharvest and value addition are integral components of strategies to improve agricultural productivity and linkages between farmers and the markets. The causes of storage losses and waste are principally connected to the managerial and technical limitations of harvesting techniques, storage and cooling facilities in difficult climatic conditions, infrastructure, packaging and marketing systems (Kiaya, 2014). Proper drying and transport facilities are therefore important to minimize storage/postharvest losses. In addition, a well-developed system of transport and infrastructure, including quality roads, ports, or air transport, reduces the distance between regions and integrates national markets as well as facilitates the movement of rice outputs to the market in a secure and timely manner.

Financial support and agricultural credit for rice farmers needs to be emphasized further. The current policy of subsidization on credit is given at interest rates of $4.5 \%$ per season. However, for many small farmers who harvest less than $3 \mathrm{t} /$ ha per season, a lack of finance and collateral has forced them to borrow money from relatives or family members instead of from agricultural credit institutions. Therefore, a strategy for coping with this problem would be for the government to offer loans with lower or zero interest rates, which should be granted regardless of a farmer's capital (this is especially relevant for small farmers). Similarly, the acquisition of flexible agricultural credit schemes will allow farmers to better access and incorporate modern technologies into their rice production. 
Additionally, more investments in research and development (R\&D) are required to enhance competitiveness. It is important that public and private sectors play important roles in supporting and nurturing an environment that is conducive to innovative activity. This progression requires access to complementary inputs and sufficient investments, especially by the private sectors. This includes high-quality research institutions and universities to inject local communities with knowledge, and an expansion of human capital used to build new technologies. Extensive collaborative actions between universities and industries in research and technological developments are additionally necessitated. A review of the analysis on the disaggregated competitiveness reveals that there is some variability in the average SCB ratios from year to year that could be explained by other factors such as weather conditions (monsoons during the main season and drought during the off-season) and pest attacks. Therefore, further research and experimentation that are applicable to specific local conditions are required to ensure that their durability in a variety of local conditions as well as for the adaptation to general agriculture environments such as temperature, soil, water conditions and local pests.

Between 2010 and 2014, the mean values of technical efficiency in the rice production were 50 to 60 percent. This average masks important differences among rice farms and points to substantial scope for further efficiency improvement. This has certainly implications for the efficiency-enhancing policies in the country. Furthermore, the findings on the estimates scale elasticities deserve further attention in policy-decision making. Apparently, there is a strong trend towards increasing returns to scale. The outputs elasticities of the inputs are higher especially for capital and seed. Correspondingly, the positive elasticity of land indicates that land is an important input which represents a high cost share (particularly for the rice farming with low land endowment) such that it is farmed intensively. This suggests the role of policies in fostering efficiency of the inputs and creating an enabling environments in terms of infrastructure and capital as well as access to the input resources that provide adequate incentives for the farmers particularly small farmers to invest in productive inputs. Accordingly, this should be a strong signal for the government to change priorities in budget allocations by providing more funds in investment that could enhance the technical efficiency of rice production. 


\subsection{Data limitations and methodological issues}

Due to the fact that the production of rice provides the majority of agricultural and economic opportunities in the case study region, this dissertation focuses on the competitiveness and efficiency of rice production. Using the extension of the Policy Analysis Matrix approach, which is based on the disaggregate competitiveness analysis, we demonstrate a simple and effective way to estimate competitiveness. Additionally, our research allowed us to determine how to take unobserved heterogeneity in the recent fixed model to analyse technical efficiency into account. Although our analysis sheds some insight into the constraints of competitiveness and efficiency in the context of the rice sector, and provide policy recommendations for future intervention programs, we acknowledge several limitations of this study.

First, the study only focuses on one granary area although there are eight granary areas in Malaysia that are projected to be completely self-sufficient in rice production by the year 2020. Therefore, the dataset is not representative of Malaysia as a whole. The results presented in this study are situation specific and cannot be extrapolated to other states or granaries with different settings and conditions. The results of a similar study conducted in other regions of Malaysia might differ to those presented in Chapter 3 depending on the context and situation of the study. Of course, different granaries may vary with respect to farm structure, management, soil condition, climate or temperature, and on-farm practices. The study should be repeated at different ecological zones and areas in order to generate more information on overall competitiveness of rice production in Malaysia.

Second, the SGMM estimation provides an appropriate framework to analyse the determinants of change in competitiveness, but certainly it does not capture all aspects of this process. While this study identifies and analyses the factors that could explain the variation in competitiveness among rice farms, it omitted many factors associated with a lack of data regarding biophysical conditions such as soil, climate, pests, diseases, and other characteristics of the farmers including age, experience and education level. These factors are important in explaining potential determinants of competitiveness. 
Additionally, the average mean value of efficiency found in rice farming was much lower during 2010 to 2014, while the variations in technical efficiency scores were much higher. These divergences are likely to be associated with the effect of unobserved heterogeneity that are not accounted in this model i.e, although the analyses account for the individual effect, the performance among the farms may differ a lot. For the rice production in Malaysia, natural conditions such as weather, pest attacks, the spread of disease and managerial skills are likely to account for this inefficiency performance. The full potential of production is not utilized in the analysis presumably due to either the omission or the lack of data available on these natural conditions and the management that is not completely captured by the noise component. This is reflected by the MADA dataset analyzed in Chapter 4. Many data sets are incomplete or indicate obvious errors that might also affect our estimation on technical efficiency.

Finally, as shown in Chapter 5, we attempted to relate technical efficiency and competitiveness in the static case. To do this, we decomposed the PCB measure into technical efficiency. In other words, this distinction demonstrates how efficiently farms utilize the inputs they possess to produce the maximum of possible outputs. While the results confirm the perception of the static competitiveness that exists in the relevant literature, they do not demonstrate the dynamic pattern of the competitiveness growth. The theoretical background of efficiency and the Total Factor Productivity (TFP) is well-established (Fare and Primont, 1995: Kumbhakar et al, 2007). The extension of the dynamic or productivity decomposition can address the mixtures of output and input as well as the potential determinants of competitiveness (Nishimizu and Page, 1986: Bruemmer et al, 2002). Nevertheless, the ignorance of such effects and concepts is predominantly due to the limitations of the data and insufficient technical knowledge on the correct measurement of outputs and inputs as well as dynamic decomposition that is ultimately dependent on data sources.

\subsection{Directions for future research}

Since we performed a disaggregated competitiveness analysis, the impacts of policies and other determinants on farm competitiveness can be monitored by extending the SCB distributions introduced in this study as new years of detailed farm-level data become available in the future. The SCB analysis could also be applied to data from earlier years to 
generate long-term panel data and information on year-to-year fluctuations such as the years leading up to the 2008 food crisis, during the food crisis, and the period after the food crisis. To provide a sounder basis for the interpretation of the data as it pertains to future rice developments, a more detailed analysis could further disaggregate SCB distributions by region, farm size, and each individual product. An interesting follow-up work could also be conducted on overall farm competitiveness. Some of the farms may produce multiple outputs and hence, the incentives might vary depending on, for example, the degree of specialization and technological requirements. Therefore, one might compare the distributions of competitiveness scores for each individual product and for the whole farm.

In this study, we performed an analysis using a large dataset exclusively covering a five-year period. The implications of the policy are informative; however, they must be interpreted with caution especially if one wants to relate to the determinants of technological improvements. The process of technology adoption usually takes longer and requires longer panel data to generate more information and implications at the farm-level. Given the availability of sufficiently long panels, a potential work could investigate the dynamic decomposition of productivity growth and the performance patterns of rice production in Malaysia. This way, we could obtain a detailed analysis of the sources of productivity growth, including technical change, technical efficiency change and returns to scale, which can shed light on the sources of differences in technological gaps or improvements.

Moreover, further research could be done with respect to explaining the potential determinants of the rice sector's competitiveness in Malaysia as a whole. This study can be replicated and extended to the different granary areas or different systems of rice production (irrigated or rain-fed). Nonetheless, the level of competitiveness might differ across regions, and may depend on natural conditions, management practices and postharvest losses that occur over time. Improvements to such estimation will provide a more practical interpretation and comparison of the competitiveness of rice production, which in turn will confirm the results of this study.

The framework that we used in Chapter 4 regarding the recent fixed effect model (Chen et al, 2014) assumes that inefficiency varies over time and this assumption is theoretically required 
in the panel data. Assuming that unobserved heterogeneity is time-invariant is more of a philosophical issue (Chen et al, 2014). For the farm-level data, this assumption is acceptable since many unobserved characteristics are fixed for either a certain period or only in the shortrun. In the context of the long series of agricultural data, the acceptance of persistent technical inefficiency within this problem seems more problematic (Colombi et al, 2014). Farms that exhibit a constant level of inefficiency are likely to drop out of the competition and exit the markets, which subsequently leads to the farm's restricted access to technology and market failure. Accordingly, future research should address these consequences in productivity analysis and the necessity of improving farm or sectoral data quality and comparability should also be fortified further.

Finally, we demonstrate the link between competitiveness and technical efficiency and how these two approaches (PAM analysis and SFA method) are related. We use PCB and SCB as indicators to explain competitiveness while SFA approach to estimate technical efficiency. Nevertheless, the decomposition of SCB is quite complex and proved to be challenging. The use of primal profit maximization is intuitive since it avoids the problem of large variations in prices, which is commonly occurring in practice. However, beyond its implementation, it requires rigorous mathematical programming and strong economic foundation. Alternatively, one could possibly decompose SCB using the cost function or cost-share equation or production frontier which requires less severe exercise when estimating both technical efficiency and allocative efficiency. 


\section{References}

Brummer, B., T. Glauben, and G. Thijssen. 2002. "Decomposition of Productivity Growth Using Distance Functions: The Case of Dairy Farms in Three European Countries." American Journal of Agricultural Economics 84(August):628-644.

Chee.,W.C., and Peng, C.C. “Country Pasture/Forage Resource Profiles. Malaysia”. Country Report. Available at: http://www.fao.org/ag/agp/agpc/doc/Counprof/Malaysia.htm.

Chen, Y.Y., P. Schmidt, and H.J. Wang. 2014. "Consistent estimation of the fixed effects stochastic frontier model." Journal of Econometrics 181(2):65-76. Available at: http://dx.doi.org/10.1016/i.jeconom.2013.05.009.

Colombi, R., Kumbhakar, S. C., Martini, G. and Vittadini, G. (2014). Closed-Skew Normality in Stochastic Frontiers with Individual E_ects and Long/Short-Run Efficiency. Journal of Productivity Analysis.

Kiaya, V. 2014. "Post-Harvest Losses and Strategies to Reduce Them." Technical paper on Post-Harvest Losses. Action Contre la Faim (ACF). January 2014.

Nishimizu, M., and J.M. Page. 1986. "Productivity Change and Dynamic Comparative Advantage The Review of Economics and Statistics, 68 (2): 241-247 (May, 1986). Published by: The MIT Press Stable URL: http://www.jstor.org/stable/1925503 COM." The Review of Economics and Statistics 68(2):241-247.

Subal Kumbhakar and Dan Wang, 2007. "Economic reforms, efficiency and productivity in Chinese banking," Journal of Regulatory Economics, Springer, vol. 32(2):105-129, October.

World Trade Organization. 2014. "Trade Policy Review. Malaysia: World Trade Organization." 